\title{
Cold cure for type 2 diabetes
}

Citation for published version (APA):

Hanssen, M. J. W. (2016). Cold cure for type 2 diabetes: Role of brown adipose tissue and skeletal muscle in glucose metabolism. [Doctoral Thesis, Maastricht University]. Uitgeverij BOXPress. https://doi.org/10.26481/dis.20160923mh

Document status and date:

Published: 01/01/2016

DOI:

10.26481/dis.20160923mh

Document Version:

Publisher's PDF, also known as Version of record

\section{Please check the document version of this publication:}

- A submitted manuscript is the version of the article upon submission and before peer-review. There can be important differences between the submitted version and the official published version of record.

People interested in the research are advised to contact the author for the final version of the publication, or visit the DOI to the publisher's website.

- The final author version and the galley proof are versions of the publication after peer review.

- The final published version features the final layout of the paper including the volume, issue and page numbers.

Link to publication

\footnotetext{
General rights rights.

- You may freely distribute the URL identifying the publication in the public portal. please follow below link for the End User Agreement:

www.umlib.nl/taverne-license

Take down policy

If you believe that this document breaches copyright please contact us at:

repository@maastrichtuniversity.nl

providing details and we will investigate your claim.
}

Copyright and moral rights for the publications made accessible in the public portal are retained by the authors and/or other copyright owners and it is a condition of accessing publications that users recognise and abide by the legal requirements associated with these

- Users may download and print one copy of any publication from the public portal for the purpose of private study or research.

- You may not further distribute the material or use it for any profit-making activity or commercial gain

If the publication is distributed under the terms of Article $25 \mathrm{fa}$ of the Dutch Copyright Act, indicated by the "Taverne" license above, 


\section{Cold cure for type 2 diabetes}

Role of brown adipose tissue and skeletal muscle in glucose metabolism

Mark Hanssen 

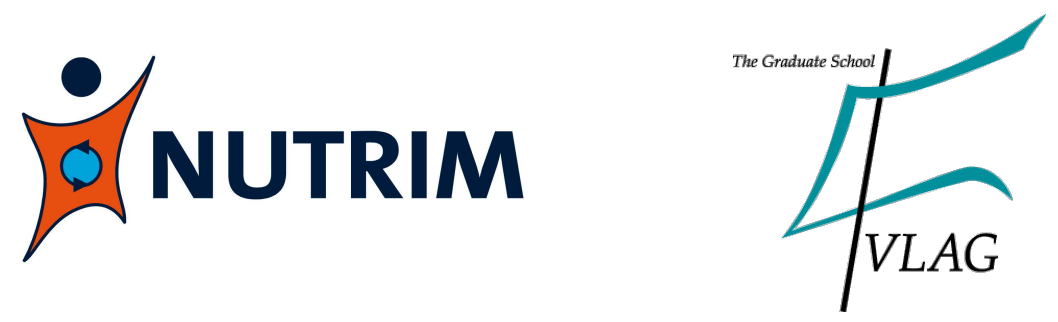

The studies presented in this thesis were performed within NUTRIM School for Nutrition and Translational Research in Metabolism, which participates in the Graduate School VLAG (Food Technology, Agrobiotechnology, Nutrition and Health Sciences), accredited by the Royal Netherlands Academy of Arts and Sciences.

\section{PERIMED}

Printing of this thesis was financially supported by Perimed AB.

(C) Mark J.W. Hanssen, 2016

Cover design: Kathy Gubbels \& Mark Hanssen

Lay-out: Mark Hanssen

Printed \& published by: Uitgeverij BOXpress, Vianen

All rights reserved. No part of this thesis may be reproduced or transmitted in any form or by any means, electronic or mechanical, including photocopying, recording, or any information storage or retrieval system, without permission in writing from the author, or, when appropriate, from the publisher of the publications. 


\title{
Cold cure for type 2 diabetes
}

\author{
Role of brown adipose tissue and skeletal muscle \\ in glucose metabolism
}

\author{
PROEFSCHRIFT \\ ter verkrijging van de graad doctor aan de Universiteit Maastricht, \\ op gezag van de Rector Magnificus, Prof. L.L.G. Soete, \\ volgens het besluit van het College van Decanen, \\ in het openbaar te verdedigen \\ op vrijdag 23 september 2016 om 14.00 uur \\ door \\ Mark Johannes Wilhelmus Hanssen \\ Geboren te Venlo op 13 maart 1987
}




\section{Promotores}

Prof. dr. W.D. van Marken Lichtenbelt

Prof. dr. P. Schrauwen

Prof. dr. F.M. Mottaghy

\section{Beoordelingscommissie}

Prof. dr. N.C. Schaper (voorzitter)

Dr. J. Bucerius

Prof dr. M. Klingenspor (Technische Universität München, Germany)

Prof dr. H. Pijl (Leids Universitair Medisch Centrum)

Prof dr. A.M.J.W. Schols 


\section{Table of contents}

$\begin{array}{lll}\text { Chapter } 1 & \text { General Introduction }\end{array}$

Chapter $2 \quad$ Glucose uptake in human brown adipose tissue 23

is impaired upon fasting-induced insulin resistance

Chapter 3 Short-term cold acclimation improves insulin sensitivity

45 in patients with type 2 diabetes mellitus

Chapter 4 Short-term cold acclimation recruits

brown adipose tissue in obese humans

Chapter 5 Serum FGF21 levels are associated with

brown adipose tissue activity in humans

Chapter 6 Brown adipose tissue activity and skeletal muscle

respiration in South Asian and Caucasian

pre-diabetic males: effects of L-arginine

Chapter 7 General discussion

Summary

Nederlandse samenvatting

155

Valorization

161

Dankwoord

List of publications

Curriculum Vitae 



\section{CHAPTER 1}

General introduction 


\section{Type 2 diabetes - beat it with BAT?}

In modern western society, the prevalence of overweight and obesity has reached epidemic proportions in recent decades (1). In 2012, almost half (48.3\%) of the Dutch adult population was considered overweight (Body Mass Index [BMI] > 25 $\mathrm{kg} / \mathrm{m}^{2}$ ), while $\sim 13 \%$ suffered from obesity (BMI $>30 \mathrm{~kg} / \mathrm{m}^{2}$ ) (2). In several other western countries these numbers are even higher: In 2010, over two-third of the US adult population was considered overweight, while over a third suffered from obesity (3). This high obesity prevalence is the main cause for the dramatic increase in the incidence and prevalence of type 2 diabetes that has occurred during the past decades (Figure 1) (4), with currently $\sim 6.4 \%$ of the world population being affected (5). The health impact of diabetes is substantial and includes long-term complications such as myocardial infarction, cerebrovascular stroke and end-stage renal disease, reduction of quality of life and reduced overall life expectancy with 5-10 years (5). This makes it currently the fifth leading cause of death globally (6).

\section{Obesity}

1994

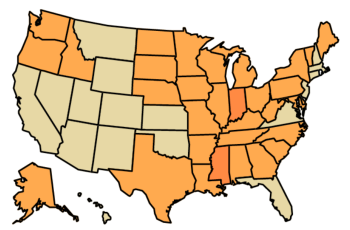

No Data $\square<14.0 \%$

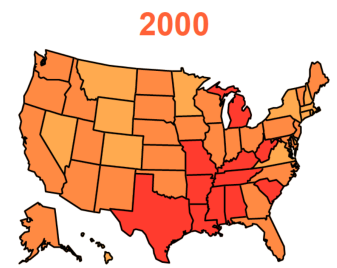

$14.0 \%-17.9 \%$

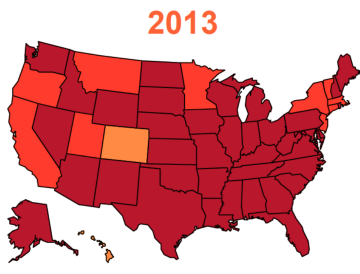

$22.0 \%-25.9 \% \square \geq 26.0 \%$

Type 2 diabetes

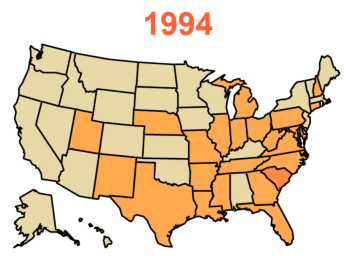

$\square$ No Data $\square<4.5 \%$

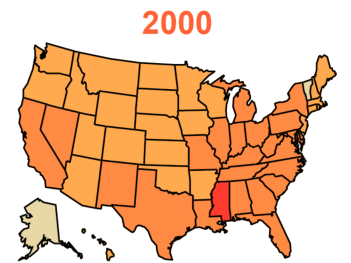

$4.5 \%-5.9 \%$

$6.0 \%-7.4 \%$

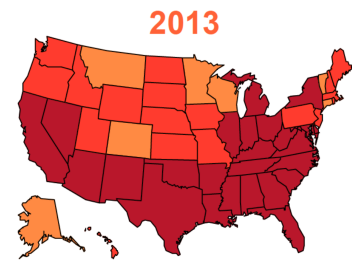

$7.5 \%-8.9 \%$ $\geq 9.0 \%$

Figure 1. Prevalence of obesity and type 2 diabetes in the US from 1994-2013. The prevalence of both conditions has increased over the last 2 decades in every state. The increased type 2 diabetes prevalence shows a strong overlap with the increased obesity prevalence, since obesity is a primary cause for development of type 2 diabetes. Similar trends are ongoing around the globe. Image obtained from CDC, Centers for Disease Control and Prevention (www.cdc.gov/diabetes/statistics). 
Type 2 diabetes is primarily caused by a reduced sensitivity to the hormone insulin, i.e. insulin resistance. In metabolically healthy conditions, increased blood glucose levels, e.g. in postprandial conditions, are counteracted by an increased secretion of insulin by the pancreas which stimulates glucose uptake and storage, especially in muscle, liver and fat cells. In insulin resistant conditions, cells are less able to take up glucose under insulin-stimulated conditions, and hence blood glucose levels rise. Obesity is a primary cause for development of insulin resistance: when the buffering capacity for lipid storage in adipose tissue is decreased, due to a fat cell overload, ectopic lipid accumulation in other tissues, such as skeletal muscle and liver, is increased (7). Subsequently, elevated cellular levels of lipid intermediates, such as diacylglycerol and ceramides, can interfere with normal intracellular insulin signaling and hence cause insulin resistance (Figure2).

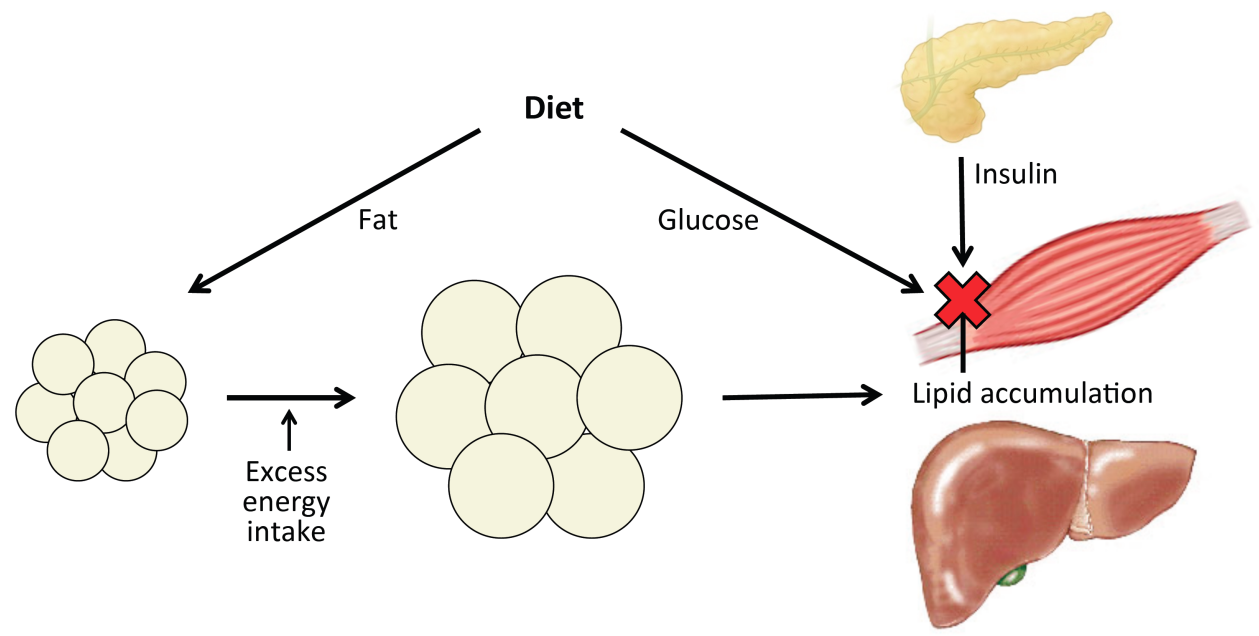

Figure 2. Schematic overview of the development of insulin resistance caused by obesity. Normally, dietary fats are stored in white adipose tissue. In case of prolonged excess energy intake white adipocytes become overloaded, resulting in lipid accumulation in non-adipose tissues, such as muscle and liver. Elevated levels of lipid intermediates can subsequently interfere with insulin signaling, leading to impaired insulin-stimulated glucose uptake capacity, i.e. insulin resistance.

Lifestyle interventions with diet and exercise programs aimed at preventing or ameliorating type 2 diabetes and/or insulin resistance have shown promising results in several major clinical trials (8-10). However, translating these interventions to the general population remains very challenging (11). Therefore, the search for novel therapeutic strategies for prevention and treatment of type 2 
diabetes is ongoing. A promising target tissue in this respect is brown adipose tissue (BAT). Since the 'rediscovery' of this tissue in human adults in 2009 (12-15) BAT has attracted considerable scientific attention as a target for both anti-obesity and anti-diabetic therapies. Due to the presence of large amounts of mitochondria containing uncoupling protein 1 (UCP1), which uncouples respiratory chain activity from ATP synthesis, BAT has the capacity to dissipate energy from substrate oxidation as heat. This heat-generating function of BAT becomes particularly apparent when subjects are exposed to cold, when BAT thermogenesis is 'activated' to maintain normothermia. Rodent studies have indicated that upon (cold-)stimulation BAT utilizes high amounts of both glucose and free fatty acids for thermogenesis, thereby actively clearing these substrates from the circulation. BAT activation is therefore capable of significantly impacting whole-body substrate metabolism and energy expenditure in these animals. If this increased catabolism in BAT can be chronically exploited in humans as well, this may not only lead to increased energy expenditure to combat obesity, but also to increased glucose disposal and oxidation. This is of particular interest in the diabetic situation, which is characterized by elevated blood glucose levels, i.e. hyperglycemia.

\section{Discovery of BAT in rodents and humans}

The first known report on BAT originates already from 1551, when the Swiss naturalist Conrad Gessner described the observation of a tissue in marmots as "neither fat nor flesh" (16). With this description he already indicated that BAT's morphological features were clearly different than those of white adipose tissue (WAT). Around the 1900's, BAT had been observed in many other mammal species. By that time BAT was often referred to as the 'hibernating gland' (17) or the 'interscapular gland' (18), as it had been originally observed in the interscapular region in hibernators. Since the first half of the $20^{\text {th }}$ century it has been know that BAT is a tissue with high respiratory capacity, much higher than its counterpart WAT $(19 ; 20)$, although its exact physiological role was still unknown at that time. In 1950, Pagé and Babineau for the first time reported pronounced hypertrophy of BAT in rats upon prolonged cold exposure (21), and about 10 years later it became clear that the primary physiological function of BAT is heat production, i.e. thermogenesis (22). Finally, around 1980, UCP1 was identified as the mitochondrial protein responsible for this unique function of BAT $(23 ; 24)$. Since then, numerous 
rodent studies have confirmed the exceptional role of BAT in maintaining normal core body temperature upon cold exposure in these animals.

The first observations of BAT in humans date back to around 1900 when autopsy studies in embryos, infants and adults discovered BAT in several anatomical regions (18). Interestingly, the most pronounced BAT depot in infants was found in the interscapular region, which corresponds to observations in smaller mammals. However, in human adults BAT was mainly found in the clavicular and neck regions. These initial observations were later confirmed by several other anatomical studies $(25 ; 26)$ and evidence in 1986 that adult human BAT indeed contained UCP1 (27), the uncoupling protein responsible for metabolic heat production in BAT. In the early 2000's, with the development of advanced imaging techniques, BAT activity was regularly observed in cancer patients undergoing positron-emissiontomography/computed tomography (PET/CT) scanning where cellular glucose uptake is visualized by injection of the radioactive glucose tracer 2-deoxy-2$\left[{ }^{18} \mathrm{~F}\right]$ fluoro-D-glucose $\left(\left[{ }^{18} \mathrm{~F}\right] \mathrm{FDG}\right)(28 ; 29)$. However, it was not until 2007 that the possible metabolic consequences of such BAT activity in humans were recognized by the biological scientific community (30). Finally, in 2009, human BAT activity was undoubtedly demonstrated by three dedicated studies using cold exposure to activate BAT, in combination with $\left[{ }^{18} \mathrm{~F}\right] \mathrm{FDG}-\mathrm{PET} / \mathrm{CT}$ scanning to visualize its glucose uptake $(12 ; 13 ; 15)$. Immunohistochemical analyses in biopsies taken from the anatomical fat regions where $\left[{ }^{18} \mathrm{~F}\right] \mathrm{FDG}$ uptake was located clearly demonstrated the presence of UCP1, confirming that this tissue was indeed BAT (13). Importantly, BAT activity was not observed when individuals were kept under warm conditions (Figure 3) (12), indicating that BAT in human adults exerts the same function as it does in rodents: metabolic heat production upon cold exposure in order to maintain a constant core body temperature. 


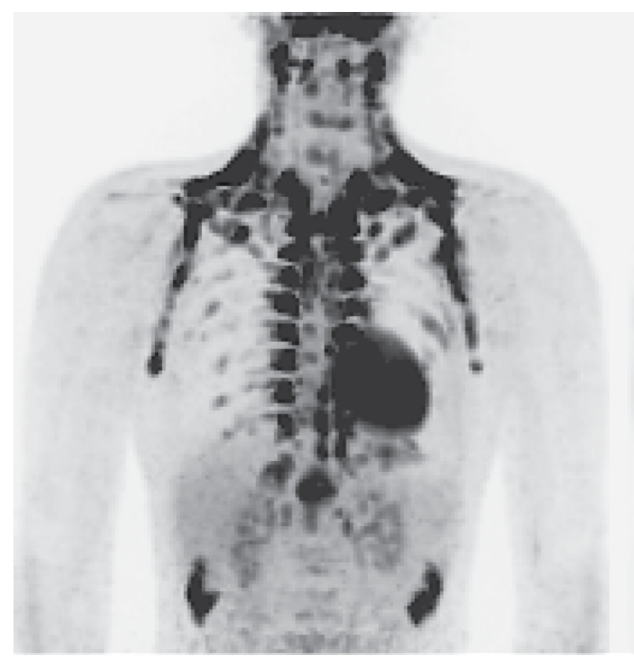

Cold $\left(16^{\circ} \mathrm{C}\right)$

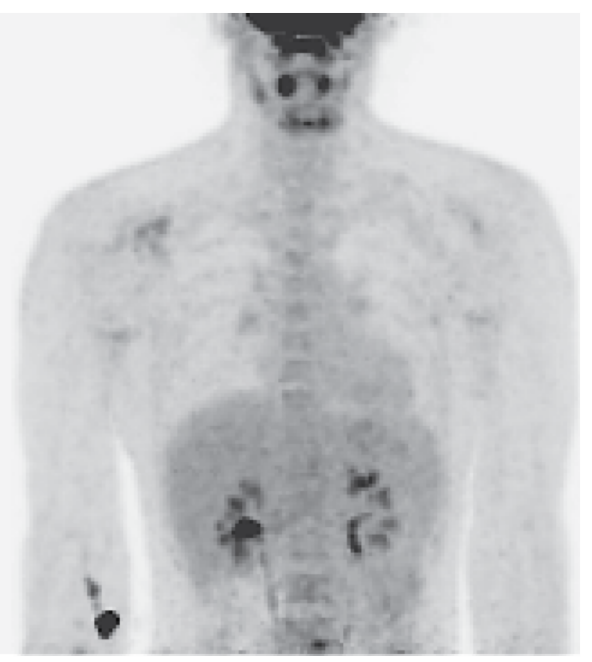

Warm $\left(22^{\circ} \mathrm{C}\right)$

Figure 3. BAT activity in humans as visualized by $\left[{ }^{18} \mathrm{~F}\right] \mathrm{FDG}-\mathrm{PET} / \mathrm{CT}$ scanning. The left PET/CT image was obtained upon cold exposure $\left(16{ }^{\circ} \mathrm{C}\right)$. The black areas indicate active uptake of $\left[{ }^{18} \mathrm{~F}\right] \mathrm{FDG}$. BAT activity can be observed in supraclavicular, neck, axillary, paraspinal and perirenal regions. The right PET/CT image was obtained in the same subject upon warm conditions and shows no BAT activity. Image adapted from (12).

Since then, several studies have reported negative relations between human BAT activity and body fatness $(12 ; 31 ; 32)$ and age (33). Interestingly, retrospective studies have also suggested that BAT presence and activity is negatively related to diabetic status (14), even when correcting for other potential confounding variables (34). In addition, multivariable analysis in a large cohort of healthy volunteers undergoing cold-stimulated $\left[{ }^{18} \mathrm{~F}\right] \mathrm{FDG}-\mathrm{PET} / \mathrm{CT}$ scanning revealed that BAT presence was an independent determinant of blood glucose levels, even after adjustments for age, sex and body fatness (31). These findings indicate that BAT may not only impact whole-body energy expenditure, but also suggest a potential role for BAT in the management of glucose homeostasis. This opens up a new therapeutic window for BAT-focused therapies in the prevention and treatment of type 2 diabetes. 


\section{Thermogenic activity is linked to glucose uptake in BAT}

The thermogenic activity of BAT is driven by stimulation via the sympathetic nervous system (SNS), which densely innervates this tissue. Upon stimulation, e.g. by acute cold exposure, these sympathetic neurons release norepinephrine (NE), which subsequently interacts with $\beta_{3}$-adrenergic receptors on the brown adipocyte cell surface. Via a series of intracellular signaling pathways, this leads to the release of free fatty acids from triglycerides, which stimulate uncoupled respiration in mitochondria via interaction with $\operatorname{UCP} 1(35 ; 36)$, and hence heat production takes place. Free fatty acids, mainly derived from the abundantly present intracellular multilocular triglyceride droplets but also from the circulation, compromise the major part of fuel needed for thermogenesis in BAT. Glucose is also oxidized in high amounts in BAT when activated, although the direct contribution of glucose oxidation to total thermogenesis in BAT is believed to be relatively small compared to fat oxidation, somewhere in the range of 10-16\% (37-39). Instead, the glucose taken up is likely mainly used for synthesis of glycerol-3-phosphate and triglycerides, and the supply of extramitochondrial ATP through glycolysis to support fatty acid esterification to triglycerides and other cellular functions (40), thus rendering it a vital role in support of fatty acid oxidation and fatty acidinduced activation of UCP1. Indeed, studies in isolated rat brown adipocytes have shown that NE-stimulation increases both oxygen consumption and glucose transport in a dose-dependent manner, indicating a close relationship between glucose uptake and (UCP1-mediated) thermogenesis (41). In addition, increases in mouse BAT temperature determined in vivo by thermal imaging parallel increases in glucose uptake, as determined by ${ }^{18}$ F-FDG-PET scanning (42). In fact, also in humans glucose uptake in BAT is positively related to non-shivering thermogenesis, i.e. the increase in energy expenditure above basal metabolic rate upon cold exposure in the absence of shivering (43). These observations underscore the direct coupling of thermogenesis with glucose utilization in BAT, and thus highlight glucose uptake as a vital component in the metabolic heat production in BAT.

The exact mechanism by which $\beta_{3}$-adrenergic stimulation induces glucose uptake in brown adipocytes is still not completely understood. Recently, serial activation of CAMP and MTORC2, and subsequent translocation of GLUT1 to the plasma membrane to facilitate glucose uptake have been suggested to be involved (44). Nonetheless, once activated, brown adipocytes take up large amounts of glucose and, consequently, BAT has one of the highest rates of glucose uptake compared 
with other metabolically active tissues (45); e.g. during cold exposure glucose uptake per unit weight is approximately 12-fold higher in BAT than in skeletal muscle in humans (46-48). Thus, despite being a relatively small organ, BAT may be able to significantly contribute to whole-body glucose disposal when stimulated.

\section{BAT recruitment in rodents - effects on glucose homeostasis and insulin sensitivity}

It is well established in rodent models that upon chronic stimulation, e.g. by prolonged cold acclimation, brown adipocyte recruitment will take place to enhance BAT's thermogenic capacity. In addition to prolonged cold exposure, chronic treatment with NE or the $\beta_{3}$-agonist $C L-316243$ at thermoneutral temperatures induces BAT recruitment as well (49). In fact, thermogenic responses of rodents to injected NE at thermoneutrality are quantitatively very similar to the amount of non-shivering thermogenesis at cold acclimation temperatures, which is almost fully dependent on BAT (39). BAT recruitment involves hypertrophy of the tissue, increased vascularization and sympathetic innervation, and increases in mitochondrial density, oxidative enzymes and UCP1 content. Another interesting phenomenon in this respect is 'browning' of WAT, a process whereby UCP1expression and hence thermogenic capacity of white adipocytes is increased in response to stimulation of $\beta_{3}$-adrenoreceptors by cold exposure or other stimuli (50). Both BAT recruitment and WAT browning substantially impact whole body substrate metabolism and promote leanness in several animal models. In particular, transplantation studies have shown that by transplanting BAT from donor mice into the visceral cavity of recipient mice, this results in improved glucose tolerance and insulin sensitivity, lower body weight, and decreased fat mass (31). In addition, increased BAT activity induced by short-term cold exposure in mice does not only improve insulin sensitivity, but is also able to drastically accelerate plasma clearance of triglycerides as a result of uptake into BAT (51), thereby improving plasma lipid profiles.

Next to cold exposure and NE-treatment, several other compounds have been identified in cell and animal studies that can induce brown adipogenesis: FGF21, irisin, IL-6, BAIBA, bone morphogenic proteins, cardiac natriuretic peptides, Larginine and several other molecules have been suggested to induce the brown fat thermogenic program. Next to promoting browning, some of such compounds 
have also been shown to improve glucose metabolism and insulin sensitivity, indicating a role for BAT recruitment in these metabolic improvements.

\section{Cold exposure to activate and recruit BAT in humans}

In agreement with findings from rodent studies, three human intervention studies have shown that prolonged intermittent cold exposure, i.e. cold acclimation, leads to BAT recruitment in young, lean individuals $(43 ; 52 ; 53)$. Interestingly, BAT recruitment was accompanied by enhanced cold-induced non-shivering thermogenesis in two of these studies (43; 52). Moreover, an anti-obesity effect of BAT recruitment was observed by Yoneshiro et al., as evidenced by a negative relation between changes in BAT activity and whole body fat mass upon cold acclimation (52). Interestingly, Blondin et al. showed that plasma glucose levels were slightly but significantly decreased after daily 2-hour cold exposures for 4 weeks in six young, lean, healthy subjects (53). This was paralleled by an increase in BAT oxidative capacity, suggesting a contribution of BAT in management of plasma glucose homeostasis in humans. Together, these findings thus suggest that enhancing BAT volume and activity may be very beneficial for patients with diabetes. However, rodent studies have indicated that insulin resistance (a main characteristic of type 2 diabetes), and specifically insulin resistance of BAT, significantly contributes to cold-intolerance and reduced cold-induced BAT glucose uptake and thermogenesis (54-56). In humans, both cold-induced and insulininduced glucose uptake in BAT is lower in insulin resistant obese than in (more insulin sensitive) lean subjects (32), indeed indicating a role for insulin resistance in BAT glucose uptake, although obesity is a confounding factor in these observations. Whether insulin resistance per se in humans is also associated with thermogenic defects in BAT is unknown. If insulin resistance is indeed a cause of reduced coldinduced glucose uptake in BAT in type 2 diabetic patients, therapies specifically aimed at activating and recruiting BAT, such as cold acclimation, may in fact not be able to affect glucose homeostasis via enhanced glucose uptake by BAT in these patients. However, if enhancement of BAT's thermogenic capacity is paralleled by enhanced BAT insulin sensitivity, this may positively impact whole-body insulin sensitivity and glucose metabolism. 


\section{Outline of the thesis}

The aim this thesis is to explore the role of human BAT in the pathophysiology and treatment of insulin resistance and type 2 diabetes. In chapter $\mathbf{2}$, we employed a prolonged-fasting model to induce insulin resistance in young healthy subjects to investigate the effects of insulin resistance on glucose uptake in BAT and nonshivering thermogenesis. Chapters $\mathbf{3}$ and $\mathbf{4}$ describe two proof-of-principal studies on the effects of short-term cold acclimation on BAT in patients with type 2 diabetes (chapter $\mathbf{3}$ ) and in normoglycemic obese subjects (chapter $\mathbf{4}$ ). In addition to BAT, we also assessed the effects of short-term cold acclimation on insulin sensitivity in type 2 diabetes patients. In chapter 5, we studied associations between BAT activity and serum levels of FGF21, a hormone that has been suggested to exert anti-diabetic effects. Individuals of South Asian origin are at increased risk to develop type 2 diabetes compared to Caucasians, which may be partly caused by reduced BAT. In chapter 6, we assessed BAT activity in prediabetic South Asian and Caucasian subjects and determined whether supplementation with L-arginine, a precursor of nitric oxide, is able to enhance BAT volume and activity in both ethnicities. Finally, in chapter 7, the main findings of this thesis are discussed and implications for future research are presented. 


\section{References}

1. Brown WV, Fujioka K, Wilson PW, Woodworth KA: Obesity: why be concerned? The American journal of medicine 2009;122:S4-11

2. Gezondheidsmonitor Volwassenen [article online], 2012. Available from http://www.volksgezondheidenzorg.info. Accessed Oct 1420152015

3. Flegal KM, Carroll MD, Kit BK, Ogden CL: Prevalence of obesity and trends in the distribution of body mass index among US adults, 1999-2010. JAMA : the journal of the American Medical Association 2012;307:491-497

4. Eckel RH, Kahn SE, Ferrannini E, Goldfine AB, Nathan DM, Schwartz MW, Smith RJ, Smith SR, Endocrine S, American Diabetes A, European Association for the Study of D: Obesity and type 2 diabetes: what can be unified and what needs to be individualized? Diabetes care 2011;34:1424-1430

5. Farag YM, Gaballa MR: Diabesity: an overview of a rising epidemic. Nephrology, dialysis, transplantation : official publication of the European Dialysis and Transplant Association European Renal Association 2011;26:28-35

6. Roglic G, Unwin N, Bennett PH, Mathers C, Tuomilehto J, Nag S, Connolly V, King H: The burden of mortality attributable to diabetes: realistic estimates for the year 2000. Diabetes care 2005;28:2130-2135

7. Goossens GH: The role of adipose tissue dysfunction in the pathogenesis of obesity-related insulin resistance. Physiology \& behavior 2008;94:206-218

8. Pan XR, Li GW, Hu YH, Wang JX, Yang WY, An ZX, Hu ZX, Lin J, Xiao JZ, Cao HB, Liu PA, Jiang $X G$, Jiang $Y Y$, Wang JP, Zheng $H$, Zhang $H$, Bennett $P H$, Howard BV: Effects of diet and exercise in preventing NIDDM in people with impaired glucose tolerance. The Da Qing IGT and Diabetes Study. Diabetes care 1997;20:537-544

9. Tuomilehto J, Lindstrom J, Eriksson JG, Valle TT, Hamalainen H, Ilanne-Parikka P, KeinanenKiukaanniemi S, Laakso M, Louheranta A, Rastas M, Salminen V, Uusitupa M, Finnish Diabetes Prevention Study G: Prevention of type 2 diabetes mellitus by changes in lifestyle among subjects with impaired glucose tolerance. The New England journal of medicine 2001;344:1343-1350

10. Knowler WC, Barrett-Connor E, Fowler SE, Hamman RF, Lachin JM, Walker EA, Nathan DM, Diabetes Prevention Program Research G: Reduction in the incidence of type 2 diabetes with lifestyle intervention or metformin. The New England journal of medicine 2002;346:393-403

11. Tuomilehto J, Schwarz P, Lindstrom J: Long-term benefits from lifestyle interventions for type 2 diabetes prevention: time to expand the efforts. Diabetes care 2011;34 Suppl 2:S210-214

12. van Marken Lichtenbelt WD, Vanhommerig JW, Smulders NM, Drossaerts JM, Kemerink GJ, Bouvy ND, Schrauwen P, Teule GJ: Cold-activated brown adipose tissue in healthy men. The New England journal of medicine 2009;360:1500-1508

13. Virtanen KA, Lidell ME, Orava J, Heglind M, Westergren R, Niemi T, Taittonen M, Laine J, Savisto NJ, Enerback S, Nuutila P: Functional brown adipose tissue in healthy adults. The New England journal of medicine 2009;360:1518-1525

14. Cypess AM, Lehman S, Williams G, Tal I, Rodman D, Goldfine AB, Kuo FC, Palmer EL, Tseng $\mathrm{YH}$, Doria A, Kolodny GM, Kahn CR: Identification and importance of brown adipose tissue in adult humans. The New England journal of medicine 2009;360:1509-1517

15. Saito $M$, Okamatsu-Ogura $Y$, Matsushita M, Watanabe K, Yoneshiro T, Nio-Kobayashi J, Iwanaga T, Miyagawa M, Kameya T, Nakada K, Kawai Y, Tsujisaki M: High incidence of 
metabolically active brown adipose tissue in healthy adult humans: effects of cold exposure and adiposity. Diabetes 2009;58:1526-1531

16. Gessner K: Conradi Gesneri medici Tigurini Historiæ animalium Lib. I. de quadrupedibus uiuiparis. Tiguri, apud Christophorum Froschoverum, 1551

17. Cramer W: On glandular adipose tissue, and its relation to other endocrine organs and to the vitamin problem. Br J Exp Pathol 1920;1:184-196

18. Bonnot E: The Interscapular Gland. Journal of anatomy and physiology 1908;43:43-58

19. Hook WE, Guzman-Barron ES: The respiration of brown adipose tissue and kidney of the hibernating and non-hibernating ground squirrel. The American journal of physiology 1941;133:56-63

20. Vijgen GH, Sparks LM, Bouvy ND, Schaart G, Hoeks J, van Marken Lichtenbelt WD, Schrauwen $\mathrm{P}$ : Increased oxygen consumption in human adipose tissue from the "brown adipose tissue" region. The Journal of clinical endocrinology and metabolism 2013;98:E1230-1234

21. Page E, Babineau LM: The effects of high fat diets and cold environment on the ascorbic acid content of the brown adipose tissue. Canadian journal of research Section E, Medical sciences 1950;28:196-201

22. Smith RE: Thermoregulatory and Adaptive Behavior of Brown Adipose Tissue. Science 1964;146:1686-1689

23. Heaton GM, Wagenvoord RJ, Kemp A, Jr., Nicholls DG: Brown-adipose-tissue mitochondria: photoaffinity labelling of the regulatory site of energy dissipation. European journal of biochemistry / FEBS 1978;82:515-521

24. Aquila $H$, Link TA, Klingenberg $M$ : The uncoupling protein from brown fat mitochondria is related to the mitochondrial ADP/ATP carrier. Analysis of sequence homologies and of folding of the protein in the membrane. The EMBO journal 1985;4:2369-2376

25. Heaton JM: The distribution of brown adipose tissue in the human. Journal of anatomy 1972;112:35-39

26. Huttunen P, Hirvonen J, Kinnula V: The occurrence of brown adipose tissue in outdoor workers. European journal of applied physiology and occupational physiology 1981;46:339-345

27. Lean ME, James $W P$, Jennings $G$, Trayhurn P: Brown adipose tissue uncoupling protein content in human infants, children and adults. Clinical science 1986;71:291-297

28. Hany TF, Gharehpapagh E, Kamel EM, Buck A, Himms-Hagen J, von Schulthess GK: Brown adipose tissue: a factor to consider in symmetrical tracer uptake in the neck and upper chest region. Eur J Nucl Med Mol Imaging 2002;29:1393-1398

29. Cohade C, Osman M, Pannu HK, Wahl RL: Uptake in supraclavicular area fat ("USA-Fat"): description on 18F-FDG PET/CT. Journal of nuclear medicine : official publication, Society of Nuclear Medicine 2003;44:170-176

30. Nedergaard J, Bengtsson T, Cannon B: Unexpected evidence for active brown adipose tissue in adult humans. American journal of physiology Endocrinology and metabolism 2007;293:E444-452

31. Matsushita M, Yoneshiro T, Aita S, Kameya T, Sugie H, Saito M: Impact of brown adipose tissue on body fatness and glucose metabolism in healthy humans. International journal of obesity 2014;38:812-817

32. Orava J, Nuutila P, Noponen T, Parkkola R, Viljanen T, Enerback S, Rissanen A, Pietilainen $\mathrm{KH}$, Virtanen KA: Blunted Metabolic Responses to Cold and Insulin Stimulation in Brown Adipose Tissue of Obese Humans. Obesity 2013; 
33. Yoneshiro $T$, Aita $S$, Matsushita $M$, Okamatsu-Ogura $Y$, Kameya $T$, Kawai $Y$, Miyagawa $M$, Tsujisaki M, Saito M: Age-related decrease in cold-activated brown adipose tissue and accumulation of body fat in healthy humans. Obesity 2011;19:1755-1760

34. Ouellet V, Routhier-Labadie A, Bellemare W, Lakhal-Chaieb L, Turcotte E, Carpentier AC, Richard D: Outdoor temperature, age, sex, body mass index, and diabetic status determine the prevalence, mass, and glucose-uptake activity of 18F-FDG-detected BAT in humans. The Journal of clinical endocrinology and metabolism 2011;96:192-199

35. Cannon B, Nedergaard J: Nonshivering thermogenesis and its adequate measurement in metabolic studies. The Journal of experimental biology 2011;214:242-253

36. Fedorenko A, Lishko PV, Kirichok Y: Mechanism of fatty-acid-dependent UCP1 uncoupling in brown fat mitochondria. Cell 2012;151:400-413

37. Ma SW, Foster DO: Uptake of glucose and release of fatty acids and glycerol by rat brown adipose tissue in vivo. Canadian journal of physiology and pharmacology 1986;64:609-614

38. Isler D, Hill HP, Meier MK: Glucose metabolism in isolated brown adipocytes under betaadrenergic stimulation. Quantitative contribution of glucose to total thermogenesis. The Biochemical journal 1987;245:789-793

39. Cannon B, Nedergaard J: Brown adipose tissue: function and physiological significance. Physiol Rev 2004;84:277-359

40. Festuccia WT, Blanchard PG, Deshaies Y: Control of Brown Adipose Tissue Glucose and Lipid Metabolism by PPARgamma. Frontiers in endocrinology 2011;2:84

41. Marette A, Bukowiecki LJ: Noradrenaline stimulates glucose transport in rat brown adipocytes by activating thermogenesis. Evidence that fatty acid activation of mitochondrial respiration enhances glucose transport. The Biochemical journal 1991;277 ( Pt 1):119-124

42. Carter EA, Bonab AA, Paul K, Yerxa J, Tompkins RG, Fischman AJ: Association of heat production with 18F-FDG accumulation in murine brown adipose tissue after stress. Journal of nuclear medicine : official publication, Society of Nuclear Medicine 2011;52:1616-1620

43. van der Lans AA, Hoeks J, Brans B, Vijgen GH, Visser MG, Vosselman MJ, Hansen J, Jorgensen JA, Wu J, Mottaghy FM, Schrauwen P, van Marken Lichtenbelt WD: Cold acclimation recruits human brown fat and increases nonshivering thermogenesis. The Journal of clinical investigation 2013;123:3395-3403

44. Olsen JM, Sato M, Dallner OS, Sandstrom AL, Pisani DF, Chambard JC, Amri EZ, Hutchinson DS, Bengtsson T: Glucose uptake in brown fat cells is dependent on mTOR complex 2promoted GLUT1 translocation. The Journal of cell biology 2014;207:365-374

45. Loyd C, Obici S: Brown fat fuel use and regulation of energy homeostasis. Current opinion in clinical nutrition and metabolic care 2014;17:368-372

46. Orava J, Nuutila P, Lidell ME, Oikonen V, Noponen T, Viljanen T, Scheinin M, Taittonen M, Niemi T, Enerback S, Virtanen KA: Different metabolic responses of human brown adipose tissue to activation by cold and insulin. Cell metabolism 2011;14:272-279

47. Vosselman MJ, van der Lans AA, Brans B, Wierts R, van Baak MA, Schrauwen $P$, van Marken Lichtenbelt WD: Systemic beta-adrenergic stimulation of thermogenesis is not accompanied by brown adipose tissue activity in humans. Diabetes 2012;61:3106-3113

48. Vosselman MJ, Brans B, van der Lans AA, Wierts R, van Baak MA, Mottaghy FM, Schrauwen $P$, van Marken Lichtenbelt WD: Brown adipose tissue activity after a high-calorie meal in humans. The American journal of clinical nutrition 2013;98:57-64 


\section{CHAPTER 1}

49. Tsukazaki K, Nikami H, Shimizu Y, Kawada T, Yoshida T, Saito M: Chronic administration of beta-adrenergic agonists can mimic the stimulative effect of cold exposure on protein synthesis in rat brown adipose tissue. J Biochem 1995;117:96-100

50. Harms M, Seale P: Brown and beige fat: development, function and therapeutic potential. Nature medicine 2013;19:1252-1263

51. Bartelt A, Bruns OT, Reimer R, Hohenberg H, Ittrich H, Peldschus K, Kaul MG, Tromsdorf UI, Weller H, Waurisch C, Eychmuller A, Gordts PL, Rinninger F, Bruegelmann K, Freund B, Nielsen $\mathrm{P}$, Merkel $\mathrm{M}$, Heeren J: Brown adipose tissue activity controls triglyceride clearance. Nature medicine 2011;17:200-205

52. Yoneshiro T, Aita S, Matsushita M, Kayahara T, Kameya T, Kawai Y, Iwanaga T, Saito M: Recruited brown adipose tissue as an antiobesity agent in humans. The Journal of clinical investigation 2013;123:3404-3408

53. Blondin DP, Labbe SM, Tingelstad HC, Noll C, Kunach M, Phoenix S, Guerin B, Turcotte EE, Carpentier AC, Richard D, Haman F: Increased brown adipose tissue oxidative capacity in cold-acclimated humans. The Journal of clinical endocrinology and metabolism 2014;99:E438-446

54. Mercer SW, Trayhurn P: The development of insulin resistance in brown adipose tissue may impair the acute cold-induced activation of thermogenesis in genetically obese (ob/ob) mice. Biosci Rep 1984;4:933-940

55. Marette A, Mauriege P, Despres JP, Tulp OL, Bukowiecki LJ: Norepinephrine- and insulinresistant glucose transport in brown adipocytes from diabetic SHR/N-cp rats. The American journal of physiology 1993;265:R577-583

56. Yoshioka K, Yoshida T, Wakabayashi Y, Nishioka H, Kondo M: The role of insulin in norepinephrine turnover and thermogenesis in brown adipose tissue after acute coldexposure. Endocrinol Jpn 1989;36:491-499 
Glucose uptake in human brown adipose tissue is impaired upon fasting-induced insulin resistance

The contents of this chapter are published in: MJW Hanssen, R Wierts, J Hoeks, A Gemmink, B Brans, FM Mottaghy, P Schrauwen, WD van Marken Lichtenbelt. Glucose uptake in human brown adipose tissue is impaired upon fasting-induced insulin resistance. Diabetologia 2015;58:586-595 


\section{ABSTRACT}

Aims/hypothesis. Human brown adipose tissue (BAT) has recently emerged as a potential target in the treatment of type 2 diabetes, owing to its capacity to actively clear glucose from the circulation-at least upon cold exposure. The effects of insulin resistance on the capacity of human BAT to take up glucose are unknown. Prolonged fasting is known to induce insulin resistance in peripheral tissues in order to spare glucose for the brain.

Methods. We studied the effect of fasting-induced insulin resistance on the capacity of BAT to take up glucose during cold exposure as well as on cold stimulated thermogenesis. BAT glucose uptake was assessed by means of coldstimulated dynamic 2-deoxy-2-[ $\left.{ }^{18} \mathrm{~F}\right]$ fluoro-D-glucose positron emission tomography/computed tomography $\left(\left[{ }^{18} \mathrm{~F}\right] \mathrm{FDG}-\mathrm{PET} / \mathrm{CT}\right)$ imaging.

Results. We show that a $54 \mathrm{~h}$ fasting period markedly decreases both cold-induced BAT glucose uptake and nonshivering thermogenesis (NST) during cold stimulation. In vivo molecular imaging and modeling revealed that the reduction of glucose uptake in BAT was due to impaired cellular glucose uptake and not due to decreased supply. Interestingly, decreased BAT glucose uptake upon fasting was related to a decrease in core temperature during cold exposure, pointing towards a role for BAT in maintaining normothermia in humans.

Conclusions/interpretation. Cold-stimulated glucose uptake in BAT is strongly reduced upon prolonged fasting. When cold-stimulated glucose uptake in BAT is also reduced under other insulin-resistant states, such as diabetes, cold-induced activation of BAT may not be a valid way to improve glucose clearance by BAT under such conditions. 


\section{INTRODUCTION}

Brown adipose tissue (BAT) is currently regarded as a potential target in the prevention and treatment of obesity and type 2 diabetes. BAT in animals appears to have a high metabolic capacity and is able to actively clear glucose from the circulation $(1 ; 2)$. It is now well recognised that BAT is present and active in human adults $(3 ; 4)$ and that its oxidative metabolism contributes to nonshivering thermogenesis (NST) during cold exposure (5).

Several rodent studies have shown that obese diabetic rodents have an impaired cold tolerance (6-9) associated with a reduced capacity for NST (6) and reduced BAT activity (8; 9). Some of these studies indicated that not obesity per se, but also insulin resistance contributes significantly to cold intolerance and reduced BAT activity $(8 ; 10 ; 11)$. In humans, several studies have recently shown negative correlations between BAT activity and adiposity $(3 ; 12 ; 13)$ and age (14). A negative association between BAT activity and diabetic status, independent of BMI and age, has also been reported in a retrospective study (15). In addition, an impaired thermogenic response to mild cold has been found in diabetic women compared with obese women (16), suggesting a role for insulin resistance in mediating these impairments. However, a confounding factor in these studies is that both obesity and ageing are characterised by reduced BAT activity, independent of diabetes status.

To address whether insulin resistance is directly involved in reducing BAT activity and NST, a 48 to $60 \mathrm{~h}$ fasting period can be employed to induce insulin resistance in young, healthy individuals (17-19). We have recently shown that this prolonged fasting leads to a $50 \%$ reduction in insulin sensitivity, as determined by the gold standard method, hyperinsulinemic-euglycemic clamp, probably due to increased nonesterified fatty acid (NEFA) levels and/or accumulation of triacylglycerols in peripheral tissues (18). As a result, glucose uptake is reduced in peripheral tissues mainly skeletal muscle, which is responsible for $\sim 80 \%$ of glucose uptake under insulin-stimulated conditions, such as during a hyperinsulinemic-euglycemic clamp (20). The physiological relevance of this peripheral insulin resistance is to spare glucose as a substrate for the brain. However, whether the capacity to stimulate glucose uptake into BAT is also reduced under insulin-resistant conditions is presently unknown. Since BAT relies on both carbohydrate and lipid oxidation for its heat production (21), an impaired glucose uptake under fasting-induced insulinresistant conditions would hamper its thermogenic capacity and could lead to 
reduced capacity to defend body temperature upon cold exposure. On the other hand, if glucose uptake into BAT could be stimulated by cold exposure under such insulin-resistant conditions, activation of glucose uptake into BAT by cold exposure or other means could serve as an interesting target to increase glucose clearance during insulin resistance.

To evaluate whether glucose uptake into BAT is impaired during fasting-induced insulin resistance, we here examined 16 young, healthy participants in which BAT glucose uptake was measured after both baseline and $54 \mathrm{~h}$ fasting conditions using dynamic 2-deoxy-2-[ $\left.{ }^{18} \mathrm{~F}\right]$ fluoro-D-glucose positron emission tomography/computed tomography $\left(\left[{ }^{18} \mathrm{~F}\right] \mathrm{FDG}-\mathrm{PET} / \mathrm{CT}\right)$ imaging under cold-stimulated conditions, in the absence of shivering (22).

\section{METHODS}

\section{Participants}

Eight male and eight female participants (age $21.9 \pm 3.1$ years; BMI $21.3 \pm 1.5$, $\mathrm{kg} / \mathrm{m}^{2}$; fat percentage $20.8 \pm 7.8 \%$ ) were included in the study. All participants were screened for medical history and status. Studies were performed between August 2012 and June 2013. All females were on oral contraceptives (ethinyl estradiol or levonorgestrel) and were not measured during their menstruation period. Exclusion criteria included diabetes mellitus, pregnancy, physical activity more than twice per week, history of cardiovascular diseases, and asthma or other obstructive pulmonary diseases.

\section{Study design}

Participants took part in two experimental protocols: a baseline condition and a fasted condition, in a randomised crossover design. These conditions both included a similar experimental day. In the fasted condition, this experimental day was preceded by a $48 \mathrm{~h}$ fasting period. A standardised evening meal was prescribed the day before the start of each experimental protocol.

For the baseline condition (Fig. 1a), consisting of the experimental day only, participants came in at 07:00 hours after an overnight fast and were asked to refrain from heavy exercise $48 \mathrm{~h}$ before the measurements. After arrival, a muscle biopsy was taken from the vastus lateratis muscle (23), and a light breakfast (energy content $<10 \%$ of basal metabolic rate $[B M R]$ ) was given subsequently. Body composition was determined by means of dual $x$-ray absorptiometry 
(Discovery A, Hologic, Bedford, MA, USA). After a $4 \mathrm{~h}$ fasting period, an individualised cooling protocol was performed at 11:45 hours followed by $\left[{ }^{18} \mathrm{~F}\right] \mathrm{FDG}$ PET/CT scanning (Gemini TF PET-CT, Philips, Eindhoven, the Netherlands) at 14:30 hours. For this purpose, a cannula was inserted in the left antecubital vein for blood sampling during thermoneutral and mild cold conditions and injection of the tracer. Participants swallowed a telemetric pill (CoreTemp HT150002, HQ, Palmetto, FL, USA), and iButtons (Maxim Integrated Products, San Jose, CA, USA) were placed on 14 ISO-defined sites (24) for measurements of core and skin temperatures, respectively. A chest strap (Polar T31; Polar, Kempele, Finland) was attached for measurement of heart rate and a pressure cuff (MTP, Medisana, Kerkrade, the Netherlands) was placed on the left arm for measurement of blood pressure. Laser Doppler probes were attached for skin perfusion measurements at the ventral sides of the hand, forearm and hallux, and at the abdomen halfway between the umbilicus and the left lateral side of the body (PF5000, Perimed, Järfälla, Sweden) (22). Shivering intensity was monitored by electromyography (EMG) sensors (PASAQ, IDEE, Maastricht, the Netherlands) placed at vastus lateralis, pectoralis major and lattissimus dorsi muscle (5). A face-mask was used for continuous measurement of energy expenditure (EE) by means of indirect calorimetry (Omnical, IDEE).

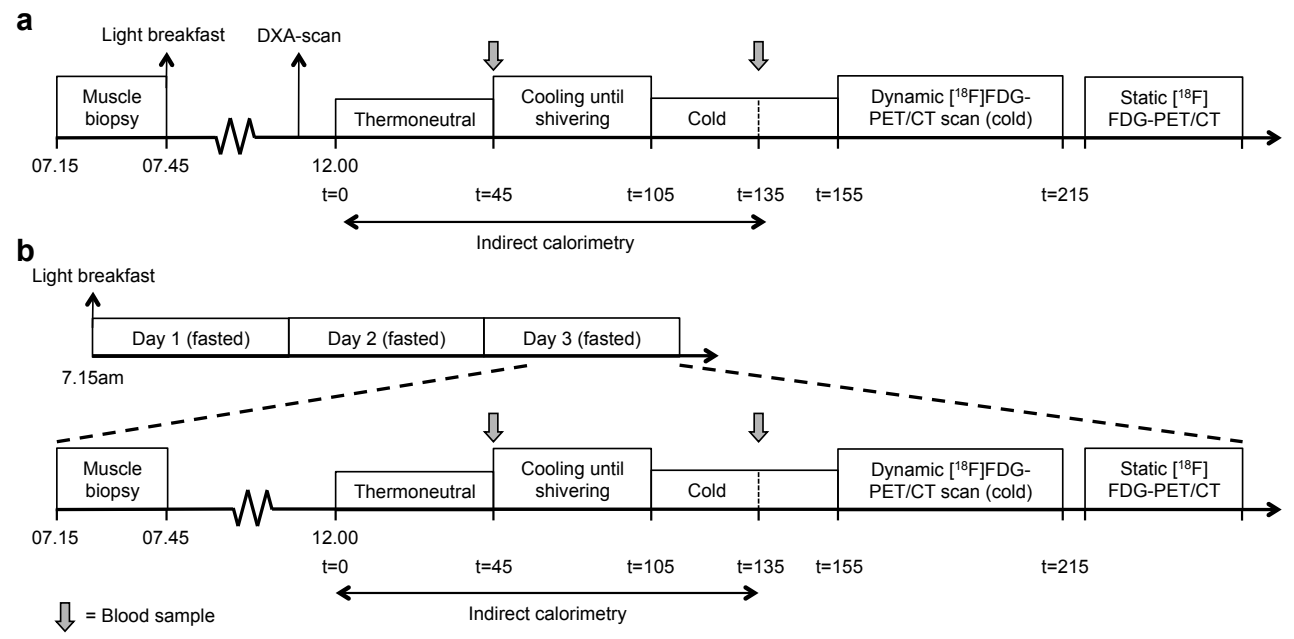

Figure 1. Study protocols for (a) the baseline condition and (b) the fasted condition 
For the fasted condition (Fig. 1b), participants came in at 07:00 hours on day 1 after an overnight fast and were given a light breakfast (energy content $<10 \%$ of BMR). Subsequently, participants stayed in a controlled room in our research unit for $48 \mathrm{~h}$ to ensure compliance to the fasting regime (no solid foods, calorie-free drinks only). They were given the opportunity for supervised light physical exercise (walking, stretching) for 30-60 min/day. On day 3, a muscle biopsy was taken in the morning at 07:15 hours, and the cooling protocol and $\left[{ }^{18} \mathrm{~F}\right] \mathrm{FDG}-\mathrm{PET} / \mathrm{CT}$ scanning was performed in the afternoon, similar to the experimental day during the baseline condition.

\section{Individualised cooling protocol and PET/CT scanning protocol}

The cooling and PET/CT scanning protocol was performed as described previously (22). Briefly, participants were wrapped in a water-perfused suit (ThermaWrap Universal 3166, MTRE Advanced Technologies, Yavne, Israel) and were measured at thermoneutrality for $45 \mathrm{~min}$. Hereafter, participants were cooled until a temperature just above their shivering point and measured for $30 \mathrm{~min}$ at this maximal NST temperature; NST was calculated as the percentage increase in energy expenditure above BMR (measured at thermoneutrality) at a temperature just above the individual's shivering temperature. Subsequently, participants were brought to the PET/CT scanner where imaging started with a low dose CT scan (120 $\mathrm{kV}, 30 \mathrm{mAs})$. Participants were then injected with $74 \mathrm{MBq}$ of $\left[{ }^{18} \mathrm{~F}\right] \mathrm{FDG}$ at the start of the PET scanning protocol. Both a dynamic (22) and static (3) scan (six to seven bed positions, 6 min per bed position) were acquired as described previously.

\section{PET analysis}

PET/CT scans were analysed using PMOD software (version 3.0, PMOD technologies, Zurich, Switzerland). Both the researcher (MJW Hanssen) and an experienced nuclear medicine physician (B Brans) interpreted the PET/CT images. Glucose uptake rates in BAT were determined from the dynamic PET data, as described previously (22). Two-tissue compartment modelling was employed to iteratively derive values for the individual rate constants $K_{1}$ to $k_{4}$ using a nonlinear least squares method (25), whereby $\mathrm{k}_{4}$ was fixed at zero (Supplement Fig. 1).

For determination of mean and maximal $\left[{ }^{18} \mathrm{~F}\right] \mathrm{FDG}$ uptake in BAT, expressed as standardised uptake values (SUV): $\left(\left[{ }^{18} \mathrm{~F}\right] \mathrm{FDG}\right.$ uptake $[\mathrm{kBq} / \mathrm{ml}) /($ injected dose $[\mathrm{kBq}] /$ patient weight $[\mathrm{g}])$, regions of interest were manually outlined in the static 
PET scan (26). A threshold of 1.5 SUV and Hounsfield units between -10 and -180 were used to define BAT, as described previously (26).

Fixed volumes of interest were selected in supraclavicular BAT, subcutaneous and visceral white adipose tissue (WAT), skeletal muscle (SM), liver and brain to compare $\left[{ }^{18} \mathrm{~F}\right]$ FDG uptake (calculated as SUV mean) among these tissues, as described previously (27).

\section{Skeletal muscle mitochondrial isolation and respiration}

Skeletal muscle mitochondria were isolated as described previously (22), with minor modifications. Briefly, a portion ( $200 \mathrm{mg}$ ) of the muscle tissue was immediately placed in ice-cold isolation buffer (22) and minced with precooled scissors followed by an enzymatic digestion with protease (Subtilisin A, Sigma Aldrich, Saint Louis, MO, USA). Muscle pieces were then centrifuged at 8,500 g for 5 min at $4^{\circ} \mathrm{C}$. After removal of the supernatant fraction, the pellet was resuspended in isolation buffer and homogenised in a glass potter tube. The homogenate was transferred to a centrifuge tube and centrifuged at 1,000 g for 10 $\min$ at $4^{\circ} \mathrm{C}$. The resulting supernatant fraction was filtered through cheesecloth, and centrifuged at $10,000 \mathrm{~g}$ for $10 \mathrm{~min}$ at $4^{\circ} \mathrm{C}$. The resulting mitochondrial pellet was resuspended in $20 \mu \mathrm{l}$ isolation buffer, and protein content was determined by Fluram assay (28). Subsequently, high-resolution respirometry on a 2-chamber Oxygraph (Oroboros Instruments, Innsbruck, Austria) with automatic palmitate titration was performed, as described previously (22). Successful mitochondrial respiration measurements were achieved in 11 participants (six males and five females; baseline and fasted assays successful).

\section{Blood analysis}

Plasma concentrations of glucose, free glycerol, total glycerol and NEFAs were determined on a Cobas FARA centrifugal spectrophotometer (Roche Diagnostics, Basel, Switzerland), as described previously (26). Triacylglycerol levels were calculated as the difference between total and free glycerol. Serum insulin was analysed with a Human Insulin Specific RIA kit (Millipore, Billerica, MA, USA) on a gamma counter (2470 Automatic Counter Wizard², PerkinElmer, Waltham, MA, USA). Plasma catecholamines were analysed on HPLC and by fluorimetric detection (29). Serum thyroid-stimulating hormone (TSH) and free thyroxine (FT4) were analysed as described previously (26). 


\section{Statistical analysis}

Statistical analyses were performed with SPSS Statistics 20.0 for MAC (IBM, Armonk, NY, USA). Reported data are expressed as means \pm SD, unless stated otherwise. A Shapiro-wilk test was used to test for normal distribution of relevant variables and non-parametric tests were used when appropriate. Two-sided paired samples $\mathrm{t}$ tests were used to compare findings between baseline and fasted conditions and between thermoneutral and mild cold conditions. Two-sided independent samples $t$ tests were used to compare findings between men and women. Pearson correlations were used to identify correlations between variables. The level of statistical significance was set at $p<0.05$.

\section{Study approval}

The Ethics Committee of Maastricht University Medical Centre+ approved the study protocol and all participants provided written informed consent. Procedures were conducted according to the principles of the Declaration of Helsinki.

\section{RESULTS}

\section{Effect of fasting on plasma variables}

NEFA levels were markedly higher after fasting compared with the baseline condition (1172 \pm 284 vs $600 \pm 221 \mu \mathrm{mol} / \mathrm{l}$, respectively; $p<0.001$; Table 1), and plasma glucose (5.0 \pm 0.3 vs $3.9 \pm 0.5 \mathrm{mmol} / \mathrm{l}$, baseline vs fasted, respectively; $p<$ $0.001)$ and insulin $(51.4 \pm 22.9$ vs $38.9 \pm 16.9 \mathrm{pmol} / \mathrm{l}$, baseline vs fasted, respectively; $p=0.066$ ) were both decreased upon fasting. Norepinephrine concentrations were similar ( $0.97 \pm 0.45$ vs $0.95 \pm 0.40 \mathrm{nmol} / \mathrm{l}$, baseline vs fasted, respectively; $p=0.90$ ), while epinephrine concentrations tended to be higher upon fasting ( $0.18 \pm 0.11$ vs $0.25 \pm 0.15 \mathrm{nmol} / \mathrm{l}$, baseline vs fasted respectively; $p=0.07$ ). 
Table 1. Plasma hormone and metabolite concentrations at thermoneutral temperature and during mild cold exposure, in the baseline vs fasted condition.

\begin{tabular}{|c|c|c|c|c|}
\hline \multirow[b]{2}{*}{ Variable } & \multicolumn{2}{|l|}{ Baseline } & \multicolumn{2}{|l|}{ Fasted } \\
\hline & Thermoneutral & Mild cold & Thermoneutral & Mild cold \\
\hline NEFA $(\mu \mathrm{mol} / \mathrm{I})$ & $600 \pm 221$ & $815 \pm 200^{+}$ & $1172 \pm 284^{* * *}$ & $1588 \pm 529 * * *,^{+}$ \\
\hline Glucose (mmol/l) & $5.0 \pm 0.3$ & $5.0 \pm 0.3$ & $3.9 \pm 0.5^{* * *}$ & $3.9 \pm 0.5^{* * *}$ \\
\hline Insulin (pmol/l) & $51.4 \pm 22.9$ & $56.3 \pm 20.1$ & $38.9 \pm 16.7$ & $44.4 \pm 11.8$ \\
\hline Norepinephrine (nmol/l) & $0.97 \pm 0.45$ & $2.52 \pm 1.18^{+\dagger}$ & $0.95 \pm 0.40$ & $3.57 \pm 2.11^{++}$ \\
\hline Epinephrine (nmol/l) & $0.18 \pm 0.11$ & $0.19 \pm 0.09$ & $0.25 \pm 0.15$ & $0.35 \pm 0.23^{+}$ \\
\hline $\mathrm{TSH}(\mathrm{mU} / \mathrm{l})$ & $2.0 \pm 1.0$ & $1.9 \pm 1.1^{\dagger}$ & $1.1 \pm 0.6^{* *}$ & $1.3 \pm 0.7$ \\
\hline Free T4 (pmol/l) & $14.5 \pm 1.5$ & $14.6 \pm 1.8$ & $14.1 \pm 2.2$ & $14.7 \pm 2.2^{+}$ \\
\hline
\end{tabular}

${ }^{* *} p<0.01$, baseline vs fasted, ${ }^{* * *} p<0.001$, baseline vs fasted, ${ }^{\dagger} p<0.05$, mild cold vs thermoneutral, ${ }^{+\dagger} p<0.01$, mild cold vs thermoneutral

\section{Changes in energy expenditure upon fasting}

Energy expenditure was significantly increased upon mild cold exposure in both the baseline (from $4.6 \pm 0.6$ to $5.2 \pm 0.9 \mathrm{~kJ} / \mathrm{min}, \mathrm{p}<0.01$ ) and the fasted condition (from $4.9 \pm 0.8$ to $5.2 \pm 0.9 \mathrm{~kJ} / \mathrm{min}, \mathrm{p}<0.01$ ). NST, expressed as per cent increase in energy expenditure upon cold exposure, was significantly lower in the fasted condition ( $12.7 \pm 9.1 \%$ vs $6.7 \pm 5.1 \%, p<0.01$; Table 2 and Fig. $2 d)$. In addition, the absolute increase in energy expenditure upon cold exposure was significantly lower upon fasting ( $0.6 \pm 0.5$ vs $0.3 \pm 0.3 \mathrm{~kJ} / \mathrm{min}$, baseline vs fasted respectively; $p<0.05)$. However, since BMR showed a slight increase upon fasting $(\sim 6 \%, p<0.01)$, total whole-body energy expenditure during cold exposure was similar between fasting and baseline conditions ( $p>0.05)$.

The respiratory quotient (RQ) was significantly lower upon fasting (Table 2). Cold exposure elicited no significant change in RQ or plasma glucose levels in either condition, while it increased plasma NEFAs in both conditions (Table 1).

\section{Decreased BAT glucose uptake upon fasting}

In the baseline condition, cold-induced BAT activity was detected in 15 out of 16 participants. Average $\left[{ }^{18} \mathrm{~F}\right] \mathrm{FDG}$ uptake (SUV mean) of all upper body BAT depots was $2.3 \pm 0.8$ and maximal $\left[{ }^{18} \mathrm{~F}\right] \mathrm{FDG}$ uptake (SUV max) in BAT was $10.6 \pm 6.5$. There were no significant differences in BAT glucose uptake between males and females, which is in accordance with previous findings $(22 ; 30)$. Outdoor temperature did not affect cold-stimulated BAT activity. We could detect BAT activity upon fasting in 14 out of the 15 participants that also showed BAT activity at baseline. However, fasting resulted in a marked decrease in cold-induced glucose uptake in BAT: average BAT $\left[{ }^{18} \mathrm{~F}\right] \mathrm{FDG}$ uptake decreased to $1.7 \pm 0.7 \mathrm{SUV}$ and maximal $\left[{ }^{18} \mathrm{~F}\right] \mathrm{FDG}$ 
uptake decreased to $4.7 \pm 4.4$ SUV (both $p<0.01$ compared with baseline condition; Table 2). Analysis of dynamic PET/CT imaging of the supraclavicular region revealed similar results. The average supraclavicular BAT glucose uptake rate of all participants was $6.0 \pm 3.4 \mu \mathrm{mol} \mathrm{min}^{-1} 100 \mathrm{~g}^{-1}$ in the baseline condition, and decreased to $2.7 \pm 1.7 \mu \mathrm{mol} \mathrm{min}{ }^{-1} 100 \mathrm{~g}^{-1}$ upon fasting ( $p<0.001$, Fig. $2 \mathrm{a}-\mathrm{c}$ ).

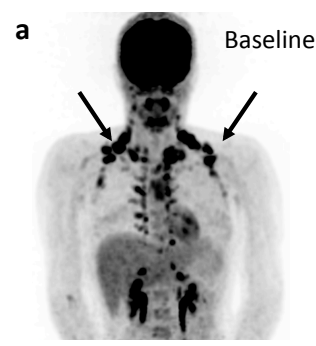

C
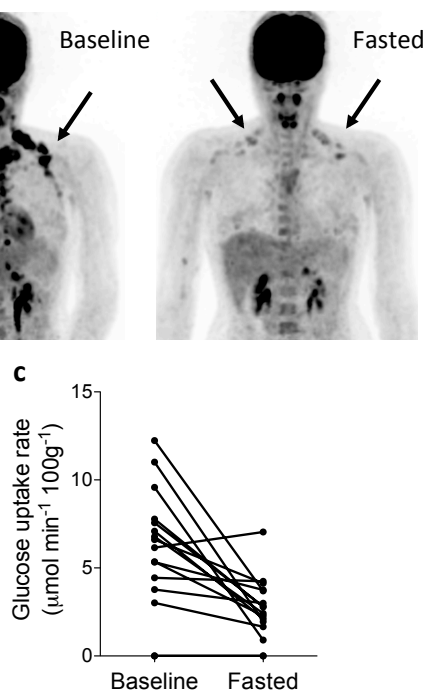

d

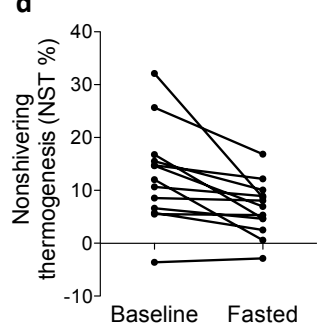

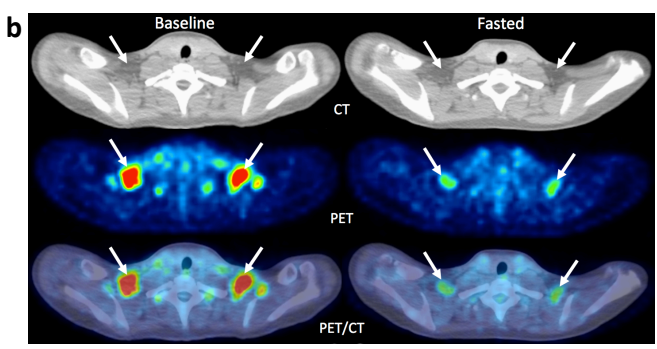

e

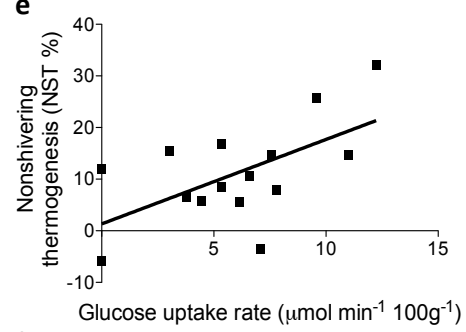

f

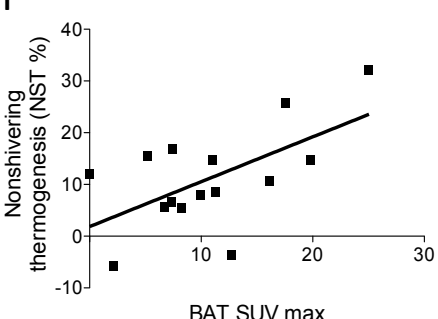

Figure 2. BAT glucose uptake rate and NST are significantly decreased upon fasting. A significant association between BAT activity and NST is found in the baseline condition. (a) $\left[{ }^{18}\right.$ F]FDG-PET images after cold exposure in a female participant in the baseline (left) and fasted (right) condition. Black arrows indicate supraclavicular BAT activity. (b) Transversal CT, PET and PET/CT fusion slices (as indicated) of the supraclavicular region showing $\left[{ }^{18} \mathrm{~F}\right] \mathrm{FDG}$ uptake in BAT locations (white arrows) after cold exposure in the baseline and the fasted condition. (c, d) Individual data on BAT glucose uptake rate and NST (\%). (e, f) Associations between NST (\%) and BAT glucose uptake rate $\left(r^{2}=0.347, p<\right.$ 0.05), and between NST (\%) and maximal BAT activity (BAT SUV max; $r^{2}=0.356, p<0.05$ ) in the baseline condition. 

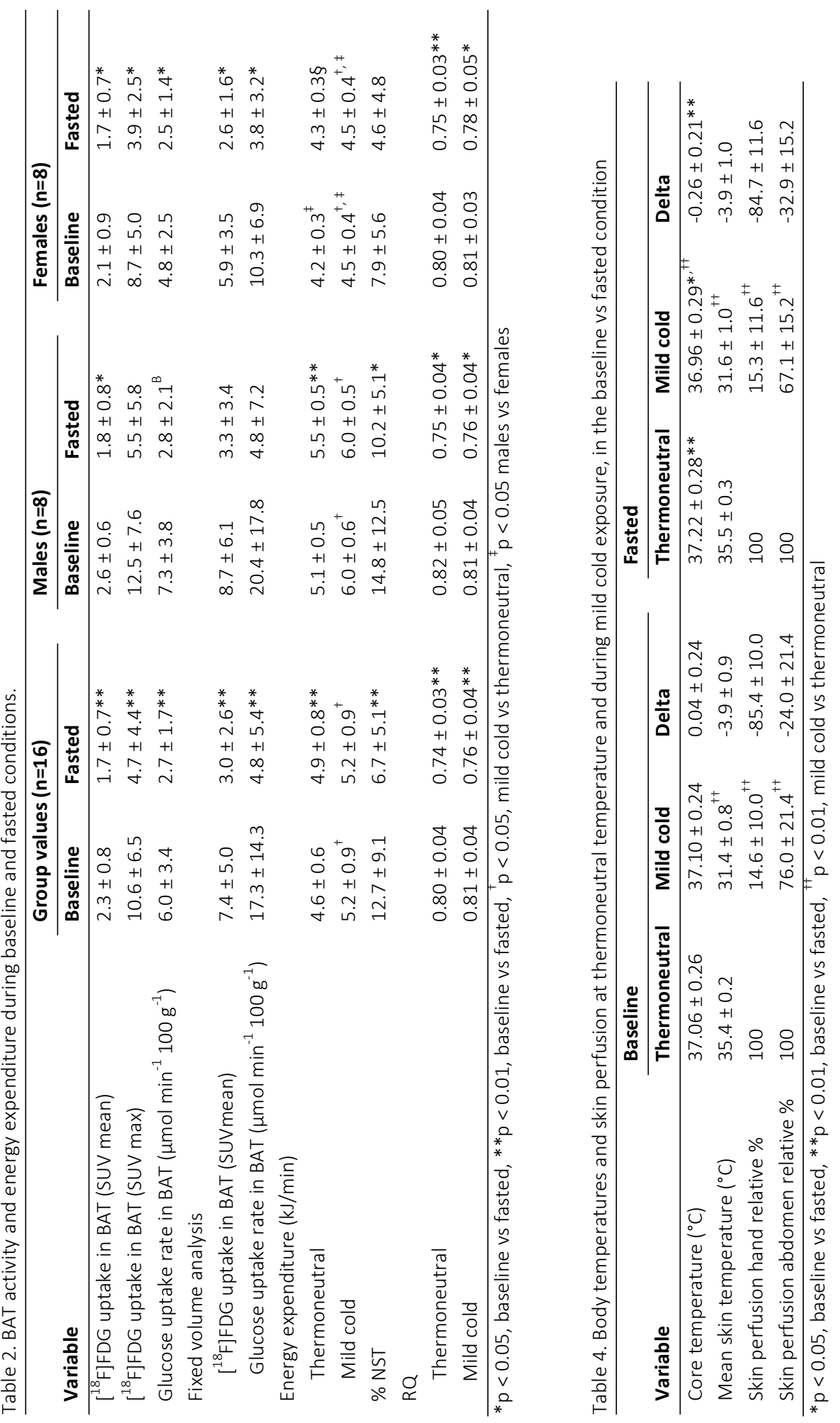
To investigate glucose fluxes into BAT upon fasting in more detail, two-tissue compartment modeling of the dynamic PET/CT data was employed (Supplement Fig. 1). $K_{1}$ values, representing the $\left[{ }^{18} \mathrm{~F}\right] \mathrm{FDG}$ influx rate constant from plasma into BAT (including both interstitial and intracellular space), were not different between the baseline and fasted condition $\left(0.09 \pm 0.04\right.$ vs $0.11 \pm 0.03 \mathrm{ml} \mathrm{min}^{-1} \mathrm{ml}^{1}$, respectively, $p=0.146$; Table 3 ). In addition, the distribution volume (DV) of free (nonphosphorylated) $\left.{ }^{18} \mathrm{~F}\right] \mathrm{FDG}$ in BAT was not different between the baseline and fasted condition $(0.32 \pm 0.13$ vs $0.26 \pm 0.09 \mathrm{ml} / \mathrm{ml}$, respectively, $\mathrm{p}=0.185)$. Interestingly, phosphorylation fraction value, reflecting the proportion of $\left[{ }^{18} \mathrm{~F}\right] \mathrm{FDG}$ that enters the tissue (including both interstitial and intracellular space) that is eventually metabolized $\left(k_{3} /\left[k_{2}+k_{3}\right]\right)$, was significantly lower upon fasting $(0.25 \pm$ 0.11 vs $0.11 \pm 0.06$, baseline vs fasted, respectively, $p<0.01$ ).

BAT glucose uptake rate and NST were significantly correlated in the baseline condition (Fig. 2e), as were maximal $\left[{ }^{18} \mathrm{~F}\right]$ FDG uptake in BAT and NST (Fig. 2f). Changes in NST and BAT glucose uptake from the baseline to the fasting condition were not related.

Table 3. Rate constants for two-tissue compartment modelling of $\left[{ }^{18}\right.$ F]FDG metabolism in BAT

\begin{tabular}{lll}
\hline & Baseline & Fasted \\
\hline $\mathrm{K}_{1}, \mathrm{ml} \mathrm{min}^{-1} \mathrm{ml}^{-1}$ & $0.09 \pm 0.04$ & $0.11 \pm 0.03$ \\
$\mathrm{k}_{2}, \mathrm{~min}^{-1}$ & $0.33 \pm 0.17$ & $0.45 \pm 0.13$ \\
$\mathrm{~K}_{3}, \mathrm{~min}^{-1}$ & $0.10 \pm 0.06$ & $0.05 \pm 0.02^{* *}$ \\
DV of free $\left[{ }^{18} \mathrm{~F}\right] \mathrm{FDG}\left(\mathrm{K}_{1} / \mathrm{K}_{2}\right), \mathrm{ml}$ plasma/ml tissue & $0.32 \pm 0.13$ & $0.26 \pm 0.09$ \\
Phosphorylation fraction $\left[\mathrm{K}_{3} /\left(\mathrm{k}_{2}+\mathrm{k}_{3}\right)\right]$ & $0.25 \pm 0.11$ & $0.11 \pm 0.06^{* *}$ \\
\hline
\end{tabular}

${ }^{* *} p<0.01$, baseline vs fasted, $n=14$. DV, distribution volume

\section{Glucose uptake in other tissues}

In contrast to marked decreases in $\left[{ }^{18} \mathrm{~F}\right] \mathrm{FDG}$ uptake in BAT, no changes in $\left[{ }^{18} \mathrm{~F}\right] \mathrm{FDG}$ uptake during cold stimulation were observed in skeletal muscle, visceral WAT, liver and brain in the fasted compared with the baseline condition (Fig. 3). Subcutaneous WAT showed a small but significant increase in cold-stimulated glucose uptake upon fasting $(0.21 \pm 0.07$ to $0.26 \pm 0.09$ SUV mean, $p<0.05)$.

\section{Skeletal muscle mitochondrial respiration}

Next to BAT, skeletal muscle is a putative alternative contributor to NST via mitochondrial proton leak, resulting in respiration that is not coupled to ATP production (31). Analysis of mitochondrial oxygen consumption using isolated mitochondria revealed no differences in oligomycin-insensitive (state 40) 
respiration, reflecting basal proton leak, between the baseline and fasted samples $\left(175.0 \pm 68.7\right.$ vs $164.5 \pm 63.1 \mathrm{pmol} \mathrm{O}_{2} \mathrm{~s}^{-1} \mathrm{mg}^{-1}$ mitochondrial protein, respectively, $\mathrm{p}$ $>0.05$; Supplement Fig. 2a), indicating no contribution of skeletal muscle mitochondrial proton leak to the decrease in NST upon fasting. Fatty acids stimulated the oligomycin-insensitive (state 40) respiration in a dose-dependent manner. However, calculated half-maximal effective concentration $\left(E_{50}\right)$ values $(278 \pm 236$ vs $235 \pm 194 \mathrm{nmol} / \mathrm{l}$, baseline vs fasted respectively, $p>0.05$; Supplement Fig. 2b) and maximal fatty acid-induced uncoupled respiration values (Vmax; $2486 \pm 690$ vs $2082 \pm 818 \mathrm{pmol} \mathrm{O}_{2} \mathrm{~s}^{-1} \mathrm{mg}^{-1}$, baseline vs fasted respectively, p $>0.05$; Supplement Fig. 2c) were similar in both conditions, indicating comparable sensitivity to the uncoupling effects of fatty acids in the baseline and fasted condition.

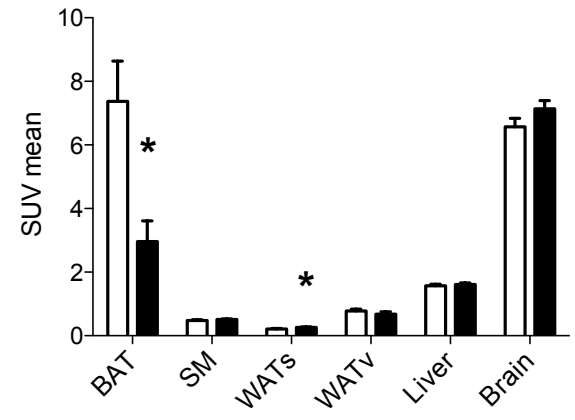

Figure 3. Mean ( \pm SEM) uptake of $\left[{ }^{18}\right.$ F]FDG in BAT and other tissues during the baseline (white bars) and fasted (black bars) conditions. ${ }^{*} p<0.05$ fasted vs baseline. SM, skeletal muscle; WATs, subcutaneous white adipose tissue; WATV, visceral white adipose tissue. $n=16$ (for brain $n=9$ )

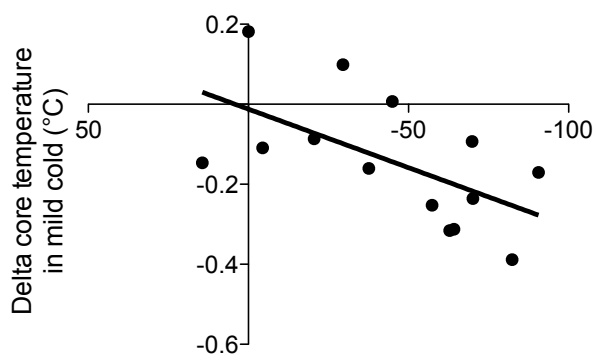

Delta BAT glucose uptake rate (\%)

Figure 4. Relationship between the difference in core temperature during cold exposure between the fasted and the baseline condition ( $\Delta$ core temperature in mild cold) and the difference in BAT glucose uptake rate between these conditions ( $\Delta$ glucose uptake rate); $r^{2}=0.350, p<0.05$

\section{Core and skin temperatures and skin perfusion}

Temperature of the water-perfused suit showed a similar decrease during the cooling protocol in the baseline (from $30.3 \pm 0.6^{\circ} \mathrm{C}$ to $25.4 \pm 0.8^{\circ} \mathrm{C}$ ) and the fasted condition (from $30.3 \pm 0.5^{\circ} \mathrm{C}$ to $25.6 \pm 0.9^{\circ} \mathrm{C}$ ). Consequently, the decrease in mean skin temperature during the cooling protocol was also similar between conditions $\left(-3.9 \pm 0.9^{\circ} \mathrm{C}\right.$ vs $-3.9 \pm 1.0^{\circ} \mathrm{C}, \mathrm{p}=0.628$, respectively; Table 4$)$. In addition, skin perfusion of the hand and abdomen were not different between the conditions. 
Interestingly, core temperature showed a significant decrease upon cold exposure in the fasted condition $\left(-0.26 \pm 0.21^{\circ} \mathrm{C}, \mathrm{p}<0.001\right)$, in contrast to an unchanged core temperature in the baseline condition $\left(0.04 \pm 0.24^{\circ} \mathrm{C}, \mathrm{p}=0.557\right)$. The difference in cold-induced core temperature between the fasted and the baseline condition was significantly correlated to the difference in BAT glucose uptake rate $\left(r^{2}=0.350, p<\right.$ 0.05; Fig. 4) and BAT phosphorylation fraction $\left(r^{2}=0.308, p<0.05\right)$ between these conditions.

\section{DISCUSSION}

BAT has been proposed as a target to stimulate glucose disposal under insulinresistant conditions, such as type 2 diabetes. When peripheral tissues are resistant for the effect of insulin to stimulate glucose uptake, this leads to impaired insulininduced glucose clearance. However, even under such insulin-resistant conditions, glucose uptake in peripheral tissues can still be increased via non-insulin dependent pathways, such as the AMPK pathway that can be activated by exercise or by pharmacological means (32). Whether cold-induced activation of BAT could also be a target to improve glucose clearance under insulin-resistant conditions in humans is so far unknown. Here we used prolonged fasting as a model to induce insulin resistance, and examined whether cold stimulation could still activate glucose uptake into BAT under such insulin-resistant conditions. Prolonged fasting is an interesting model, as peripheral insulin resistance develops to preserve glucose as a substrate for the brain; however, even under hyperinsulinemiceuglycemic clamp conditions, when glucose availability is ample, peripheral glucose uptake is still reduced after $60 \mathrm{~h}$ of fasting, as we have shown recently (18). Although we were not able to repeat measurements of whole-body insulin resistance here, we followed a very similar protocol as in our previous publication and levels of plasma NEFAs, glucose and insulin are in agreement with this previous study, convincing us that participants were indeed more insulin-resistant upon fasting in the present study. We now show that cold-induced glucose uptake into BAT is markedly reduced after prolonged fasting. If these results also apply to other insulin-resistant conditions, it may suggest that isolated cold therapy may not be able to improve glucose homeostasis via glucose clearance by BAT under such conditions.

The dynamic PET scanning protocol allowed us to investigate disturbances in coldinduced BAT glucose uptake upon prolonged fasting in more detail, using two- 
tissue compartment modelling. Theoretically, decreased glucose uptake rates into BAT could be either due to decreased glucose availability to the tissue (e.g. due to decreased blood flow, decreased plasma glucose or decreased glucose extraction) and/or due to decreased cellular glucose uptake rate. Interestingly, we found no significant changes in $\left[{ }^{18} \mathrm{~F}\right] \mathrm{FDG}$ influx rates $\left(\mathrm{K}_{1}\right)$ and $\left[{ }^{18} \mathrm{~F}\right] \mathrm{FDG}$ distribution volume in BAT upon fasting, indicating that the decrease in BAT glucose uptake rate was not due to a lower supply of glucose towards BAT, i.e. glucose transport to BAT interstitial space was not hampered. Rather, the model indicates a lower cellular uptake and/or decreased phosphorylation rate of glucose, as indicated by the lower phosphorylation fraction in the fasted condition. As stated above, it should be noted that glucose transport into BAT reflects movement of $\left[{ }^{18} \mathrm{~F}\right] \mathrm{FDG}$ to both intracellular and interstitial space (33) and that two-tissue compartment modelling does not completely discriminate between (GLUT-mediated) glucose transport into brown adipocytes and/or subsequent phosphorylation by hexokinase. We are therefore not able to distinguish between brown adipocyte $\left[{ }^{18} \mathrm{~F}\right] \mathrm{FDG}$ uptake or $\left[{ }^{18} \mathrm{~F}\right] \mathrm{FDG}$ phosphorylation as the main determinant of decreased BAT $\left[{ }^{18} \mathrm{~F}\right] \mathrm{FDG}$ uptake upon fasting. As in other insulin-resistant conditions both of these processes are disturbed as well (34); this points towards comparable mechanisms at play in BAT during fasting-induced insulin-resistant conditions.

Interestingly, the decrease in cold-stimulated glucose uptake after fasting is specific for BAT, since this was not observed in other tissues. In subcutaneous WAT, $\left[{ }^{18}\right.$ F]FDG uptake was increased, which may be explained by an increased triacylglycerol/fatty acid cycling, whereby $\alpha$-glycerol phosphate, which provides the backbone for esterification of NEFAs, is derived from plasma glucose uptake, as demonstrated previously (35). The energy required for this process might actually contribute to the increase in energy expenditure that we measured upon fasting (36). In skeletal muscle, cold-induced glucose uptake was not affected by fasting; these results may indicate that even though cold exposure may not be able to increase glucose clearance under insulin-resistant conditions via BAT, the effect of cold exposure on other glucose-consuming tissues may still be worth exploring as a therapy to boost glucose clearance under insulin-resistant states.

Consistent with previous publications $(37$; 38), we found that BMR was increased upon fasting, most likely due to increased whole-body sympathetic activity, as indicated by the elevated epinephrine levels. Furthermore, we found that NST was decreased upon fasting, which can be partly explained by higher BMR, and we found a correlation between BAT glucose uptake rate and NST at baseline, but not 
in the fasted state. At first instance, this latter finding could argue against a direct relationship between BAT thermogenic activity and whole-body energy expenditure. However, it should be noted that $\left[{ }^{18} \mathrm{~F}\right] \mathrm{FDG}$ uptake is not a direct measure of the thermogenic activity of BAT. Although a relationship between $\left[{ }^{18} \mathrm{~F}\right] F D G$ uptake and thermogenesis in BAT will apply under most conditions, a shift in substrate oxidation towards fatty acid metabolism during fasting might result in increased reliance on fatty acid oxidation for BAT's heat production. Thus, using only glucose uptake as a measure of BAT activity could possibly lead to an underestimation of true BAT thermogenesis under fasted conditions. Future studies using alternative tracers, such as $\left[{ }^{18} \mathrm{~F}\right]$ THA (as a measure of NEFA uptake) and ${ }^{11} \mathrm{C}$-acetate (as a measure of oxidative metabolism), are needed to determine the thermogenic activity of BAT under prolonged fasting conditions. Nevertheless, it is interesting to note that we did find that the fasting-induced decrease in BAT glucose uptake was related to a decrease in core temperature upon cold exposure. Based on our data, it is therefore tempting to speculate that, although a reduction in cold-stimulated glucose uptake into BAT upon fasting may be beneficial to spare glucose availability for the brain, an impaired capacity to regulate body temperature may be the consequence. To the best of our knowledge, this is the first study that shows a direct link between changes in BAT glucose uptake and core temperature, indicating a role for BAT in maintaining core temperature upon cold exposure in humans.

In conclusion, this study shows that under prolonged fasting-induced insulinresistant conditions, cold-stimulated glucose uptake into BAT is reduced, due to a reduced cellular glucose uptake, and is accompanied with reduced NST. Furthermore, our data indicate that the decrease in cold-stimulated BAT glucose uptake upon fasting is related to a decrease in core temperature during cold exposure, suggesting a role for BAT in maintaining a constant core temperature in cold environment. If the observed reduction in the capacity of BAT to take up glucose upon cold exposure is also applicable to other insulin-resistant conditions, such as type 2 diabetes, our data may indicate that a focus on cold-induced stimulation of BAT alone may not be a valid way to improve glucose clearance under such conditions. However, follow-up studies are needed to examine whether glucose uptake into BAT can be activated by other means under insulin-resistant conditions. Specifically, studies in type 2 diabetic patients are urgently awaited. 


\section{REFERENCES}

1. Harms M, Seale P: Brown and beige fat: development, function and therapeutic potential. Nature medicine 2013;19:1252-1263

2. Schulz TJ, Tseng YH: Brown adipose tissue: development, metabolism and beyond. The Biochemical journal 2013;453:167-178

3. van Marken Lichtenbelt WD, Vanhommerig JW, Smulders NM, Drossaerts JM, Kemerink GJ, Bouvy ND, Schrauwen P, Teule GJ: Cold-activated brown adipose tissue in healthy men. The New England journal of medicine 2009;360:1500-1508

4. Virtanen KA, Lidell ME, Orava J, Heglind M, Westergren R, Niemi T, Taittonen M, Laine J, Savisto NJ, Enerback S, Nuutila P: Functional brown adipose tissue in healthy adults. The New England journal of medicine 2009;360:1518-1525

5. Ouellet V, Labbe SM, Blondin DP, Phoenix S, Guerin B, Haman F, Turcotte EE, Richard D, Carpentier AC: Brown adipose tissue oxidative metabolism contributes to energy expenditure during acute cold exposure in humans. The Journal of clinical investigation 2012;122:545-552

6. Trayhurn P: Thermoregulation in the diabetic-obese $(\mathrm{db} / \mathrm{db})$ mouse. The role of nonshivering thermogenesis in energy balance. Pflugers Arch 1979;380:227-232

7. Matz JM, LaVoi KP, Epstein PN, Blake MJ: Thermoregulatory and heat-shock protein response deficits in cold-exposed diabetic mice. The American journal of physiology 1996;270:R525-532

8. Yoshioka K, Yoshida T, Wakabayashi Y, Nishioka H, Kondo M: The role of insulin in norepinephrine turnover and thermogenesis in brown adipose tissue after acute coldexposure. Endocrinol Jpn 1989;36:491-499

9. Mercer SW, Trayhurn P: The development of insulin resistance in brown adipose tissue may impair the acute cold-induced activation of thermogenesis in genetically obese (ob/ob) mice. Biosci Rep 1984;4:933-940

10. Marette A, Deshaies Y, Collet AJ, Tulp O, Bukowiecki L: Major thermogenic defect associated with insulin resistance in brown adipose tissue of obese diabetic SHR/N-cp rats. The American journal of physiology 1991;261:E204-213

11. Burcelin R, Kande J, Ricquier D, Girard J: Changes in uncoupling protein and GLUT4 glucose transporter expressions in interscapular brown adipose tissue of diabetic rats: relative roles of hyperglycaemia and hypoinsulinaemia. The Biochemical journal 1993;291 ( Pt 1):109-113

12. Saito $M$, Okamatsu-Ogura $Y$, Matsushita M, Watanabe K, Yoneshiro T, Nio-Kobayashi J, Iwanaga T, Miyagawa M, Kameya T, Nakada K, Kawai Y, Tsujisaki M: High incidence of metabolically active brown adipose tissue in healthy adult humans: effects of cold exposure and adiposity. Diabetes 2009;58:1526-1531

13. Cypess AM, Lehman S, Williams G, Tal I, Rodman D, Goldfine AB, Kuo FC, Palmer EL, Tseng $\mathrm{YH}$, Doria A, Kolodny GM, Kahn CR: Identification and importance of brown adipose tissue in adult humans. The New England journal of medicine 2009;360:1509-1517 
14. Yoneshiro T, Aita S, Matsushita M, Okamatsu-Ogura Y, Kameya T, Kawai Y, Miyagawa M, Tsujisaki M, Saito M: Age-related decrease in cold-activated brown adipose tissue and accumulation of body fat in healthy humans. Obesity 2011;19:1755-1760

15. Ouellet V, Routhier-Labadie A, Bellemare W, Lakhal-Chaieb L, Turcotte E, Carpentier AC, Richard D: Outdoor temperature, age, sex, body mass index, and diabetic status determine the prevalence, mass, and glucose-uptake activity of 18F-FDG-detected BAT in humans. The Journal of clinical endocrinology and metabolism 2011;96:192-199

16. Lean ME, Murgatroyd PR, Rothnie I, Reid IW, Harvey R: Metabolic and thyroidal responses to mild cold are abnormal in obese diabetic women. Clin Endocrinol (Oxf) 1988;28:665-673

17. Bergman BC, Cornier MA, Horton TJ, Bessesen DH: Effects of fasting on insulin action and glucose kinetics in lean and obese men and women. American journal of physiology Endocrinology and metabolism 2007;293:E1103-1111

18. Hoeks J, van Herpen NA, Mensink M, Moonen-Kornips E, van Beurden D, Hesselink MK, Schrauwen P: Prolonged fasting identifies skeletal muscle mitochondrial dysfunction as consequence rather than cause of human insulin resistance. Diabetes 2010;59:2117-2125

19. Salgin B, Marcovecchio ML, Humphreys SM, Hill N, Chassin LJ, Lunn DJ, Hovorka R, Dunger DB: Effects of prolonged fasting and sustained lipolysis on insulin secretion and insulin sensitivity in normal subjects. American journal of physiology Endocrinology and metabolism 2009;296:E454-461

20. Defronzo RA, Tripathy D: Skeletal muscle insulin resistance is the primary defect in type 2 diabetes. Diabetes care 2009;32 Suppl 2:S157-163

21. Cannon B, Nedergaard J: Metabolic consequences of the presence or absence of the thermogenic capacity of brown adipose tissue in mice (and probably in humans). International journal of obesity 2010;34 Suppl 1:S7-16

22. van der Lans AA, Hoeks J, Brans B, Vijgen GH, Visser MG, Vosselman MJ, Hansen J, Jorgensen JA, Wu J, Mottaghy FM, Schrauwen P, van Marken Lichtenbelt WD: Cold acclimation recruits human brown fat and increases nonshivering thermogenesis. The Journal of clinical investigation 2013;123:3395-3403

23. Bergstrom J, Hultman E, Roch-Norlund AE: Muscle glycogen synthetase in normal subjects. Basal values, effect of glycogen depletion by exercise and of a carbohydrate-rich diet following exercise. Scandinavian journal of clinical and laboratory investigation 1972;29:231-236

24. van Marken Lichtenbelt WD, Daanen HA, Wouters L, Fronczek R, Raymann RJ, Severens NM, Van Someren EJ: Evaluation of wireless determination of skin temperature using iButtons. Physiology \& behavior 2006;88:489-497

25. Kelley $\mathrm{DE}$, Williams $\mathrm{KV}$, Price JC: Insulin regulation of glucose transport and phosphorylation in skeletal muscle assessed by PET. The American journal of physiology 1999;277:E361-369

26. Vosselman MJ, van der Lans AA, Brans B, Wierts R, van Baak MA, Schrauwen $P$, van Marken Lichtenbelt WD: Systemic beta-adrenergic stimulation of thermogenesis is not accompanied by brown adipose tissue activity in humans. Diabetes 2012;61:3106-3113 
27. Vosselman MJ, Brans B, van der Lans AA, Wierts R, van Baak MA, Mottaghy FM, Schrauwen $P$, van Marken Lichtenbelt WD: Brown adipose tissue activity after a high-calorie meal in humans. The American journal of clinical nutrition 2013;98:57-64

28. Hoeks J, Briede JJ, de Vogel J, Schaart G, Nabben M, Moonen-Kornips E, Hesselink MK, Schrauwen P: Mitochondrial function, content and ROS production in rat skeletal muscle: effect of high-fat feeding. FEBS letters 2008;582:510-516

29. Willemsen JJ, Ross HA, Jacobs MC, Lenders JW, Thien T, Swinkels LM, Benraad TJ: Highly sensitive and specific HPLC with fluorometric detection for determination of plasma epinephrine and norepinephrine applied to kinetic studies in humans. Clinical chemistry 1995; 41:1455-1460

30. Orava J, Nuutila P, Lidell ME, Oikonen V, Noponen T, Viljanen T, Scheinin M, Taittonen M, Niemi T, Enerback S, Virtanen KA: Different metabolic responses of human brown adipose tissue to activation by cold and insulin. Cell metabolism 2011;14:272-279

31. Wijers SL, Schrauwen P, Saris WH, van Marken Lichtenbelt WD: Human skeletal muscle mitochondrial uncoupling is associated with cold induced adaptive thermogenesis. PloS one 2008;3:e1777

32. O'Neill HM: AMPK and Exercise: Glucose Uptake and Insulin Sensitivity. Diabetes \& metabolism journal 2013;37:1-21

33. Williams KV, Price JC, Kelley DE: Interactions of impaired glucose transport and phosphorylation in skeletal muscle insulin resistance: a dose-response assessment using positron emission tomography. Diabetes 2001;50:2069-2079

34. Shulman GI: Cellular mechanisms of insulin resistance. The Journal of clinical investigation 2000;106:171-176

35. Wolfe RR, Peters EJ, Klein S, Holland OB, Rosenblatt J, Gary H, Jr.: Effect of short-term fasting on lipolytic responsiveness in normal and obese human subjects. The American journal of physiology 1987;252:E189-196

36. Weber JM, Reidy SP: Extending food deprivation reverses the short-term lipolytic response to fasting: role of the triacylglycerol/fatty acid cycle. The Journal of experimental biology 2012;215:1484-1490

37. Mansell PI, Fellows IW, Macdonald IA: Enhanced thermogenic response to epinephrine after 48-h starvation in humans. The American journal of physiology 1990;258:R87-93

38. Zauner C, Schneeweiss B, Kranz A, Madl C, Ratheiser K, Kramer L, Roth E, Schneider B, Lenz $\mathrm{K}$ : Resting energy expenditure in short-term starvation is increased as a result of an increase in serum norepinephrine. The American journal of clinical nutrition 2000;71:15111515

39. Dhawan V, Moeller JR, Strother SC, Evans AC, Rottenberg DA: Effect of selecting a fixed dephosphorylation rate on the estimation of rate constants and rCMRGlu from dynamic [18F] fluorodeoxyglucose/PET data. Journal of nuclear medicine : official publication, Society of Nuclear Medicine 1989;30:1483-1488 


\section{SUPPLEMENTAL FIGURES}

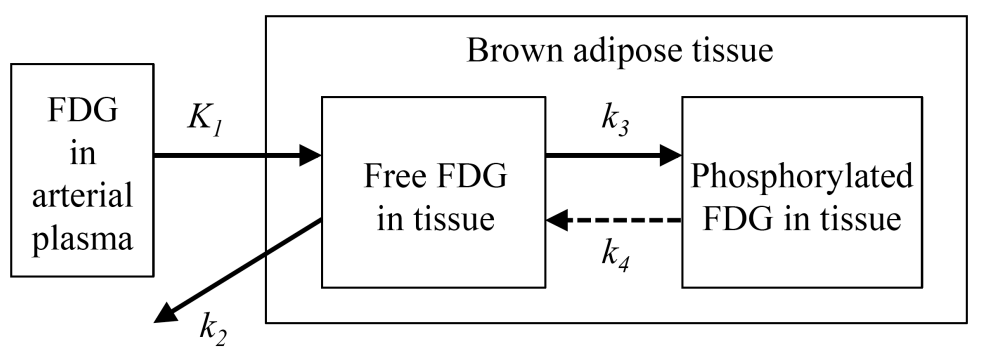

Supplement Figure 1. Two-tissue compartment model for $\left[{ }^{18} \mathrm{~F}\right] \mathrm{FDG}$ uptake in BAT. The parameters $\mathrm{K}_{1}$ through $\mathrm{k}_{4}$ represent first order rate constants, which govern the dynamics of $\left[{ }^{18} \mathrm{~F}\right] \mathrm{FDG}$ between the compartments. The forward transport rate constant $K_{1}$ reflects movement of free $\left[{ }^{18} F\right] F D G$ from arterial plasma into a tissue compartment, including both intracellular and interstitial space. The outward transport rate constant $\mathrm{k}_{2}$ represents movement of $\left[{ }^{18} \mathrm{~F}\right] \mathrm{FDG}$ from this tissue compartment back into venous plasma, and therefore reflects $\left[{ }^{18} \mathrm{~F}\right] \mathrm{FDG}$ that is returning to plasma because it has not been transported into the adipocyte (returning from interstitial space) and/or because it has been transported into the adipocyte but not phosphorylated (returning from intracellular space) (33). Hexokinase-mediated phosphorylation of $\left[{ }^{18} \mathrm{~F}\right] \mathrm{FDG}$, and thereby trapping of the tracer in the adipocyte as $\left[{ }^{18} \mathrm{~F}\right] \mathrm{FDG}-6$-phosphate, is represented by the rate constant $\mathrm{k}_{3}$. Because free $\left[{ }^{18} \mathrm{~F}\right] \mathrm{FDG}$ can be present in both interstitial and intracellular space, and it first needs to be transported into the adipocyte before being phosphorylated, changes in $k_{3}$ between experimental conditions could also be influenced by changes in transport into the adipocyte. Dephosphorylation of $\left[{ }^{18} \mathrm{~F}\right] \mathrm{FDG}-6$-phosphate $\left(k_{4}\right)$ is assumed to be negligible (39).
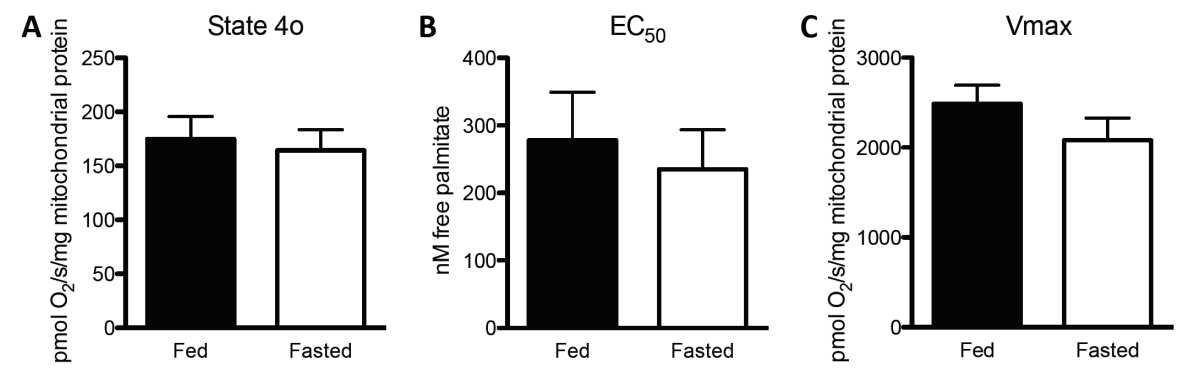

Supplement Figure 2. No effects of fasting on leak respiration in skeletal muscle. (A) Basal mitochondrial leak (state 40) respiration, in the presence of pyruvate and the ATP-synthase inhibitor oligomycin. (B) Half-maximal effective concentration $\left(E_{50}\right)$ of palmitate concentration-response curves. (C) Maximal palmitate-induced leak respiration (Vmax). Values expressed as mean \pm SEM. $\mathrm{n}=11$. 
GLUCOSE UPTAKE IN BAT UPON FASTING-INDUCED INSULIN RESISTANCE 


\section{Short-term cold acclimation improves insulin sensitivity in patients with type 2 diabetes mellitus}

The contents of this chapter are published in: MJW Hanssen, J Hoeks, B Brans, AAJJ van der Lans, G Schaart, JJ van den Driessche,

JA Jörgensen, MV Boekschoten, MKC Hesselink, B Havekes, S Kersten, FM Mottaghy, WD van Marken Lichtenbelt, P Schrauwen. Short-term cold acclimation improves insulin sensitivity in patients with type 2 diabetes mellitus. Nature Medicine 2015;21:863-5 


\section{ABSTRACT}

Cold exposure may be a potential therapy for diabetes by increasing brown adipose tissue (BAT) mass and activity. Here we report that $10 \mathrm{~d}$ of cold acclimation (14-15 ${ }^{\circ} \mathrm{C}$ ) increased peripheral insulin sensitivity by $\sim 43 \%$ in eight type 2 diabetes subjects. Basal skeletal muscle GLUT4 translocation markedly increased, without effects on insulin signaling or AMP-activated protein kinase (AMPK) activation and only a minor increase in BAT glucose uptake. 


\section{INTRODUCTION}

Cold-induced adaptive thermogenesis has gained considerable interest due to the 'rediscovery' of brown adipose tissue (BAT) in adult humans in 2009 (1-3). In response to these findings, activation of human BAT has been proposed as a potential treatment for type 2 diabetes (T2D) because such activation leads to the dissipation of energy as heat, which is expected to not only increase energy expenditure but also boost the oxidation of triglycerides and glucose as substrates. Thus it is expected that patients with T2D treated in this way would display not only weight loss, but also improvements in lipid and glucose homeostasis (4; 5). Indeed, in rodents enhanced BAT activity has been shown to prevent the development of obesity and diabetes under obesogenic conditions (6). We (7) and others $(8 ; 9)$ have recently shown that chronic cold exposure (cold acclimation) leads to increases in both BAT quantity and activity in humans, suggesting that BAT can be recruited upon cold acclimation. Here, we investigated whether cold acclimation for 10 days could be used to recruit BAT and improve glucose homeostasis in eight individuals with T2D (Supplemental Table 1).

\section{RESULTS \& DISCUSSION}

Body weight and clinical blood parameters were unaffected by cold acclimation (Supplemental Table 2), and thyroid stimulating hormone (TSH) concentrations decreased while free thyroxine (T4) concentrations increased after cold acclimation (Supplemental Table 2).

As a measure of BAT activity, we determined acute cold-induced 2-deoxy-2$\left[{ }^{18} \mathrm{~F}\right]$ fluoro-D-glucose $\left(\left[{ }^{18} \mathrm{~F}\right] \mathrm{FDG}\right)$ uptake by positron emission tomography/computed tomography PET/CT scanning (Fig. 1a,b). Upon cold acclimation, $\left[{ }^{18}\right.$ F]FDG uptake (standardize uptake values; SUVmax (data not shown) and SUVmean) in the supraclavicular BAT region increased in all subjects (Fig. 1c). Also, CT radio density (in Hounsfield units) of the BAT depot increased in 7 out of 8 subjects after cold acclimation (Fig. 1d), suggesting that triglyceride content was reduced, indicative of BAT activation (10). However, we noted that even after cold acclimation the observed $\left[{ }^{18} \mathrm{~F}\right] \mathrm{FDG}$ uptake in BAT in the T2D patients in our study was very low compared with those in the literature, which were for young, healthy subjects $(7 ; 11)$. We also measured cold-induced $\left[{ }^{18} \mathrm{~F}\right] \mathrm{FDG}$ uptake in several muscle groups from the cold acclimated patients. Skeletal muscle $\left[{ }^{18} \mathrm{~F}\right] \mathrm{FDG}$ uptake tended 
to increase in most of the investigated muscle groups, and the resulting average skeletal muscle $\left[{ }^{18} \mathrm{~F}\right] \mathrm{FDG}$ uptake was indeed increased after cold acclimation (Fig. $1 e, f)$.

We next examined whether glucose uptake in other adipose tissue depots increased upon cold acclimation, which could indicate 'beiging' (conversion of white adipose tissue (WAT) into adipose tissue containing UCP1-expressing adipocytes). However, $\left[{ }^{18} \mathrm{~F}\right]$ FDG uptake was unaffected by cold acclimation in WAT depots, such as subcutaneous and visceral fat (Fig. 1e). We also performed microarray analysis in subcutaneous WAT biopsies from the human subjects taken before and after 10 days of cold acclimation, and compared it to WAT obtained from cold acclimated mice. No signs of beiging could be detected in the human WAT samples, and most genes identified as beiging markers were unaffected by the cold acclimation (Fig. 1g). Together, these results indicate that after cold acclimation glucose uptake specifically increases in the supraclavicular BAT depot upon acute cold exposure, but BAT activity remains very low in these individuals.

We previously showed that activation of BAT by acute mild cold exposure correlates with cold-induced nonshivering thermogenesis (NST) (7; 12) and that NST increases upon cold acclimation in lean, healthy subjects (7). Here we found that after, but not before, cold acclimation, acute mild cold exposure increased energy expenditure compared to energy expenditure in the thermoneutral zone (TNZ; Fig. 1h), indicating increased capacity for NST upon cold acclimation. To investigate adaptation to the cold, we determined subjective ratings for sensation, thermal comfort and shivering. All ratings were improved at day 10 of cold acclimation compared to day 3, which was the first day with 6 hours of cold exposure (Supplemental Fig. 1). Subjective ratings of hunger, fullness and satiety before and after lunch were not different between day 10 and day 3 (data not shown). Mean skin and core temperatures, skin blood flow and blood pressure during cold exposure was unaffected by cold acclimation (Supplemental Table 3). 

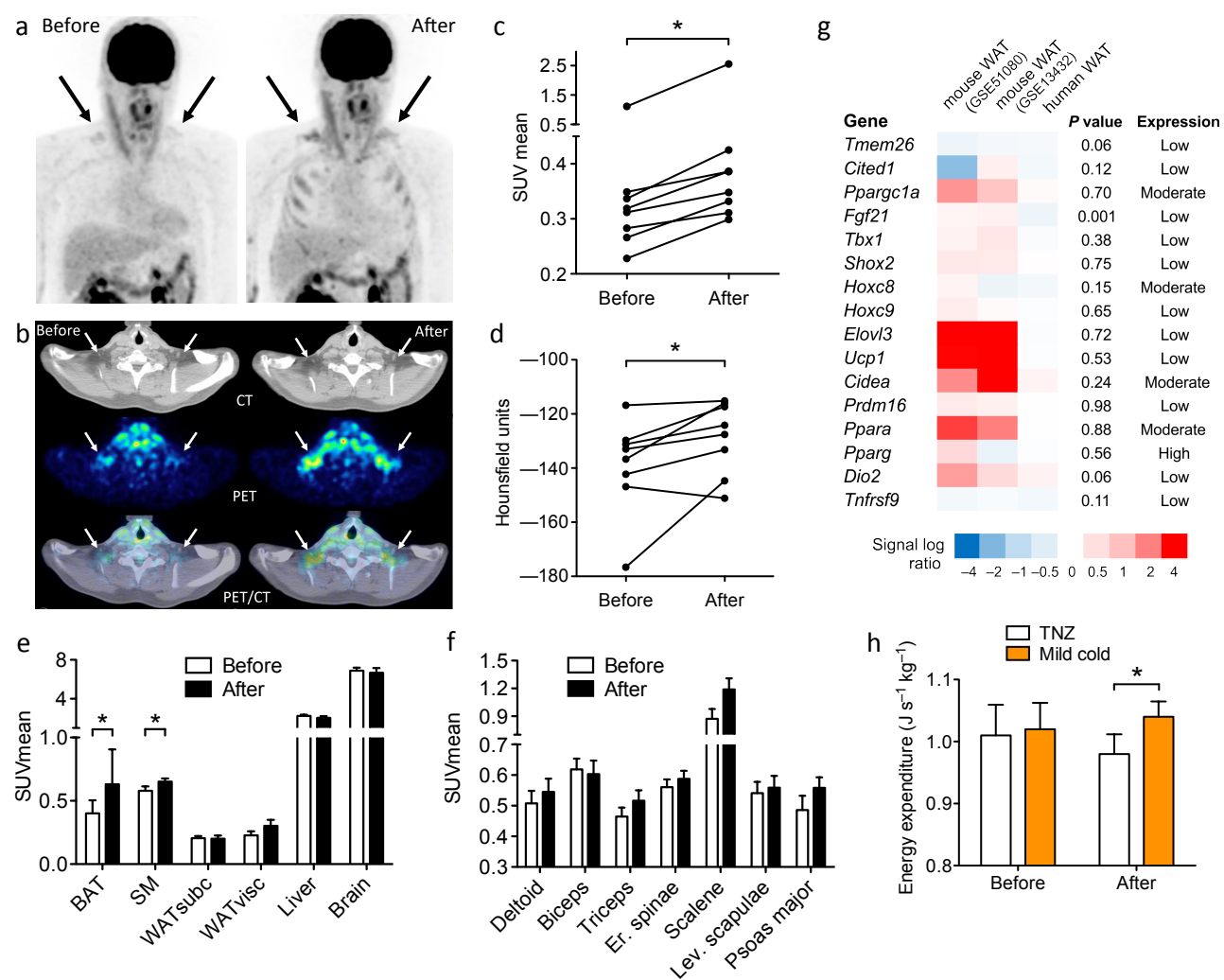

Figure 1. Glucose uptake in the supraclavicular BAT region before and after cold acclimation and WAT beiging. (a) $\left[{ }^{18}\right.$ F]FDG-PET images after acute cold exposure in one representative individual of the eight in the study before (left) and after (right) cold acclimation. Black arrows indicate supraclavicular BAT activity. (b) Transversal CT, PET and PET/CT fusion slices of the supraclavicular region showing $\left[{ }^{18}\right.$ F]FDG uptake in BAT locations (white arrows) in the same individual as in a. (c,d) Cold-induced glucose uptake (expressed as SUVmean) (c) and CT radio density (in Hounsfield units) (d) in the supraclavicular BAT region in all individual subjects. (e) Cold-induced glucose uptake in the supraclavicular BAT region, subcutaneous (WATsubc) and visceral WAT (WATvisc), liver, brain and upper-body skeletal muscle (SM). $n=8,{ }^{*} P<0.05$; error bars, mean \pm s.e.m. (f) Cold-induced glucose uptake in individual skeletal muscle groups used to calculate average SM uptake in e. Er. spinae, erector spinae; Lev. scapulae, levator scapulae. $n=8$; error bars, mean \pm s.e.m. (g) Gene expression changes of selected genes involved in thermogenesis and/or beiging, or suggested as marker genes for beige adipose tissue, in subcutaneous WAT of human subjects with T2D (right column) and subcutaneous WAT from mice subjected to either $10 \mathrm{~d}$ (left column; GSE51080) or $7 \mathrm{~d}$ (middle column; GSE13432) of cold exposure $\left(\sim 5^{\circ} \mathrm{C}\right)$. P values represent intensity-based moderated t-statistic (IBMT)-regularized paired t-test raw $\mathrm{P}$ values. (h) Energy expenditure in thermoneutral conditions and upon acute cold exposure. TNZ, thermoneutral zone. $\mathrm{n}=8$; comparisons between data before and after cold acclimation or between thermoneutral and mild cold conditions were analyzed using Wilcoxon signed-rank tests; ${ }^{*} \mathrm{P}<0.05$; error bars, mean \pm s.e.m. 
To investigate whether cold acclimation improved glucose homeostasis in individuals with T2D, we used hyperinsulinemic-euglycemic clamps, the goldstandard technique, to determine insulin sensitivity before and after cold acclimation. Of note, clamps were performed at thermoneutrality. Insulin sensitivity was markedly increased after cold acclimation, as indicated by on average a $43 \%$ increase in the glucose infusion rate during the clamp (Fig. 2a). In fact, the increase in insulin sensitivity even exceeded the improvements in insulin sensitivity that are seen upon long-term exercise training (13), which is generally considered to be the best strategy to prevent or treat T2D. Improved whole-body insulin sensitivity was mainly accounted for by a marked increase in insulinstimulated glucose disposal (Fig. 2b), reflecting improvement of peripheral insulin sensitivity. Basal endogenous glucose production (EGP) was not affected by cold acclimation, but insulin-induced suppression of EGP, reflecting hepatic insulin sensitivity, tended to improve upon cold acclimation (Fig. 2c and Supplemental Table 4). After cold acclimation nonesterified fatty acid concentrations were lower during the clamp (Fig. 2d), which indicated improved adipose tissue insulin sensitivity (14). Metabolic flexibility, the ability to shift from predominantly fat oxidation in the fasted state to glucose oxidation upon insulin stimulation, also tended to increase (data not shown), most likely as a reflection of improved insulin-stimulated glucose uptake into skeletal muscle (15).

Because the increase in insulin sensitivity was much more pronounced than anticipated and the activity of BAT remained very low in the treated individuals, we performed detailed analyses of skeletal muscle biopsies obtained after an overnight fast, both before and after 10 days of cold acclimation. As mitochondrial function is a main determinant of insulin sensitivity in individuals with T2D (16), we first examined whether cold acclimation altered skeletal muscle mitochondrial oxidative capacity and/or leak respiration. However, none of the mitochondrial respiration states were affected by cold acclimation (Supplemental Fig. 2a-e). Oxidative phosphorylation complexes and PGC-1 $\alpha$ protein content, as markers of mitochondrial content and biogenesis, respectively, were unaffected by cold acclimation (Supplemental Fig. 2f,g). Skeletal muscle fat content was also unaffected by cold acclimation (Supplemental Fig. 2h). Recently, it was suggested that sarcolipin may regulate futile $\mathrm{Ca}^{2+}$ cycling in skeletal muscle and contribute to non-shivering thermogenesis (17). However, the protein contents of sarcolipin and the sarcoendoplasmic reticulum calcium-transporting ATPase (Serca) isoform Serca2 were unchanged upon cold acclimation (Supplemental Fig. 2i,j), although 
sarcolipin protein expression correlated with NST after cold acclimation (NST [ $\mathrm{J} \mathrm{s}^{-1}$ $\left.\mathrm{kg}^{-1}\right], \mathrm{r}=0.893, \mathrm{P}=0.007$ ).

Skeletal muscle insulin sensitivity can be more directly affected by enhancement of the insulin-signaling cascade or by activation of AMPK (18). We therefore examined biopsies taken before the hyperinsulinemic-euglycemic clamp to determine whether insulin signaling in skeletal muscle was affected by cold acclimation. Notably, phosphorylation of the serine-threonine kinase AKT at both Thr308 (data not shown) and Ser473 (Fig. 2e), as well as total AKT (data not shown), were unaffected by cold acclimation. Furthermore, phosphorylation of the Rab GTPaseactivating protein AS160 was also unaffected by cold acclimation (Fig 2f). We subsequently examined whether altered AMPK activation could contribute to the enhanced insulin sensitivity. However, total AMPK content (data not shown), phosphorylation of AMPK (p-AMPK; from $1600 \pm 408$ to $1598 \pm 124 \mathrm{AU}, \mathrm{P}>0.05, n$ $=7$, data are mean \pm s.e.m.) and p-AMPK/AMPK ratio (Fig. $2 \mathrm{~g}$ ) were unaffected by cold acclimation. In skeletal muscle, GLUT1 and GLUT4 are both involved in glucose uptake. Notably, while GLUT1 protein content was unaffected by cold acclimation (from $0.72 \pm 0.11$ to $0.63 \pm 0.08 \mathrm{AU}, \mathrm{P}>0.05, \mathrm{n}=7$, data are mean \pm s.e.m.), we observed that total GLUT4 protein content tended to increase after 10 days of cold acclimation (Fig. 2h). Subsequently, we performed immunostaining of GLUT4 on muscle biopsy sections taken before the clamp to investigate the subcellular distribution of GLUT4 within the muscle cells. Whereas before cold acclimation GLUT4 was evenly distributed over the muscle cell, the pattern was clearly different after cold acclimation, with pronounced staining of GLUT4 at the cell membrane (Fig. 2i) - indicative of translocation of GLUT4 to the membrane to facilitate glucose uptake - occurring even under basal conditions. We quantified GLUT4 localization, which revealed an on average $60 \%$ enrichment of GLUT4 in cell membranes after cold acclimation (Fig. 2j). 
a

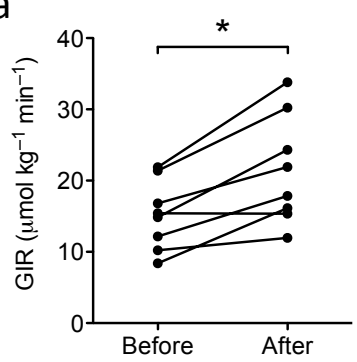

C

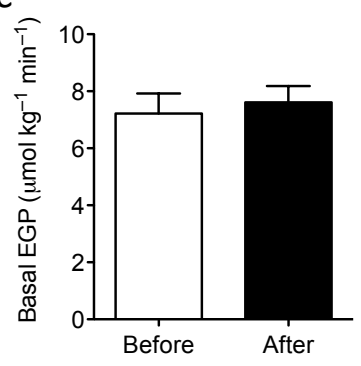

e

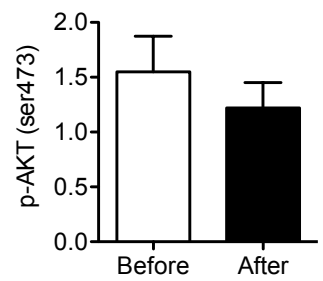

h

h Before After Before After

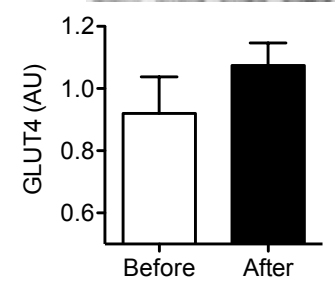

j

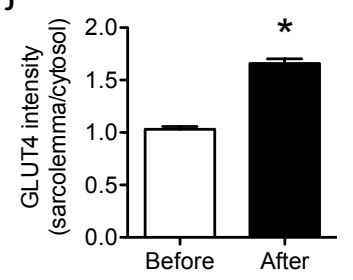

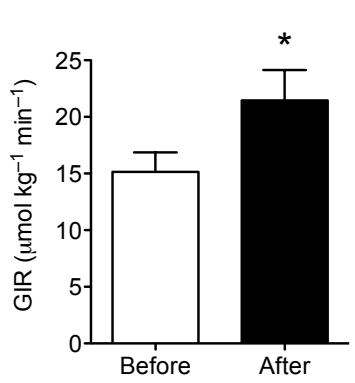

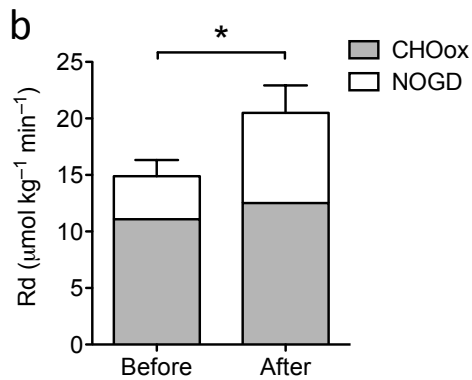

d

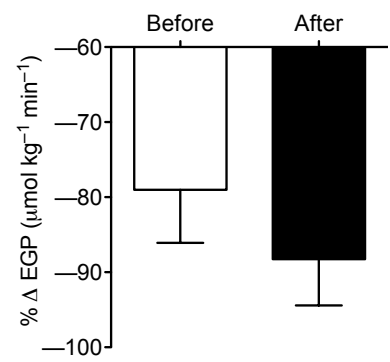

f

Before After Before After p-AS160 — - — -

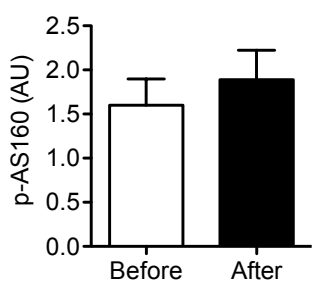

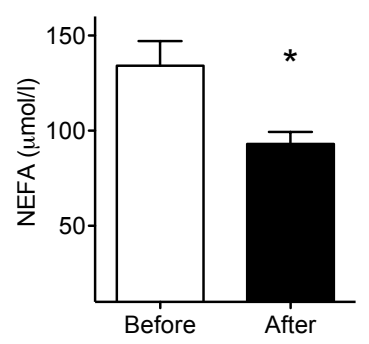

g Before After Before After p-AMPK

AMPK

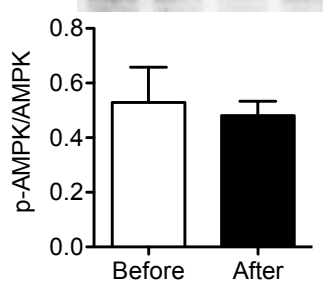

i

\section{Subject 1}

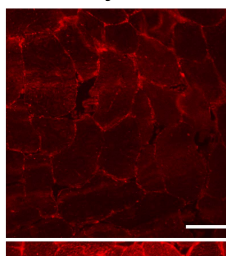

Subject 2

Subject 3

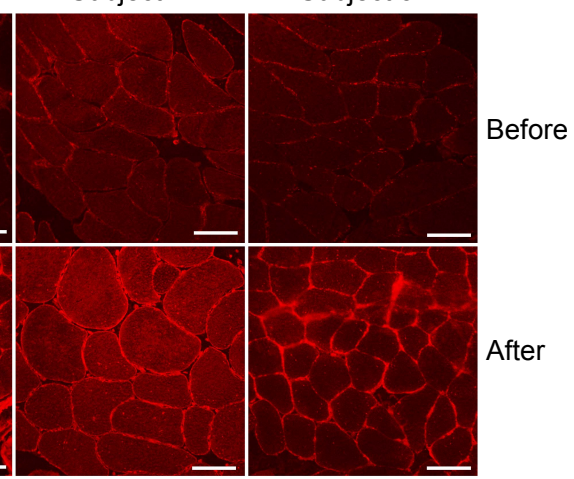


Figure 2. Insulin sensitivity and skeletal muscle GLUT4 localization before and after cold acclimation. (a) Individual data (left) and group mean \pm s.e.m. (right) for glucose infusion rate (GIR), corrected for body weight, during hyperinsulinemic-euglycemic clamp; $n=8$. (b) Insulin-stimulated glucose disposal $(\mathrm{Rd})$, as a combination of glucose oxidation (CHOox) and nonoxidative glucose disposal (NOGD); $n=8$. (c) Basal (non-insulin-stimulated) endogenous glucose production (EGP; left) and insulin-induced suppression of EGP (\% $\triangle E G P$ ) (right); $n=8$. (d) Plasma nonesterified fatty acid (NEFA) concentrations during the hyperinsulinemic-euglycemic clamp; $n=8$. (e-h) Western blot data for phosphorylation of AKT at Ser473 (e), phosphorylation of AS160 (f), ratio of phosphorylated AMPK (p-AMPK) and AMPK (g) and GLUT4 ( $P=0.063)(\mathrm{h})$, including representative blots of two individuals with T2D, in noninsulin-stimulated skeletal muscle biopsies; $n=7$. (i) Representative images (of 3-5 images per individual) of GLUT4 immunostaining on 5 - $\mu$ m-thick fresh-frozen non-insulin-stimulated skeletal muscle tissue sections from three individuals in the study. Scale bars, $60 \mu \mathrm{m}$. (j) Quantification of average GLUT4 staining intensities at the sarcolemma and the cytosol ( $n=7$ ). Throughout, comparisons between data before and after cold acclimation were analyzed using Wilcoxon signedrank tests. ${ }^{*} P<0.05$; error bars, mean \pm s.e.m.

The observation of increased GLUT4 in the membrane is consistent with the higher $\left[{ }^{18} \mathrm{~F}\right] F D G$ uptake in skeletal muscle after cold acclimation (Fig 1e,f). Therefore, our data suggest that cold acclimation leads to an enrichment of GLUT4 at the sarcolemma, which may facilitate the uptake of glucose. This GLUT4 translocation could not be explained by AMPK activation or improved insulin signaling. Also, subjects did not report overt shivering in the final days of the cold acclimation, and enhanced skeletal muscle GLUT4 translocation after cold acclimation was observed in the overnight fasted, thermoneutral state. Therefore alternative mechanisms need to be explored: it has recently been proposed that - $\beta$-adrenergic stimulation is able to activate GLUT4 translocation (19), and daily cold exposure may increase sympathetic activity. Alternatively, it has recently been shown that BAT may release endocrine factors that can engage other metabolic tissues (20), and it would be worth exploring if some of these endocrine factors have insulinsensitizing effects on skeletal muscle.

In conclusion, our findings indicate that cold acclimation for 10 days has very marked positive effects on whole-body and skeletal muscle insulin sensitivity and thereby provide a new avenue to improve the metabolic health of patients with T2D. 


\section{METHODS}

\section{Participants}

Eight overweight male individuals with T2D (age $59.3 \pm 5.8$ years, body weight 92.0 $\pm 11.7 \mathrm{~kg}, \mathrm{BMI} 29.8 \pm 3.2 \mathrm{~kg} / \mathrm{m} 2$, body fat $26.2 \pm 4.0 \%)$ were included in this study. We performed a power calculation with insulin sensitivity as primary outcome. Based on an expected difference in insulin sensitivity of $20 \%$, with a power of 0.80 and an $\alpha$ of 0.05 (2-sided), we calculated that 11 subjects would be needed (G*Power 3.1 software, F. Faul, E. Erdfelder, A.G. Lang and A. Buchner, University of Trier, Trier, Germany; http://www.gpower.hhu.de). Since the effects on insulin sensitivity were much more pronounced than anticipated in the power calculation, we terminated the study upon completion of all tests in eight subjects, in agreement with our external monitoring board. All subjects were screened for medical history, and exclusion criteria included uncontrolled hypertension, active cardiovascular disease, liver or kidney dysfunction, smoking and use of insulin, beta-blockers or other medication known to interfere with BAT function. Individuals included in the study were diagnosed with $T 2 D$, which was well controlled ( $\mathrm{HbA} 1 \mathrm{c} 50.1 \pm 6.6 \mathrm{mmol} / \mathrm{mol})$, at least 1.5 years before the start of the study. All subjects used metformin, and four subjects also used sulfonylurea agents (see Supplemental Table 1 for detailed subject characteristics). Studies were performed between January and September 2014.

\section{Study approval}

The study was approved by the Ethics Committee of Maastricht University Medical Center and all participants provided written informed consent. Procedures were conducted according to the principles of the Declaration of Helsinki.

\section{Study design}

Body composition was determined by dual X-ray absorptiometry (Discovery A, Hologic, Bedford, MA, USA). Subjects then started the 10-day cold acclimation intervention. Before and after 10 days of cold acclimation, an individualized cooling protocol was performed, immediately followed by $\left[{ }^{18} \mathrm{~F}\right] \mathrm{FDG}-\mathrm{PET} / \mathrm{CT}$ scanning (Gemini TF PET-CT, Philips, Eindhoven, the Netherlands) for quantification of BAT activity, as described previously (7). On a separate day, an abdominal subcutaneous fat biopsy and a muscle biopsy from the vastus lateralis muscle (21) was taken after an overnight fast. Subsequently, peripheral insulin sensitivity was 
assessed by a 3-hour hyperinsulinemic-euglycemic clamp, performed at thermoneutrality. During the 10-day cold acclimation protocol, subjects were exposed to an environmental temperature of $14-15^{\circ} \mathrm{C}$ for 10 consecutive days: $2 \mathrm{~h}$ on day 1 , 4 h on day 2 , and 6 h on days 3 through 10 . On day 11 after the start, coldinduced BAT activity measurements were repeated ( $2.5 \mathrm{~h}$ in mild cold). On the following day (day 12) subjects were again exposed to an environmental temperature of $14-15{ }^{\circ} \mathrm{C}$ for $6 \mathrm{~h}$, and this was followed by the second hyperinsulinemic-euglycemic clamp on day 13 . Subjects were instructed to maintain their normal antidiabetic medication use throughout the whole acclimation period, except for the days on which the clamps were performed.

Subjects consumed standardized meals on the evenings before each experimental day and were asked to refrain from heavy exercise at least $48 \mathrm{~h}$ before each of these measurements.

\section{Cold acclimation}

During cold acclimation, subjects were dressed in shorts and T-shirts and remained sedentary while staying in the cold room. Food intake in the cold room was kept constant and subjects were instructed not to change their normal dietary regime outside the cold room. Hunger and satiety questionnaires were completed before and after lunch. At selected time points, blood pressure was monitored, VAS scales on sensation, thermal comfort and shivering were completed and incremental AUCs (iAUC) were calculated to determine subjective responses during cold acclimation (7).

\section{Individualized cooling and PET/CT imaging}

Individualized cooling protocols were performed after a $4 \mathrm{~h}$ fasting period. Subjects were wrapped in a water-perfused suit (ThermaWrap Universal 3166, MTRE Advanced Technologies Ltd, Yavne, Israel) and were measured at thermoneutrality for $45 \mathrm{~min}$, after which they were cooled until a temperature just above their shivering point and measured for an additional $30 \mathrm{~min}$ at this temperature. Core and skin temperatures, heart rate, skin perfusion and energy expenditure were measured continuously and blood pressure was measured every 15 min during the cooling protocol, as described previously (7). Nonshivering thermogenesis (NST) was calculated as the absolute increase (corrected for body weight) in energy expenditure upon acute mild cold exposure above basal metabolic rate (measured at thermoneutrality). Subsequently, $74 \mathrm{MBq}$ of $\left[{ }^{18} \mathrm{~F}\right] \mathrm{FDG}$ was injected 
intravenously. One hour after injection the PET/CT scanning protocol started with a low-dose CT scan (120 kV, 30 mAs). Directly hereafter, a static PET scan (6 to 7 bed positions, $6 \mathrm{~min}$ per bed position) was performed (22). All PET-CT scans were analyzed using PMOD software (version 3.0, PMOD Technologies, Zurich, Switzerland) by both the researcher (M.J.W.H.) and an experienced nuclear medicine physician (B.B.). Fixed volumes of interest (VOIs) were selected in the supraclavicular adipose tissue region (between -10 and -180 Hounsfield units [HU]), subcutaneous and visceral WAT, liver, brain and in the deltoid, biceps, triceps and erector spinae muscles, as described previously (23). Additionally, $2.67 \mathrm{~cm}^{3}$ VOls were placed in the scalene, levator scapulae and psoas major muscles, and average uptake in these 7 muscle groups is presented as average skeletal muscle activity. The VOls were used to compare $\left[{ }^{18} \mathrm{~F}\right] \mathrm{FDG}$ uptake (calculated as SUVmean) and HU between these tissues and between scans before and after cold acclimation.

\section{Hyperinsulinemic-euglycemic clamp}

Hyperinsulinemic-euglycemic $\left(40 \mathrm{mU} \mathrm{m}^{-2} \mathrm{~min}^{-1}\right)$ clamps were performed according to DeFronzo (24), with primed infusion of $\left[6,6-{ }^{2} \mathrm{H}_{2}\right]$ glucose $\left(0.04 \mathrm{mg} \mathrm{kg}^{-1}\right.$ $\left.\min ^{-1}\right)$. Steele's single-pool non-steady state equations (25) were used to calculate rates of glucose appearance $\left(R_{a}\right)$, glucose disposal $\left(R_{d}\right)$, nonoxidative glucose disposal (NOGD; mainly reflecting glycogen synthesis) and endogenous glucose production (EGP), as previously described(26). Basal and insulin-stimulated substrate oxidation was measured by indirect calorimetry (Omnical, IDEE, Maastricht, The Netherlands) and calculated according to Frayn (27).

\section{Blood analysis}

Blood samples were collected before and during the clamp (in the basal and insulin-stimulated states). Plasma metabolites were determined according to standard procedures. Plasma concentrations of glucose (ABX Glucose HK CP Radiometer, Horiba $A B X$ ) and nonesterified fatty acids (NEFA-HR set, Wako Chemicals) were determined on a Cobas FARA centrifugal spectrophotometer (Roche Diagnostica). Plasma insulin concentrations were quantified using an immunometric assay (Advia Centaur, Siemens Diagnostics). Serum TSH and T4, and plasma catecholamines were analyzed as described previously (7). 


\section{WAT microarray analysis}

Abdominal subcutaneous WAT was rinsed from blood, snap frozen in melting isopentane and stored at $-80^{\circ} \mathrm{C}$ until analyzed. Gene expression analysis was performed by microarray and compared to publically available WAT microarray data sets from cold-acclimated mice.

RNA was purified from human fat biopsies using Trizol (Life Technologies, Calsbad, CA, USA) followed by an additional round of purification with RNeasy Minikit columns (Qiagen, Venlo, The Netherlands). RNA quality was assessed using RNA 6000 Nano chips on the Agilent 2100 Bioanalyzer (Agilent Technologies, Amsterdam, The Netherlands). Purified RNA (100 ng) was labeled with the Affymetrix WT PLUS reagent kit (Affymetrix, Santa Clara, CA, USA) and hybridized to an Affymetrix Human Gene 1.1 ST array plate (Affymetrix). Hybridization, washing, and scanning were carried out on an Affymetrix GeneTitan platform according to the manufacturer's instructions. Arrays were normalized using the Robust Multiarray Average method (28; 29). Probe sets were defined according to Dai et al. (30). In this method probes are assigned to Entrez IDs as a unique gene identifier. The $P$ values were calculated using an Intensity-Based Moderated Tstatistic (IBMT) (31). The microarray data have been submitted to the Gene Expression Omnibus (accession number GSE67297). Expression changes in the subcutaneous white fat depot of mice subjected to either 10 days or 7 days of cold exposure ( 5 degrees) were extracted from publicly available microarray datasets (GSE51080 and GSE13432) using the analysis pipeline described above.

\section{Ex vivo skeletal muscle mitochondrial respiration}

A portion of the muscle biopsy was directly frozen in melting isopentane and stored at $-80^{\circ} \mathrm{C}$ until assayed. Another portion ( $\sim 30 \mathrm{mg}$ ) was immediately placed in ice-cold preservation medium (BIOPS, OROBOROS instruments, Innsbruck, Austria) and used for the preparation of permeabilized skeletal muscle fibers ( $2.5 \mathrm{mg}$ wet weight) (32), which were analyzed for mitochondrial oxidative capacity using an oxygraph (OROBOROS Instruments) according to Hoeks et al. (33). In separate experiments, mitochondrial leak respiration was measured as the residual respiration following addition of $1 \mu \mathrm{g} / \mathrm{ml}$ of the ATP synthase-inhibitor oligomycin, using pyruvate $(5 \mathrm{mM})$ as a substrate (in the presence of $4 \mathrm{mM}$ malate). All oxygen consumption measurements were performed in quadruplicate. One muscle biopsy failed after cold acclimation; therefore, values for 7 subjects are presented. 


\section{Muscle biopsy analyses}

Protein expression was determined by western blotting according to standard procedures. Primary antibodies (AKT, phospho-AKT(Ser473), phospho-AKT (Thr308), phospho-AS160, phospho-AMPK, AMPK(Thr172) and GLUT1; diluted 1:1,000) were all from Cell Signaling Technology, Bioké, Leiden, the Netherlands and were all detected using a horseradish peroxidase-conjugated secondary swine anti-rabbit IgG antibody (DAKO, Glostrup, Denmark; diluted 1:2,000) and measured using enhanced chemiluminescence (Pierce, Thermo Scientific, Rockford, IL, USA). Primary antibodies directed against GLUT4 (Santa Cruz, BioConnect, Huissen, the Netherlands) UCP3, OXPHOS-cocktail, Serca2 ATPase (all from Abcam, BioConnect); PGC1 $\alpha$ (Calbiochem, Darmstadt, Germany), sarcolipin (Millipore, Schiphol-Rijk, the Netherlands) and $\alpha$-sarcomeric actin (loading control; Sigma, Zwijndrecht, the Netherlands) were detected using appropriate secondary antibodies conjugated with IRDye680 or IRDye800 and detected with the Odyssey Near Infrared System (Licor, Westburg, Leusden, the Netherlands). Intramyocellular lipid (IMCL) content was determined in fresh cryosections $(5 \mu \mathrm{m})$ by Oil red $\mathrm{O}$ staining combined with fibertyping and immunolabeling of the basal membrane marker laminin, as described previously (34). For GLUT4 imaging, double immunofluorescence assays were performed on 5 - $\mu$ m-thick fresh-frozen tissue sections, which were fixated for 15 min with 3.7\% formaldehyde in PBS and then treated for 5 min with $0.5 \%$ Triton $\mathrm{X}-100$ in PBS. Sections were incubated overnight at $4{ }^{\circ} \mathrm{C}$ with a mix of primary antibodies directed to GLUT4 (Santa Cruz, BioConnect, Huissen, the Netherlands) and laminin (Sigma, Zwijndrecht, the Netherlands). After three washing steps with PBS, Alexa Fluor555- and Alexa Fluor488-conjugated secondary antibodies were incubated for $45 \mathrm{~min}$ at room temperature. After a final washing step with PBS, sections were mounted in Mowiol. Images were observed using a Nikon E800 fluorescence microscope with NIS-elements Imaging Software (Nikon Europe BV, Amsterdam, the Netherlands) and were captured with identical exposure time and gain settings in 'before' and 'after' conditions. Without any adjustments with respect to color intensity, brightness or contrast, RGB-stacked images were quantified using the Plot Profile tool in ImageJ. Thus, we measured the intensity of GLUT4-dependent signals (16 bits) throughout the sections. Measured data on intensity were used to generate overlying plots of GLUT4 and laminin. The GLUT4derived staining intensity at the membrane was quantified at multiple locations per individual (13.7 \pm 2.9 locations before and $15.4 \pm 3.2$ locations after cold acclimation, respectively) in randomly chosen cross-sections of muscle biopsies, 
and was divided over the mean GLUT4 intensity in 10 pixels located in the cytosol of the very same cell. Thus, a score $>1.0$ implied that relatively more GLUT4 was detected in the membrane than in cytosolic regions and hence reflected GLUT4 translocation.

\section{Statistical analysis}

Statistical analyses were performed with PSAW Statistics 20.0 for MAC (SPSS). Nonparametric paired-sample Wilcoxon signed-rank tests were used to compare findings before and after cold acclimation and between thermoneutral and mild cold conditions. Spearman rank correlations were used to identify correlations between variables. $P$ values $<0.05$ were considered statistically significant. 


\section{REFERENCES}

1. van Marken Lichtenbelt WD, Vanhommerig JW, Smulders NM, Drossaerts JM, Kemerink GJ, Bouvy ND, Schrauwen P, Teule GJ: Cold-activated brown adipose tissue in healthy men. The New England journal of medicine 2009;360:1500-1508

2. Virtanen KA, Lidell ME, Orava J, Heglind M, Westergren R, Niemi T, Taittonen M, Laine J, Savisto NJ, Enerback S, Nuutila P: Functional brown adipose tissue in healthy adults. The New England journal of medicine 2009;360:1518-1525

3. Cypess AM, Lehman S, Williams G, Tal I, Rodman D, Goldfine AB, Kuo FC, Palmer EL, Tseng YH, Doria A, Kolodny GM, Kahn CR: Identification and importance of brown adipose tissue in adult humans. The New England journal of medicine 2009;360:1509-1517

4. Bartelt A, Bruns OT, Reimer R, Hohenberg H, Ittrich H, Peldschus K, Kaul MG, Tromsdorf UI, Weller H, Waurisch C, Eychmuller A, Gordts PL, Rinninger F, Bruegelmann K, Freund B, Nielsen $\mathrm{P}$, Merkel $\mathrm{M}$, Heeren J: Brown adipose tissue activity controls triglyceride clearance. Nature medicine 2011;17:200-205

5. Stanford KI, Middelbeek RJ, Townsend KL, An D, Nygaard EB, Hitchcox KM, Markan KR, Nakano K, Hirshman MF, Tseng YH, Goodyear LJ: Brown adipose tissue regulates glucose homeostasis and insulin sensitivity. The Journal of clinical investigation 2013;123:215-223

6. Townsend $\mathrm{KL}$, Tseng $\mathrm{YH}$ : Brown fat fuel utilization and thermogenesis. Trends in endocrinology and metabolism: TEM 2014;25:168-177

7. van der Lans AA, Hoeks J, Brans B, Vijgen GH, Visser MG, Vosselman MJ, Hansen J, Jorgensen JA, Wu J, Mottaghy FM, Schrauwen P, van Marken Lichtenbelt WD: Cold acclimation recruits human brown fat and increases nonshivering thermogenesis. The Journal of clinical investigation 2013;123:3395-3403

8. Yoneshiro T, Aita S, Matsushita M, Kayahara T, Kameya T, Kawai Y, Iwanaga T, Saito M: Recruited brown adipose tissue as an antiobesity agent in humans. The Journal of clinical investigation 2013;123:3404-3408

9. Blondin DP, Labbe SM, Tingelstad HC, Noll C, Kunach M, Phoenix S, Guerin B, Turcotte EE, Carpentier AC, Richard D, Haman F: Increased brown adipose tissue oxidative capacity in cold-acclimated humans. The Journal of clinical endocrinology and metabolism 2014;99:E438-446

10. Ouellet V, Labbe SM, Blondin DP, Phoenix S, Guerin B, Haman F, Turcotte EE, Richard D, Carpentier AC: Brown adipose tissue oxidative metabolism contributes to energy expenditure during acute cold exposure in humans. The Journal of clinical investigation 2012;122:545-552

11. Yoneshiro T, Aita S, Matsushita M, Kameya T, Nakada K, Kawai Y, Saito M: Brown adipose tissue, whole-body energy expenditure, and thermogenesis in healthy adult men. Obesity 2011;19:13-16

12. Hanssen MJ, Wierts R, Hoeks J, Gemmink A, Brans B, Mottaghy FM, Schrauwen P, van Marken Lichtenbelt WD: Glucose uptake in human brown adipose tissue is impaired upon fasting-induced insulin resistance. Diabetologia 2015;58:586-595 
13. Meex RC, Schrauwen-Hinderling VB, Moonen-Kornips E, Schaart G, Mensink M, Phielix E, van de Weijer T, Sels JP, Schrauwen P, Hesselink MK: Restoration of muscle mitochondrial function and metabolic flexibility in type 2 diabetes by exercise training is paralleled by increased myocellular fat storage and improved insulin sensitivity. Diabetes 2010;59:572579

14. Storlien L, Oakes ND, Kelley DE: Metabolic flexibility. The Proceedings of the Nutrition Society 2004;63:363-368

15. Galgani JE, Heilbronn LK, Azuma K, Kelley DE, Albu JB, Pi-Sunyer X, Smith SR, Ravussin E, Look AARG: Metabolic flexibility in response to glucose is not impaired in people with type 2 diabetes after controlling for glucose disposal rate. Diabetes 2008;57:841-845

16. Schrauwen-Hinderling VB, Kooi ME, Hesselink MK, Jeneson JA, Backes WH, van Echteld CJ, van Engelshoven JM, Mensink $M$, Schrauwen $P$ : Impaired in vivo mitochondrial function but similar intramyocellular lipid content in patients with type 2 diabetes mellitus and BMImatched control subjects. Diabetologia 2007;50:113-120

17. Bal NC, Maurya SK, Sopariwala DH, Sahoo SK, Gupta SC, Shaikh SA, Pant M, Rowland LA, Bombardier E, Goonasekera SA, Tupling AR, Molkentin JD, Periasamy M: Sarcolipin is a newly identified regulator of muscle-based thermogenesis in mammals. Nature medicine 2012;18:1575-1579

18. Ruderman NB, Carling D, Prentki M, Cacicedo JM: AMPK, insulin resistance, and the metabolic syndrome. The Journal of clinical investigation 2013;123:2764-2772

19. Sato M, Dehvari N, Oberg Al, Dallner OS, Sandstrom AL, Olsen JM, Csikasz RI, Summers RJ, Hutchinson DS, Bengtsson T: Improving type 2 diabetes through a distinct adrenergic signaling pathway involving mTORC2 that mediates glucose uptake in skeletal muscle. Diabetes 2014;63:4115-4129

20. Wang GX, Zhao XY, Meng ZX, Kern M, Dietrich A, Chen Z, Cozacov Z, Zhou D, Okunade AL, Su X, Li S, Bluher M, Lin JD: The brown fat-enriched secreted factor Nrg4 preserves metabolic homeostasis through attenuation of hepatic lipogenesis. Nature medicine 2014;20:1436-1443

21. Bergstrom J, Hultman E, Roch-Norlund AE: Muscle glycogen synthetase in normal subjects. Basal values, effect of glycogen depletion by exercise and of a carbohydrate-rich diet following exercise. Scandinavian journal of clinical and laboratory investigation 1972;29:231-236

22. Vosselman MJ, van der Lans AA, Brans B, Wierts $R$, van Baak MA, Schrauwen $P$, van Marken Lichtenbelt WD: Systemic beta-adrenergic stimulation of thermogenesis is not accompanied by brown adipose tissue activity in humans. Diabetes 2012;61:3106-3113

23. Vosselman MJ, Brans B, van der Lans AA, Wierts R, van Baak MA, Mottaghy FM, Schrauwen $P$, van Marken Lichtenbelt WD: Brown adipose tissue activity after a high-calorie meal in humans. The American journal of clinical nutrition 2013;98:57-64

24. DeFronzo RA, Tobin JD, Andres R: Glucose clamp technique: a method for quantifying insulin secretion and resistance. The American journal of physiology 1979;237:E214-223

25. Steele R: Influences of glucose loading and of injected insulin on hepatic glucose output. Annals of the New York Academy of Sciences 1959;82:420-430 
26. Phielix E, Mensink M: Type 2 diabetes mellitus and skeletal muscle metabolic function. Physiology \& behavior 2008;94:252-258

27. Frayn $\mathrm{KN}$ : Calculation of substrate oxidation rates in vivo from gaseous exchange. Journal of applied physiology: respiratory, environmental and exercise physiology 1983;55:628634

28. Bolstad BM, Irizarry RA, Astrand M, Speed TP: A comparison of normalization methods for high density oligonucleotide array data based on variance and bias. Bioinformatics 2003;19:185-193

29. Irizarry RA, Bolstad BM, Collin F, Cope LM, Hobbs B, Speed TP: Summaries of Affymetrix GeneChip probe level data. Nucleic acids research 2003;31:e15

30. Dai M, Wang P, Boyd AD, Kostov G, Athey B, Jones EG, Bunney WE, Myers RM, Speed TP, Akil H, Watson SJ, Meng F: Evolving gene/transcript definitions significantly alter the interpretation of GeneChip data. Nucleic acids research 2005;33:e175

31. Sartor MA, Tomlinson CR, Wesselkamper SC, Sivaganesan S, Leikauf GD, Medvedovic M: Intensity-based hierarchical Bayes method improves testing for differentially expressed genes in microarray experiments. BMC bioinformatics 2006;7:538

32. Phielix E, Schrauwen-Hinderling VB, Mensink M, Lenaers E, Meex R, Hoeks J, Kooi ME, Moonen-Kornips E, Sels JP, Hesselink MK, Schrauwen P: Lower intrinsic ADP-stimulated mitochondrial respiration underlies in vivo mitochondrial dysfunction in muscle of male type 2 diabetic patients. Diabetes 2008;57:2943-2949

33. Hoeks J, van Herpen NA, Mensink M, Moonen-Kornips E, van Beurden D, Hesselink MK, Schrauwen P: Prolonged fasting identifies skeletal muscle mitochondrial dysfunction as consequence rather than cause of human insulin resistance. Diabetes 2010;59:2117-2125

34. Koopman R, Schaart G, Hesselink MK: Optimisation of oil red O staining permits combination with immunofluorescence and automated quantification of lipids. Histochemistry and cell biology 2001;116:63-68 


\section{SUPPLEMENTAL FIGURES AND TABLES}

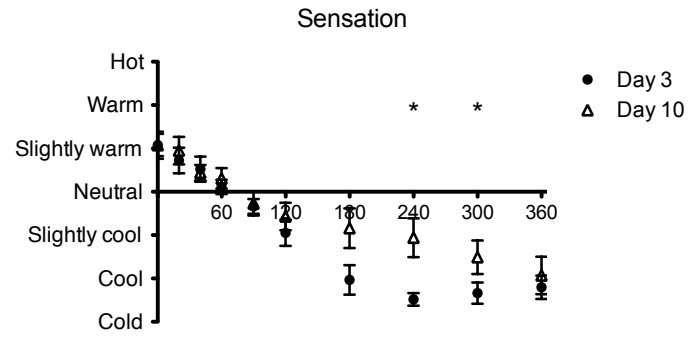

Thermal comfort

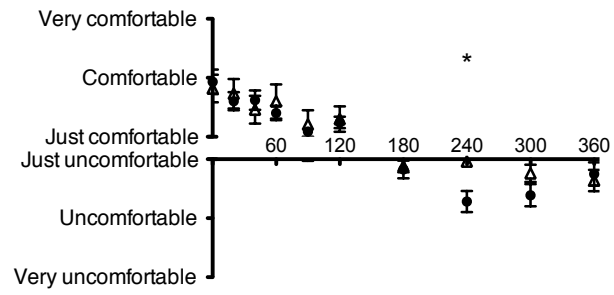

Shivering

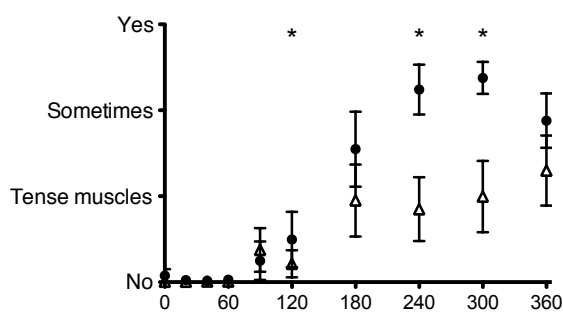

Supplemental Figure 1. Subjective responses. Thermal sensation, thermal comfort and self-reported shivering, determined at several time points (from $\mathrm{t}=0 \mathrm{~min}$ until $\mathrm{t}=360 \mathrm{~min}$ ) after entering the cold room, on day 10 compared to day 3 of the cold acclimation period ( $P$ values for iAUCs: 0.036, 0.069 and 0.017 , respectively). $n=8$; comparisons between day 3 and day 10 were analyzed using Wilcoxon signed-rank tests; ${ }^{*} P<0.05$, day 3 vs. day 10 for specific time point; error bars, mean \pm s.e.m. 
a

State 2

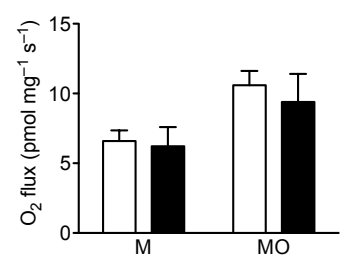

e

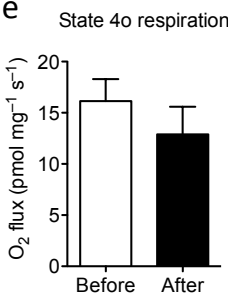

h

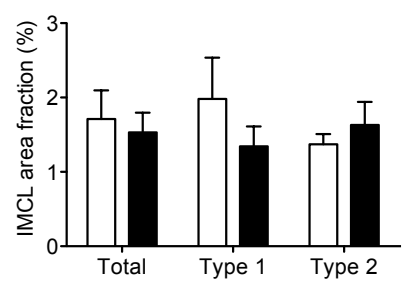

b

$f$
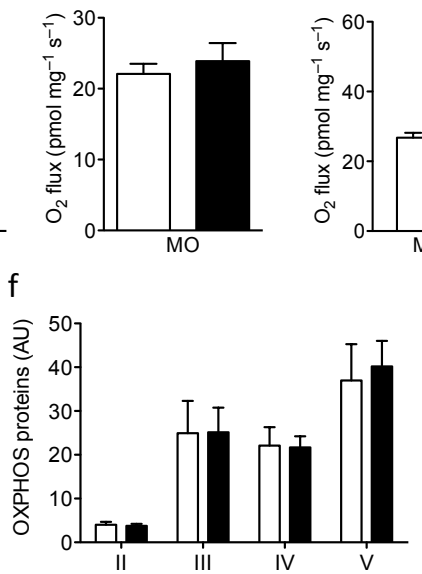

i

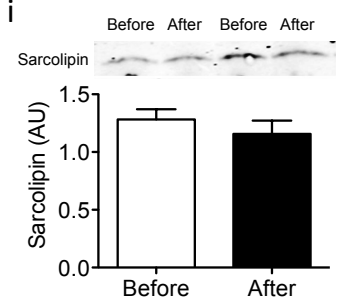

d State U

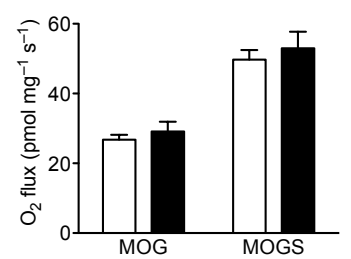

g

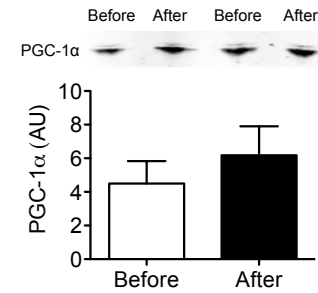

j

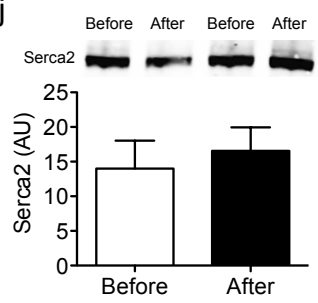

Supplemental Figure 2. Skeletal muscle mitochondrial respiration, intramyocellular lipid content, and OXPHOS, PGC-1 $\alpha$, Serca2 and sarcolipin protein content. (a-e) Respiration measurements in permeabilized muscle fibers. $\mathrm{M}$, malate; $\mathrm{O}$, octanoyl carnitine; $\mathrm{P}$, pyruvate; $\mathrm{G}$, glutamate; $\mathrm{S}$, succinate. (a) Respiration upon substrates only (state 2). (b,c) ADP-stimulated respiration fuelled by mitochondrial complex I and complex II-linked substrates. (d) Maximally uncoupled respiration upon addition of the chemical uncoupler FCCP (state $U$, maximal electron transport chain capacity). (e) Oxygen consumption not linked to ATP synthesis upon addition of the ATP-ase inhibitor oligomycin (state 40, mitochondrial leak respiration). (f) Expression of oxidative phosphorylation protein (OXPHOS) complexes II through V. (g) PGC-1 $\alpha$ protein content, including representative Western blots of two individuals with T2D before and after cold acclimation. (h) Total intramyocellular lipid (IMCL) content and IMCL content in type 1 and type 2 muscle fibers. (i,j) Sarcolipin (i) and Serca2 (j) protein content, including representative Western blots of two individuals with T2D before and after cold acclimation. White bars, before cold acclimation; black bars, after cold acclimation. $n=7$; comparisons between data before and after cold acclimation were analyzed using Wilcoxon signedrank tests; error bars, mean \pm s.e.m. 
Supplemental Table 1. Subject characteristics.

\begin{tabular}{|c|c|c|c|c|c|}
\hline Patient & Age & BMI & $\begin{array}{l}\text { Diabetes } \\
\text { duration (years) }\end{array}$ & Medication & $\begin{array}{l}\text { HbA1c } \\
(\mathrm{mmol} / \mathrm{mol})\end{array}$ \\
\hline 1 & 65 & 29.7 & 6 & $\begin{array}{l}\text { Metformin (500mg 2x/day), } \\
\text { Glimepiride ( } 2 \mathrm{mg}, 1 \mathrm{x} / \text { day) }\end{array}$ & 48.6 \\
\hline 2 & 66 & 36.1 & 13 & Metformin (1000mg, 2x/day) & 42.1 \\
\hline 3 & 58 & 27.9 & 6.5 & Metformin (1000mg, 2x/day) & 49.7 \\
\hline 4 & 63 & 29.3 & 10 & $\begin{array}{l}\text { Metformin }(1000 \mathrm{mg}, 2 x / \text { day), } \\
\text { Glimepiride }(5 \mathrm{mg}, 1 \mathrm{x} / \text { day) }\end{array}$ & 62.8 \\
\hline 5 & 57 & 31.4 & 3.5 & Metformin (500mg, 2x/day) & 45.4 \\
\hline 6 & 49 & 25.6 & 5 & $\begin{array}{l}\text { Metformin ( } 850 \mathrm{mg}, 3 x / \text { day), } \\
\text { Glimepiride }(6 \mathrm{mg}, 1 \mathrm{x} / \text { day) }\end{array}$ & 60.7 \\
\hline 7 & 54 & 31.0 & 6 & $\begin{array}{l}\text { Metformin ( } 850 \mathrm{mg}, 2 x / \text { day), } \\
\text { Vildagliptin ( } 50 \mathrm{mg}, 2 x / \text { day) }\end{array}$ & 54.1 \\
\hline 8 & 62 & 28.5 & 8 & $\begin{array}{l}\text { Metformin }(850 \mathrm{mg}, 3 x / \text { day), } \\
\text { Gliclazide }(80 \mathrm{mg}, 2 x / \text { day) }\end{array}$ & 54.1 \\
\hline
\end{tabular}

Supplemental Table 2. Body weight and fasting blood parameters before and after cold acclimation.

\begin{tabular}{|c|c|c|}
\hline Variable & Before & After \\
\hline Body weight (kg) & $92.0 \pm 10.7$ & $92.5 \pm 10.8$ \\
\hline Glucose (mmol/l) & $7.9 \pm 1.0$ & $8.2 \pm 3.2$ \\
\hline Insulin (pmol/l) & $115.4 \pm 53.7$ & $99.3 \pm 45.7$ \\
\hline NEFA $(\mu \mathrm{mol} / \mathrm{l})$ & $644 \pm 210$ & $672 \pm 158$ \\
\hline Fructosamine $(\mu \mathrm{mol} / \mathrm{l})$ & $248 \pm 23$ & $255 \pm 25$ \\
\hline $\mathrm{TSH}(\mathrm{mU} / \mathrm{I})$ & $2.9 \pm 2.3$ & $0.9 \pm 1.2^{A}$ \\
\hline Free T4 (pmol/l) & $12.9 \pm 1.1$ & $13.9 \pm 1.8$ \\
\hline Noradrenaline (pg/ml) & $403 \pm 474$ & $328 \pm 146$ \\
\hline Phosphate (mmol/l) & $1.03 \pm 0.10$ & $0.98 \pm 0.13$ \\
\hline Urea (mmol/l) & $5.1 \pm 1.8$ & $4.7 \pm 1.2$ \\
\hline Creatinine $(\mu \mathrm{mol} / \mathrm{l})$ & $77.3 \pm 10.5$ & $79.8 \pm 9.4$ \\
\hline VGT (U/I) & $34.6 \pm 13.6$ & $32.6 \pm 14.1$ \\
\hline ASAT (U/I) & $39.1 \pm 15.6$ & $36.8 \pm 8.7$ \\
\hline $\operatorname{ALAT}(\mathrm{U} / \mathrm{I})$ & $40.5 \pm 17.5$ & $43.5 \pm 26.7$ \\
\hline Billirubine $(\mu \mathrm{mol} / \mathrm{l})$ & $11.9 \pm 9.0$ & $10.3 \pm 6.3$ \\
\hline Total cholesterol (mmol/l) & $3.4 \pm 1.0$ & $3.3 \pm 0.9$ \\
\hline HDL cholesterol (mmol/l) & $1.1 \pm 0.2$ & $1.1 \pm 0.2$ \\
\hline LDL cholesterol (mmol/l) & $1.6 \pm 1.0$ & $1.6 \pm 0.9$ \\
\hline Triglycerides (mmol/l) & $1.67 \pm 0.87$ & $1.47 \pm 0.66$ \\
\hline Total protein (g/l) & $68.4 \pm 2.3$ & $67.8 \pm 2.7$ \\
\hline Albumin (g/l) & $37.2 \pm 2.4$ & $37.7 \pm 2.3$ \\
\hline
\end{tabular}

${ }^{A} \mathrm{P}<0.05$, before vs. after cold acclimation. Values are expressed as mean \pm s.d. 
Supplemental Table 3. Blood pressure, body temperatures and skin perfusion during thermoneutral and mild cold conditions, before and after cold acclimation.

\begin{tabular}{|c|c|c|c|c|c|c|}
\hline \multirow[b]{2}{*}{ Variable } & \multicolumn{3}{|l|}{ Before } & \multicolumn{3}{|l|}{ After } \\
\hline & $\begin{array}{l}\text { Thermo- } \\
\text { neutral }\end{array}$ & Mild cold & Delta & $\begin{array}{l}\text { Thermo- } \\
\text { neutral }\end{array}$ & Mild cold & Delta \\
\hline $\begin{array}{l}\text { Systolic blood } \\
\text { pressure (mm Hg) }\end{array}$ & $\begin{array}{l}125.0 \pm \\
10.0\end{array}$ & $\begin{array}{l}149.1 \pm \\
13.9^{B}\end{array}$ & $24.1 \pm 6.9$ & $\begin{array}{l}122.3 \pm \\
11.1\end{array}$ & $\begin{array}{l}149.4 \pm \\
20.9^{B}\end{array}$ & $27.1 \pm 11.0$ \\
\hline $\begin{array}{l}\text { Diastolic blood } \\
\text { pressure }(\mathrm{mm} \mathrm{Hg})\end{array}$ & $74.4 \pm 4.7$ & $85.3 \pm 9.5^{B}$ & $10.8 \pm 6.4$ & $72.8 \pm 7.4$ & $85.6 \pm 7.4^{B}$ & $12.8 \pm 3.4$ \\
\hline $\begin{array}{l}\text { Mean arterial } \\
\text { pressure }(\mathrm{mm} \mathrm{Hg})\end{array}$ & $91.3 \pm 5.9$ & $\begin{array}{l}106.5 \pm \\
9.7^{B}\end{array}$ & $15.3 \pm 6.2$ & $89.3 \pm 8.0$ & $\begin{array}{l}106.9 \pm \\
11.3^{B}\end{array}$ & $17.5 \pm 4.1$ \\
\hline $\begin{array}{l}\text { Heart rate } \\
\text { (beats/min) }\end{array}$ & $67.1 \pm 8.4$ & $58.3 \pm 6.9^{B}$ & $-8.8 \pm 4.2$ & $66.6 \pm 6.7$ & $59.3 \pm 5.6^{B}$ & $-7.3 \pm 5.3$ \\
\hline Suit temperature $\left({ }^{\circ} \mathrm{C}\right)$ & $29.9 \pm 0.6$ & $22.8 \pm 0.9$ & $-7.1 \pm 0.7$ & $30.1 \pm 0.6$ & $23.0 \pm 0.7$ & $-7.2 \pm 1.0$ \\
\hline $\begin{array}{l}\text { Core temperature } \\
\left({ }^{\circ} \mathrm{C}\right)\end{array}$ & $36.9 \pm 0.1$ & $36.7 \pm 0.4$ & $-0.1 \pm 0.3$ & $36.9 \pm 0.2$ & $36.9 \pm 0.3$ & $-0.1 \pm 0.3$ \\
\hline $\begin{array}{l}\text { Mean skin } \\
\text { temperature }\left({ }^{\circ} \mathrm{C}\right)\end{array}$ & $35.2 \pm 0.3$ & $28.9 \pm 1.1$ & $-6.4 \pm 1.3$ & $35.5 \pm 0.3^{\mathrm{A}}$ & $28.8 \pm 1.1$ & $-6.7 \pm 1.2$ \\
\hline $\begin{array}{l}\text { Skin perfusion hand } \\
\text { relative } \%\end{array}$ & 100 & $9.2 \pm 7.1^{B}$ & $-90.8 \pm 7.1$ & 100 & $\begin{array}{l}14.6 \pm \\
23.4^{B}\end{array}$ & $\begin{array}{l}-85.4 \pm \\
23.4\end{array}$ \\
\hline $\begin{array}{l}\text { Skin perfusion } \\
\text { underarm relative \% }\end{array}$ & 100 & $\begin{array}{l}33.5 \pm \\
12.1^{B}\end{array}$ & $\begin{array}{l}-66.5 \pm \\
12.1\end{array}$ & 100 & $\begin{array}{l}34.0 \pm \\
24.6^{B}\end{array}$ & $\begin{array}{l}-66.0 \pm \\
24.6\end{array}$ \\
\hline
\end{tabular}

${ }^{A} P<0.05$, before vs. after cold acclimation; ${ }^{B} P<0.05$, thermoneutral vs. mild cold. Values are expressed as mean \pm s.d. 
Supplemental Table 4. Substrate kinetics during hyperinsulinemic-euglycemic clamp.

\begin{tabular}{|c|c|c|}
\hline & Before & After \\
\hline \multicolumn{3}{|l|}{$\mathrm{R}_{\mathrm{d}}$ glucose $\left(\mu \mathrm{mol} \mathrm{kg}{ }^{-1} \mathrm{~min}^{-1}\right)$} \\
\hline Basal & $8.1 \pm 1.8$ & $8.9 \pm 1.5$ \\
\hline Clamp & $14.9 \pm 4.1$ & $20.5 \pm 6.9^{A}$ \\
\hline Delta ( $R_{d}$ clamp $-R_{d}$ basal) & $6.8 \pm 4.0$ & $11.6 \pm 7.1^{\mathrm{A}}$ \\
\hline \multicolumn{3}{|l|}{$\operatorname{EGP}\left(\mu \mathrm{mol} \mathrm{kg}{ }^{-1} \min ^{-1}\right)$} \\
\hline Basal & $7.2 \pm 2.0$ & $7.6 \pm 1.6$ \\
\hline Clamp & $1.5 \pm 1.4$ & $0.9 \pm 1.3$ \\
\hline Delta (EGP clamp - EGP basal) & $-5.7 \pm 2.0$ & $-6.7 \pm 2.1$ \\
\hline$\%$ Delta & $-79.0 \pm 20.0$ & $-88.3 \pm 17.5$ \\
\hline \multicolumn{3}{|l|}{ Carbohydrate oxidation ( $\mu \mathrm{mol} \mathrm{kg}{ }^{-1} \mathrm{~min}^{-1}$ ) } \\
\hline Basal & $6.7 \pm 2.5$ & $5.8 \pm 2.8$ \\
\hline Clamp & $11.1 \pm 4.5$ & $12.5 \pm 2.2$ \\
\hline Delta (CHO ox clamp - CHO ox basal) & $4.4 \pm 3.3$ & $6.7 \pm 2.0$ \\
\hline \multicolumn{3}{|l|}{$\operatorname{NOGD}\left(\mu \mathrm{mol} \mathrm{kg}{ }^{-1} \min ^{-1}\right)$} \\
\hline Basal & $1.4 \pm 2.4$ & $3.0 \pm 2.7$ \\
\hline Clamp & $3.8 \pm 5.4$ & $8.0 \pm 7.1$ \\
\hline Delta (NOGD clamp - NOGD basal) & $2.4 \pm 3.8$ & $4.9 \pm 6.5$ \\
\hline \multicolumn{3}{|l|}{ Lipid oxidation $\left(\mu \mathrm{mol} \mathrm{kg}{ }^{-1} \mathrm{~min}^{-1}\right)$} \\
\hline Basal & $1.2 \pm 0.2$ & $1.1 \pm 0.2$ \\
\hline Clamp & $0.8 \pm 0.4$ & $0.6 \pm 0.2$ \\
\hline Delta (lipid ox clamp - lipid ox basal) & $-0.3 \pm 0.2$ & $-0.5 \pm 0.2$ \\
\hline
\end{tabular}




\section{Short-term cold acclimation recruits brown adipose tissue in obese humans}

The contents of this chapter are published in:

MJW Hanssen*, AAJJ van der Lans*, B Brans, J Hoeks, K Jardon, G Schaart, FM Mottaghy, P Schrauwen, WD van Marken Lichtenbelt. Short-term cold acclimation recruits brown adipose tissue in obese humans. Diabetes 2016; 65: 1179-1189

* Both authors contributed equally 


\section{ABSTRACT}

Recruitment of brown adipose tissue (BAT) has emerged as a potential tool to combat obesity and associated metabolic complications. Short-term cold acclimation has been shown not only to enhance the presence and activity of BAT in lean humans but also to improve the metabolic profile of skeletal muscle to benefit glucose uptake in patients with type 2 diabetes. Here we examined whether short-term cold acclimation also induced such adaptations in 10 metabolically healthy obese male subjects.

A 10-day cold acclimation period resulted in increased cold-induced glucose uptake in BAT, as assessed by 2-deoxy-2-[ $\left.{ }^{18} \mathrm{~F}\right]$ fluoro-D-glucose positron emission tomography/computed tomography. BAT activity was negatively related to age, with a similar trend for body fat percentage. In addition, cold-induced glucose uptake in BAT was positively related to glucose uptake in visceral white adipose tissue, although glucose uptake in visceral and subcutaneous white adipose tissue depots was unchanged upon cold acclimation. Cold-induced skeletal muscle glucose uptake tended to increase upon cold acclimation, which was paralleled by increased basal GLUT4 localization in the sarcolemma, as assessed through muscle biopsies. Proximal skin temperature was increased and subjective responses to cold were slightly improved at the end of the acclimation period.

These metabolic adaptations to prolonged exposure to mild cold may lead to improved glucose metabolism or prevent the development of obesity-associated insulin resistance and hyperglycemia. 


\section{INTRODUCTION}

Because of the ever-growing prevalence of global obesity, there is an ongoing search for effective strategies to enhance energy expenditure (EE) and subsequently counteract obesity and its negative metabolic consequences. Adaptive thermogenesis - that is, an increased capacity for heat production upon prolonged exposure to cold (1) - has gained considerable renewed interest in this context, especially because of the recent appreciation of considerable amounts of metabolically active brown adipose tissue (BAT) in adult humans (2-4). BAT is highly specialized to convert energy from substrate oxidation directly into heat through the action of uncoupling protein 1 (UCP1), thereby contributing to the maintenance of a constant internal body temperature upon exposure to cold. Because of this "energy-wasting" process, BAT activation results in increased EE, which could reverse or protect against obesity. Indeed, several rodent studies have demonstrated that BAT activation and recruitment by prolonged exposure to cold or $\beta$-adrenergic stimulation ameliorates diet-induced obesity and improves its associated complications, such as disturbed glucose and lipid homeostasis(5; 6). In animals, prolonged cold stimulation also induces browning of distinct white adipose tissue (WAT) depots, likely contributing to improved substrate metabolism (7). This phenomenon also has recently been observed in human subcutaneous WAT upon severe and prolonged adrenergic stress (8).

In humans, as in mice, exposure to cold is one of the most powerful physiological stimuli for activation of BAT (9). As such, using dedicated cooling protocols to activate BAT, we have shown that BAT is present and active upon acute exposure to cold in $90-100 \%$ of lean, young adults and that BAT activity is related to nonshivering thermogenesis (NST) $(10 ; 11)$. In addition, several studies have reported negative relations between BAT activity and age and body fatness in humans (3; 12), likely the result of "whitening" of classical BAT depots (13), most notably the supraclavicular BAT depot. Interestingly, both older age (14) and obesity (15) are also associated with a blunted NST response upon exposure to mild cold. This has led to the hypothesis that recruitment of BAT by cold acclimatization could enhance cold-induced EE, thereby counteracting WAT accumulation and its possible negative metabolic consequences. We (11) and others (16-18) recently showed that BAT can be effectively recruited in lean individuals by means of prolonged intermittent exposure to cold, that is, cold acclimation. Interestingly, BAT recruitment was indeed paralleled by enhanced cold-induced NST $(11 ; 16)$. 
Moreover, Yoneshiro et al. showed a negative relation between changes in BAT activity and whole-body fat mass after daily 2-hour cold exposure to cold $\left(17^{\circ} \mathrm{C}\right)$ for 6 weeks, suggesting an anti-obesity effect of BAT recruitment in humans (16). Importantly, these studies were all performed in young, lean and healthy subjects. A 10-day cold acclimation period in patients with type 2 diabetes resulted in only a minor increase in metabolic activity of the supraclavicular BAT region (19). However, in addition to being overweight these patients were also older and presented already very low activity of this BAT region at baseline. Therefore, it remains to be established whether significant amounts of BAT can be recruited in obese subjects within a wide age range and whether this is associated with enhanced NST.

In addition to BAT, skeletal muscle (SM), and visceral and subcutaneous adipose tissue metabolism also may be affected by prolonged exposure to cold, as has been suggested by animal studies $(7 ; 20 ; 21)$ and our recent observation of enhanced basal GLUT4 translocation upon cold acclimation in patients with type 2 diabetes (19). However, it is not known whether prolonged, intermittent exposure to cold can elicit such improvements in metabolically healthy obese subjects as well. Therefore, we studied here changes in NST, BAT presence and activity, browning of WAT, and SM metabolic parameters after a 10-day cold acclimation period in healthy obese males.

\section{METHODS}

\section{Subjects}

Ten overweight/obese healthy male participants were included in this study (Table 1). All participants were screened for medical history and status. Exclusion criteria included diabetes mellitus, history of cardiovascular disease, use of b-blockers, liver or kidney dysfunction, asthma or any other obstructive pulmonary disease, and severe physical activity more than twice per week. Studies were performed between March 2014 and February 2015.

\section{Study approval}

The Ethics Committee of Maastricht University Medical Center approved the study protocol, and all participants provided written informed consent. Procedures were conducted according to the principles of the Declaration of Helsinki. 
Table 1. Subject characteristics.

\begin{tabular}{lll}
\hline Characteristic & Average & Range \\
\hline Age $($ years $)$ & $36.0 \pm 13.0$ & $19-59$ \\
Weight $(\mathrm{kg})$ & $108.4 \pm 18.3$ & $78.9-129.4$ \\
Height $(\mathrm{m})$ & $1.81 \pm 0.07$ & $1.68-1.89$ \\
BMI $\left(\mathrm{kg} / \mathrm{m}^{2}\right)$ & $32.9 \pm 3.5$ & $28.1-36.8$ \\
Fat mass $(\mathrm{kg})$ & $32.6 \pm 10.2$ & $20.1-44.9$ \\
Fat percentage $(\%)$ & $29.2 \pm 5.3$ & $19.4-33.8$ \\
\hline
\end{tabular}

BMI, Body Mass Index. Data are expressed as mean \pm SD.

\section{Study design}

A 10-day cold acclimation intervention was performed as previously described (11; 19). Before the cold acclimation period, body composition was determined by means of DXA (Discovery A; Hologic, Bedford, MA). An individualized cooling protocol was subsequently performed, followed by 2-deoxy-2-[ $\left.{ }^{18} \mathrm{~F}\right]$ fluoro-D-glucose $\left(\left[{ }^{18} \mathrm{~F}\right] \mathrm{FDG}\right)$ positron emission tomography (PET)/computed tomography (CT) (Gemini TF PET/CT; Philips, Eindhoven, the Netherlands) for quantification of cold induced BAT activity. In addition, on a separate day and under thermoneutral conditions, a biopsy was taken from the vastus lateralis muscle in the morning after an overnight fast. During the subsequent cold acclimation period, subjects were exposed to an environmental temperature of $14-15^{\circ} \mathrm{C}$ for 10 consecutive days, with exposure to cold for $2 \mathrm{~h}$ on the 1 st day, $4 \mathrm{~h}$ on the $2 \mathrm{nd}$ day, and $6 \mathrm{~h}$ on the $3 \mathrm{rd}$ through the 10th days. At the beginning of the 10th day a second muscle biopsy was taken (at thermoneutral conditions), and the individualized cooling protocol and $\left[{ }^{18}\right.$ F]FDG-PET/CT were repeated on day 11 . Body weight was measured before and after cold acclimation. Subjects consumed standardized meals (42\%, 35\%, and $23 \%$ energy from carbohydrates, fat, and protein, respectively) on the evenings before the experimental days. They were asked to refrain from heavy exercise for at least $48 \mathrm{~h}$ before the measurements.

\section{Cold acclimation}

During cold acclimation, subjects were dressed in T-shirts and shorts and remained sedentary. Subjects were instructed not to change their dietary habits and food intake in the cold room throughout the 10-day cold acclimation period. At prescribed time points ( $t=0,20,40,60,90,120,180,240,300$, and $360 \mathrm{~min}$ ), blood pressure was monitored and visual analog scales for sensation, thermal comfort, and shivering were completed. Incremental areas under the curve (iAUCs) 
of these visual analog scales were calculated using the trapezoid rule. Wireless temperature sensors (iButton; Maxim Integrated Products, San Jose, CA) were placed on 14 International Organization for Standardization (ISO)-defined sites on days 3,7 , and 10 to measure skin temperature (22). Mean skin temperature was calculated as the average temperature of measurements at these 14 sites, distal skin temperature as the average temperature of the left foot and right hand, and proximal skin temperature as the average temperature of the chest, abdomen, scapula, and lower back. iAUCs from $t=20-350$ min were calculated to determine physiological skin temperature responses during cold acclimation.

\section{Individualized cooling and PET/CT}

An individualized cooling protocol was performed after a 4-h fasting period as previously described $(11 ; 19)$. Briefly, subjects were wrapped in a water-perfused suit (ThermaWrap Universal 3166; MTRE Advanced Technologies Ltd., Yavne, Israel) and were measured at thermoneutrality for $45 \mathrm{~min}$. Thereafter, subjects were gradually cooled to a temperature just above the individual's shivering point and were measured for $30 \mathrm{~min}$ at this temperature. Core and skin temperatures, skin perfusion, heart rate, and EE (determined by means of indirect calorimetry using EZCAL; Maastricht Instruments, Maastricht, the Netherlands) were measured continuously, and blood pressure was monitored every 15 min during the cooling protocol. NST was calculated as the percent increase in EE upon exposure to mild cold above the basal metabolic rate (measured at thermoneutrality). At the end of the thermoneutral period and at the end of the cold period, blood was drawn from a catheter placed in an antecubital vein. A bolus of $74 \mathrm{MBq}\left[{ }^{18} \mathrm{~F}\right] \mathrm{FDG}$ was subsequently injected intravenously. One hour after injection the PET/CT protocol started with a low-dose CT scan (120 kV, $30 \mathrm{mAs}$ ), immediately followed by a static PET scan ( 6 or 7 bed positions, $4 \mathrm{~min} /$ bed position) covering the skull to the abdomen.

\section{PET/CT analysis}

PET/CT scans were analyzed using PMOD software (version 3.0; PMOD Technologies, Zurich, Switzerland) by two of the researchers (M.J.W.H. and A.A.J.J.v.d.L.) and an experienced nuclear medicine physician (B.B.). BAT activity was defined as $\left[{ }^{18} \mathrm{~F}\right] \mathrm{FDG}$ uptake $>1.5$ standardized uptake value (SUV) in fat tissue (Hounsfield units between -10 and -180). SUV was calculated as ([18F]FDG uptake $[\mathrm{kBq} / \mathrm{mL}]) /($ injected dose $[\mathrm{kBq}] /$ patient weight $[\mathrm{g}]$ ). Regions of interest were semi- 
automatically outlined for determination of mean (SUVmean) and maximal (SUVmax) $\left[{ }^{18} \mathrm{~F}\right]$ FDG uptake in BAT locations.

Since not all subjects showed pronounced BAT activity, defined by the SUV threshold of $>1.5$, fixed volumes of interest (VOIs) $\left(2.67 \mathrm{~cm}^{3}\right)$ were also carefully selected in the supraclavicular adipose tissue region (Hounsfield units between -10 and -180 ). These VOIs were placed in the area with the highest $\left[{ }^{18} \mathrm{~F}\right] \mathrm{FDG}$ uptake in the baseline PET scan and in the same anatomic position in the second PET scan to compare activity of this putative BAT region in the same anatomic location before and after cold acclimation (23). VOls were also placed in the liver and brain and in seven SM groups (deltoid, biceps and triceps brachii, erector spinae, scalene, levator scapulae, and psoas major muscles), as previously described (19; 24). Average activity of these seven muscle groups is presented as average SM $\left[{ }^{18} \mathrm{~F}\right] \mathrm{FDG}$ uptake. Subcutaneous WAT was measured in the dorsolumbar region near vertebrae L3, as well as in the abdominal WAT region in the same transverse slices (both $8 \mathrm{~cm}^{3}$ ). Visceral WAT was measured behind the xiphoid $\left(1.3 \mathrm{~cm}^{3}\right)$, at the omental WAT region at the level of the spleen and stomach $\left(4 \mathrm{~cm}^{3}\right)$, at the paracolic WAT region $\left(4 \mathrm{~cm}^{3}\right)$, and at the infrarenal WAT region $\left(8 \mathrm{~cm}^{3}\right)$ (Supplemental Fig. 1). Average activity of these regions is presented as average subcutaneous WAT and average visceral WAT $\left[{ }^{18} \mathrm{~F}\right] \mathrm{FDG}$ uptake, respectively. The VOIs were used to compare $\left[{ }^{18} \mathrm{~F}\right] \mathrm{FDG}$ uptake (calculated as SUVmean) between these tissues and between scans before and after cold acclimation.

\section{Ex vivo SM respiration}

After the biopsy, a portion of the muscle tissue was immediately frozen in melting isopentane and stored at $-80^{\circ} \mathrm{C}$ until assayed. Another portion ( $30 \mathrm{mg}$ ) was instantly placed in ice-cold preservation medium (BIOPS; OROBOROS Instruments, Innsbruck, Austria) and used for the preparation of permeabilized muscle fibers (25). These were subsequently analyzed for mitochondrial oxidative capacity using an oxygraph (OROBOROS Instruments) according to the method described by Hoeks et al. (26).

In separate measurements, mitochondrial leak respiration was determined as the residual respiration upon addition of $1 \mu \mathrm{g} / \mathrm{mL}$ of the ATP synthase-inhibitor oligomycin, using pyruvate ( $5 \mathrm{mmol} / \mathrm{L}$ ) as a substrate (in the presence of $4 \mathrm{mmol} / \mathrm{L}$ malate). All oxygen consumption measurements were performed in quadruplicate. Respiration data were normalized for mitochondrial DNA copy number (ratio of ND1 to lipoprotein lipase), as described previously (25). One muscle biopsy failed 
before cold acclimation; therefore, values for nine subjects are presented.

\section{Muscle biopsy analysis}

Protein levels were determined by Western blotting according to standard procedures. Primary antibodies directed against GLUT4 (sc-1608; Santa Cruz Biotechnology Bio-Connect, Huissen, the Netherlands), total OXPHOS human Western blot antibody cocktail (ab110411; Abcam, Cambridge, U.K.), and $\alpha$ sarcomeric actin (loading control; A2172; Sigma, Zwijndrecht, the Netherlands) were detected using appropriate secondary antibodies conjugated with IRDye680 or IRDye800 and detected with the Odyssey Near Infrared System (LI-COR, Westburg, Leusden, the Netherlands).

For GLUT4 imaging, immunofluorescence assays were performed as previously described (19), using primary antibodies directed to GLUT4 (sc-1608; Santa Cruz Biotechnology) and laminin (L9393; Sigma), and Alexa Fluor 555- and Alexa Fluor 488- conjugated secondary antibodies. Slices were observed using a Nikon E800 fluorescence microscope with NIS-Elements imaging software (Nikon Europe BV, Amsterdam, the Netherlands) and were captured with identical exposure time and gain settings in paired ("before-and-after") samples. Without any adjustments with respect to color intensity, brightness, or contrast, RGB-stacked images were quantified using the Plot Profile tool in ImageJ software. Quantification was performed by a researcher (M.J.W.H.) who was blinded to subject identity and sample time (before vs. after). The intensity of GLUT4-dependent signals (16 bits) was measured throughout the sections, and measured data on intensity were used to generate overlying plots of GLUT4 and laminin. GLUT4-derived staining intensity at the sarcolemma (average of five pixels) was quantified at multiple locations per individual (21.4 \pm 4.7 locations before and $20.4 \pm 4.2$ locations after cold acclimation) at randomly chosen cross-sections of muscle biopsies. This was divided over the average GLUT4 staining intensity in 15 pixels located in the cytosol of the same cell. Thus a GLUT4 intensity sarcolemma-to-cytosol ratio >1.0 indicates that relatively more GLUT4 was detected in the cell membrane than in cytosolic regions and hence reflects GLUT4 translocation.

\section{Blood analysis}

Blood samples were analyzed according to standard laboratory procedures, as described previously (11). 


\section{Statistical analysis}

Statistical analyses were performed with PASW Statistics 22.0 for Mac (IBM, Armonk, NY). The Shapiro-Wilk test was used to test for normal distribution of all parameters. For normally distributed data, two-sided paired-sample t tests were used to compare findings before and after cold acclimation and between thermoneutral and mild cold conditions; Wilcoxon signed rank tests were used for non-normally distributed data. Pearson correlations were used to identify correlations between variables. A $\mathrm{P}$ value $<0.05$ was considered statistically significant.

\section{RESULTS}

\section{Energy expenditure}

Before and after cold acclimation, subjects were evaluated for metabolic responses upon acute exposure to mild cold using an individualized cooling protocol. Compared with thermoneutrality, acute exposure to mild cold caused a signifi cant increase in EE before (from $5.9 \pm 0.8$ to $6.5 \pm 0.8 \mathrm{~kJ} \mathrm{~min}^{-1}, \mathrm{P}<0.01$ ) as well as after (from $5.7 \pm 0.7$ to $6.5 \pm 0.8 \mathrm{~kJ} \mathrm{~min}^{-1}, \mathrm{P}<0.01$ ) the cold acclimation period. NST was not significantly different upon cold acclimation $(9.7 \pm 9.1 \%$ before vs. $13.8 \pm 8.9 \%$ after, $P=0.38)$. Although $E E$ during exposure to cold was similar, the basal metabolic rate was slightly lower after cold acclimation (5.9 \pm 0.8 before vs. $5.7 \pm$ $0.7 \mathrm{~kJ} / \mathrm{min}$ after, $\mathrm{P}=0.06$ ) (Fig. $1 \mathrm{~A}$ ). Respiratory quotient did not change upon acute exposure to cold, neither before (from $0.79 \pm 0.06$ to $0.80 \pm 0.05, P=0.32$ ) nor after (from $0.77 \pm 0.04$ to $0.77 \pm 0.06, P=0.31$ ) cold acclimation, and was similar between measurements in both thermoneutral $(P=0.46)$ and mild cold conditions $(P=0.52)$. 
A

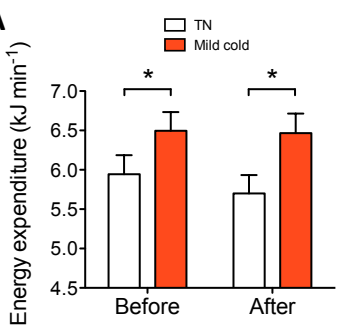

C

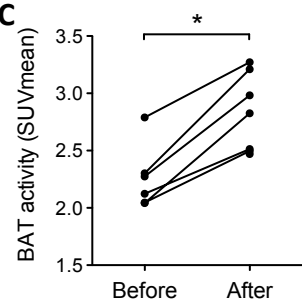

B
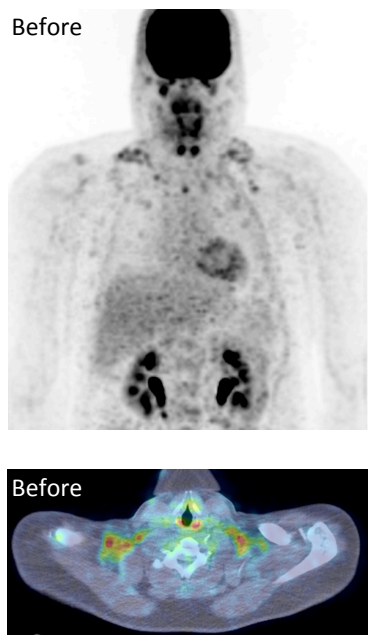
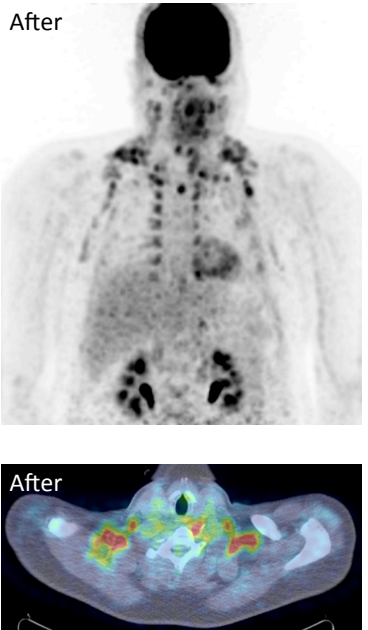
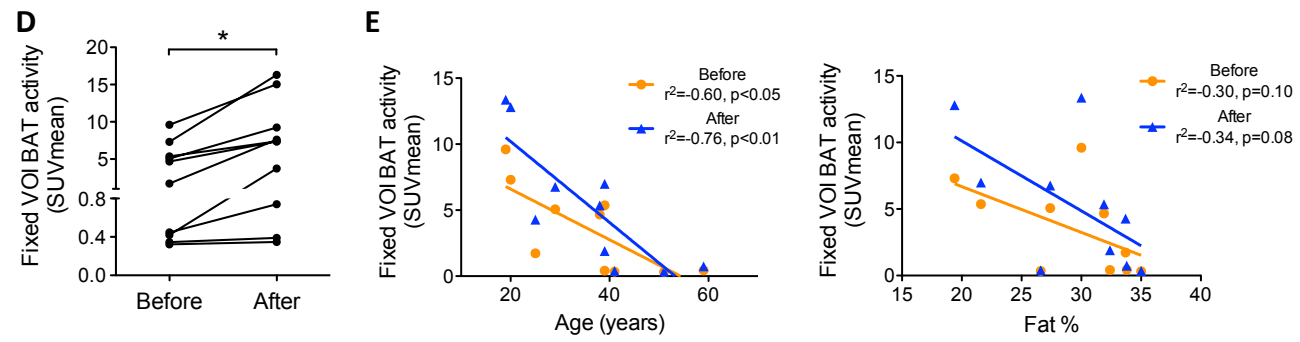

Figure 1. EE and BAT activity before and after exposure to cold in obese subjects, and comparison of BAT activity between obese and lean cold-acclimated subjects. A: EE during thermoneutral (TN) and mild cold conditions, before and after cold acclimation. ${ }^{*} \mathrm{P}<0.05$, TN vs. mild cold. B: Upper-body $\left[{ }^{18} \mathrm{~F}\right]$ FDG-PET/CT image of an obese subject upon exposure to mild cold, before (left) and after (right) cold acclimation (top); transverse PET/CT fusion slices of the supraclavicular region showing $\left[{ }^{18} \mathrm{~F}\right] \mathrm{FDG}$ uptake in BAT locations upon exposure to mild cold, before (left) and after (right) cold acclimation (bottom). C: Individual data on BAT activity for the BAT-positive subjects. ${ }^{*} \mathrm{P}<0.05$, before vs. after cold acclimation. D: Individual data on activity of the supraclavicular BAT region measured by the fixed volume method in all subjects. ${ }^{*} P<0.05$, before vs. after cold acclimation. E: Correlation between BAT activity and age (left) and body fat percentage (right), before and after cold acclimation. Data are expressed as mean \pm SEM.

\section{Increased BAT activity upon cold acclimation}

Before cold acclimation, pronounced BAT activity (SUV >1.5) was observed in 6 of 10 subjects. Of note, the age range of these BAT-positive subjects was 19-39 years, whereas the age range of the BAT-negative subjects was 39-59 years. In the six BAT-positive subjects, BAT regions were semi-automatically outlined: cold 
acclimation resulted in increased mean (SUVmean from $2.3 \pm 0.3$ to $2.9 \pm 0.3 ; \mathrm{P}<$ 0.01) (Fig. 1B and C) and maximal (SUVmax from $8.8 \pm 3.7$ to $18.9 \pm 5.5 ; P<0.01$ ) upper-body BAT activity in these subjects. Interestingly, one of the subjects who did not show pronounced BAT activity before did present detectable BAT after cold acclimation. Because BAT activity (defined by SUV >1.5) could not be detected in all subjects before cold acclimation, we also used the fixed volume method to determine BAT activity in predetermined VOIs in the supraclavicular adipose tissue depot. This method allows comparison of $\left[{ }^{18} \mathrm{~F}\right] \mathrm{FDG}$ uptake in this putative BAT region in the same anatomic location before versus after cold acclimation and in subjects with low amounts of BAT. This fixed VOI method revealed that activity of the supraclavicular BAT region was increased in all subjects upon cold acclimation $(P<0.05)$ (Fig. 1D). Of note, SUVs using this method (Fig. 1D) are generally higher than mean SUVs when total BAT volume is outlined (Fig. 1C), since these VOIs are placed only in the area of maximal BAT activity.

BAT activity was negatively related to age. A similar trend was observed for fat percentage (Fig. 1E) both before and after cold acclimation.

\section{WAT and SM $\left[{ }^{18} \mathrm{~F}\right]$ FDG uptake}

Cold-induced $\left[{ }^{18} \mathrm{~F}\right] \mathrm{FDG}$ uptake in WAT was measured in VOIs placed in several subcutaneous and visceral white fat depots (Supplemental Fig. 1). Average visceral WAT $\left[{ }^{18} \mathrm{~F}\right]$ FDG uptake, as well as $\left[{ }^{18} \mathrm{~F}\right] \mathrm{FDG}$ uptake by all individual visceral WAT regions, was significantly higher than subcutaneous WAT $\left[{ }^{18} \mathrm{~F}\right]$ FDG uptake $(\mathrm{P}<0.05$ for all visceral WAT regions) (Fig. 2B ). None of the WAT depots showed significant changes in activity upon cold acclimation. Compared with the supraclavicular BAT region, $\left[{ }^{18} \mathrm{~F}\right]$ FDG uptake in both visceral and subcutaneous WAT was significantly lower both before and after cold acclimation ( $\mathrm{P}<0.05$ for both) (Fig. 2A). Interestingly, next to BAT, $\left[{ }^{18} \mathrm{~F}\right] \mathrm{FDG}$ uptake in visceral WAT was also negatively related to age $\left(r^{2}=-0.55 ; P<0.05\right)$ (Fig. 2D) and body fat percentage $\left(r^{2}=-0.65 ; P\right.$ $<0.01$ ) (Fig. 2E ). Activity of all fat depots was strongly interrelated, with significant correlations between $\left[{ }^{18} \mathrm{~F}\right] \mathrm{FDG}$ uptake in BAT and visceral WAT $\left(r^{2}=0.65, \mathrm{P}<0.01\right.$ before and $r^{2}=0.72, P<0.01$ after cold acclimation) (Fig. $2 F$ ) and between visceral and subcutaneous WAT $\left(r^{2}=0.65, P<0.01\right.$ before and $r^{2}=0.49, P<0.05$ after cold acclimation).

Cold-induced $\left[{ }^{18} \mathrm{~F}\right] \mathrm{FDG}$ uptake into SM was determined in several different upperbody muscle groups. Before cold acclimation, $\left[{ }^{18} \mathrm{~F}\right] \mathrm{FDG}$ uptake was highest in the scalene muscles $\left(P<0.05\right.$ compared with all other muscles). Average SM $\left[{ }^{18} F\right] F D G$ 
uptake was not related to either age $\left(r^{2}=0.05 ; P=0.53\right)$ or body fat percentage $\left(r^{2}\right.$ $=0.00 ; P=0.94)$. Upon cold acclimation, triceps brachii showed a small but significant increase in $\left[{ }^{18} \mathrm{~F}\right]$ FDG uptake (SUVmean from $0.55 \pm 0.10$ to $0.59 \pm 0.09 ; \mathrm{P}$ $<0.05$ ); a similar trend was observed for the scalene muscles $(P=0.07)$ (Fig. $2 C$ ). The resulting average SM $\left[{ }^{18} \mathrm{~F}\right] \mathrm{FDG}$ uptake tended to be higher after cold acclimation (SUVmean $0.76 \pm 0.17$ before vs. $0.87 \pm 0.30$ after cold acclimation; $P=$ 0.06) (Fig. 2A).

A
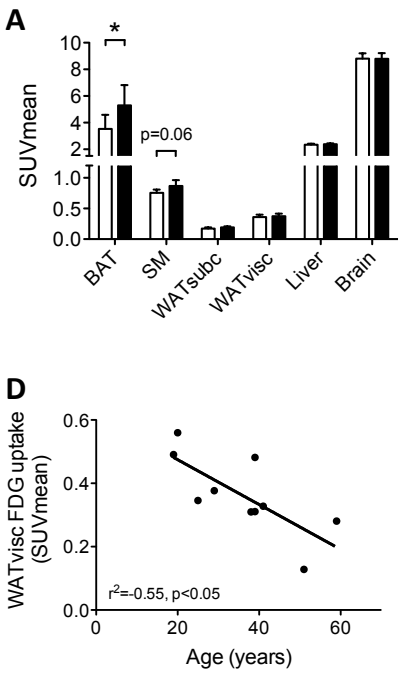
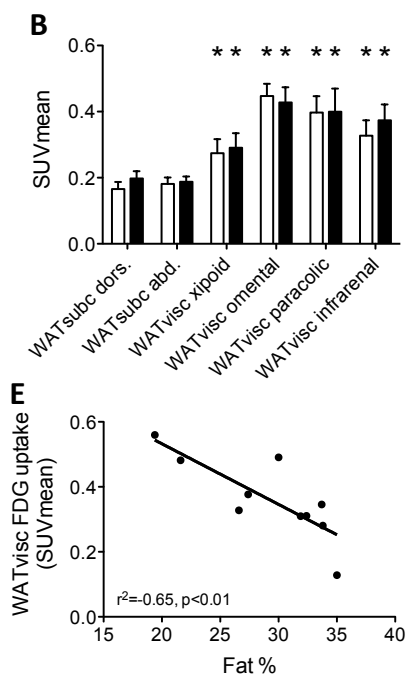

C

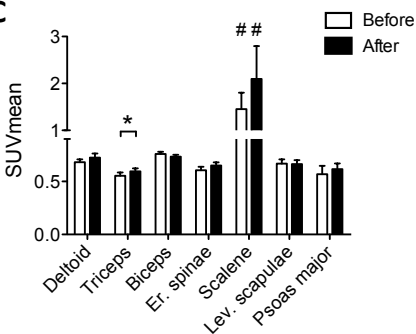

$\mathbf{F}$

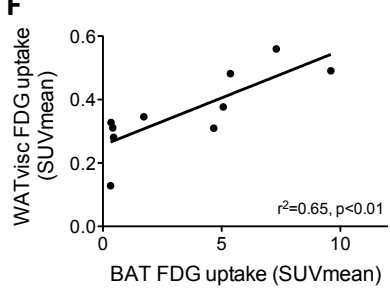

Figure 2. Cold-induced $\left[{ }^{18} \mathrm{~F}\right]$ FDG uptake in WAT and SM before and after cold acclimation. A: $\left[{ }^{18} \mathrm{~F}\right] \mathrm{FDG}$ uptake in BAT, liver, brain, and average SM, subcutaneous WAT (WATsubc), and visceral WAT (WATVisc) before and after cold acclimation. ${ }^{*} \mathrm{P}<0.05$, before vs. after cold acclimation. Data are expressed as mean \pm SEM. B: $\left[{ }^{18}\right.$ F]FDG uptake in individual subcutaneous and visceral WAT regions used to calculate average WATsubc and WATvisc activity, respectively, in A. Abd., abdominal; dors., dorsal. ${ }^{*} P<0.05$, compared with average subcutaneous WAT $\left[{ }^{18} \mathrm{~F}\right] \mathrm{FDG}$ uptake. Data are expressed as mean \pm SEM. C: $\left[{ }^{18}\right.$ F]FDG uptake in individual SM groups used to calculate average SM $\left[{ }^{18}\right.$ F]FDG uptake in A. Er. spinae, erector spinae; Lev. scapulae, levator scapulae. ${ }^{*} P<0.05$, before vs. after cold acclimation; \#P $<0.05$ compared with $\left[{ }^{18} \mathrm{~F}\right] \mathrm{FDG}$ uptake in all other muscle groups. Data are expressed as mean \pm SEM. D: Correlation between visceral WAT $\left[{ }^{18} \mathrm{~F}\right] \mathrm{FDG}$ uptake and age. E: Correlation between visceral WAT $\left[{ }^{18} \mathrm{~F}\right] \mathrm{FDG}$ uptake and body fat percentage. F: Correlation between $\left[{ }^{18} \mathrm{~F}\right] \mathrm{FDG}$ uptake in visceral WAT and supraclavicular BAT. 


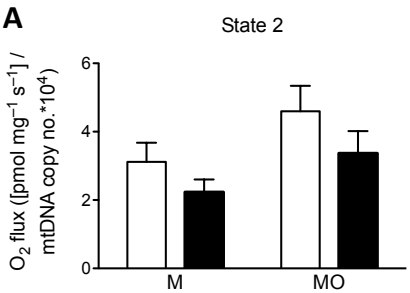

B State 3 - fat oxidation
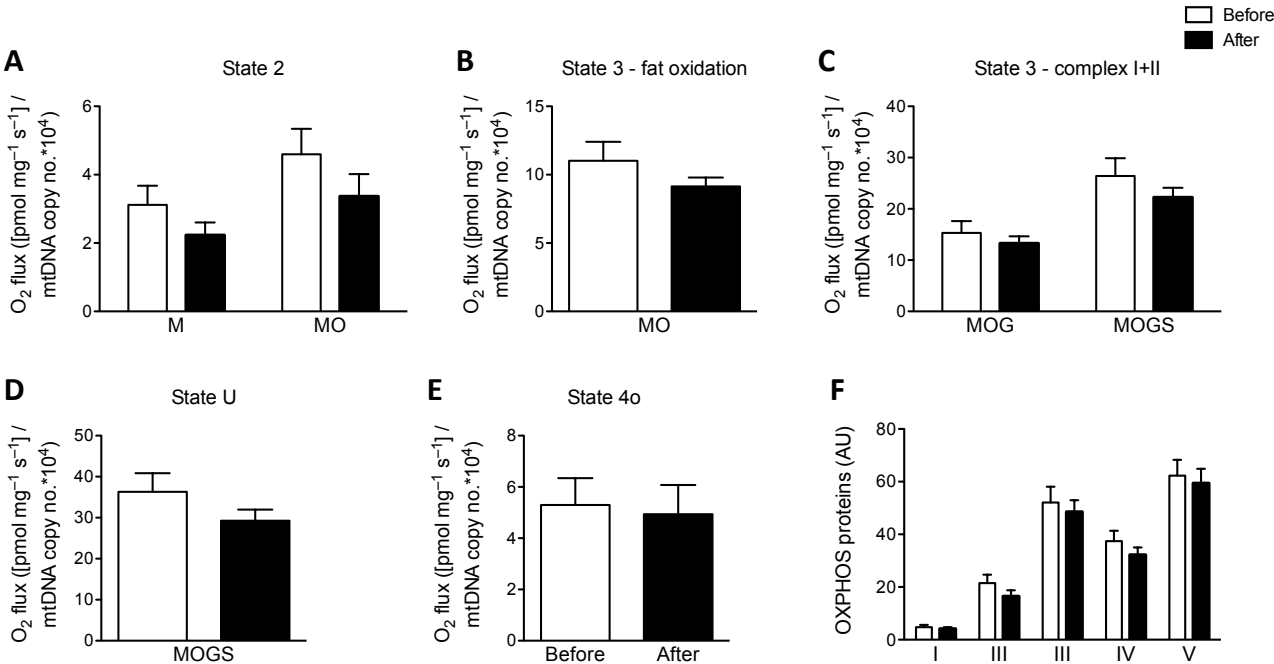

G

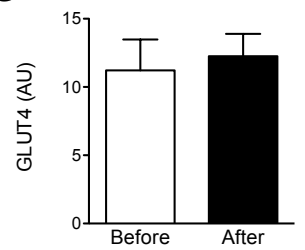

I

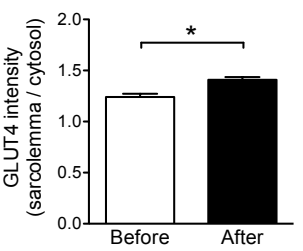

H

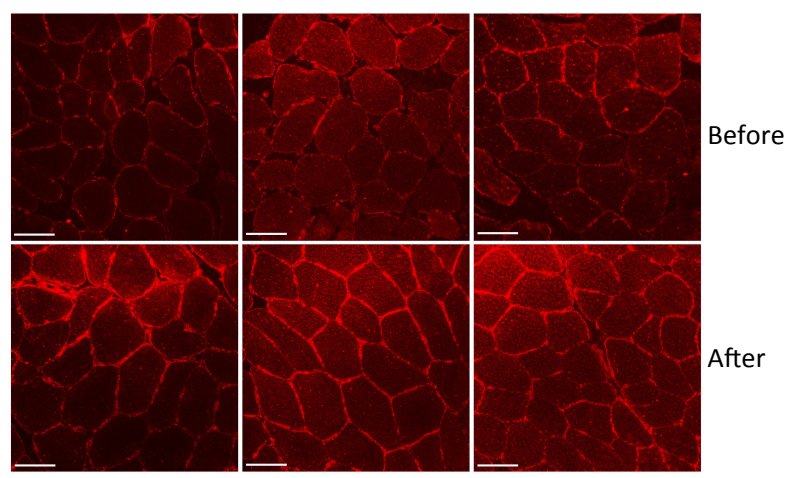

Figure 3. SM mitochondrial respiration, OXPHOS, and GLUT4 protein content and GLUT4 localization, before and after cold acclimation. A-E: Respiration measurements in permeabilized muscle fibers. $M$, malate; O, octanoyl carnitine; G, glutamate; $S$, succinate. A: Respiration upon the addition of substrates only (state 2). B and C: ADP-stimulated respiration fueled by several mitochondrial complex I- and complex II-linked substrates (state 3). D: Maximally uncoupled respiration upon the addition of the chemical uncoupler FCCP (state U; i.e., maximal electron transport chain capacity). E: Respiration not linked to ATP synthesis upon the addition of the ATPase inhibitor oligomycin (state 40, mitochondrial leak respiration). F: Expression of oxidative phosphorylation (OXPHOS) protein complexes I through V. G: GLUT4 protein expression. H: Three representative images of GLUT4 immunostaining on 5-mm-thick fresh-frozen SM tissue sections from fasted muscle biopsies taken before (top) and after (bottom) cold acclimation. Scale bars $=60 \mathrm{~mm}$. I: Quantification of the ratio of GLUT4 staining intensity at the sarcolemma and cytosol. Data are expressed as mean \pm SEM. ${ }^{*} P<$ 0.05 . 


\section{SM respiration and protein expression}

SM biopsies were taken from vastus lateralis muscle before and after cold acclimation and analyzed for mitochondrial respiration. No effects of cold acclimation on mitochondrial oxygen consumption were found in any of the mitochondrial respiration states analyzed (Fig. 3A-E). Thus, neither maximally coupled, ADP-stimulated respiration (Fig. $3 B$ and C) nor maximally uncoupled, FCCP-stimulated respiration (Fig. 3D) nor mitochondrial leak respiration (Fig. 3E) were affected by the cold acclimation period. In addition, protein levels of oxidative phosphorylation complexes I through $\mathrm{V}$ were not significantly affected by cold acclimation (Fig. 3F).

Total GLUT4 protein level was also unchanged upon cold acclimation (Fig. 3G). However, the subcellular distribution pattern of GLUT4 was clearly altered after cold acclimation, with enhanced GLUT4 enrichment at the cell membrane (ratio of GLUT4 staining intensity in the sarcolemma and cytosol changed from $1.24 \pm 0.09$ before to $1.41 \pm 0.08$ after cold acclimation; $\mathrm{P}<0.01$ ) (Fig. $3 \mathrm{H}$ and I), indicating increased GLUT4 translocation to the sarcolemma in the basal state. This enhanced GLUT4 localization at the sarcolemma is consistent with the observation of increased $\left[{ }^{18} \mathrm{~F}\right] \mathrm{FDG}$ uptake in SM upon cold acclimation.

\section{Plasma biochemistry}

No changes in fasting thermoneutral plasma glucose, insulin, nonesterified fatty acid, triglyceride, thyroid hormone, and catecholamine concentrations were observed upon cold acclimation (Table 2). Acute exposure to mild cold resulted in decreased glucose concentrations both before and after cold acclimation, whereas only after cold acclimation was this accompanied by decreased insulin concentrations (Table 2).

Norepinephrine concentration increased upon acute exposure to mild cold in both measurements, whereas epinephrine concentration decreased after cold acclimation (Table 2). Interestingly, the change in norepinephrine concentration upon acute exposure to cold showed a nonsignificant correlation with BAT activity before cold acclimation $\left(r^{2}=0.42 ; P=0.08\right)$, but this correlation was significant after cold acclimation $\left(r^{2}=0.53 ; P<0.05\right)$. 

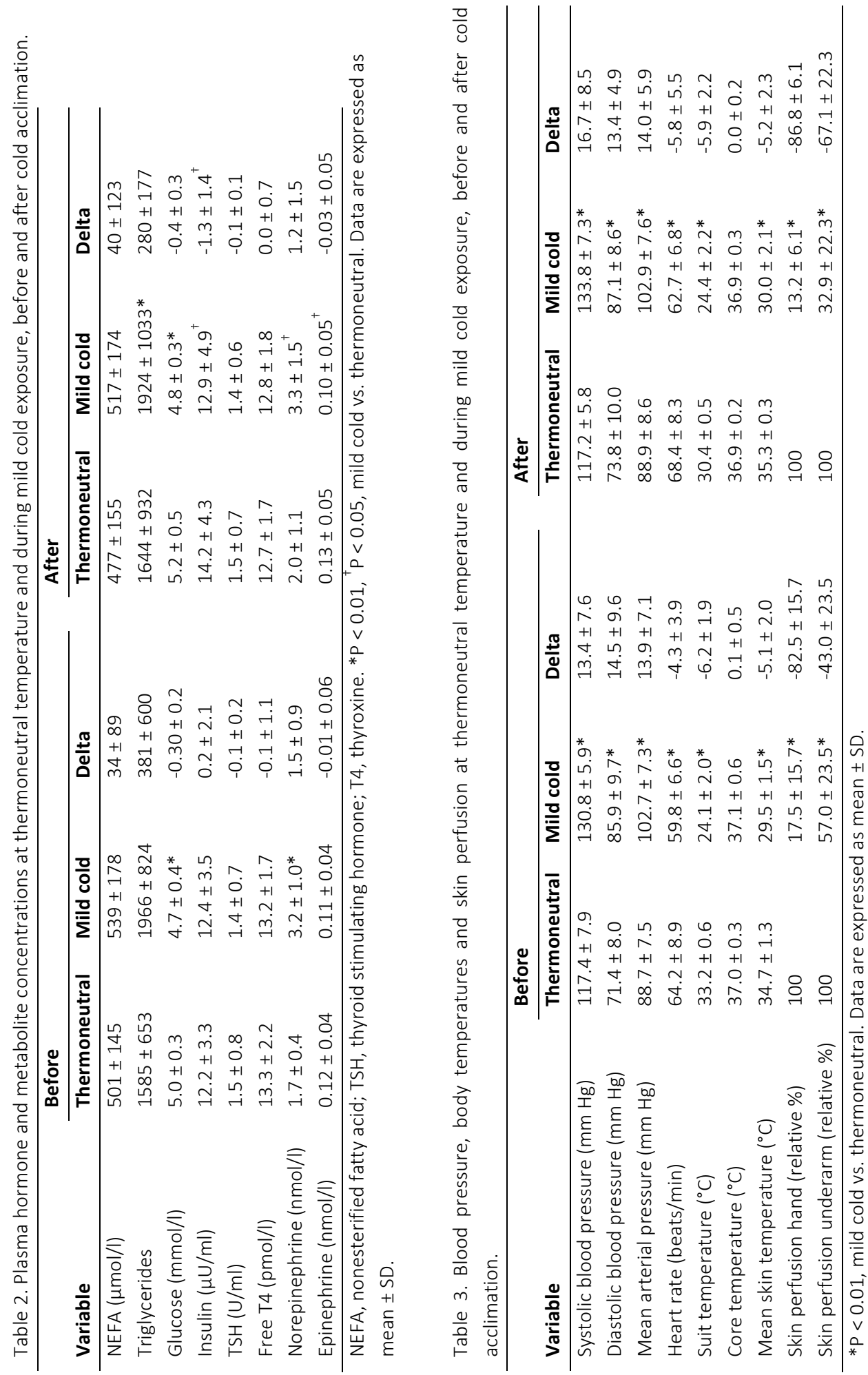


\section{Body temperatures, blood pressure, skin perfusion}

Temperature of the water-perfused suit used during the individualized cooling protocol was similar at thermoneutral $\left(30.2 \pm 0.6\right.$ vs. $\left.30.4 \pm 0.5^{\circ} \mathrm{C} ; \mathrm{P}=0.30\right)$ and mild cold conditions $\left(24.1 \pm 2.0\right.$ vs. $\left.24.4 \pm 2.2^{\circ} \mathrm{C} ; \mathrm{P}=0.59\right)$ before versus after cold acclimation, respectively. Consequently, mean skin temperature was also lowered to the same extent before $\left(25.1 \pm 2.0^{\circ} \mathrm{C}\right)$ and after $\left(25.2 \pm 2.3^{\circ} \mathrm{C}\right)$ cold acclimation upon acute cooling $(\mathrm{P}<0.05)$ (Table 3$)$. In addition, core temperature, blood pressure, and heart rate were similar during thermoneutral conditions and showed similar responses upon acute cooling (Table 3). Skin perfusion at the hand was also unaffected by cold acclimation, whereas skin perfusion at the underarm was reduced to a larger extent upon acute cooling after cold acclimation $(-43 \pm 23.5 \%$ before vs. $-67.1 \pm 22.3 \%$ after cold acclimation; $P=0.050$ ) (Table 3 ), indicating enhanced vasoconstriction.

Skin temperatures and blood pressure, in addition to subjective responses to exposure to cold, were also recorded at several time points during the cold acclimation days, and iAUCs for these parameters were calculated. The iAUC for thermal sensation was significantly decreased $(-28.0 \%$; $P<0.05$; i.e., a sensation closer to neutral), and self-reported shivering was also lowered, albeit not significantly $(-15.0 \% ; P=0.099)$, on day 10 compared with day 3 (first day of 6 h of exposure to cold) of the cold acclimation period (Fig. 4A), indicating subjective habituation to the colder environment. Interestingly, while mean and distal skin temperature responses were unchanged, proximal skin temperature was markedly higher upon cold acclimation (Fig. 4B). Blood pressure was higher at $t=20 \mathrm{~min}$ after entering the cold room at day $10(P<0.05$, compared with day 3$)$, after which it showed a similar pattern for the remaining time points (Fig. 4C).

\section{DISCUSSION}

This is the first study to show that in obese subjects significant amounts of BAT can be recruited by short-term cold acclimation. In addition, we show that glucose uptake of several adipose tissue depots is strongly interrelated, although BAT is the only fat depot that shows increased glucose uptake upon cold acclimation. In SM, cold acclimation leads to enhanced GLUT4 localization at the sarcolemma, which is paralleled by increased glucose uptake upon acute exposure to cold. 
A

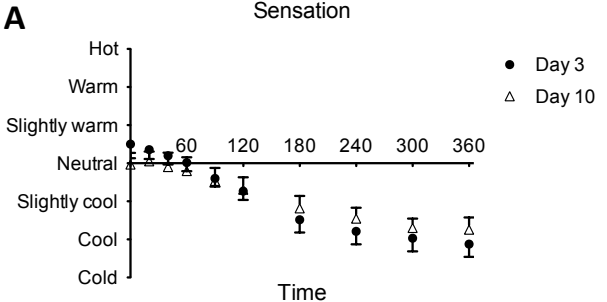

Time

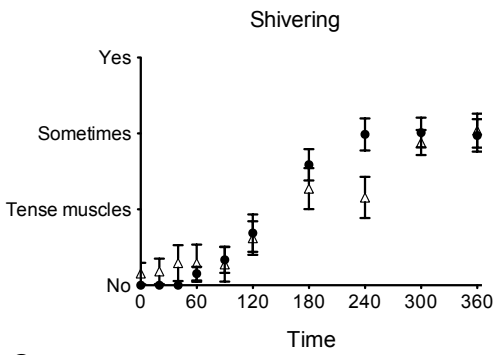

C

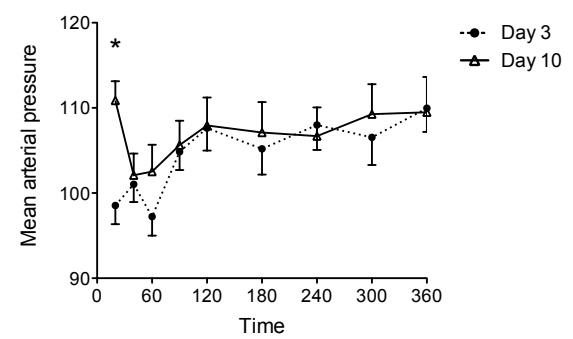

B
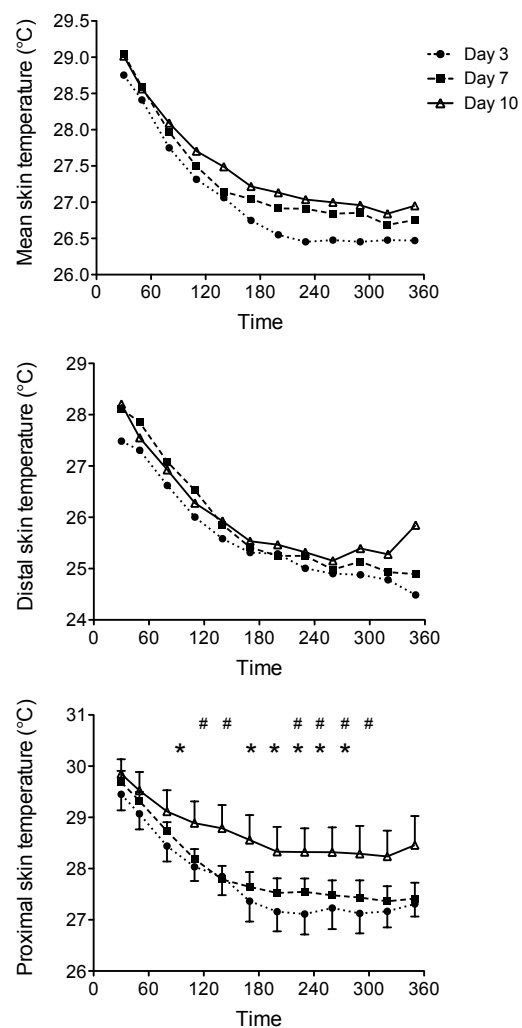

Figure 4. Subjective responses, skin temperatures, and blood pressure during cold acclimation. A: Changes in thermal sensation (top) and self-reported shivering (bottom) after entering the cold room on day 10 compared with day 3 of the cold acclimation period. B: Changes in mean (top), distal (middle), and proximal (bottom) skin temperatures after entering the cold room on day 10 compared with days 3 and 7. C: Change in mean arterial pressure after entering the cold room on day 10 compared with day 3. Data are expressed as mean \pm SEM. ${ }^{*} P<0.05$, at a specific time point on day 10 vs. day $3 ; \# P<0.05$ at a specific time point on day 10 vs. day 7 .

Adaptive thermogenesis by means of prolonged exposure to mild cold and other ways to activate and recruit BAT have emerged as potential tools to combat obesity and its associated metabolic complications, such as insulin resistance. So far, recruitment of significant amounts of BAT has only been shown in young, lean, healthy subjects upon cold acclimation $(11 ; 16 ; 17)$, and in morbidly obese subjects following massive weight loss (27), whereas in older subjects with type 2 diabetes cold acclimation led to only a minor increase in BAT activity (19). Here we show that substantial amounts of BAT can be recruited in healthy obese subjects by cold acclimation and confirm the negative relations between age, body fat, and BAT activity that were reported earlier (12). In addition, when comparing our previously 
published BAT activity values for young, lean male subjects (age < 30 years) (11) with those in the young obese subjects from this study (age 19- 29 years; $n=4$ ), SUVs are indeed lower in the obese group (SUVmean $2.35 \pm 0.31$ vs. $2.60 \pm 0.32$ and SUVmax $9.43 \pm 4.49$ vs. $15.90 \pm 5.75$ in obese vs. lean subjects, respectively). When comparing BAT activity after cold acclimation, however, SUVs become comparable between these obese and lean individuals (SUVmean $3.07 \pm 0.71$ vs. $2.89 \pm 0.37$ and SUVmax $22.26 \pm 2.56$ vs. $19.9 \pm 6.32$ in obese vs. lean subjects, respectively). Although these observations need to be confirmed in larger groups of subjects, this may indicate that the capacity to recruit BAT at a young age is not hampered by obesity per se. This is also consistent with data from rodent studies showing BAT "whitening" upon intake of a high-fat diet (28) and evidence that such whitened adipocytes can again be interconverted into brown/beige adipocytes with a high thermogenic capacity upon cold stimulation (29).

The intense cold acclimation protocol (i.e., $6 \mathrm{~h}$ of cold exposure per day) that we used in this proof-of-principle study may not be directly therapeutically applicable for obese subjects. However, other recent studies of lean subjects have shown that more prolonged, less intense exposures to cold can also enhance BAT $(16 ; 18)$. It would therefore be interesting to explore the effects of such prolonged, mild cold regimens on BAT and substrate metabolism in obese subjects.

BAT recruitment was not associated with enhanced NST. In previous studies we (11) and others (16) reported that BAT recruitment by cold acclimation in lean, young subjects was paralleled by an increase in NST. In older, overweight patients with type 2 diabetes impaired NST upon acute exposure to cold has been observed (19; 30), whereas NST improved upon cold acclimation (19). Pronounced interindividual differences in metabolic responses to exposure to cold and possible type 2 error might explain the absence of such an effect in the obese subjects in our current study. In fact, the increased proximal skin temperatures measured on the final cold acclimation day actually point toward increased heat production during cold exposure, assuming that core temperatures were unaffected, as also shown during the individualized cooling protocols. It should also be noted, however, that despite several reported associations between BAT activity and NST, it is still unclear to what extent BAT activity directly contributes to measured whole-body oxidative metabolism in humans $(31 ; 32)$; thus, an increase in BAT activity is not necessarily directly reflected in increased NST. Future studies should therefore focus on further unraveling the contribution of BAT activity to NST by using individualized cooling protocols similar to those used here. 
Contrary to BAT, $\left[{ }^{18} \mathrm{~F}\right]$ FDG uptake in visceral and subcutaneous WAT depots did not change upon cold acclimation, which argues against the notion that browning occurred in these adipose depots. However, a possible subtle degree of browning may in fact not be detectable because of the limited resolution of the PET scanner. An alternative explanation may be that browning in the sense of recruitment of brite/beige adipocytes in these depots is without physiological significance with respect to glucose uptake. Of note, in two previous publications we did not find any thermogenic gene induction in subcutaneous WAT biopsies after 10 days of cold acclimation $(11 ; 19)$. It is likely that a greater or more prolonged adrenergic stimulus is required to induce browning within these white adipose depots. Sidossis et al. (8) recently showed that upon severe and prolonged adrenergic stress (i.e., in burn victims), browning of subcutaneous WAT became apparent, which was associated with increased whole-body EE.

The negative relation between body fat and visceral WAT activity within our obese cohort confirms recent observations of lower fasting visceral WAT activity per volume in obese versus lean subjects (33). This effect is likely caused by the presence of more insulin-resistant adipocytes and impaired perfusion and vascular function in obesity, despite associations of obesity with the infiltration of macrophages in visceral WAT, which could actually augment glucose uptake (3335). Such visceral WAT dysfunction may be involved in impaired systemic glucose disposal and insulin resistance (36), although it has also been suggested that lower visceral WAT activity per volume is counterbalanced by an expanded total fat mass, thereby providing a larger "sink" for glucose disposal (37).

We previously examined a possible role of SM in cold-induced thermogenesis and found no effects of cold acclimation on mitochondrial oxidative capacity or markers for mitochondrial uncoupling in young lean subjects (11) and subjects with type 2 diabetes (19). Here, we further confirm these findings in healthy obese subjects. In addition, we showed pronounced improvements in insulin-induced glucose uptake into SM upon cold acclimation in these subjects with type 2 diabetes, which was accompanied by enhanced GLUT4 translocation from the cytosol to the sarcolemma in the basal state (19). Although we did not intend to assess insulin sensitivity when we planned the current study, we were able to repeat GLUT4 immunofluorescence staining and quantification in fasting SM biopsies. As such, we were able to show enhanced basal GLUT4 translocation in healthy normoglycemic obese subjects as well, indicating a greater capacity for glucose uptake. These findings coincided with an increased cold-induced $\left[{ }^{18} \mathrm{~F}\right] \mathrm{FDG}$ uptake into SM after 


\section{CHAPTER 4}

cold acclimation, as visualized by PET/CT. The underlying mechanisms for these effects in SM remain to be elucidated; a recently newly identified adrenergic signaling pathway involving MTORC2 (38) or signaling molecules secreted by brown adipocytes (39) might play a role in this phenomenon.

In conclusion, we show that significant amounts of BAT can be recruited in obese subjects by means of intermittent exposure to cold. In addition, cold acclimation has a pronounced effect on SM, displaying enhanced GLUT4 translocation to facilitate glucose uptake. These metabolic adaptations to prolonged exposure to cold may induce improvements in whole-body glucose metabolism. The long-term effects of cold acclimation on BAT, SM, and whole-body metabolism remain to be elucidated. 


\section{REFERENCES}

1. van Marken Lichtenbelt WD, Schrauwen P: Implications of nonshivering thermogenesis for energy balance regulation in humans. American journal of physiology Regulatory, integrative and comparative physiology 2011;301:R285-296

2. Virtanen KA, Lidell ME, Orava J, Heglind M, Westergren R, Niemi T, Taittonen M, Laine J, Savisto NJ, Enerback S, Nuutila P: Functional brown adipose tissue in healthy adults. The New England journal of medicine 2009;360:1518-1525

3. van Marken Lichtenbelt WD, Vanhommerig JW, Smulders NM, Drossaerts JM, Kemerink GJ, Bouvy ND, Schrauwen P, Teule GJ: Cold-activated brown adipose tissue in healthy men. The New England journal of medicine 2009;360:1500-1508

4. Cypess AM, Lehman S, Williams G, Tal I, Rodman D, Goldfine AB, Kuo FC, Palmer EL, Tseng YH, Doria A, Kolodny GM, Kahn CR: Identification and importance of brown adipose tissue in adult humans. The New England journal of medicine 2009;360:1509-1517

5. Vallerand AL, Lupien J, Bukowiecki LJ: Cold exposure reverses the diabetogenic effects of high-fat feeding. Diabetes 1986;35:329-334

6. Bartelt A, Bruns OT, Reimer R, Hohenberg H, Ittrich H, Peldschus K, Kaul MG, Tromsdorf UI, Weller H, Waurisch C, Eychmuller A, Gordts PL, Rinninger F, Bruegelmann K, Freund B, Nielsen $\mathrm{P}$, Merkel $\mathrm{M}$, Heeren J: Brown adipose tissue activity controls triglyceride clearance. Nature medicine 2011;17:200-205

7. Harms M, Seale P: Brown and beige fat: development, function and therapeutic potential. Nature medicine 2013;19:1252-1263

8. Sidossis LS, Porter C, Saraf MK, Borsheim E, Radhakrishnan RS, Chao T, Ali A, Chondronikola M, Mlcak R, Finnerty CC, Hawkins HK, Toliver-Kinsky T, Herndon DN: Browning of Subcutaneous White Adipose Tissue in Humans after Severe Adrenergic Stress. Cell metabolism 2015;22:219-227

9. Saito $M$ : Brown adipose tissue as a regulator of energy expenditure and body fat in humans. Diabetes \& metabolism journal 2013;37:22-29

10. Hanssen MJ, Wierts R, Hoeks J, Gemmink A, Brans B, Mottaghy FM, Schrauwen P, van Marken Lichtenbelt WD: Glucose uptake in human brown adipose tissue is impaired upon fasting-induced insulin resistance. Diabetologia 2015;58:586-595

11. van der Lans AA, Hoeks J, Brans B, Vijgen GH, Visser MG, Vosselman MJ, Hansen J, Jorgensen JA, Wu J, Mottaghy FM, Schrauwen P, van Marken Lichtenbelt WD: Cold acclimation recruits human brown fat and increases nonshivering thermogenesis. The Journal of clinical investigation 2013;123:3395-3403

12. Yoneshiro T, Aita S, Matsushita M, Okamatsu-Ogura Y, Kameya T, Kawai Y, Miyagawa M, Tsujisaki M, Saito M: Age-related decrease in cold-activated brown adipose tissue and accumulation of body fat in healthy humans. Obesity 2011;19:1755-1760

13. Blondin DP, Labbe SM, Noll C, Kunach M, Phoenix S, Guerin B, Turcotte EE, Haman F, Richard D, Carpentier AC: Selective Impairment of Glucose but Not Fatty Acid or Oxidative Metabolism in Brown Adipose Tissue of Subjects With Type 2 Diabetes. Diabetes 2015;64:2388-2397

14. Kingma BR, Frijns AJ, Saris WH, van Steenhoven AA, Lichtenbelt WD: Increased systolic blood pressure after mild cold and rewarming: relation to cold-induced thermogenesis and age. Acta physiologica 2011;203:419-427

15. Wijers SL, Saris WH, van Marken Lichtenbelt WD: Cold-induced adaptive thermogenesis in lean and obese. Obesity 2010;18:1092-1099 
16. Yoneshiro T, Aita S, Matsushita M, Kayahara T, Kameya T, Kawai $Y$, Iwanaga $T$, Saito M: Recruited brown adipose tissue as an antiobesity agent in humans. The Journal of clinical investigation 2013;123:3404-3408

17. Blondin DP, Labbe SM, Tingelstad HC, Noll C, Kunach M, Phoenix S, Guerin B, Turcotte EE, Carpentier AC, Richard D, Haman F: Increased brown adipose tissue oxidative capacity in cold-acclimated humans. The Journal of clinical endocrinology and metabolism 2014;99:E438-446

18. Lee P, Smith S, Linderman J, Courville AB, Brychta RJ, Dieckmann W, Werner CD, Chen KY, Celi FS: Temperature-acclimated brown adipose tissue modulates insulin sensitivity in humans. Diabetes 2014;63:3686-3698

19. Hanssen MJ, Hoeks J, Brans B, van der Lans AA, Schaart G, van den Driessche JJ, Jorgensen JA, Boekschoten MV, Hesselink MK, Havekes B, Kersten S, Mottaghy FM, van Marken Lichtenbelt WD, Schrauwen P: Short-term cold acclimation improves insulin sensitivity in patients with type 2 diabetes mellitus. Nature medicine 2015;21:863-865

20. Shabalina IG, Petrovic N, de Jong JM, Kalinovich AV, Cannon B, Nedergaard J: UCP1 in brite/beige adipose tissue mitochondria is functionally thermogenic. Cell reports 2013;5:1196-1203

21. Gasparetti AL, de Souza CT, Pereira-da-Silva M, Oliveira RL, Saad MJ, Carneiro EM, Velloso LA: Cold exposure induces tissue-specific modulation of the insulin-signalling pathway in Rattus norvegicus. The Journal of physiology 2003;552:149-162

22. van Marken Lichtenbelt WD, Daanen HA, Wouters L, Fronczek R, Raymann RJ, Severens NM, Van Someren EJ: Evaluation of wireless determination of skin temperature using iButtons. Physiology \& behavior 2006;88:489-497

23. van der Lans AA, Wierts R, Vosselman MJ, Schrauwen P, Brans B, van Marken Lichtenbelt WD: Cold-activated brown adipose tissue in human adults: methodological issues. American journal of physiology Regulatory, integrative and comparative physiology 2014;307:R103-113

24. Vosselman MJ, Brans B, van der Lans AA, Wierts R, van Baak MA, Mottaghy FM, Schrauwen $P$, van Marken Lichtenbelt WD: Brown adipose tissue activity after a high-calorie meal in humans. The American journal of clinical nutrition 2013;98:57-64

25. Phielix E, Schrauwen-Hinderling VB, Mensink M, Lenaers E, Meex R, Hoeks J, Kooi ME, Moonen-Kornips E, Sels JP, Hesselink MK, Schrauwen P: Lower intrinsic ADP-stimulated mitochondrial respiration underlies in vivo mitochondrial dysfunction in muscle of male type 2 diabetic patients. Diabetes 2008;57:2943-2949

26. Hoeks J, van Herpen NA, Mensink M, Moonen-Kornips E, van Beurden D, Hesselink MK, Schrauwen P: Prolonged fasting identifies skeletal muscle mitochondrial dysfunction as consequence rather than cause of human insulin resistance. Diabetes 2010;59:2117-2125

27. Vijgen GH, Bouvy ND, Teule GJ, Brans B, Hoeks J, Schrauwen P, van Marken Lichtenbelt WD: Increase in brown adipose tissue activity after weight loss in morbidly obese subjects. The Journal of clinical endocrinology and metabolism 2012;97:E1229-1233

28. Shimizu I, Aprahamian T, Kikuchi R, Shimizu A, Papanicolaou KN, MacLauchlan S, Maruyama S, Walsh K: Vascular rarefaction mediates whitening of brown fat in obesity. The Journal of clinical investigation 2014;124:2099-2112

29. Rosenwald M, Perdikari A, Rulicke T, Wolfrum C: Bi-directional interconversion of brite and white adipocytes. Nature cell biology 2013;15:659-667

30. Lean ME, Murgatroyd PR, Rothnie I, Reid IW, Harvey R: Metabolic and thyroidal responses to mild cold are abnormal in obese diabetic women. Clin Endocrinol (Oxf) 1988;28:665-673 
31. Blondin DP, Labbe SM, Phoenix S, Guerin B, Turcotte EE, Richard D, Carpentier AC, Haman F: Contributions of white and brown adipose tissues and skeletal muscles to acute coldinduced metabolic responses in healthy men. The Journal of physiology 2015;593:701-714

32. Muzik O, Mangner TJ, Leonard WR, Kumar A, Janisse J, Granneman JG: 150 PET measurement of blood flow and oxygen consumption in cold-activated human brown fat. Journal of nuclear medicine : official publication, Society of Nuclear Medicine 2013;54:523531

33. Oliveira AL, Azevedo DC, Bredella MA, Stanley TL, Torriani M: Visceral and subcutaneous adipose tissue FDG uptake by PET/CT in metabolically healthy obese subjects. Obesity 2015;23:286-289

34. Christen T, Sheikine Y, Rocha VZ, Hurwitz S, Goldfine AB, Di Carli M, Libby P: Increased glucose uptake in visceral versus subcutaneous adipose tissue revealed by PET imaging. JACC Cardiovascular imaging 2010;3:843-851

35. Virtanen KA, Lonnroth P, Parkkola R, Peltoniemi P, Asola M, Viljanen T, Tolvanen T, Knuuti $J$, Ronnemaa T, Huupponen R, Nuutila P: Glucose uptake and perfusion in subcutaneous and visceral adipose tissue during insulin stimulation in nonobese and obese humans. The Journal of clinical endocrinology and metabolism 2002;87:3902-3910

36. Ng JM, Azuma K, Kelley C, Pencek R, Radikova Z, Laymon C, Price J, Goodpaster BH, Kelley DE: PET imaging reveals distinctive roles for different regional adipose tissue depots in systemic glucose metabolism in nonobese humans. American journal of physiology Endocrinology and metabolism 2012;303:E1134-1141

37. Virtanen KA, lozzo P, Hallsten K, Huupponen R, Parkkola R, Janatuinen T, Lonnqvist F, Viljanen $T$, Ronnemaa $T$, Lonnroth $P$, Knuuti J, Ferrannini E, Nuutila P: Increased fat mass compensates for insulin resistance in abdominal obesity and type 2 diabetes: a positronemitting tomography study. Diabetes 2005;54:2720-2726

38. Sato M, Dehvari N, Oberg Al, Dallner OS, Sandstrom AL, Olsen JM, Csikasz RI, Summers RJ, Hutchinson DS, Bengtsson T: Improving type 2 diabetes through a distinct adrenergic signaling pathway involving mTORC2 that mediates glucose uptake in skeletal muscle. Diabetes 2014;63:4115-4129

39. Villarroya J, Cereijo R, Villarroya F: An endocrine role for brown adipose tissue? American journal of physiology Endocrinology and metabolism 2013;305:E567-572 


\section{SUPPLEMENTAL FIGURE}
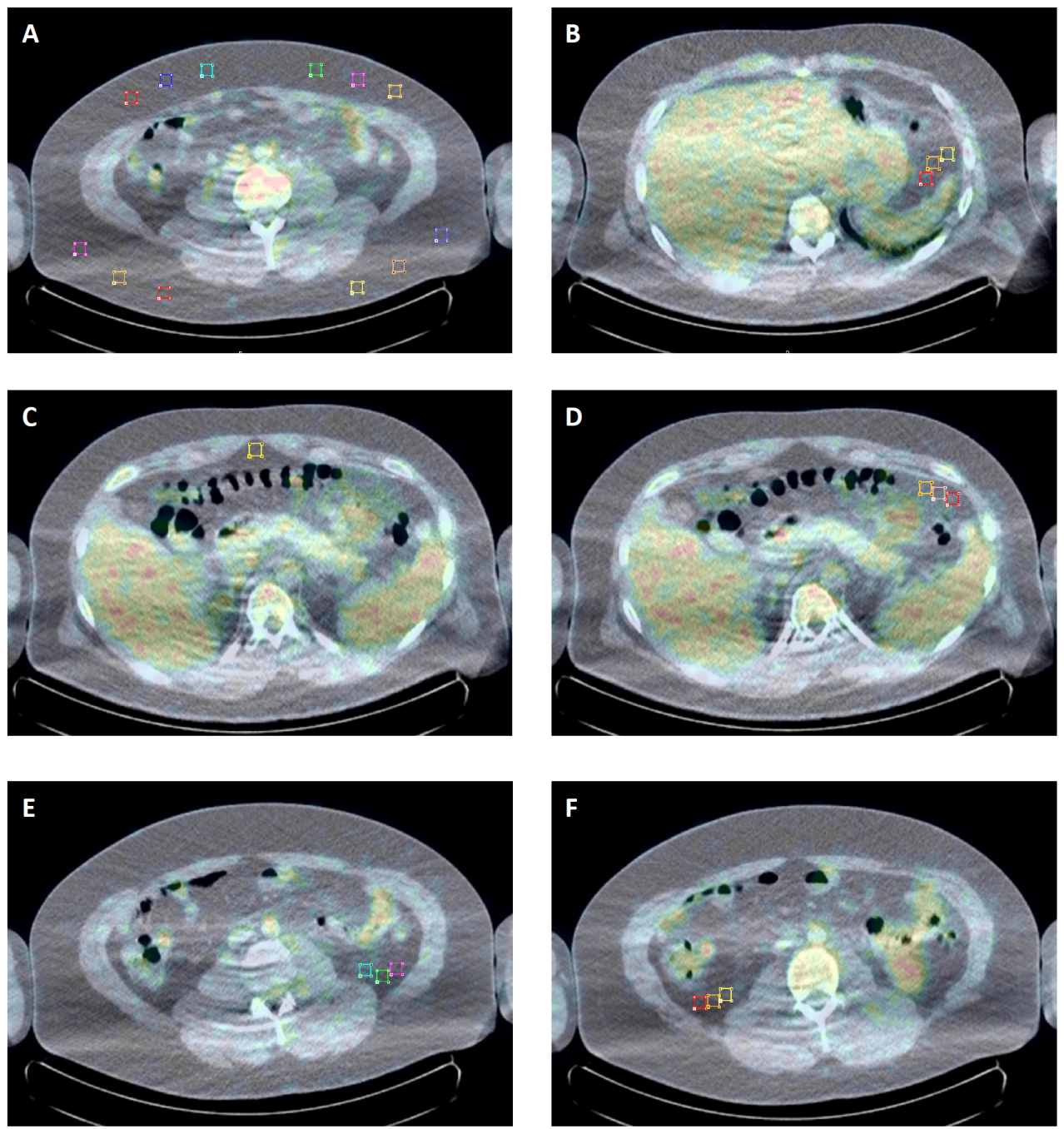

Supplemental Figure 1. Analysis of ${ }^{18}$ F]FDG uptake in subcutaneous and visceral WAT regions. (A) VOIs $\left(1.33 \mathrm{~cm}^{3}\right.$ per VOI) placed in the dorsolumbar subcutaneous WAT region near vertebrae L-3, as well as in the abdominal subcutaneous WAT region in the same transversal slice (total VOI volume both $\left.8 \mathrm{~cm}^{3}\right)$. (B-F) VOIs $\left(1.33 \mathrm{~cm}^{3}\right.$ per VOI) placed in visceral WAT regions: (B) the omental WAT region at the level of spleen and stomach; (C) behind the xipoid; (D) the paracolic WAT region; $(E, F)$ the infrarenal WAT region, left (E) and right (F). 
COLD ACCLIMATION IN OBESE HUMANS 


\section{Serum FGF21 levels are associated with brown adipose tissue activity in humans}

The contents of this chapter are published in:

MJW Hanssen*, E Broeders*, RJ Samms, MJ Vosselman, AAJJ van der Lans, CC Cheng, AC Adams, WD van Marken Lichtenbelt, P Schrauwen. Serum FGF21 levels are associated with brown adipose tissue activity in humans. Scientific Reports 2015;5:10275

* Both authors contributed equally 


\section{ABSTRACT}

The obesity pandemic has spurred a need for novel therapies to prevent and treat metabolic complications. The recent rediscovery of brown adipose tissue (BAT) in humans made this tissue a possible therapeutic target due to its potentially substantial contributions to energy homeostasis. Fibroblast growth factor 21 (FGF21) has been identified as a facilitator of cold-induced thermogenesis in humans. Furthermore, pre-clinical studies revealed that FGF21 administration leads to improvement in the metabolic consequences of obesity, such as dyslipidemia and type 2 diabetes. Here we studied plasma FGF21 levels in two cohorts of human subjects, in whom BAT activity was determined using an individualized cooling protocol by $\left[{ }^{18} \mathrm{~F}\right]$ FDG-PET/CT scan. Importantly, we found that circulating FGF21 levels correlated with BAT activity during acute cold exposure in male subjects. In addition, FGF21 levels were related to the change in core temperature upon acute cold exposure, indicating a role in maintaining normothermia, possibly via activation of BAT. Furthermore, cold acclimation increased BAT activity in parallel with increased FGF21 levels.

In conclusion, our results demonstrate that FGF21 levels in humans are related to BAT activity, suggesting that FGF21 may represent a novel mechanism via which BAT activity in humans may be enhanced. 


\section{INTRODUCTION}

The obesity pandemic is associated with major metabolic disturbances, including type 2 diabetes, non-alcoholic fatty liver disease (NAFLD) and cardiovascular disease. Lifestyle interventions aimed at increasing physical activity and decreasing food intake can be effective in treating these disorders, however, due to poor adherence such interventions are not easily translated to the general population. As such, there is an ongoing need for novel therapies that may alleviate obesityinduced metabolic complications, especially as currently available therapies offer only modest efficacy. Fibroblast growth factor-21 (FGF21) was originally discovered in 2000 as a new member of the FGF superfamily (1). The first hint at its metabolic effects came about when FGF21 was identified as a factor able to augment glucose uptake in an adipocyte screen (2). Subsequently, FGF21 was shown to have favorable metabolic effects in vivo (3; 4). Transgenic mice with FGF21 overexpression in liver demonstrated improved insulin sensitivity and resistance to weight gain on a high-fat diet (2). Systemic administration of recombinant human FGF21 in mice leads to lowered blood glucose levels, improved insulin-sensitivity (2), amelioration of dyslipidemia, and preservation of $\beta$-cell function (5). Mice infused with FGF21 also exhibit elevated energy expenditure $(E E)(6 ; 7)$, likely due to a thermogenic response in white (WAT) and brown adipose tissue (BAT) (8; 9). Recently, the results of the first phase 1B study using an FGF21 analog, termed LY2405319, conducted in obese type 2 diabetic patients, became available. This trial demonstrated that the majority of FGF21's metabolic effects are translatable to humans (10). Specifically, chronic treatment with varying doses of LY2405319 resulted in improvements in plasma lipid profiles, and decreases in fasting insulin levels and body weight.

Since the rediscovery of brown adipose tissue (BAT) in humans in 2009, the search for novel ways to activate BAT in humans has intensified. We (11) and others (12) have shown that acute cold is able to promote activation of BAT in the majority of human volunteers. Moreover, cold acclimation for 10 days led to an increased capacity to activate BAT upon acute cold stimulation (13). The mechanism via which cold activates BAT is not known, nor are all the pathways involved in BAT activation in humans. Alongside more classical activators of BAT, such as thyroid hormone and the sympathetic nervous system (SNS), novel pathways including the bone morphogenic proteins (BMPs) $(14 ; 15)$, irisin $(16 ; 17)$ and FGF21 $(2 ; 18)$ have been proposed as stimulators of BAT activity and recruitment. Interestingly, cold 
exposure has been reported to increase circulating levels of FGF21 in addition to enhanced FGF21 expression in BAT, leading to uncoupling protein-1 (UCP-1) transcription $(8 ; 19 ; 20)$.

In addition to activity directly in BAT, FGF21 has recently been demonstrated to stimulate the browning of WAT in a variety of animal studies $(2 ; 21 ; 22)$. Following a three-day cold-exposure challenge, a threefold increase in FGF21 mRNA was observed in BAT in mice (8), accompanied by a robust induction of FGF21 mRNA in peripheral WAT depots. Furthermore, in human primary beige (or brite) adipocytes FGF21 has been reported to increase thermogenic gene expression and capacity, as indicated by increased basal and uncoupled respiration (23).

In human subjects, changes in serum FGF21 concentrations correlated positively with cold-induced non-shivering induced thermogenesis (18). However, so far the relationship between FGF21 and BAT activation has not been studied in vivo in humans. The present study was aimed at elucidating whether elevation of circulating FGF21 levels in humans is associated with the activation of BAT and thereby test if this activation may be in part responsible for the beneficial metabolic effects of FGF21 treatment

Here, we studied the relationship between circulating FGF21 levels and BAT activity and the effect of acute and prolonged cold exposure (cold acclimation) on these parameters. To this end, we measured plasma FGF21 levels in a large number of subjects from previous studies $(13 ; 24-26)$, who were exposed to an individualized cooling protocol (27) for evaluation of BAT activity using an $\left[{ }^{18} \mathrm{~F}\right] \mathrm{FDG}-\mathrm{PET} / \mathrm{CT}$ scan. Our results reveal that FGF21 levels are positively correlated with BAT activity during acute cold exposure. In addition, chronic cold acclimation increases BAT activity in parallel with an increase in FGF21 levels.

\section{METHODS}

\section{Study protocol}

In this study data from 59 lean, healthy subjects, who participated in previously published studies, was used $(13 ; 24-26)$. Written informed consent was obtained from all subjects.

All females were on specific one-phase oral contraceptives (ethinylestradiol/levonorgestrel $20 \mu \mathrm{g} / 100 \mu \mathrm{g}$ ) and were not measured during the menstruation period. All subjects underwent an individualized cooling protocol and $\left[{ }^{18} \mathrm{~F}\right]$ FDG-PET/CT imaging at Maastricht University Medical Centre for the 
measurement of BAT activity in the period from April 2010 to June 2013. A total of 25 subjects were exposed to an air-cooling protocol $(24 ; 25)$, while the other 34 subjects underwent a cooling protocol with a water-perfused suit $(13 ; 26)$. Of the latter group, 17 subjects were exposed to an environmental temperature of 15$16^{\circ} \mathrm{C}$ for 10 consecutive days: 2 hours on the first day, 4 hours on the second day, and 6 hours per day for the remaining days. BAT activity and FGF21 levels were determined before and after cold acclimatization.

For both the water-cooling protocol and the air-cooling protocol subjects were asked to refrain from heavy exercise 48 hours preceding the test day. In addition, subjects swallowed a telemetric pill (CoreTemp HT150002; HQ Inc) for measurement of core temperature during both protocols.

\section{Individualized cooling protocols}

In the water-cooling protocol, subjects were measured in the early afternoon (starting at 11.45 a.m.) after a 4-hour fasting period. An intravenous cannula was inserted in the antecubital vein, through which blood was sampled in thermoneutral ( $t=45 \mathrm{~min}$ ) and mild cold ( $t=120-150 \mathrm{~min}$ ) conditions, and through which the tracer was administered. After thermoneutral measurements, subjects were exposed to mild cold according to an individualized cooling protocol as described earlier (13). Briefly, subjects were wrapped in a water-perfused suit. The first 45 minutes subjects were kept at thermoneutral conditions, after which a gradual step-wise decrease in temperature followed (water temperature was lowered with $4{ }^{\circ} \mathrm{C}$ every 15 minutes) until shivering occurred. After the onset of shivering, subjects were warmed up for 5 minutes after which the temperature was set slightly above shivering level. Subjects were measured for another 30 minutes during this mild cold exposure. Indirect calorimetry (EZCAL, IDEE, Maastricht University) was used to measure energy expenditure continuously during the cooling protocol. Subsequently, subjects were injected with $75 \mathrm{MBq}$ of $\left[{ }^{18} \mathrm{~F}\right] \mathrm{FDG}$ and transported to the scanner for $\left[{ }^{18} \mathrm{~F}\right] \mathrm{FDG}-\mathrm{PET} / \mathrm{CT}$ imaging for quantification of $\left[{ }^{18} \mathrm{~F}\right] \mathrm{FDG}$ uptake into BAT. Mild cold exposure was continued while subjects were inside the PET/CT scanner (Gemini TF PET-CT, Philips, The Netherlands).

The 25 subjects that underwent the air-cooling protocol came to the laboratory at 08.30 AM after an overnight fast and were placed inside an air permeable climate tent (Colorade Altitude Training, Louisville, CO). Inside this tent the air temperature was regulated by an air conditioner to maintain the air temperature with an 
accuracy of $1{ }^{\circ} \mathrm{C}$ (24). To guarantee a comfortable position during the measurements, subjects were placed in a semi-supine position. Subjects underwent a personalized cooling protocol (27) to guarantee maximum nonshivering thermogenesis. Indirect calorimetry was used to measure energy expenditure during three hours. During the first hour ( $t=0-60)$, measurements were performed in thermoneutrality $\left(24-25{ }^{\circ} \mathrm{C}\right.$ with standardized clothing, 0.49 clo) followed by a gradual step-wise decrease of the room temperature during the second hour. This was continued until the subjects subjectively reported shivering. At the first signs of shivering, the air temperature was increased by steps of $1{ }^{\circ} \mathrm{C}$ until shivering stopped and temperatures were then kept stable at these points. Blood was drawn from the antecubital vein catheter at $\mathrm{t}=55 \mathrm{~min}$ (during thermoneutrality) and at $\mathrm{t}=115 \mathrm{~min}$ (during cold-exposure). After one hour of cold exposure ( $\mathrm{t}=120 \mathrm{~min}$ ) $50-75 \mathrm{MBq}$ of $\left[{ }^{18} \mathrm{~F}\right] \mathrm{FDG}$ was injected through a venous catheter and cold exposure was continued for another hour, during which subjects were instructed to lay still to prevent uptake of FDG in the muscles. At $t=180$ min subjects were transported to the PET/CT-scanner for quantification of $\left[{ }^{18} \mathrm{~F}\right] \mathrm{FDG}$ uptake into BAT.

\section{PET/CT scanning protocol}

The scanning protocol and data interpretation methods were identical to those used in earlier studies by our group (11). For the static PET scans (performed in all subjects) subjects were intravenously injected with $50-75 \mathrm{MBq}(1.35 \mathrm{mCi})$ of $\left[{ }^{18} \mathrm{~F}\right]$ FDG. Sixty minutes after tracer injection imaging started with a low-dose CT scan (120 kV, $30 \mathrm{mAs})$, immediately followed by a PET scan. A total of six to seven bed positions ( 5 min per bed position) were necessary to cover the area where BAT is usually found (i.e., abdominal, thoracic, and neck region). The PET image was used to determine the $\left[{ }^{18} \mathrm{~F}\right] \mathrm{FDG}$ uptake, and the CT image was used for PET attenuation correction and localization of the $\left[{ }^{18} \mathrm{~F}\right] \mathrm{FDG}$ uptake sites. The voxel size of both reconstructed image sets was $4 \times 4 \times 4 \mathrm{~mm}^{3}$. For the dynamic PET scans (performed only during the water-cooling protocol) subjects were first transported to the PET/CT scanner after which imaging started with a low dose CT scan (30 mAs, $120 \mathrm{kV}$ ). Subsequently, subjects were injected with $74 \mathrm{MBq}$ of $\left[{ }^{18} \mathrm{~F}\right] \mathrm{FDG}$ at the start of the 60-min dynamic PET scanning protocol. Images were reconstructed according to the following time frames: $10 \times 15$ seconds, $5 \times 30$ seconds, $5 \times 60$ seconds, $5 \times 120$ seconds, and $8 \times 300$ seconds. After the dynamic PET scan, a static PET scan was performed as described above. 


\section{PET analysis}

The scans were analyzed using PMOD software (version 3.0; PMOD Technologies). Both the researcher and an experienced nuclear medicine physician (B.B) interpreted the PET/CT images. Regions of interest were manually outlined, and a threshold of 1.5 SUV (standardized uptake value) and Hounsfield units between 10 and -180 were used to define BAT, as described earlier by our group (13). For the static PET scans, BAT activity was expressed in standard uptake values (SUV, $\left[{ }^{18} \mathrm{~F}\right]$ FDG uptake $(\mathrm{kBq} / \mathrm{ml}) /($ injected dose $[\mathrm{kBq}] /$ patient weight $[\mathrm{g}])$ ). BAT activity of each region was determined as average SUV (SUVmean) and as SUVtotal (SUVmean times the volume of the region). Dynamic PET data were used to construct time activity curves of the supraclavicular BAT regions, and the aortic arch was used as an image-derived input function. BAT glucose uptake rates were calculated using Patlak curve fitting (28) and a lumped constant of 1.14 (29).

\section{Blood analysis}

All samples were frozen and stored at $-70{ }^{\circ} \mathrm{C}$ until analysis. Circulating FGF21 was analyzed using sandwich ELISA (R\&D Systems, Minneapolis, MN, USA), and verified using an in-house ELISA as described previously (3).

\section{Statistical analysis}

Statistical analysis was performed by PASW Statistics version 20.0 for MacBook Pro. Reported data is expressed as means \pm SD. Two-tailed paired t-tests were used in order to compare data before and after cold exposure and data before and after intervention. Shapiro-Wilk test was used to assess normal distributions of plasma FGF21 concentrations for both cooling protocols separately. Linear regression analyses were used to identify correlations between FGF21 concentrations and other variables. Backward multivariate linear regression analyses were used to identify significant independent predictors for BAT activity.

\section{Study approval}

The Ethics Committee of Maastricht University Medical Centre+ approved the study protocol and all subjects provided written informed consent. Procedures were conducted according to the principles of the Declaration of Helsinki. 


\section{RESULTS}

\section{Subject characteristics}

Two different types of individualized acute cooling protocols, water-cooling and air-cooling, were used in our studies. Subject characteristics for the two types of cooling protocols are presented in Table 1 . Note that the air-cooling protocol was performed in male subjects only. Body composition was not significantly different between the two groups of males.

Table 1. Subject characteristics.

\begin{tabular}{lllll}
\hline & Air cooling & & Water cooling & \\
\cline { 2 - 2 } \cline { 5 - 5 } Characteristic & Males $(\mathbf{n}=\mathbf{2 5})$ & & Males $(\mathbf{n}=\mathbf{1 6})$ & Females $(\mathbf{n}=\mathbf{1 7})$ \\
\hline Age $(\mathrm{y})$ & $23.1 \pm 3.6$ & & $22.3 \pm 2.8$ & $22.2 \pm 3.5$ \\
Body weight $(\mathrm{kg})$ & $72.6 \pm 7.6$ & & $71.1 \pm 8.9$ & $61.4 \pm 6.9^{\mathrm{A}}$ \\
BMI $\left(\mathrm{kg} / \mathrm{m}^{2}\right)$ & $21.9 \pm 1.8$ & & $21.9 \pm 2.2$ & $21.1 \pm 1.6$ \\
FFM $(\mathrm{kg})$ & $59.8 \pm 5.8$ & & $60.3 \pm 7.9$ & $43.3 \pm 3.7^{\mathrm{A}}$ \\
Fat mass (\%) & $16.3 \pm 4.0$ & & $14.7 \pm 2.9$ & $28.1 \pm 4.9^{\mathrm{A}}$ \\
BMR (kcal/day) & $1706 \pm 140$ & & $1784 \pm 164$ & $1459 \pm 127^{\mathrm{A}}$ \\
\hline
\end{tabular}

${ }^{A} p<0.01$, males vs. females within the water-cooling group.

The increase in energy expenditure upon acute cold exposure (expressed as \% nonshivering thermogenesis [NST]) and BAT activity in male subjects was not different between the cooling protocols, whereas females showed a lower BAT glucose uptake rate than males ( $p=0.009$; Table 2 ). It is important to note that the aircooling protocol was performed in the morning, whereas the water-cooling protocol was performed in the afternoon. Given that FGF21 levels display a strong circadian rhythm $(30 ; 31)$ with decreased FG21 levels during the day, we chose to analyze results for the two protocols separately. Indeed, in male subjects FGF21 levels at thermoneutrality were significantly higher in the air-cooling protocol (performed in the morning) compared to the water cooling protocol (performed in the afternoon): $85.0 \pm 57.0$ vs. $48.0 \pm 24.8 \mathrm{pg} / \mathrm{ml}$, resp., $p=0.008$ ). For both protocols, male FGF21 levels were normally distributed according to Shapiro-Wilk test ( 2 outliers were excluded in the air-cooling group).

\section{FGF21 and BAT activity upon acute cold exposure and other interventions}

Female subjects trended towards higher circulating FGF21 concentrations compared to males at thermoneutrality $(73.4 \pm 46.9$ vs. $48.0 \pm 24.8 \mathrm{pg} / \mathrm{ml}$ resp., $\mathrm{p}=$ 0.071 ), the difference becoming statistically significant during cold exposure (79.6 
\pm 46.0 vs. $37.9 \pm 24.0$ pg/ml resp., $p=0.007$; Table 2). For both males and females in the water cooling group FGF21 concentrations did not change significantly upon acute cold exposure, whereas FGF21 decreased modestly, but significantly in the air-cooled group (males only) upon cold exposure (from $78.0 \pm 48.0$ to $70.8 \pm 44.3$ $\mathrm{pg} / \mathrm{ml}, \mathrm{p}=0.006$, Table 2).

Table 2. Serum FGF21 concentrations, BAT activity and energy expenditure under thermoneutral conditions and mild cold exposure.

\begin{tabular}{|c|c|c|c|}
\hline \multirow[b]{2}{*}{ Variable } & \multirow{2}{*}{$\begin{array}{l}\text { Air cooling } \\
\text { Males }(n=25)\end{array}$} & \multicolumn{2}{|l|}{ Water cooling } \\
\hline & & Males $(n=16)$ & Females $(n=17)$ \\
\hline \multicolumn{4}{|l|}{ FGF21 (pg/ml) } \\
\hline Thermoneutral & $78.0 \pm 48.0$ & $48.0 \pm 24.8^{\mathrm{B \#}}$ & $73.4 \pm 46.9^{\#}$ \\
\hline Mild cold & $70.8 \pm 44.3^{\mathrm{A}^{*}}$ & $37.9 \pm 24.0^{B^{* *}}$ & $79.6 \pm 46.0^{C}$ \\
\hline \multicolumn{4}{|l|}{ Static $\left[{ }^{18}\right.$ F]FDG-PET analysis } \\
\hline$\left[{ }^{18} \mathrm{~F}\right] \mathrm{FDG}$ uptake in BAT (SUVmean) & $2.4 \pm 0.4$ & $2.6 \pm 0.4$ & $2.2 \pm 0.9$ \\
\hline$\left[{ }^{18} \mathrm{~F}\right] \mathrm{FDG}$ uptake in BAT (SUVmax) & $11.3 \pm 6.8$ & $14.2 \pm 6.7$ & $10.7 \pm 6.8$ \\
\hline \multicolumn{4}{|l|}{ Dynamic $\left[{ }^{18} \mathrm{~F}\right] \mathrm{FDG}-\mathrm{PET}$ analysis } \\
\hline GUR in BAT $(\mu \mathrm{mol} / \mathrm{min} / 100 \mathrm{~g})$ & N/A & $7.9 \pm 3.0$ & $5.1 \pm 2.8^{C}$ \\
\hline \multicolumn{4}{|l|}{ Fixed volume analysis } \\
\hline$\left[{ }^{18} \mathrm{~F}\right] \mathrm{FDG}$ uptake in BAT (SUVmean) & $7.4 \pm 5.4$ & $9.0 \pm 4.6$ & $6.7 \pm 4.2$ \\
\hline GUR in BAT $(\mu \mathrm{mol} / \mathrm{min} / 100 \mathrm{~g})$ & N/A & $25.4 \pm 14.9$ & $14.8 \pm 9.8^{C}$ \\
\hline \multicolumn{4}{|l|}{ Energy expenditure (kJ/min) } \\
\hline Thermoneutral & $5.0 \pm 0.4$ & $5.2 \pm 0.5^{\#}$ & $4.2 \pm 0.4^{C}$ \\
\hline Mild cold & $5.5 \pm 0.5^{\mathrm{A}}$ & $5.8 \pm 0.5^{\mathrm{A \#}}$ & $4.6 \pm 0.6^{A, C}$ \\
\hline NST (\%) & $11.7 \pm 7.3$ & $13.1 \pm 8.9^{\#}$ & $9.5 \pm 8.0$ \\
\hline
\end{tabular}

GUR, glucose uptake rate. ${ }^{A} p<0.05$, mild cold vs. thermoneutral; ${ }^{B} p<0.05$, air cooling vs. water cooling; ${ }^{C} p<0.05$, males vs. females within the water cooling group. $\# n=15, * n=20 * * n=10$. N/A, not measured in these subjects.

Given that FGF21 levels display a strong circadian rhythmicity as mentioned above, it is difficult to conclude whether acute cold exposure has an effect on FGF21 levels, as such an effect may be confounded by the circadian decrease in FGF21. Therefore, we determined plasma FGF21 levels in two other studies, in which we investigated the effect of acute interventions other than cold on BAT activity. Specifically, we recently demonstrated that systemic $\beta$-adrenergic stimulation by infusion of the nonselective $\beta$-agonist isoprenaline (24) did not activate BAT. In addition, we showed that ingestion of a high-calorie meal (50\% of daily required energy intake) increases glucose uptake in BAT, although this was not related to thermogenesis (25). For both experiments, we determined FGF21 levels at baseline and after 2 hours of intervention. We found that FGF21 levels decreased 
significantly upon both isoprenaline infusion (from $100.0 \pm 52.9 \mathrm{pg} / \mathrm{ml}$ at baseline to $63.2 \pm 32.3 \mathrm{pg} / \mathrm{ml}$ at $110 \mathrm{~min}$ after start of infusion, $\mathrm{p}<0.001 ; \mathrm{n}=12$ ), and after intake of a high-calorie meal (from $92.2 \pm 45.6 \mathrm{pg} / \mathrm{ml}$ at baseline to $65.6 \pm 33.5$ $\mathrm{pg} / \mathrm{ml}$ at $120 \mathrm{~min}$ after meal ingestion, $\mathrm{p}=0.003 ; \mathrm{n}=10$, one outlier was excluded from analysis). The decreases in FGF21 levels in these two studies were much more pronounced compared to the decrease in FGF21 levels upon acute cold exposure (from $78.0 \pm 48.0$ to $70.8 \pm 44.3 \mathrm{pg} / \mathrm{ml}$ ), suggesting that acute cold exposure blunts the circadian decrease in FGF21 that is normally seen in the morning.

\section{FGF21 concentration relates to BAT activity}

We next investigated whether FGF21 levels and BAT activity during acute cold exposure were related. Given that blood samples between the cooling protocols were collected at different time points we analyzed correlations for each protocol separately.

In the air-cooling protocol (males only), thermoneutral FGF21 levels tended to be correlated with several quantitative measures of BAT activity: SUVmax $\left(r^{2}=0.162\right.$, $p=0.057$; Figure $1 \mathrm{~A}$ ) and SUVmean (fixed volume analysis; $r^{2}=0.222, p=0.056$ ). Thermoneutral FGF21 levels and BAT volume and activity were significantly correlated in the male subjects of the water-cooling group; BAT volume $\left(r^{2}=0.278\right.$, $p=0.043)$, SUVtotal $\left(r^{2}=0.289, p=0.039\right.$; figure $\left.1 B\right)$, and a (non-significant) trend was observed with BAT glucose uptake rate (fixed volume analysis; $r^{2}=0.247, p=$ 0.059). When FGF21 levels during cold exposure were used, the latter correlations became significant; BAT volume $\left(r^{2}=0.527, p=0.017\right)$, sUVtotal $\left(r^{2}=0.596, p=\right.$ 0.009 ) and glucose uptake rate (fixed volume analysis; $r^{2}=0.506, p=0.021$; Figure 1C).

In addition, multivariate linear regression analysis in these males, including thermoneutral FGF21 levels, age, BMI and fat percentage as independent variables, showed that FGF21 level was the only significant independent predictor for total BAT volume ( $p=0.043$ ) and activity (SUVtotal; $p=0.039)$.

Interestingly, when including the female subjects in the water-cooling group, the relationships between FGF21 and BAT activity were no longer significant. Moreover, when data from female subjects alone $(n=17)$ were considered, no associations between FGF21 concentrations and BAT activity were found, indicating a sex specific relationship. In none of the individual cohorts nor in the entire population were any relationships between FGF21 levels and cold-induced NST observed. 
Interestingly, basal FGF21 levels correlated positively with the change in core temperature upon cold exposure for both males $\left(r^{2}=0.49, p=0.008\right)$ and females $\left(r^{2}=0.27, p=0.049\right)$ in the water-cooling group $\left(r^{2}=0.343, p=0.001\right.$ for both sexes together; Figure 1D), and a similar trend was observed in the air-cooling group $\left(r^{2}=0.159, p=0.059\right)$. Thus, high levels of FGF21 are associated with an increase in core temperature, while low levels of FGF21 are associated with a decrease in core temperature upon cold exposure.

A
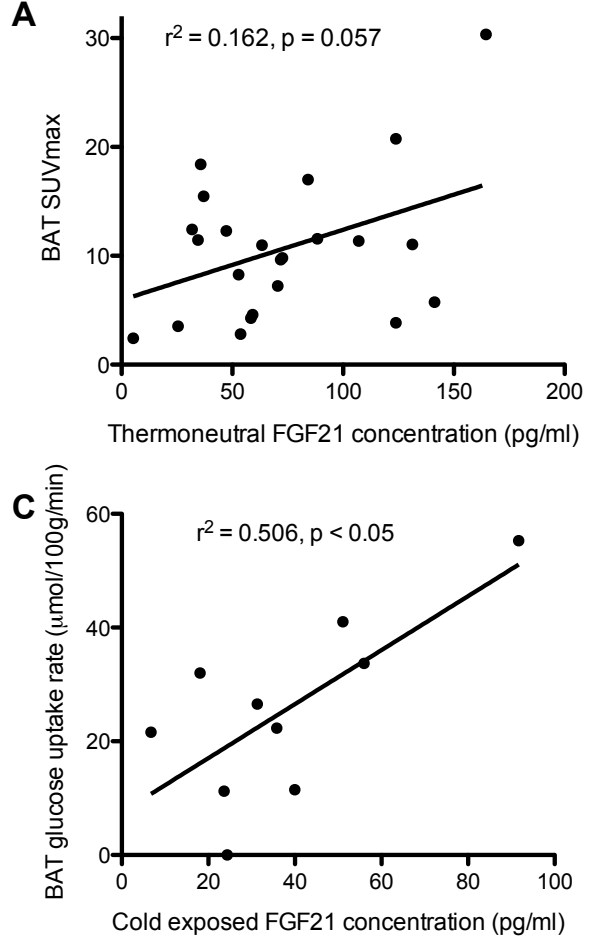

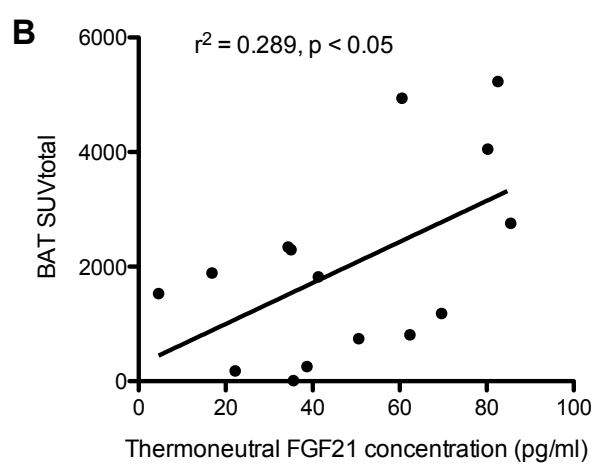

D

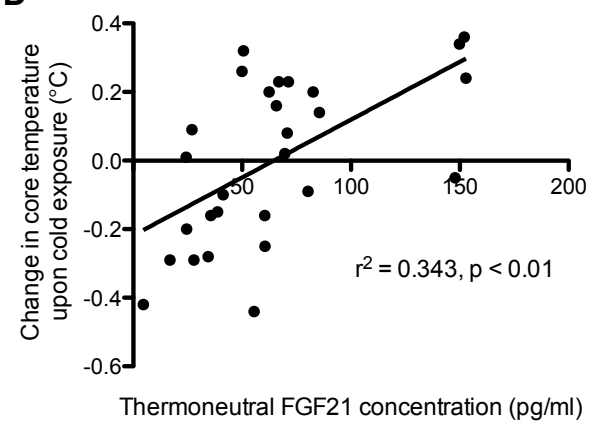

Figure 1. Serum FGF21 concentrations are related to BAT activity. Relationship between basal serum FGF21 concentrations and measures of BAT activity in (A) male subjects of the air-cooling group and (B) male subjects of the water-cooling group. A positive correlation was also found between FGF21 concentrations during cold exposure and BAT glucose uptake in the male subjects from the watercooling group (C). Basal FGF21 levels correlated positively with the change in core temperature upon cold exposure (D).

\section{Increased FGF21 and BAT activity after cold acclimation}

We have recently shown that 10 days of cold acclimation leads to an increase in BAT activity in lean, healthy subjects (13). Here, we determined if FGF21 was also increased by cold acclimation. Indeed, in parallel with increased BAT activity 
(Figure 2A), basal FGF21 levels were increased from $54.0 \pm 34.4$ to $70.2 \pm 47.7$ $\mathrm{pg} / \mathrm{ml}(\mathrm{p}=0.028$; Figure $2 \mathrm{~B}$ ), while FGF21 levels during cold exposure were also slightly higher after cold acclimation, although the latter did not reach significance $(63.0 \pm 39.2$ vs. $72 \pm 39.2 \mathrm{pg} / \mathrm{ml}, \mathrm{p}=0.23$ ). After cold acclimation, the significant correlation between BAT activity and FGF21 levels in the basal (SUVtotal; $r^{2}=$ 0.806, $p=0.002$ ) and cold exposed (SUVtotal: $r^{2}=0.507, p=0.048$ ) state in male subjects was still present. However, the change in FGF21 concentration upon 10 days of cold acclimation did not correlate significantly with the change in BAT activity $\left(r^{2}=0.357, p=0.156\right)$.
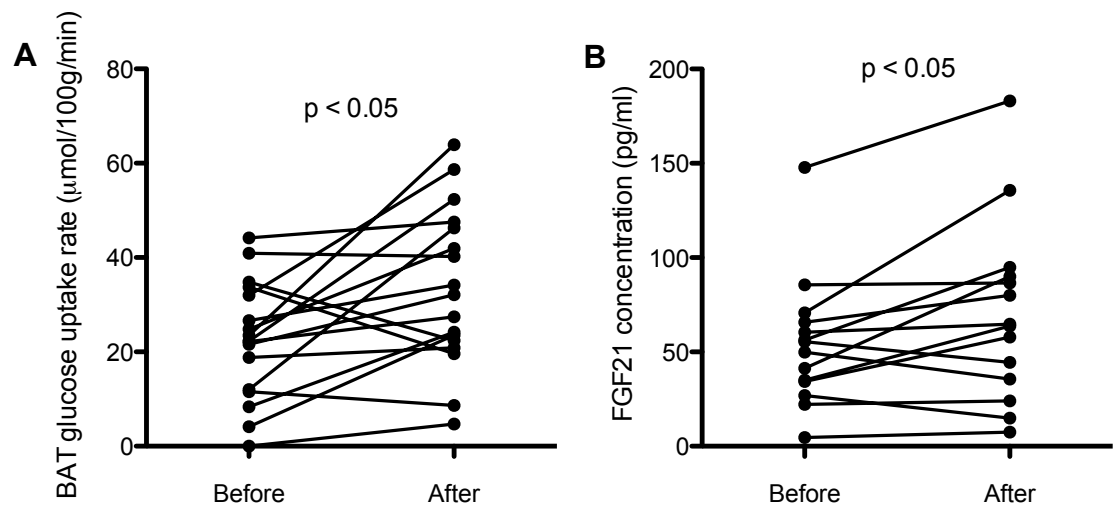

Figure 2. BAT activity and FGF21 concentrations are increased after a 10-day cold acclimation period. BAT glucose uptake rate (A) and basal serum FGF21 concentration (B) are increased after a 10-day cold acclimation period.

\section{DISCUSSION}

Our data show that serum FGF21 levels correlate positively with cold-induced brown adipose tissue activity in humans. Interestingly, this correlation was only present in male subjects. Multivariate analysis revealed that the level of FGF21 is the strongest determinant of maximal BAT activity. In addition, we show that FGF21 levels are increased upon a 10-day cold acclimation period, in parallel with increased BAT activity. These results indicate a strong link between circulating FGF21 levels and BAT activity upon cold exposure, supporting the notion that FGF21 is a cold-induced activator of BAT (23). Also of interest is the positive association between serum FGF21 levels and the change in core temperature upon 
cold exposure, indicating a novel role for FGF21 in defending core temperature in the face of reduced ambient temperature, possibly via activation of BAT.

FGF21 has emerged as an important potential target for the treatment of the metabolic complications associated with diabetes and obesity $(32 ; 33)$. Due in part to its inherently complex biological action studies have documented positive effects on glucose and lipid metabolism, including improvements in insulin sensitivity, lower blood lipid and glucose levels and preserved $\beta$-cell function in mice $(2 ; 5 ; 7 ; 34)$ and improved plasma lipid profiles, reduced insulin levels and body weight in humans (10). Furthermore, FGF21 has recently been shown to be involved in human cold-induced thermogenesis. Lee et al. (23) suggested that this effect is mediated by FGF21-induced activation of BAT. Although they used a very limited number of subjects $(n=5)$, they also showed that the diurnal reduction in circulating FGF21 levels was blunted upon mild cold exposure and that this blunting effect was markedly greater in BAT-positive compared to BAT-negative subjects (23). The positive correlation between basal FGF21 levels and BAT activity that we found in our study in a large cohort confirms a role for FGF21 in BAT activation.

The apparent lack of effect of acute cold exposure on plasma FGF21 levels would contradict a role for FGF21 in cold-induced BAT activation. However, it is known that FGF21 levels have a strong circadian rhythm, with a fall in FGF21 levels in the morning. Although we are limited by the lack of a paired control group in which FGF21 levels are determined under thermoneutral conditions without any other intervention, acute cold exposure did blunt the FGF21 diurnal decrease when compared to two other short-term interventions (isoprenaline infusion and highcalorie meal intake), in which FGF21 levels did drop. Although blood drawing time points were slightly different during these intervention and we cannot exclude that isoprenaline infusion and/or meal intake could be responsible for the decrease in FGF21 levels, we feel it is more likely that this decrease is due to diurnal variation in FGF21 levels, as our data nicely fits data that has been published before $(18 ; 35)$. Moreover, it was recently shown that meal intake did not influence the diurnal decrease in FGF21 (35). Therefore, it is most likely that indeed cold exposure is able to blunt the circadian decrease in FGF21, although it remains to be established whether FGF21 has a direct effect on activating BAT in humans. Specifically, we would suggest that human clinical interventions with infusion of recombinant FGF21 are needed to reveal potential direct effects of FGF21 on BAT activity. It has previously been hypothesized that the elevation in energy expenditure following 
pharmacological FGF21 exposure is responsible for the rapid weight loss observed with this agent given that no effect on food intake is reported with treatment (32; 36). It is important to consider that in patients treated with an FGF21 analogue weight loss was also evident (10), and it will be interesting to determine whether FGF21 mediated elevation of energy expenditure, possibly due to an effect on BAT, is translatable to man.

In addition to the effects of acute cold exposure, we show that a 10-day cold acclimation period leads to elevated plasma FGF21 levels accompanied by increased BAT activity. Therefore, it is tempting to speculate that this prolonged cold exposure is sufficient for BAT to exert effects on systemic FGF21 levels via secretion of FGF21 into the circulation, as has been shown in rodents (19). On the other hand, we did not find any direct relationship between the changes in FGF21 levels and BAT activity upon cold acclimation. How cold acclimation in humans could increase FGF21 levels is unknown. During the 10-day cold acclimation period, especially at the first few days, subjects often reported shivering, thereby mimicking active muscle contractions during exercise. It has recently been shown that a 2-week exercise intervention also increases serum FGF21 levels (37), likely due to PI3-kinase/Akt1-mediated FGF21 secretion by skeletal muscle (38). It is conceivable that shivering can induce similar FGF21 secretory pathways in skeletal muscle that may partly account for the increased serum FGF21 levels after the 10day cold acclimation period.

In summary, taken as a whole our data show that plasma FGF21 levels in humans are associated with cold-induced BAT activity. We go on to show that cold acclimation increases both serum FGF21 levels and BAT activity. Further studies are needed to reveal a direct effect of FGF21 on BAT activation; however, if successful, therapies aimed at improving metabolic health via induction of BAT thermogenesis should consider FGF21 as an important target. 


\section{REFERENCES}

1. Nishimura $T$, Nakatake $\mathrm{Y}$, Konishi $\mathrm{M}$, Itoh $\mathrm{N}$ : Identification of a novel FGF, FGF-21, preferentially expressed in the liver. Biochimica et biophysica acta 2000;1492:203-206

2. Kharitonenkov A, Shiyanova TL, Koester A, Ford AM, Micanovic R, Galbreath EJ, Sandusky GE, Hammond LJ, Moyers JS, Owens RA, Gromada J, Brozinick JT, Hawkins ED, Wroblewski VJ, Li DS, Mehrbod F, Jaskunas SR, Shanafelt AB: FGF-21 as a novel metabolic regulator. The Journal of clinical investigation 2005;115:1627-1635

3. Adams AC, Halstead CA, Hansen BC, Irizarry AR, Martin JA, Myers SR, Reynolds VL, Smith HW, Wroblewski VJ, Kharitonenkov A: LY2405319, an Engineered FGF21 Variant, Improves the Metabolic Status of Diabetic Monkeys. PloS one 2013;8:e65763

4. Adams AC, Coskun T, Rovira AR, Schneider MA, Raches DW, Micanovic R, Bina HA, Dunbar JD, Kharitonenkov A: Fundamentals of FGF19 \& FGF21 action in vitro and in vivo. PLoS One 2012;7:e38438

5. Wente W, Efanov AM, Brenner M, Kharitonenkov A, Koster A, Sandusky GE, Sewing S, Treinies I, Zitzer H, Gromada J: Fibroblast growth factor-21 improves pancreatic beta-cell function and survival by activation of extracellular signal-regulated kinase $1 / 2$ and Akt signaling pathways. Diabetes 2006;55:2470-2478

6. Coskun T, Bina HA, Schneider MA, Dunbar JD, Hu CC, Chen Y, Moller DE, Kharitonenkov A: Fibroblast growth factor 21 corrects obesity in mice. Endocrinology 2008;149:6018-6027

7. Xu J, Lloyd DJ, Hale C, Stanislaus S, Chen M, Sivits G, Vonderfecht S, Hecht R, Li YS, Lindberg RA, Chen JL, Jung DY, Zhang Z, Ko HJ, Kim JK, Veniant MM: Fibroblast growth factor 21 reverses hepatic steatosis, increases energy expenditure, and improves insulin sensitivity in diet-induced obese mice. Diabetes 2009;58:250-259

8. Fisher FM, Kleiner S, Douris N, Fox EC, Mepani RJ, Verdeguer F, Wu J, Kharitonenkov A, Flier JS, Maratos-Flier E, Spiegelman BM: FGF21 regulates PGC-1alpha and browning of white adipose tissues in adaptive thermogenesis. Genes \& development 2012;26:271-281

9. Chau MD, Gao J, Yang Q, Wu Z, Gromada J: Fibroblast growth factor 21 regulates energy metabolism by activating the AMPK-SIRT1-PGC-1alpha pathway. Proceedings of the National Academy of Sciences of the United States of America 2010;107:12553-12558

10. Gaich G, Chien JY, Fu H, Glass LC, Deeg MA, Holland WL, Kharitonenkov A, Bumol T, Schilske HK, Moller DE: The effects of LY2405319, an FGF21 analog, in obese human subjects with type 2 diabetes. Cell metabolism 2013;18:333-340

11. van Marken Lichtenbelt WD, Vanhommerig JW, Smulders NM, Drossaerts JM, Kemerink GJ, Bouvy ND, Schrauwen P, Teule GJ: Cold-activated brown adipose tissue in healthy men. The New England journal of medicine 2009;360:1500-1508

12. Virtanen KA, Lidell ME, Orava J, Heglind M, Westergren R, Niemi T, Taittonen M, Laine J, Savisto NJ, Enerback S, Nuutila P: Functional brown adipose tissue in healthy adults. The New England journal of medicine 2009;360:1518-1525

13. van der Lans AA, Hoeks J, Brans B, Vijgen GH, Visser MG, Vosselman MJ, Hansen J, Jorgensen JA, Wu J, Mottaghy FM, Schrauwen P, van Marken Lichtenbelt WD: Cold acclimation recruits human brown fat and increases nonshivering thermogenesis. The Journal of clinical investigation 2013;123:3395-3403

14. Tseng YH, Kokkotou E, Schulz TJ, Huang TL, Winnay JN, Taniguchi CM, Tran TT, Suzuki R, Espinoza DO, Yamamoto Y, Ahrens MJ, Dudley AT, Norris AW, Kulkarni RN, Kahn CR: New role of bone morphogenetic protein 7 in brown adipogenesis and energy expenditure. Nature 2008;454:1000-1004 
15. Whittle AJ, Carobbio S, Martins L, Slawik M, Hondares E, Vazquez MJ, Morgan D, Csikasz RI, Gallego R, Rodriguez-Cuenca S, Dale M, Virtue S, Villarroya F, Cannon B, Rahmouni K, Lopez $M$, Vidal-Puig A: BMP8B increases brown adipose tissue thermogenesis through both central and peripheral actions. Cell 2012;149:871-885

16. Bostrom P, Wu J, Jedrychowski MP, Korde A, Ye L, Lo JC, Rasbach KA, Bostrom EA, Choi JH, Long JZ, Kajimura S, Zingaretti MC, Vind BF, Tu H, Cinti S, Hojlund K, Gygi SP, Spiegelman BM: A PGC1-alpha-dependent myokine that drives brown-fat-like development of white fat and thermogenesis. Nature 2012;481:463-468

17. Puigserver P, Wu Z, Park CW, Graves R, Wright M, Spiegelman BM: A cold-inducible coactivator of nuclear receptors linked to adaptive thermogenesis. Cell 1998;92:829-839

18. Lee P, Brychta RJ, Linderman J, Smith S, Chen KY, Celi FS: Mild cold exposure modulates fibroblast growth factor 21 (FGF21) diurnal rhythm in humans: relationship between FGF21 levels, lipolysis, and cold-induced thermogenesis. The Journal of clinical endocrinology and metabolism 2013;98:E98-102

19. Hondares E, Iglesias R, Giralt A, Gonzalez FJ, Giralt M, Mampel T, Villarroya F: Thermogenic activation induces FGF21 expression and release in brown adipose tissue. The Journal of biological chemistry 2011;286:12983-12990

20. Chartoumpekis DV, Habeos IG, Ziros PG, Psyrogiannis Al, Kyriazopoulou VE, Papavassiliou AG: Brown adipose tissue responds to cold and adrenergic stimulation by induction of FGF21. Molecular medicine 2011;17:736-740

21. Badman MK, Pissios P, Kennedy AR, Koukos G, Flier JS, Maratos-Flier E: Hepatic fibroblast growth factor 21 is regulated by PPARalpha and is a key mediator of hepatic lipid metabolism in ketotic states. Cell metabolism 2007;5:426-437

22. Inagaki T, Dutchak P, Zhao G, Ding X, Gautron L, Parameswara V, Li Y, Goetz R, Mohammadi M, Esser V, Elmquist JK, Gerard RD, Burgess SC, Hammer RE, Mangelsdorf DJ, Kliewer SA: Endocrine regulation of the fasting response by PPARalpha-mediated induction of fibroblast growth factor 21. Cell metabolism 2007;5:415-425

23. Lee $P$, Linderman JD, Smith S, Brychta RJ, Wang J, Idelson C, Perron RM, Werner CD, Phan GQ, Kammula US, Kebebew E, Pacak K, Chen KY, Celi FS: Irisin and FGF21 are cold-induced endocrine activators of brown fat function in humans. Cell metabolism 2014;19:302-309

24. Vosselman MJ, van der Lans AA, Brans B, Wierts $R$, van Baak MA, Schrauwen $P$, van Marken Lichtenbelt WD: Systemic beta-adrenergic stimulation of thermogenesis is not accompanied by brown adipose tissue activity in humans. Diabetes 2012;61:3106-3113

25. Vosselman MJ, Brans B, van der Lans AA, Wierts R, van Baak MA, Mottaghy FM, Schrauwen $P$, van Marken Lichtenbelt WD: Brown adipose tissue activity after a high-calorie meal in humans. The American journal of clinical nutrition 2013;98:57-64

26. Hanssen MJ, Wierts R, Hoeks J, Gemmink A, Brans B, Mottaghy FM, Schrauwen P, van Marken Lichtenbelt WD: Glucose uptake in human brown adipose tissue is impaired upon fasting-induced insulin resistance. Diabetologia 2015;58:586-595

27. van der Lans AA, Wierts R, Vosselman MJ, Schrauwen P, Brans B, van Marken Lichtenbelt WD: Cold-activated brown adipose tissue in human adults: methodological issues. American journal of physiology Regulatory, integrative and comparative physiology 2014;307:R103113

28. Patlak CS, Blasberg RG, Fenstermacher JD: Graphical evaluation of blood-to-brain transfer constants from multiple-time uptake data. Journal of cerebral blood flow and metabolism : official journal of the International Society of Cerebral Blood Flow and Metabolism 1983;3:17 
29. Orava J, Nuutila P, Lidell ME, Oikonen V, Noponen T, Viljanen T, Scheinin M, Taittonen $M$, Niemi T, Enerback S, Virtanen KA: Different metabolic responses of human brown adipose tissue to activation by cold and insulin. Cell metabolism 2011;14:272-279

30. Andersen B, Beck-Nielsen H, Hojlund K: Plasma FGF21 displays a circadian rhythm during a 72-h fast in healthy female volunteers. Clinical endocrinology 2011;75:514-519

31. Oishi K, Uchida D, Ishida N: Circadian expression of FGF21 is induced by PPARalpha activation in the mouse liver. FEBS letters 2008;582:3639-3642

32. Antonellis PJ, Kharitonenkov A, Adams AC: FGF21: insights into mechanism of action from preclinical studies. Journal of animal science 2014;92:407-413

33. Kharitonenkov A, Adams AC: Inventing new medicines: The FGF21 story. Molecular metabolism 2014;3:221-229

34. Camporez JP, Jornayvaz FR, Petersen MC, Pesta D, Guigni BA, Serr J, Zhang D, Kahn M, Samuel VT, Jurczak MJ, Shulman GI: Cellular Mechanisms by Which FGF21 Improves Insulin Sensitivity in Male Mice. Endocrinology 2013;154:3099-3109

35. Yu H, Xia F, Lam KS, Wang Y, Bao Y, Zhang J, Gu Y, Zhou P, Lu J, Jia W, Xu A: Circadian rhythm of circulating fibroblast growth factor 21 is related to diurnal changes in fatty acids in humans. Clinical chemistry 2011;57:691-700

36. Veniant MM, Hale C, Helmering J, Chen MM, Stanislaus S, Busby J, Vonderfecht S, Xu J, Lloyd DJ: FGF21 Promotes Metabolic Homeostasis via White Adipose and Leptin in Mice. PLoS One 2012; 7:e40164

37. Cuevas-Ramos D, Almeda-Valdes P, Meza-Arana CE, Brito-Cordova G, Gomez-Perez FJ, Mehta R, Oseguera-Moguel J, Aguilar-Salinas CA: Exercise increases serum fibroblast growth factor 21 (FGF21) levels. PLoS One 2012;7:e38022

38. Izumiya Y, Bina HA, Ouchi N, Akasaki Y, Kharitonenkov A, Walsh K: FGF21 is an Akt-regulated myokine. FEBS letters 2008;582:3805-3810 


\section{CHAPTER 6}

\section{Brown adipose tissue activity and skeletal muscle respiration in South Asian and Caucasian pre-diabetic males: effects of L-arginine}




\section{ABSTRACT}

Introduction. Individuals of South Asian origin are at increased risk to develop type 2 diabetes and associated comorbidities compared to other ethnicities. Disturbances in energy metabolism may contribute to this increased risk. Skeletal muscle and brown adipose tissue (BAT) are both important players human energy metabolism. Here, we investigated whether BAT activity and skeletal muscle respiratory capacity were different between overweight pre-diabetic South Asian males and matched Caucasian males. In addition, the effects of six weeks supplementation with L-arginine, a precursor of nitric oxide, on BAT and skeletal muscle were investigated.

Methods. Nine pre-diabetic South Asian males (age $46 \pm 7$ years, BMI $30.1 \pm 3.5 \mathrm{~kg}$ $\mathrm{m}^{-2}$ ) and nine Caucasian males (age $49 \pm 5$ years, BMI $30.3 \pm 3.9 \mathrm{~kg} \mathrm{~m}^{-2}$ ) were included. Subjects ingested either L-arginine or placebo supplements ( $9 \mathrm{~g} /$ day) for six weeks in a randomized double-blind cross-over design, with a 4-week washout period. After each intervention period, BAT activity was assessed by $\left[{ }^{18} \mathrm{~F}\right] \mathrm{FDG}$ PET/CT scanning and body composition was assessed by DEXA. In addition, a fasting skeletal muscle biopsy was taken and analyzed for respiratory capacity.

Results. BAT volume and BAT activity were not different between South Asians and Caucasians. In addition, cold-induced $\left[{ }^{18}\right.$ F]FDG uptake in white adipose tissue and skeletal muscle was similar between ethnicities. Interestingly, skeletal muscle respiratory capacity was lower in South Asians then in Caucasians. A 6-week intervention with L-arginine supplementation increased lean mass. However, this did not result in any significant changes in BAT or skeletal muscle respiratory capacity.

Conclusion. Impaired skeletal muscle oxidative capacity may underlie disturbances in whole-body energy metabolism in South Asians. Thus, therapies aimed at improving skeletal muscle mitochondrial function may be crucial to reduce the risk for the development of adverse metabolic conditions in the South Asian population. 


\section{INTRODUCTION}

The worldwide increase in the prevalence of obesity has led to a concomitant dramatic increase in the prevalence of type 2 diabetes mellitus, with currently $\sim 6.4 \%$ of the world population being affected. A population with a particularly high risk to develop obesity and type 2 diabetes, is the South Asian population. Even compared to several other ethnic minorities, in which an increased type 2 diabetes risk is present as well $(1 ; 2)$, South Asians are especially prone to develop type 2 diabetes and associated comorbidities. However, not only South Asians that have migrated to Western European $(2 ; 3)$ and Northern American (4) countries exhibit this increased type 2 diabetes risk, but even South Asians residing in their original Indian subcontinent. In fact, the Indian subcontinent is forecasted to have the greatest worldwide diabetes burden in 2030, also due to rapid urbanization and associated lifestyle changes (5). Importantly, their increased diabetes risk is a primary cause for not only an excess cardiovascular disease burden (6), but also for worse outcomes following cardiovascular surgery $(7 ; 8)$. Given these alarming statistics, it is highly relevant to uncover underlying mechanisms involved in the higher prevalence of type 2 diabetes in the South Asian population (9). An important contributor is a highly common disadvantageous metabolic phenotype, consisting of central obesity, insulin resistance and dyslipidemia (10; 11), which is likely caused by a disturbed energy metabolism, e.g. a reduced (fat) oxidative capacity (12). Skeletal muscle mitochondrial function plays a pronounced role in whole-body energy expenditure and is a main determinant of insulin sensitivity (13). Therefore, impaired skeletal muscle oxidative capacity may play a crucial role in such disturbances.

Next to skeletal muscle, brown adipose tissue (BAT) has recently emerged as a player in human energy metabolism as well. Interestingly, reduced BAT volume and activity have been associated with both adiposity (14) and diabetic status (15), and a recent study has shown reduced BAT volume in young South Asian compared to young Caucasian adults (10). Thus, enhancing BAT volume and activity could be a potential therapeutic approach to ameliorate diabetes risk in South Asians. So far, significant amounts of BAT recruitment in humans have only been shown by means of prolonged intermittent cold exposure (i.e. cold acclimation) (16-18) or massive weight loss (19). Other means to recruit BAT are urgently awaited.

Animal studies have suggested that nitric oxide (NO) plays a pivotal role in mitochondrial biogenesis in BAT and skeletal muscle (20); mice that lack the 
enzyme endothelial NO synthase (eNOS), which catalyzes the conversion of Larginine to NO, display diminished BAT volume, fewer mitochondria in BAT and muscle, lower energy expenditure and aggravated insulin resistance (21). In addition, both animal and human studies have shown that enhancing NO bioavailability, by supplementation of its precursor L-arginine, results in enhanced energy expenditure, improved glucose metabolism and reduced fat mass $(22 ; 23)$, possibly due to effects on BAT (24-27). Interestingly, South Asians have shown lower flow-mediated vasodilation compared to Caucasians (28), which points towards lower NO bioavailability. Therefore, increasing NO bioavailability might be especially promising in this South Asian population to enhance BAT mass and skeletal muscle mitochondrial function, and thereby exert positive effects on whole-body energy and substrate metabolism.

We here studied differences in whole-body substrate metabolism, BAT activity, and skeletal muscle respiration in 9 overweight pre-diabetic Dutch South Asian and 9 matched Dutch Caucasian subjects. In addition, the effect of 6 weeks of L-arginine supplementation on these parameters was investigated.

\section{METHODS}

\section{Participants}

Nine pre-diabetic overweight (body mass index [BMI], 25-35 kg/m ${ }^{2}$ ) Dutch South Asian males (age, $45.8 \pm 7.2$ years) and nine age- and BMI-matched pre-diabetic Dutch Caucasian males (age, $48.8 \pm 5.1$ years) were included in the study. Ethnicity was defined as having four grandparents of South Asian or white Caucasian origin, respectively. Subjects underwent a medical screening including their medical history, a physical examination, blood biochemistry tests, and an oral glucose tolerance test (OGTT) to exclude individuals with undiagnosed type 2 diabetes according to the 2014 American Diabetes Association (ADA) criteria (29). Prediabetes was defined as having either fasting plasma glucose levels between 5.6 and $6.9 \mathrm{mmol} / \mathrm{l}$ or plasma glucose levels $2 \mathrm{~h}$ after an OGTT between 7.8 and 11.1 $\mathrm{mmol} / \mathrm{l}$ (29). Exclusion criteria included uncontrolled hypertension, hyper- or hypothyroidism, liver or kidney dysfunction, rigorous exercise, smoking and use of beta-blockers. Three South Asians (2x ACE inhibitor, 1x angiotensine II-blocker) and none of the Caucasians were taking antihypertensive medication before and during the intervention periods. 


\section{Study approval}

The study was approved by the Ethics Committee of Maastricht University Medical Center and all participants provided written informed consent. Procedures were conducted according to the principles of the Declaration of Helsinki.

\section{Study design}

Subjects ingested either L-arginine (Argimax, Hankintatukku Oy, Karkkila, Finland) or placebo supplements ( $9 \mathrm{~g} /$ day) for six weeks in a randomized double-blind crossover design, with a 4-week washout period. Supplements were divided over 3 gifts: after breakfast, lunch and dinner. Subjects were instructed to maintain their normal dietary habits during the 6-week intervention periods. Each intervention period was followed by two experimental days. During the first day an individualized cooling protocol and $\left[{ }^{18} \mathrm{~F}\right] \mathrm{FDG}-\mathrm{PET} / \mathrm{CT}$ scanning (Gemini TF PET-CT, Philips Healthcare, Best, the Netherlands) for quantification of BAT volume and activity was performed (16). On the second day, a fasting skeletal muscle biopsy was taken from the vastus lateralis muscle and body composition was determined by means of dual x-ray absorptiometry (DEXA, Discovery A, Hologic, Bedford, MA, USA). Subjects were instructed to refrain from heavy physical exercise $48 \mathrm{~h}$ before the first experimental day, and standardized evening meals were prescribed the day before each experimental day.

The study was conducted between November 2014 and October 2015.

\section{Individualized cooling and PET/CT scanning}

The individualized cooling protocol $(16 ; 30)$ on the first experimental day was initiated at noon, after a 4 -h fasting period. For this purpose, a cannula was inserted in the right antecubital vein for blood sampling during thermoneutral and mild cold conditions and injection of the $\left[{ }^{18} \mathrm{~F}\right] \mathrm{FDG}$ tracer. iButtons (Maxim Integrated Products, San Jose, CA, USA) were placed on 14 ISO-defined sites and a telemetric pill was swallowed for measurements of skin and core temperatures, respectively. A pressure cuff (MTP, Medisana, Kerkrade, the Netherlands) was placed on the left arm for measurement of blood pressure and a chest strap (Polar T31, Polar, Kempele, Finland) was attached for measurement of heart rate. Skin perfusion was measured at the ventral side of the right hand and forearm by means of Laser Doppler Flowmetry (FP5000, Perimed, Järfälla, Sweden). Energy expenditure was measured continuously via a face-mask connected to an indirect calorimeter (EZcal, IDEE, Maastricht, the Netherlands). 
Subjects were wrapped in a water-perfused suit (ThermaWrap Universal 3166, MTRE Advanced Technologies, Yavne, Israel), and measurements started with a 45minute thermoneutral period. Hereafter, subjects were gradually cooled until a temperature just above their shivering point (which took approximately 30 minutes), and measured for another 30 minutes at this mild cold temperature; non-shivering thermogenesis (NST) was calculated as the percentage increase in energy expenditure above BMR (measured at thermoneutrality) at the temperature just above an individual's shivering temperature. Subsequently, 74 $\mathrm{MBq}$ of $\left.{ }^{18} \mathrm{~F}\right] \mathrm{FDG}$ was injected intravenously, while subjects remained in the mild cold water-perfused suit. One hour after injection the PET/CT imaging protocol started with low-dose CT scan (120 kV, 30mAs), immediately followed by a static PET scan ( 6 to 7 bed positions, 4 min per bed position) covering the range from the skull to the abdomen.

\section{PET/CT analysis}

PET-CT scans were analyzed using PMOD software (version 3.0, PMOD Technologies, Zurich, Switzerland) by both the researcher (MJWH) and an experienced nuclear medicine physician (BB). BAT activity was defined as $\left[{ }^{18} \mathrm{~F}\right] \mathrm{FDG}$ uptake >1.5 standardized uptake value (SUV) in fat tissue (Hounsfield units [HU] between -10 and -180). SUV was calculated as: ( $\left.{ }^{18} \mathrm{~F}\right] \mathrm{FDG}$ uptake $[\mathrm{kBq} / \mathrm{ml}]) /($ injected dose $[\mathrm{kBq}] /$ patient weight $[\mathrm{g}]$ ). Regions of interest were semiautomatically outlined for determination of mean (SUVmean) and maximal (SUVmax) $\left[{ }^{18}\right.$ F]FDG uptake in BAT locations. All upper body BAT depots were included in this analysis.

Not all subjects showed pronounced BAT activity, defined with the SUV threshold of $>1.5$. Therefore, fixed volumes of interest (VOIs; $2.67 \mathrm{~cm}^{3}$ ) were also carefully selected in the supraclavicular adipose tissue region ( $\mathrm{HU}$ between -10 and -180) in the area with the highest $\left[{ }^{18} \mathrm{~F}\right] \mathrm{FDG}$ uptake. VOls were also placed in subcutaneous and visceral white adipose tissue (WAT), skeletal muscle (deltoid, erector spinae, biceps and triceps brachii muscles; average activity of these muscle groups is presented as average skeletal muscle $\left[{ }^{18} \mathrm{~F}\right] \mathrm{FDG}$ uptake), liver and brain, as described previously (31). As such, we were able to compare $\left[{ }^{18} \mathrm{~F}\right] \mathrm{FDG}$ uptake (calculated as SUVmean) between these tissues and between placebo and arginine interventions. 


\section{Ex vivo skeletal muscle respiration}

The muscle biopsy was acquired at the second day in the morning after an overnight fast. The muscle tissue was instantly placed in ice-cold preservation medium (BIOPS, OROBOROS Instruments, Innsbruck, Austria) and used for the preparation of permeabilized muscle fibers, as described previously (32). Subsequently, oxygen consumption of these permeabilized muscle fibers (2.5-3.0 mg wet weight) was measured using an oxygraph (OROBOROS Instruments, Innsbruck, Austria), in essence according to Hoeks et al. (33). Respiration chambers were hyperoxygenated to $\sim 360 \mu \mathrm{mol} / / \mathrm{O}_{2}$. State 2 respiration was initiated by addition of malate $(4 \mathrm{mM})$ and octanoylcarnitine $(4 \mathrm{mM})$. Subsequently, ADP was added to evaluate coupled (state 3 ) respiration. Coupled respiration was then maximized by subsequent addition of glutamate $(10 \mathrm{mM})$ and succinate $(10 \mathrm{mM})$. Finally, the chemical uncoupler FCCP was titrated to evaluate the maximal capacity of the electron transport chain (State $U$ ). The integrity of the outer mitochondrial membrane was assessed by addition of cytochrome $C(20 \mu \mathrm{M})$ upon maximal coupled respiration. Respiration measurements that displayed a cytochrome $C$ response $>10 \%$ above maximal coupled respiration were excluded from analysis. All measurements were performed in quadruplicate.

\section{Statistical analysis}

Statistical analyses were performed with PASW Statistics 22.0 for Mac (IBM, Armonk, NY, USA). Normal distribution of all relevant parameters was tested with Sharpiro-Wilk test, for all subjects combined and the separate study groups (South Asians and Caucasians). For normally distributed data, two-sided independent sample t tests were used to compare finding between the study groups, and twosided paired sample t tests were used to compare findings between placebo and Larginine treatments. For not normally distributed data, Mann-Whitney $U$ tests and Wicoxon signed rank tests were used, respectively. ANVOCA was used to correct parameters for fat free mass. Pearson correlations were used to identify correlations between variables. P-values $<0.05$ were considered statistically significant. Data are reported as mean $\pm S D$, unless stated otherwise. 


\section{RESULTS}

\section{Subject characteristics and body composition}

South Asian and Caucasian subjects were comparable with respect to age (45.8 \pm 7.2 vs. $48.8 \pm 5.1$ years, resp., $p=0.258)$ and $\mathrm{BMI}\left(30.1 \pm 3.5\right.$ vs. $30.3 \pm 3.9 \mathrm{~kg} \mathrm{~m}^{-2}$, resp., $p=0.90$ ) at the start of the intervention, although South Asians were significantly shorter than Caucasians (Table 1). In addition, fasting plasma glucose levels were similar (Table 1). No statistically significant differences in fat mass or fat free mass were observed between the groups upon either placebo or L-arginine treatment (Table 1). L-arginine treatment did not affect body composition compared with placebo treatment in South Asians or Caucasians when analyzed separately (Table 1). However, when analyzing both groups together, lean mass was significantly higher upon L-arginine compared with placebo treatment $(63.8 \pm$ 7.7 vs. $63.1 \pm 7.3 \mathrm{~kg}$, resp., $\mathrm{p}<0.05$, Table 2 ).

Table 1. Body composition.

\begin{tabular}{|c|c|c|c|c|c|c|}
\hline Baseline & \multicolumn{2}{|c|}{ South Asian (n=9) } & \multicolumn{2}{|c|}{ Caucasian (n=9) } & \multicolumn{2}{|l|}{ All $(n=18)$} \\
\hline Age (years) & $45.8 \pm 7.2$ & & $48.8 \pm 5.1$ & & $47.3 \pm 6.3$ & \\
\hline Height (m) & $1.76 \pm 0.05$ & & $1.82 \pm 0.05^{*}$ & & $1.79 \pm 0.06$ & \\
\hline $\mathrm{BMI}\left(\mathrm{kg} \mathrm{m}^{-2}\right)$ & $30.1 \pm 3.5$ & & $30.3 \pm 3.9$ & & $30.2 \pm 3.6$ & \\
\hline Glucose $\left(\mathrm{mmol} \mathrm{I}^{-1}\right)$ & $5.6 \pm 0.5$ & & $5.7 \pm 0.7$ & & $5.6 \pm 0.6$ & \\
\hline Treatment & Placebo & L-arginine & Placebo & L-arginine & Placebo & L-arginine \\
\hline Body weight (kg) & $92.9 \pm 13.6$ & $92.9 \pm 12.6$ & $98.9 \pm 13.7$ & $99.7 \pm 14.1$ & $95.9 \pm 13.6$ & $96.3 \pm 13.4$ \\
\hline $\mathrm{BMI}\left(\mathrm{kg} \mathrm{m}^{-2}\right)$ & $29.9 \pm 3.8$ & $29.9 \pm 3.4$ & $29.9 \pm 4.1$ & $30.2 \pm 4.1$ & $29.9 \pm 3.8$ & $30.0 \pm 3.7$ \\
\hline Fat mass (kg) & $30.1 \pm 7.6$ & $29.7 \pm 6.7$ & $29.7 \pm 6.5$ & $29.8 \pm 6.2$ & $29.9 \pm 6.9$ & $29.7 \pm 6.3$ \\
\hline Fat $\%$ & $31.7 \pm 4.0$ & $31.3 \pm 3.7$ & $30.0 \pm 3.2$ & $29.9 \pm 2.9$ & $30.9 \pm 3.6$ & $30.6 \pm 3.3$ \\
\hline Fat free mass (kg) & $61.0 \pm 6.8$ & $61.6 \pm 7.0$ & $65.6 \pm 7.4$ & $66.3 \pm 8.2$ & $63.1 \pm 7.3$ & $63.8 \pm 7.7^{+}$ \\
\hline $\mathrm{BMD}\left(\mathrm{g} \mathrm{cm}^{-3}\right)$ & $1.22 \pm 0.06$ & $1.22 \pm 0.05$ & $1.27 \pm 0.07$ & $1.27 \pm 0.09$ & $1.24 \pm 0.07$ & $1.24 \pm 0.07$ \\
\hline
\end{tabular}

BMI, body mass index; BMD, bone mineral density. ${ }^{*} p<0.05$, South Asian vs. Caucasian; ${ }^{\dagger} p<0.05$, placebo vs. L-arginine.

\section{Energy expenditure and substrate metabolism}

Energy expenditure was measured in resting thermoneutral conditions (BMR) and mild cold conditions (NST). BMR was significantly lower in South Asians compared to Caucasians upon both placebo (5.8 \pm 0.5 vs. $5.0 \pm 0.6 \mathrm{~kJ} \mathrm{~min}^{-1}$, resp, p < 0.05) and L-arginine $\left(5.7 \pm 0.7\right.$ vs. $5.0 \pm 0.6 \mathrm{~kJ} \mathrm{~min}^{-1}$, resp., $\left.p<0.05\right)$ treatment (Figure $\left.1 \mathrm{~A}\right)$. Upon placebo treatment, cold exposure resulted in a significant increase in energy expenditure only in the South Asians. Consequently, \%NST was higher in South Asians compared to Caucasians (11.8 \pm 10.9 vs. $1.6 \pm 6.5 \%$, resp., $p<0.05$; Figure 1B). However, after L-arginine treatment, cold exposure significantly increased 
energy expenditure in both groups (Figure 1A), with no significant difference in $\%$ NST between the groups (Figure 1B).

Differences in BMR between South Asians and Caucasians were no longer apparent after corrections for fat free mass with ANCOVA (placebo, p-value intercept = 0.082; L-arginine, $\mathrm{p}$-value intercept $=0.135$; Figure $1 \mathrm{C}$ ).
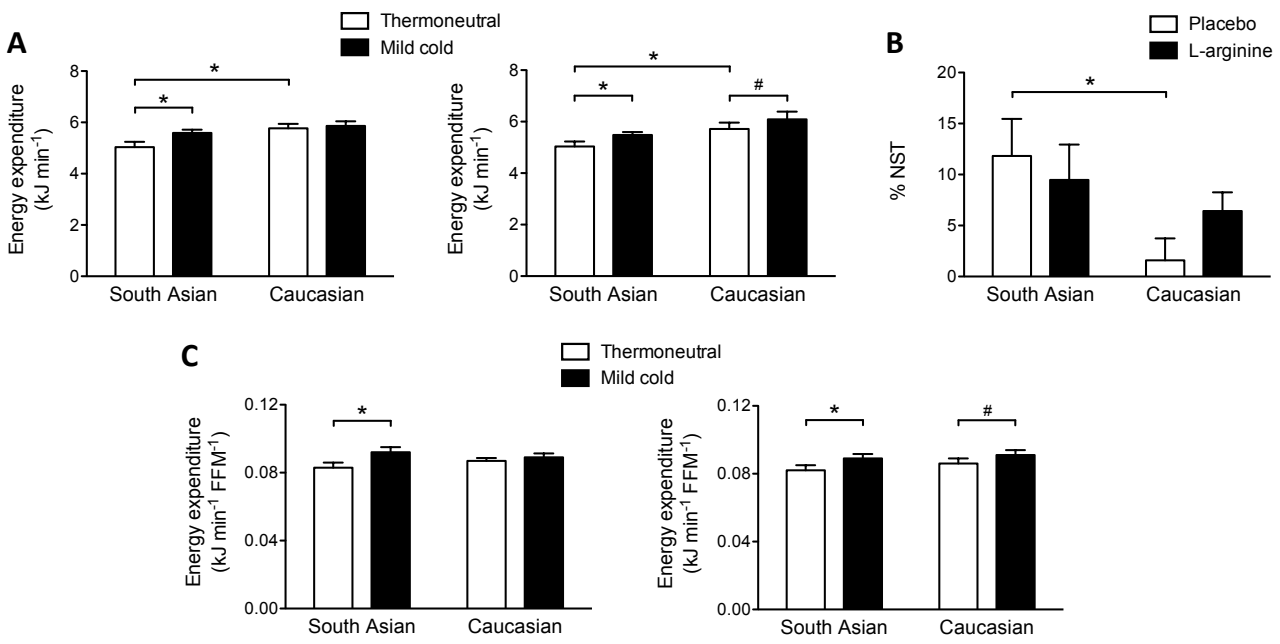

$\square$ Thermoneutral

Mild cold
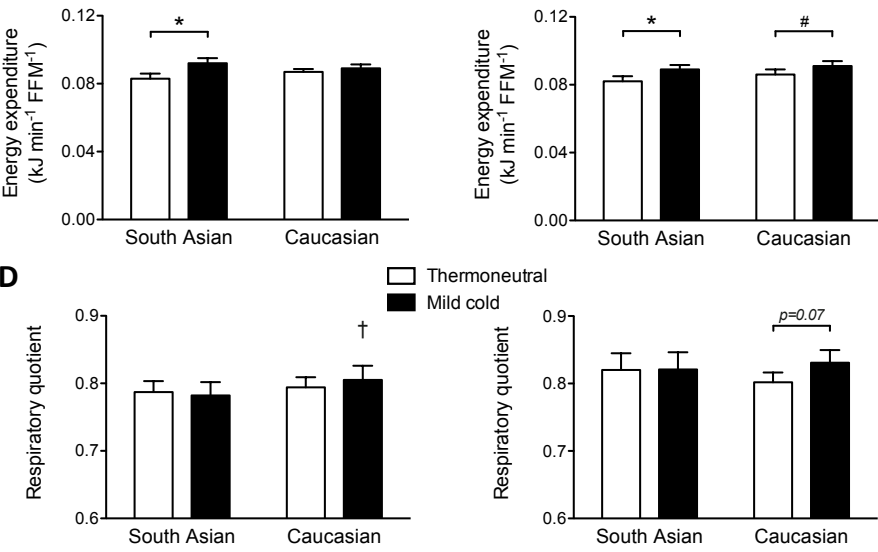

Thermoneutral

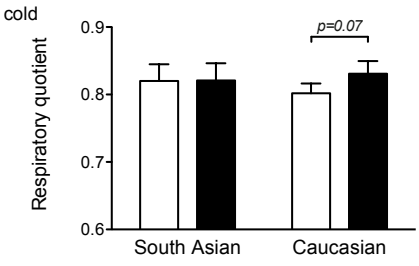

Figure 1. Energy expenditure during thermoneutral and mild cold conditions, after placebo and Larginine treatment. (A) Energy expenditure in thermoneutral and mild cold conditions, after placebo (left) and L-arginine (right) treatment in South Asians and Caucasians. (B) Non-shivering thermogenesis (\%NST) after placebo and L-arginine treatment in South Asians and Caucasians. (C) Energy expenditure corrected for fat free mass (FFM), in thermoneutral and mild cold conditions, after placebo (left) and L-arginine (right) treatment in South Asians and Caucasians. (D) Respiratory quotient in thermoneutral and mild cold conditions, after placebo (left) and L-arginine (right) treatment in South Asians and Caucasians. Data are presented as mean \pm SEM. ${ }^{*} p<0.05 ; \# p<0.01$; $+p<0.05$, placebo vs. L-arginine treatment.

Respiratory quotient (RQ) was similar between South Asians and Caucasians. After placebo treatment, no significant changes in $R Q$ upon cold exposure were observed in either group (Figure 1D). However, after L-arginine treatment $R Q$ tended to increase upon cold exposure in the Caucasians $(0.80 \pm 0.04$ vs. $0.83 \pm$ 
0.06, thermoneutral vs. mild cold, resp., $p=0.07$ ), indicating relatively higher carbohydrate oxidation. Consequently, RQ during cold exposure was significantly higher after L-arginine then after placebo treatment $(0.83 \pm 0.06$ vs. $0.80 \pm 0.06$, resp., $p<0.05$ ) in these Caucasian subjects (Figure 1D). A similar trend for higher cold-induced $\mathrm{RQ}$ after $\mathrm{L}$-arginine treatment was observed when analyzing all subjects combined ( $0.79 \pm 0.06$ vs. $0.83 \pm 0.07$, placebo vs. L-arginine, resp., $p=$ 0.08).

\section{BAT activity}

Pronounced cold-induced BAT activity (SUV > 1.5) could be detected in 8 out of 9 South Asians and 8 out of 9 Caucasians after placebo treatment. Of these subjects, 3 South Asians and 2 Caucasians did not present BAT activity in the supraclavicular fat region, where often the most pronounced BAT depots are found. However, they did show small amounts of BAT activity in the neck, mediastinum (para-aortic) and/or paravertebral fat depots. Mean (SUVmean $2.0 \pm 0.9$ vs. $2.0 \pm 0.8$, South Asian vs. Caucasian, resp., $p=0.863$ ) and maximal (SUVmax $5.5 \pm 3.9$ vs. $7.0 \pm 6.1$, South Asian vs. Caucasian, resp., $p=0.666$ ) BAT activity were not significantly different between the groups after placebo treatment (Figures 2A, 2B). In addition, detectable BAT volumes were similar (119 \pm 189 vs. $144 \pm 171 \mathrm{ml}$, South Asian vs. Caucasian, resp, $p=0.605)$. L-arginine treatment did not affect mean and maximal BAT activity (Figures 2A, 2B) and detectable BAT volume (South Asians: $119 \pm 189$ vs. $111 \pm 208 \mathrm{ml}, \mathrm{p}=0.859$; Caucasians: $144 \pm 171$ vs. $129 \pm 141 \mathrm{ml}, \mathrm{p}=0.779$; placebo vs. L-arginine, resp.) compared to placebo treatment in either group (Figures 2A, 2B), or when analyzing both groups combined.

Because BAT activity, as defined by SUV > 1.5, could not be detected in all subjects, we also used the fixed volume method (31) to specifically determine activity in predetermined VOls in the supraclavicular adipose tissue depot. This method revealed similar results as described above: there were no significant differences in fixed VOI BAT activity between South Asians and Caucasians and no differences between placebo and L-arginine treatment in either group (Figure $2 \mathrm{C}$ ). In addition, radiodensity of this supraclavicular BAT depot (expressed in Hounsfield units) was not significantly different between groups or between treatments (Figure 2D). Interestingly, mean and maximal supraclavicular BAT activity were positively related to cold-induced supraclavicular skin temperatures after placebo treatment, when analyzing both groups together (Figure 2E, 2F). 
A

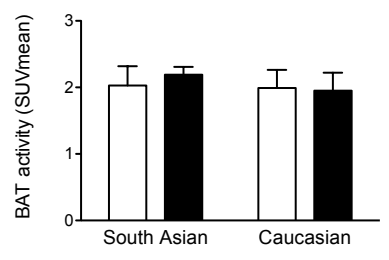

D

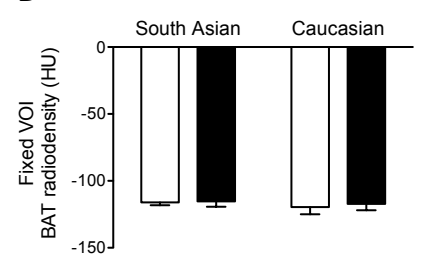

B
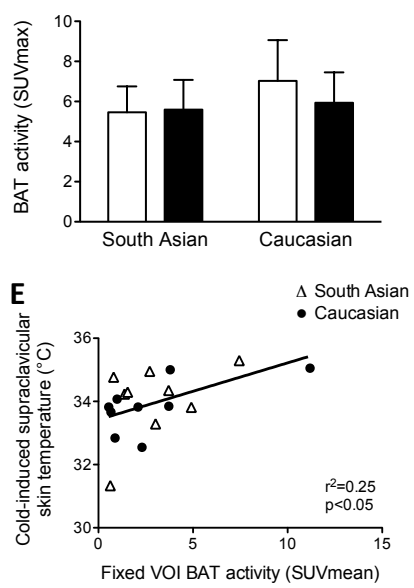
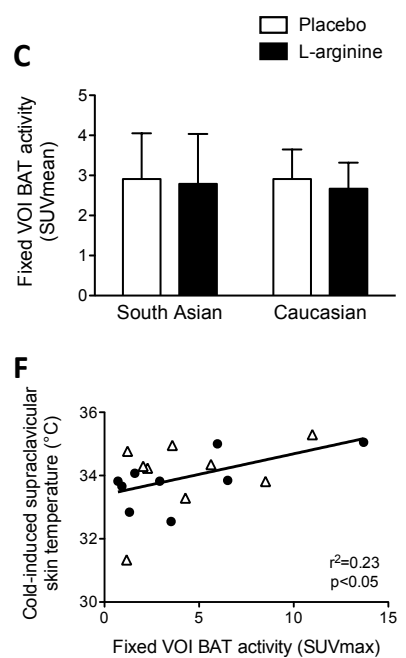

Figure 2. Cold-induced BAT activity after placebo and L-arginine treatment, in South Asians and Caucasians. (A) Average upper body BAT activity (SUVmean) after placebo and arginine treatment, in South Asians and Caucasians. (B) Maximal upper body BAT activity (SUVmax) after placebo and arginine treatment, in South Asians and Caucasians. (C) Activity of the supraclavicular BAT region measured by the fixed VOI method after placebo and arginine treatment, in South Asians and Caucasians. (D) Radiodensity (in Hounsfield units; HU) of the supraclavicular BAT region measured by the fixed VOI method after placebo and arginine treatment, in South Asians and Caucasians. (E, F) Correlation between cold-induced supraclavicular skin temperature and mean (E) and maximal (F) activity of the supraclavicular BAT region after placebo treatment. Data are presented as mean \pm SEM.

Next to BAT, we also determined $\left[{ }^{18} \mathrm{~F}\right] \mathrm{FDG}$ uptake (expressed as SUVmean) in skeletal muscle, subcutaneous and visceral WAT, liver and brain. Similar to BAT, $\left[{ }^{18} \mathrm{~F}\right]$ FDG uptake in these tissues was not different between South Asians and Caucasians and not affected by L-arginine treatment (Table 2).

Table 2. $\left[{ }^{18}\right.$ F]FDG uptake in skeletal muscle, subcutaneous and visceral WAT, liver and brain, in South Asians and Caucasians after placebo and $\mathrm{L}$-arginine treatment.

\begin{tabular}{|c|c|c|c|c|c|c|}
\hline \multirow[b]{2}{*}{ SUVmean } & \multicolumn{2}{|c|}{ South Asian $(n=9)$} & \multicolumn{2}{|c|}{ Caucasian $(n=9)$} & \multicolumn{2}{|l|}{ All $(n=18)$} \\
\hline & Placebo & L-arginine & Placebo & L-arginine & Placebo & L-arginine \\
\hline SM & $0.61 \pm 0.09$ & $0.61 \pm 0.06$ & $0.62 \pm 0.06$ & $0.61 \pm 0.06$ & $0.62 \pm 0.08$ & $0.61 \pm 0.06$ \\
\hline WATsubc & $0.20 \pm 0.03$ & $0.19 \pm 0.03$ & $0.18 \pm 0.04$ & $0.18 \pm 0.04$ & $0.19 \pm 0.03$ & $0.18 \pm 0.04$ \\
\hline WATvisc & $0.29 \pm 0.10$ & $0.30 \pm 0.09$ & $0.33 \pm 0.08$ & $0.32 \pm 0.06$ & $0.31 \pm 0.09$ & $0.31 \pm 0.08$ \\
\hline Liver & $2.42 \pm 0.29$ & $2.59 \pm 0.31$ & $2.44 \pm 0.17$ & $2.54 \pm 0.24$ & $2.43 \pm 0.23$ & $2.56 \pm 0.27$ \\
\hline Brain & $8.25 \pm 1.65$ & $8.11 \pm 1.27$ & $8.58 \pm 1.02$ & $8.74 \pm 1.59$ & $8.41 \pm 1.34$ & $8.42 \pm 1.44$ \\
\hline
\end{tabular}

SM, skeletal muscle; WATsubc, subcutaneous white adipose tissue; WATvisc, visceral white adipose tissue. 


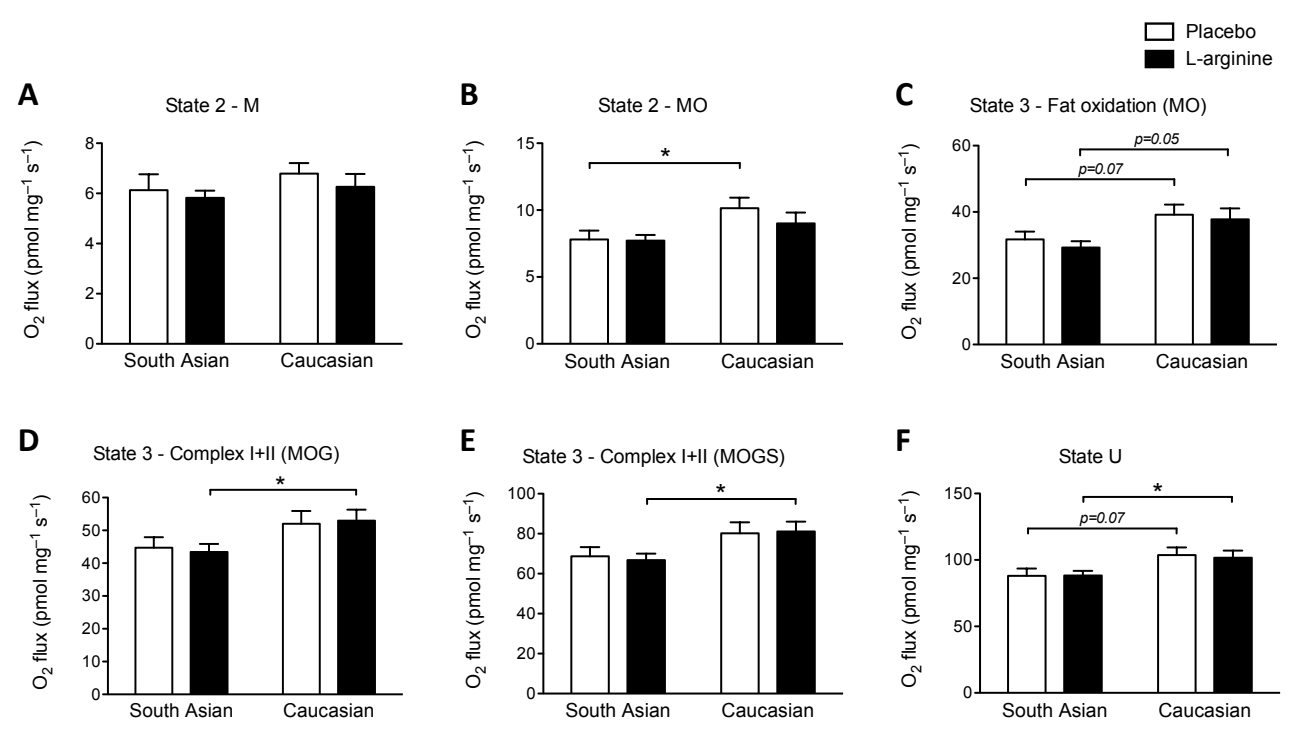

Figure 3. Skeletal muscle respiration after placebo and L-arginine treatment. Respiration measurements in permeabilized muscle fibers. M, malate; O, octanoyl carnitine; G, glutamate; $\mathrm{S}$, succinate. (A, B) Respiration upon addition of substrates only (state 2): (A) malate, (B) malate + octanoyl carnitine. (C-E) ADP-stimulated respiration upon addition of several mitochondrial complex I and complex II-linked substrates (state 3): (C) malate + octanoyl carnitine, (D) malate + octanoyl carnitine + glutamate, (E) malate + octanoyl carnitine + glutamate + succinate. (F) Maximally uncoupled respiration upon addition of the chemical uncoupler FCCP (i.e. maximal electron transport chain capacity; state $U$ ). Data are presented as mean \pm SEM. ${ }^{*} p<0.05$.

\section{Ex vivo skeletal muscle respiration}

Skeletal muscle oxidative capacity was assessed by respiration measurements in permeabilized muscle fibers using a multisubstrate protocol. State 2 respiration (i.e. respiration in the presence of substrates only) upon addition of malate + octanoylcarnintine was significantly lower in South Asians compared to Caucasians after placebo treatment (Figure 3B). Furthermore, ADP-stimulated respiration (state 3 ) on lipid substrates (malate + octanoyl carnitine) as well as maximal FCCPstimulated uncoupled respiration (state $U$ ) tended to be lower in South Asians compared to Caucasians after placebo treatment (Figures 3C, 3F). L-arginine treatment did not result in significant changes in any of the respiratory states analyzed, neither in South Asians nor in Caucasians nor when analyzing both groups combined. However, several trends that were present after placebo treatment yielded significant results after L-arginine treatment. Thus, state 3 respiration as well as maximally uncoupled respiration was significantly lower in South Asians compared to Caucasians after L-arginine treatment (Figures 3D-F), 
indicating lower skeletal muscle oxidative capacity in South Asians. Tissue wet weights used for respiration measurements were similar between groups and between treatments (South Asians: $2.70 \pm 0.13$ vs. $2.72 \pm 0.17 \mathrm{mg}$; Caucasians 2.81 \pm 0.22 vs. $2.75 \pm 0.10 \mathrm{mg}$, placebo vs. L-arginine, resp., $p>0.05$ for all comparisons). Maximal FCCP-stimulated uncoupled respiration upon placebo treatment tended to correlate negatively with fasting plasma glucose levels, measured at baseline $\left(r^{2}=-0.19, p=0.07\right)$.

\section{Body temperatures, heart rate, blood pressure and skin perfusion}

Temperature of the water-perfused suit during cold exposure was similar between South Asians and Caucasians and between treatments (Table 3). Core temperatures did not change significantly upon acute cold exposure in either group, after both placebo and L-arginine treatment. However, core temperature during cold exposure was significantly higher upon L-arginine compared to placebo treatment in South Asians (37.0 \pm 0.3 vs. $36.8 \pm 0.4{ }^{\circ} \mathrm{C}$, resp., $\mathrm{p}<0.05$ ), and when analyzing all subjects combined (36.9 \pm 0.3 vs. $36.8 \pm 0.6^{\circ} \mathrm{C}$, resp., $p<0.5$; Table 3 ). No significant differences were observed in thermoneutral and cold-induced mean skin temperatures and proximal skin temperatures between the groups or between treatments. Distal skin temperature at thermoneutrality was slightly but significantly lower in South Asians compared to Caucasians upon placebo treatment (33.1 \pm 1.3 vs. $34.3 \pm 0.9{ }^{\circ} \mathrm{C}$, resp., $p<0.05$; Table 3$)$, although this difference was no longer present upon L-arginine treatment. Heart rate during thermoneutral and cold conditions was similar between South Asians and Caucasians. However, heart rate during cold conditions was significantly higher after L-arginine compared to placebo treatment in South Asians (63 \pm 7 vs. $60 \pm 6$ bpm, resp., $p<0.05$ ), and when analyzing all subjects combined (61 \pm 7 vs. $59 \pm 6$ bpm, resp., $p<0.05)$. Mean arterial pressure was significantly lower in South Asians compared to Caucasians ( $88 \pm 6$ vs. $101 \pm 10 \mathrm{~mm} \mathrm{Hg}$, resp., $p<0.05$ ), but was not different between treatments. This difference between the groups could not be ascribed to the higher number of subjects taking antihypertensive medication in the South Asian group ( $n=3$, compared to $n=0$ in Caucasians), since this difference was still apparent after exclusion of these subjects from analysis. Skin perfusion at the hand and underarm during cold exposure was not different between treatments in either group, although skin perfusion at the underarm was significantly lower in Caucasians compared to South Asians upon placebo 
treatment $(37.6 \pm 15.3$ vs. $61.1 \pm 14.3 \%$, resp., $p<0.05)$. The latter difference was not present upon L-arginine treatment.

Table 3. Body temperatures, heart rate, blood pressure and skin perfusion in thermoneutral and mild cold conditions, after placebo and L-arginine treatment.

\begin{tabular}{|c|c|c|c|c|c|c|}
\hline & \multicolumn{2}{|c|}{ South Asian $(n=9)$} & \multicolumn{2}{|c|}{ Caucasian $(n=9)$} & \multicolumn{2}{|l|}{ All $(n=18)$} \\
\hline & Placebo & L-arginine & Placebo & L-arginine & Placebo & L-arginine \\
\hline \multicolumn{7}{|l|}{ Temp suit $\left({ }^{\circ} \mathrm{C}\right)$} \\
\hline Thermoneutral & $30.0 \pm 0.38$ & $29.9 \pm 0.4$ & $29.9 \pm 0.4$ & $29.5 \pm 0.4$ & $29.9 \pm 0.4$ & $29.7 \pm 0.4$ \\
\hline Cold & $23.5 \pm 2.2^{*}$ & $23.5 \pm 2.0^{*}$ & $24.2 \pm 0.8^{*}$ & $24.1 \pm 1.2^{*}$ & $23.9 \pm 1.7^{*}$ & $23.8 \pm 1.6^{*}$ \\
\hline \multicolumn{7}{|l|}{ Core temp $\left({ }^{\circ} \mathrm{C}\right)$} \\
\hline Thermoneutral & $36.8 \pm 0.3$ & $36.9 \pm 0.2$ & $36.9 \pm 0.2$ & $37.0 \pm 0.2$ & $36.8 \pm 0.3$ & $36.9 \pm 0.2$ \\
\hline Cold & $36.8 \pm 0.4$ & $37.0 \pm 0.3^{+}$ & $36.9 \pm 0.2$ & $36.9 \pm 0.3$ & $36.8 \pm 0.3$ & $36.9 \pm 0.3^{+}$ \\
\hline \multicolumn{7}{|l|}{ Mean skin temp $\left({ }^{\circ} \mathrm{C}\right)$} \\
\hline Thermoneutral & $34.7 \pm 0.6$ & $34.9 \pm 0.5$ & $35.0 \pm 0.3$ & $35.0 \pm 0.5$ & $34.9 \pm 0.5$ & $35.0 \pm 0.5$ \\
\hline Cold & $29.1 \pm 2.0^{*}$ & $28.9 \pm 1.9^{*}$ & $29.8 \pm 1.1^{*}$ & $29.7 \pm 1.2^{*}$ & $29.4 \pm 1.6^{*}$ & $29.3 \pm 1.6^{*}$ \\
\hline \multicolumn{7}{|c|}{ Proximal skin temp $\left({ }^{\circ} \mathrm{C}\right)$} \\
\hline Thermoneutral & $35.2 \pm 0.4$ & $35.3 \pm 0.4$ & $34.9 \pm 0.5$ & $35.2 \pm 0.7$ & $35.1 \pm 0.5$ & $35.2 \pm 0.6$ \\
\hline Cold & $28.0 \pm 2.7 *$ & $28.3 \pm 2.4^{*}$ & $29.2 \pm 1.6^{*}$ & $29.2 \pm 1.4^{*}$ & $28.6 \pm 2.3 *$ & $28.8 \pm 1.9 *$ \\
\hline \multicolumn{7}{|l|}{ Distal skin temp $\left({ }^{\circ} \mathrm{C}\right)$} \\
\hline Thermoneutral & $33.1 \pm 1.3$ & $33.9 \pm 0.9$ & $34.3 \pm 0.8^{5}$ & $34.6 \pm 0.8$ & $33.7 \pm 1.2$ & $34.1 \pm 0.9$ \\
\hline Cold & $28.9 \pm 1.4^{*}$ & $28.6 \pm 1.6^{*}$ & $29.5 \pm 1.4^{*}$ & $29.7 \pm 1.4^{*}$ & $29.2 \pm 1.4^{*}$ & $29.2 \pm 1.6^{*}$ \\
\hline \multicolumn{7}{|l|}{ Heart rate (bpm) } \\
\hline Thermoneutral & $65 \pm 9$ & $69 \pm 10^{+}$ & $68 \pm 10$ & $68 \pm 9$ & $66 \pm 9$ & $68 \pm 9$ \\
\hline Cold & $60 \pm 6$ & $63 \pm 7^{\#+}$ & $57 \pm 6 *$ & $60 \pm 8 *$ & $59 \pm 6 *$ & $61 \pm 7 *^{+}$ \\
\hline \multicolumn{7}{|l|}{ MAP (mm Hg) } \\
\hline Thermoneutral & $88 \pm 6$ & $88 \pm 7$ & $101 \pm 10^{\$}$ & $96 \pm 6$ & $94 \pm 11$ & $92 \pm 8$ \\
\hline Cold & $103 \pm 9 *$ & $104 \pm 10 *$ & $110 \pm 10 * \$$ & $105 \pm 6 *$ & $107 \pm 10^{*}$ & $105 \pm 8^{*}$ \\
\hline \multicolumn{7}{|l|}{ SP hand (\%) } \\
\hline Thermoneutral & 100 & 100 & 100 & 100 & 100 & 100 \\
\hline Cold & $14.8 \pm 7.8^{*}$ & $16.5 \pm 22.1^{*}$ & $12.5 \pm 10.9 *$ & $12.5 \pm 11.7^{*}$ & $13.6 \pm 9.3^{*}$ & $14.8 \pm 17.8^{*}$ \\
\hline \multicolumn{7}{|l|}{ SP underarm (\%) } \\
\hline Thermoneutral & 100 & 100 & 100 & 100 & 100 & 100 \\
\hline Cold & $61.1 \pm 14.3^{*}$ & $55.4 \pm 23.7^{\#}$ & $37.6 \pm 15.2^{* \$}$ & $52.3 \pm 19.9^{\#}$ & $48.3 \pm 18.7^{*}$ & $53.8 \pm 20.7^{*}$ \\
\hline
\end{tabular}

Temp, temperature; MAP, mean arterial pressure $\left(=2 / 3^{*}\right.$ diastolic blood pressure $+1 / 3 *$ systolic blood pressure); SP, skin perfusion. ${ }^{*} p<0.001$, thermoneutral vs. mild cold, $\# p<0.05$ thermoneutral vs. mild cold, $\uparrow p<0.05$, placebo vs. L-arginine, $\$ p<0.05$, South Asian vs. Caucasian.

\section{DISCUSSION}

The South Asian population is at increased risk for development of type 2 diabetes and associated adverse metabolic disorders compared to other ethnicities. An important contributor to this increased risk is a highly common disadvantageous metabolic phenotype, which is likely partly caused by a disturbed energy metabolism. Reduced skeletal muscle respiratory capacity and reduced BAT volume and activity are potential main contributors to disturbed whole-body 
energy metabolism in the South Asian population. Here, we report that BAT volume and activity are not different in pre-diabetic middle-aged South Asian males compared to age- and BMI-matched Caucasian males. Interestingly, skeletal muscle respiratory capacity was lower in South Asians then in Caucasians. A 6-week intervention with L-arginine supplementation increased lean mass. There were no significant changes in BAT or skeletal muscle respiratory capacity, although the ethnical differences in skeletal muscle respiratory capacity became slightly more pronounced after L-arginine treatment.

Previous studies have shown contradicting results when comparing BAT volume and activity between young, healthy South Asians and matched Caucasians: Admiraal et al. (34) reported no differences in BAT between these ethnicities, while Bakker et al. (10) showed equal BAT activity, but lower BAT volume in South Asian compared to Caucasian subjects. It should be noted that the latter study used personalized cooling protocols to activate BAT, while Admiraal et al. used fixed cold temperatures $\left(17{ }^{\circ} \mathrm{C}\right)$ which might have resulted in underestimations of BAT volume based on ${ }^{18}$ F]FDG-PET/CT scan (35). However, here we show in older prediabetic subjects, using personalized cooling protocols, that neither BAT activity nor detectable BAT volume is different between South Asian and Caucasian subjects, thus contradicting the notion that reduced BAT activity may contribute to an excess diabetes risk in South Asians. It is important to note that BAT activity in our current study was assessed by solely measuring $\left[{ }^{18} \mathrm{~F}\right] \mathrm{FDG}$ (i.e. radioactive labeled glucose) uptake, while combustion of intracellular lipid stores is believed to be the main contributor to actual heat production in BAT (36). This is a general problem with the use of $\left[{ }^{18} \mathrm{~F}\right] \mathrm{FDG}$ as the current golden standard to visualize BAT, and it could therefore still be possible that the capacity to oxidize lipids by BAT is affected by ethnical background, e.g. due to different thermogenic gene programs. In addition, future studies using alternative tracers, such as $\left[{ }^{18} \mathrm{~F}\right] \mathrm{THA}$ (as a measure of nonesterified fatty acid uptake) and ${ }^{11} \mathrm{C}$-acetate (as a measure of oxidative metabolism) are needed to compare total BAT substrate metabolism between ethnicities.

Recruitment of BAT in animal models is associated with leanness and improvements in metabolic phenotype $(37 ; 38)$. In humans, thus far, prolonged intermittent cold exposure is the only known means to increase BAT activity and volume (16-18), without significantly limiting dietary intake. Despite several previously reported positive metabolic health effects of L-arginine in humans (22; 
23), L-arginine treatment did not affect BAT activity in either ethnic group in our current study.

It has previously been reported in rodents that the effects of L-arginine on BAT are strongly dependent on BAT's functional status, i.e. while L-arginine was able to partially affect some steps of mitochondrial biogenesis in brown adipocytes at thermoneutrality, pronounced mitochondriogenesis occurred only during cold acclimation, and this process was further enhanced by L-arginine supplementation during cold acclimation (24). This further emphasizes the role of cold as the primary physiological stimulus for BAT activation and recruitment, in both mice and humans.

Skeletal muscle mitochondrial oxidative capacity has been repeatedly linked to metabolic dysfunction, such as insulin resistance, although the causal relationships are less clear (39). It has recently been reported that in lean African-American women, who showed lower peripheral insulin sensitivity compared to matched Caucasian women, also lower skeletal muscle mitochondrial respiration was present, indicating a role for ethnicity in these impairments (40). We here show that also in a cohort of overweight pre-diabetic South Asian men, skeletal muscle oxidative capacity was lower compared to matched Caucasians. Such ethnically inherited defects in mitochondrial capacity may render South Asians more prone to the development of disturbances in skeletal muscle energy metabolism. Although this was not directly reflected in our measurements of resting whole-body energy expenditure, which showed equal BMR between ethnicities when corrected for FFM, a previous study has shown reduced whole-body oxidative capacity $\left(\mathrm{VO}_{2} \mathrm{max}\right)$ during exercise in South Asians (12). This is consistent with the idea that defects in muscle metabolism are unlikely to be evidenced in resting conditions, since energy demand is hardly a metabolic challenge for muscle mitochondria under such conditions (41). Thus, exercising conditions are likely more appropriate to detect disturbances in whole-body metabolism caused by reduced skeletal muscle oxidative capacity in South Asians.

L-arginine supplementation did not affect skeletal muscle oxidative capacity in our study, although differences in oxidative capacity between ethnicities were more pronounced upon L-arginine treatment compared to placebo treatment. Evidence for a role of the L-arginine-NO pathway in skeletal muscle mitochondrial function originates primarily from cell studies and studies in eNOS deficient mice that display impaired mitochondrial biogenesis (20). However, to the best of our knowledge there are no other studies directly assessing the effects of L-arginine on 
skeletal muscle oxidative capacity, neither in mice nor in humans. It would be highly interesting to study the efficacy of other treatments or compounds that are known to enhance skeletal muscle mitochondrial respiration in South Asians as compared to Caucasians. In this respect, exercise interventions (42) and resveratrol supplementation (43) have shown promising results in previous studies, and it would thus be interesting to study whether such treatments can be of extra benefit in South Asian subjects to improve skeletal muscle respiration and metabolic health.

In conclusion, we show that BAT volume and activity are not different between South Asian pre-diabetic males and age- and BMI-matched Caucasian males. Interestingly, skeletal muscle oxidative capacity was lower in South Asians. Six weeks of L-arginine supplementation did not affect BAT activity or skeletal muscle respiration. These data suggest that impaired skeletal muscle oxidative metabolism may be an important underlying cause for disturbances in whole-body energy metabolism in South Asians. Thus, therapies aimed at improving skeletal muscle mitochondrial function may be crucial to ameliorate the risk for the development of adverse metabolic conditions in the South Asian population. 


\section{REFERENCES}

1. Agyemang C, Addo J, Bhopal R, Aikins Ade G, Stronks K: Cardiovascular disease, diabetes and established risk factors among populations of sub-Saharan African descent in Europe: a literature review. Globalization and health 2009;5:7

2. Admiraal WM, Holleman F, Snijder MB, Peters RJ, Brewster LM, Hoekstra JB, Stronks K, van Valkengoed IG: Ethnic disparities in the association of impaired fasting glucose with the 10year cumulative incidence of type 2 diabetes. Diabetes research and clinical practice 2014;103:127-132

3. Meeks KA, Freitas-Da-Silva D, Adeyemo A, Beune EJ, Modesti PA, Stronks K, Zafarmand $\mathrm{MH}$, Agyemang $\mathrm{C}$ : Disparities in type 2 diabetes prevalence among ethnic minority groups resident in Europe: a systematic review and meta-analysis. Internal and emergency medicine 2015;11:327-340

4. Kanaya AM, Herrington D, Vittinghoff E, Ewing SK, Liu K, Blaha MJ, Dave SS, Qureshi F, Kandula NR: Understanding the high prevalence of diabetes in U.S. south Asians compared with four racial/ethnic groups: the MASALA and MESA studies. Diabetes care 2014;37:1621-1628

5. Shaw JE, Sicree RA, Zimmet PZ: Global estimates of the prevalence of diabetes for 2010 and 2030. Diabetes research and clinical practice 2010;87:4-14

6. Fernando E, Razak F, Lear SA, Anand SS: Cardiovascular Disease in South Asian Migrants. The Canadian journal of cardiology 2015;31:1139-1150

7. Jones DA, Gallagher S, Rathod KS, Redwood S, de Belder MA, Mathur A, Timmis AD, Ludman PF, Townend JN, Wragg A, Nicor: Mortality in South Asians and Caucasians after percutaneous coronary intervention in the United Kingdom: an observational cohort study of 279,256 patients from the BCIS (British Cardiovascular Intervention Society) National Database. JACC Cardiovascular interventions 2014;7:362-371

8. Hadjinikolaou L, Klimatsidas M, Maria lacona G, Spyt T, Samani NJ: Short- and mediumterm survival following coronary artery bypass surgery in British Indo-Asian and white Caucasian individuals: impact of diabetes mellitus. Interactive cardiovascular and thoracic surgery 2010;10:389-393

9. Bakker LE, Sleddering MA, Schoones JW, Meinders AE, Jazet IM: Pathogenesis of type 2 diabetes in South Asians. European journal of endocrinology / European Federation of Endocrine Societies 2013;169:R99-R114

10. Bakker LE, Boon MR, van der Linden RA, Arias-Bouda LP, van Klinken JB, Smit F, Verberne HJ, Jukema JW, Tamsma JT, Havekes LM, van Marken Lichtenbelt WD, Jazet IM, Rensen PC: Brown adipose tissue volume in healthy lean south Asian adults compared with white Caucasians: a prospective, case-controlled observational study. The lancet Diabetes \& endocrinology 2014;2:210-217

11. McKeigue PM, Shah B, Marmot MG: Relation of central obesity and insulin resistance with high diabetes prevalence and cardiovascular risk in South Asians. Lancet 1991;337:382-386

12. Hall LM, Moran CN, Milne GR, Wilson J, MacFarlane NG, Forouhi NG, Hariharan N, Salt IP, Sattar N, Gill JM: Fat oxidation, fitness and skeletal muscle expression of oxidative/lipid 
metabolism genes in South Asians: implications for insulin resistance? PloS one 2010;5:e14197

13. Schrauwen-Hinderling VB, Kooi ME, Hesselink MK, Jeneson JA, Backes WH, van Echteld CJ, van Engelshoven JM, Mensink $M$, Schrauwen $P$ : Impaired in vivo mitochondrial function but similar intramyocellular lipid content in patients with type 2 diabetes mellitus and BMImatched control subjects. Diabetologia 2007;50:113-120

14. van Marken Lichtenbelt WD, Vanhommerig JW, Smulders NM, Drossaerts JM, Kemerink GJ, Bouvy ND, Schrauwen P, Teule GJ: Cold-activated brown adipose tissue in healthy men. The New England journal of medicine 2009;360:1500-1508

15. Ouellet V, Routhier-Labadie A, Bellemare W, Lakhal-Chaieb L, Turcotte E, Carpentier AC, Richard D: Outdoor temperature, age, sex, body mass index, and diabetic status determine the prevalence, mass, and glucose-uptake activity of 18F-FDG-detected BAT in humans. The Journal of clinical endocrinology and metabolism 2011;96:192-199

16. van der Lans AA, Hoeks J, Brans B, Vijgen GH, Visser MG, Vosselman MJ, Hansen J, Jorgensen JA, Wu J, Mottaghy FM, Schrauwen P, van Marken Lichtenbelt WD: Cold acclimation recruits human brown fat and increases nonshivering thermogenesis. The Journal of clinical investigation 2013;123:3395-3403

17. Blondin DP, Labbe SM, Tingelstad HC, Noll C, Kunach M, Phoenix S, Guerin B, Turcotte EE, Carpentier AC, Richard D, Haman F: Increased brown adipose tissue oxidative capacity in cold-acclimated humans. The Journal of clinical endocrinology and metabolism 2014;99:E438-446

18. Yoneshiro T, Aita S, Matsushita M, Kayahara T, Kameya T, Kawai Y, Iwanaga T, Saito M: Recruited brown adipose tissue as an antiobesity agent in humans. The Journal of clinical investigation 2013;123:3404-3408

19. Vijgen GH, Bouvy ND, Teule GJ, Brans B, Hoeks J, Schrauwen P, van Marken Lichtenbelt WD: Increase in brown adipose tissue activity after weight loss in morbidly obese subjects. The Journal of clinical endocrinology and metabolism 2012;97:E1229-1233

20. Nisoli E, Falcone S, Tonello C, Cozzi V, Palomba L, Fiorani M, Pisconti A, Brunelli S, Cardile A, Francolini M, Cantoni O, Carruba MO, Moncada S, Clementi E: Mitochondrial biogenesis by NO yields functionally active mitochondria in mammals. Proceedings of the National Academy of Sciences of the United States of America 2004;101:16507-16512

21. Nisoli E, Clementi E, Paolucci C, Cozzi V, Tonello C, Sciorati C, Bracale R, Valerio A, Francolini M, Moncada S, Carruba MO: Mitochondrial biogenesis in mammals: the role of endogenous nitric oxide. Science 2003;299:896-899

22. Lucotti P, Setola E, Monti LD, Galluccio E, Costa S, Sandoli EP, Fermo I, Rabaiotti G, Gatti R, Piatti $P$ : Beneficial effects of a long-term oral L-arginine treatment added to a hypocaloric diet and exercise training program in obese, insulin-resistant type 2 diabetic patients. American journal of physiology Endocrinology and metabolism 2006;291:E906-912

23. McKnight JR, Satterfield MC, Jobgen WS, Smith SB, Spencer TE, Meininger CJ, McNeal CJ, Wu G: Beneficial effects of L-arginine on reducing obesity: potential mechanisms and important implications for human health. Amino acids 2010;39:349-357 
24. Petrovic V, Korac A, Buzadzic B, Vasilijevic A, Jankovic A, Micunovic K, Korac B: Nitric oxide regulates mitochondrial re-modelling in interscapular brown adipose tissue: ultrastructural and morphometric-stereologic studies. Journal of microscopy 2008;232:542-548

25. Wu Z, Satterfield MC, Bazer FW, Wu G: Regulation of brown adipose tissue development and white fat reduction by L-arginine. Current opinion in clinical nutrition and metabolic care 2012;15:529-538

26. Wu G, Collins JK, Perkins-Veazie P, Siddiq M, Dolan KD, Kelly KA, Heaps CL, Meininger CJ: Dietary supplementation with watermelon pomace juice enhances arginine availability and ameliorates the metabolic syndrome in Zucker diabetic fatty rats. The Journal of nutrition 2007; 137:2680-2685

27. Jobgen W, Meininger CJ, Jobgen SC, Li P, Lee MJ, Smith SB, Spencer TE, Fried SK, Wu G: Dietary L-arginine supplementation reduces white fat gain and enhances skeletal muscle and brown fat masses in diet-induced obese rats. The Journal of nutrition 2009;139:230237

28. Cubbon RM, Murgatroyd SR, Ferguson C, Bowen TS, Rakobowchuk M, Baliga V, Cannon D, Rajwani A, Abbas A, Kahn M, Birch KM, Porter KE, Wheatcroft SB, Rossiter HB, Kearney MT: Human exercise-induced circulating progenitor cell mobilization is nitric oxide-dependent and is blunted in South Asian men. Arteriosclerosis, thrombosis, and vascular biology 2010;30:878-884

29. American Diabetes A: Standards of medical care in diabetes--2014. Diabetes care 2014;37 Suppl 1:S14-80

30. Hanssen MJ, Wierts R, Hoeks J, Gemmink A, Brans B, Mottaghy FM, Schrauwen P, van Marken Lichtenbelt WD: Glucose uptake in human brown adipose tissue is impaired upon fasting-induced insulin resistance. Diabetologia 2015;58:586-595

31. Vosselman MJ, Brans B, van der Lans AA, Wierts R, van Baak MA, Mottaghy FM, Schrauwen $P$, van Marken Lichtenbelt WD: Brown adipose tissue activity after a high-calorie meal in humans. The American journal of clinical nutrition 2013;98:57-64

32. Phielix E, Schrauwen-Hinderling VB, Mensink M, Lenaers E, Meex R, Hoeks J, Kooi ME, Moonen-Kornips E, Sels JP, Hesselink MK, Schrauwen P: Lower intrinsic ADP-stimulated mitochondrial respiration underlies in vivo mitochondrial dysfunction in muscle of male type 2 diabetic patients. Diabetes 2008;57:2943-2949

33. Hoeks J, van Herpen NA, Mensink M, Moonen-Kornips E, van Beurden D, Hesselink MK, Schrauwen P: Prolonged fasting identifies skeletal muscle mitochondrial dysfunction as consequence rather than cause of human insulin resistance. Diabetes 2010;59:2117-2125

34. Admiraal WM, Verberne HJ, Karamat FA, Soeters MR, Hoekstra JB, Holleman F: Coldinduced activity of brown adipose tissue in young lean men of South-Asian and European origin. Diabetologia 2013;56:2231-2237

35. van der Lans AA, Wierts R, Vosselman MJ, Schrauwen P, Brans B, van Marken Lichtenbelt WD: Cold-activated brown adipose tissue in human adults: methodological issues. American journal of physiology Regulatory, integrative and comparative physiology 2014;307:R103-113 
36. Ouellet V, Labbe SM, Blondin DP, Phoenix S, Guerin B, Haman F, Turcotte EE, Richard D, Carpentier AC: Brown adipose tissue oxidative metabolism contributes to energy expenditure during acute cold exposure in humans. The Journal of clinical investigation 2012;122:545-552

37. Stanford KI, Middelbeek RJ, Townsend KL, An D, Nygaard EB, Hitchcox KM, Markan KR, Nakano K, Hirshman MF, Tseng YH, Goodyear LJ: Brown adipose tissue regulates glucose homeostasis and insulin sensitivity. The Journal of clinical investigation 2013;123:215-223

38. Bartelt A, Bruns OT, Reimer R, Hohenberg H, Ittrich H, Peldschus K, Kaul MG, Tromsdorf UI, Weller H, Waurisch C, Eychmuller A, Gordts PL, Rinninger F, Bruegelmann K, Freund B, Nielsen $\mathrm{P}$, Merkel $\mathrm{M}$, Heeren J: Brown adipose tissue activity controls triglyceride clearance. Nature medicine 2011;17:200-205

39. Toledo FG: Mitochondrial involvement in skeletal muscle insulin resistance. Diabetes 2014;63:59-61

40. Delany JP, Dube JJ, Standley RA, Distefano G, Goodpaster BH, Stefanovic-Racic M, Coen PM, Toledo FG: Racial differences in peripheral insulin sensitivity and mitochondrial capacity in the absence of obesity. The Journal of clinical endocrinology and metabolism 2014;99:4307-4314

41. Galgani JE, Moro C, Ravussin E: Metabolic flexibility and insulin resistance. American journal of physiology Endocrinology and metabolism 2008;295:E1009-1017

42. Fernstrom M, Tonkonogi M, Sahlin K: Effects of acute and chronic endurance exercise on mitochondrial uncoupling in human skeletal muscle. The Journal of physiology 2004;554:755-763

43. Timmers S, Konings E, Bilet L, Houtkooper RH, van de Weijer T, Goossens GH, Hoeks J, van der Krieken S, Ryu D, Kersten S, Moonen-Kornips E, Hesselink MK, Kunz I, SchrauwenHinderling VB, Blaak EE, Auwerx J, Schrauwen P: Calorie restriction-like effects of 30 days of resveratrol supplementation on energy metabolism and metabolic profile in obese humans. Cell metabolism 2011;14:612-622 


\section{CHAPTER 7}

\section{General discussion}




\section{Introduction}

BAT has recently emerged as a potential target tissue for the prevention and treatment of obesity and type 2 diabetes. Due to the presence of large amounts of mitochondria containing UCP1, which uncouples respiratory chain activity from ATP synthesis, BAT has the capacity to dissipate energy from substrate oxidation as heat. When subjects are exposed to cold, BAT thermogenesis is activated in order to maintain a constant core temperature. Once activated, BAT utilizes large amounts of glucose and free fatty acids for its metabolic heat production, thereby actively clearing these substrates from the circulation. As such, BAT activation is potentially able to impact whole body substrate metabolism. If BAT's capacity to take up and oxidize glucose can be chronically exploited, this may ameliorate hyperglycemia and may thus be beneficial for type 2 diabetes patients. In this thesis, we explored the role of BAT in the pathophysiology and treatment of insulin resistance and type 2 diabetes. In particular, we investigated whether insulin resistance is associated with impaired BAT glucose uptake. In addition, the effects of cold acclimation on BAT activity were assessed in obese subjects and in patients with type 2 diabetes. In the latter group, the effects of cold acclimation on insulin sensitivity and skeletal muscle glucose metabolism were also explored. Moreover, alternative means to activate and recruit BAT were investigated. In this final chapter, the main findings of this thesis will be discussed and interpreted. In addition, the possible clinical application of regular cold exposure via its effects on BAT and other tissues will be addressed.

\section{Cold to activate and recruit BAT}

Cold is the primary physiological stimulus for BAT activation. From rodent studies, it has long been known that prolonged exposure to cold results in BAT hypertrophy and enhanced thermogenic capacity $(1 ; 2)$. This has been associated with leanness, improvements in whole body glucose and lipid homeostasis, and increased insulin sensitivity (3-5). Recently, several human studies have indicated that BAT can also be effectively recruited in lean, young humans by means of prolonged intermittent cold exposure (6-8). Since recruitment of BAT would be of particular interest in obese individuals, who are characterized by reduced BAT volume and activity (912), we assessed whether cold acclimation would result in BAT recruitment in these subjects as well. Indeed, in chapter $\mathbf{4}$ we show that cold-induced BAT activity 
is significantly enhanced in obese subjects upon cold acclimation. In addition, patients with type 2 diabetes would likely benefic from BAT recruitment, due to its possible effects on glucose homeostasis. Thus, in chapter $\mathbf{3}$ we show that also in patients with type 2 diabetes cold-induced activity of the supraclavicular BAT region is enhanced upon cold acclimation, although even after cold acclimation this activity was relatively low when compared to BAT activity levels that have been reported for young, healthy subjects $(6 ; 13)$.

Non-shivering thermogenesis. Given the role of BAT in metabolic heat production upon cold exposure, it is to be expected that an increase in BAT would be accompanied by increased cold-induced thermogenesis. In our studies we specifically studied non-shivering thermogenesis (NST), i.e. cold-induced thermogenesis in the absence of shivering; a process that, at least in rodents, is almost fully dependent on BAT (14). In chapter $\mathbf{2}$, we confirm our previous finding of a positive relationship between cold-induced BAT activity and NST in young, healthy subjects (6), indicating a role for BAT in this process in humans. In addition, in subjects with similar characteristics it has been reported that BAT recruitment by means of prolonged intermittent cold exposure is accompanied by increased NST $(6 ; 7)$. In chapter 3 , we show that also in type 2 diabetes patients, NST is enhanced upon cold acclimation, although we did not find this in the obese subjects studied in chapter 4. Correlation analyses in human studies that describe relations between BAT and NST, suggest that BAT is not the sole tissue responsible for this process: in a combined analysis of several studies performed by our lab in which we measured both cold-induced NST and BAT activity in young, lean subjects (6; 13; 15-17), including those described in chapter $\mathbf{3}$, we found that \%NST and BAT SUVmax were related with a correlation coefficient of $r^{2}=0.29$. This indicates that only $29 \%$ of the variance in NST can explained by BAT activity, thus leaving another $71 \%$ that must be accounted for by other tissues. It should be noted that BAT activity is determined by measuring glucose uptake, while NST is measured by actual oxygen consumption and $\mathrm{CO}_{2}$ production, being better estimates of thermogenesis. This therefore may explain part of the discrepancy. However, another study estimated, based on measurements of the metabolic rate of oxygen in BAT with ${ }^{15} \mathrm{O}$ PET imaging as a measure of its oxidative metabolism, that energy consumption of active BAT thermogenesis appears to be on average $25 \mathrm{kcal} / \mathrm{day}$ (i.e. $0.073 \mathrm{~kJ} / \mathrm{min}$ ) (18). This represents only about $12 \%$ of total whole-body NST that we measured by indirect calorimetry in young, healthy subjects, which 
equaled on average $0.6 \pm 0.5 \mathrm{~kJ} / \mathrm{min}$ (chapter 2). Although the study setup used for these estimations may have led to an underestimation of maximal BAT activity (e.g. a relatively short cold exposure period was used before the start of ${ }^{15} \mathrm{O}$ PET imaging (18)), these results also indicate that other tissues may play a significant role in NST as well, and this warrants further investigation.

Body fat. If BAT activity and NST are increased upon repeated intermittent cold exposure in subjects that are normally in energy balance, this could eventually lead to reduced body weight/fat mass. After all, if energy intake is not altered, and energy expenditure during cold exposures increases, a negative energy balance is created and hence weight is lost. Indeed, several rodent studies have indicated that prolonged stimulation of energy expenditure by cold exposure is able to prevent or reverse diet-induced obesity $(3 ; 4)$. Yoneshiro et al. recently showed promising results in humans in this respect as well (7). Upon daily 2-hour coldexposure for 6 weeks in young, lean subjects, they observed a parallel increase in BAT activity and cold-induced thermogenesis and a concomitant decrease in body fat mass. Furthermore, changes in BAT activity and body fat mass were negatively correlated, suggesting an anti-obesity effect of intermittent cold exposure that is (partly) caused by BAT. The cold acclimation period that we used in our studies (10 consecutive days) is likely too short to induce such changes in body composition. Although we did not assess body composition after cold acclimation in the studies described in chapters $\mathbf{3}$ and $\mathbf{4}$, body weight was unchanged upon 10 days of cold acclimation. In addition, a previous study by our lab did not observe any changes in either body weight or body fat content (assessed by DEXA scan) upon 10 days of cold acclimation in young, lean subjects (6). In theory, based on the NST capacity that we measured in the obese subjects in chapter $4(\sim 0.55 \mathrm{~kJ} / \mathrm{min})$, these individuals expended an extra $\sim 1.8 \mathrm{MJ}$ during their time spend in the cold (54 hours in total during the 10 cold acclimation days). This equals $\sim 48$ grams of fat loss, which is likely too little to be detected by DEXA scanning. However, upon longterm cold acclimation this may lead to significant body fat and weight loss, assuming that energy intake remains unchanged. In future studies, it would therefore be interesting to determine whether longer cold acclimation periods can confirm changes in body composition and whether these changes persist when the cold exposures are ceased or reduced. 


\section{The role of BAT in whole-body glucose homeostasis and insulin sensitivity}

When BAT is thermogenically activated upon cold exposure, large amounts of glucose and fatty acids are oxidized, leading to metabolic heat production. These substrates are thereby taken up from the circulation. As such, in addition to a role in energy expenditure, BAT has the capacity to significantly impact whole-body glucose and lipid metabolism, at least in rodents (4). Especially BAT's glucose uptake capacity is of particular interest in case of hyperglycemia/type 2 diabetes. It is not completely clear whether BAT thermogenic dysfunction (e.g. in UCP1 knock out mice) is directly involved in the pathophysiology of type 2 diabetes. However, it has repeatedly been shown that BAT recruitment or browning of WAT through genetic manipulation, drugs or transplantation is able to improve glucose tolerance and enhance whole-body insulin resistance in animal models (4; $5 ; 19)$.

Next to cold- and NE-stimulation, glucose uptake in BAT can also be stimulated by insulin. In fact, BAT is one of the tissues most sensitive to the effects of insulin, both in mice (20) and in humans (21). Thus, insulin-stimulation represents another avenue by which BAT can impact whole-body glucose metabolism. Evidence for a role of impaired insulin-stimulated glucose uptake in BAT in the pathophysiology of hyperglycemia comes from BAT-specific insulin receptor knockout mice (22). These mice develop age-dependent hyperglycemia and impaired glucose tolerance compared with controls due to dysfunctional insulin signaling specifically in BAT (22). In addition, obese diabetic rodents that develop insulin resistance (both on whole body-level and in BAT (23)) show marked impairments in not only insulinstimulated glucose uptake but also cold-induced glucose uptake in BAT, indicating a coupling of these processes $(24 ; 25)$. To investigate the role of insulin resistance in BAT activity in humans we studied the induction of insulin resistance in otherwise healthy young subjects, by means of prolonged (54h) fasting (chapter $\mathbf{2}$ ). Interestingly, we found a $\sim 55 \%$ decrease in cold-induced glucose uptake rate in BAT upon prolonged fasting-induced insulin resistance. This was paralleled by a decreased NST response. This thus indicates that also in humans, insulin resistance is associated with reduced glucose uptake into BAT, which subsequently results in decreased NST. Other studies have shown positive correlations between cold- and insulin-stimulated glucose uptake in BAT, in addition to lower insulin-stimulated glucose uptake in obese compared to (more insulin sensitive) lean individuals (26). Moreover, insulin-stimulated glucose uptake in BAT was positively related to $\mathrm{M}$ values, a measure of whole-body insulin sensitivity derived from hyperinsulinemic 
euglycemic clamps (26). Based on these observations, it might be expected that in patients with type 2 diabetes, characterized by whole-body insulin resistance, insulin- and cold-stimulated glucose uptake in BAT is impaired.

Therefore, in chapter 3, we investigated cold-induced glucose uptake into BAT in eight type 2 diabetes patients. We show that cold-stimulated glucose uptake in the supraclavicular BAT region is indeed very low in these patients when compared with previously published values for young, healthy subjects $(6 ; 13)$. Because our type 2 diabetic patients were all overweight (BMI $29.8 \pm 3.2 \mathrm{~kg} / \mathrm{m}^{2}$ ) and of relatively high age $(59.3 \pm 5.8$ years), factors that are negatively related to BAT activity $(9 ; 11)$, it is not possible to determine a possible independent effect of insulin resistance/diabetic status on BAT in these patients (27). Another recent study by Blondin et al. confirmed low cold-induced glucose uptake in BAT of obese subjects and type 2 diabetes patients of similar age as ours compared to young, lean subjects (28). However, BAT glucose uptake was not different between obese and type 2 diabetes subjects in that study, arguing against the notion that insulin resistance/diabetic status independently predicts BAT glucose uptake.

Regardless of the fact whether BAT is reduced in diabetic patients, it has also been examined whether increasing BAT would result in improved insulin sensitivity and glucose metabolism. As such, additional evidence for a role of BAT in whole-body glucose disposal and insulin sensitivity in humans was recently presented by Chondronikola et al. (29). Using hyperinsulinemic euglycemic clamps, they showed that prolonged (5-8h) cold exposure significantly increased whole-body glucose disposal and insulin sensitivity in BAT positive subjects, whereas this was not observed in BAT negative subjects, indicating that BAT may indeed play a role in the etiology of diabetes. Thus, in addition to the well-known role of skeletal muscle in insulin-stimulated glucose disposal, BAT seems to be involved as well. Whether recruitment of BAT by cold acclimation would subsequently lead to improvements in whole body-insulin sensitivity in humans was for the first time explored by Lee et al. (30), who studied young, lean subjects that were overnight exposed to $24^{\circ} \mathrm{C}$ for one month and to $19{ }^{\circ} \mathrm{C}$ the next month. After the second month, BAT activity was enhanced and this was indeed accompanied by improved postprandial insulin sensitivity upon ingestion of a mixed meal (30). Such effects of BAT recruitment would be especially beneficial in patients with type 2 diabetes, who are characterized by hyperglycemia and insulin resistance. Because we previously showed a positive effect of cold acclimation on BAT activity in healthy, lean subjects, we next studied the effects of cold acclimation on both BAT, and on 
whole-body insulin sensitivity in type 2 diabetes patients. Insulin sensitivity was assessed by the golden standard hyperinsulinemic-euglycemic clamp. In line with previous findings, we observed a small increase in activity of the supraclavicular BAT region in all type 2 diabetes patients upon 10 days of cold acclimation. However, even after cold acclimation activity of the supraclavicular BAT region was relatively low and did not even reach the commonly used threshold to define BAT (SUV > 1.5) in most subjects. Interestingly, we also observed a very marked increase of $\sim 43 \%$ in insulin sensitivity upon 10 days of cold acclimation in these subjects. However, the small amount of BAT recruitment is likely not enough to exert such large effects on whole-body insulin sensitivity and glucose disposal. Calculations based dynamic $\left[{ }^{18} \mathrm{~F}\right]$ FDG-PET data support this idea: Orava et al. showed that insulin-stimulated glucose uptake in BAT equaled $\sim 3 \mu \mathrm{mol} / \mathrm{min} / 100 \mathrm{~g}$ in obese subjects (26). For a BAT mass of 100 grams, which would seem an overestimation for the type 2 diabetes patients that we studied, total insulinstimulated glucose uptake by BAT would thus be $\sim 3 \mu \mathrm{mol} / \mathrm{min}$. Since whole-body insulin-stimulated glucose disposal in the type 2 diabetes patients equaled about $1950 \mu \mathrm{mol} / \mathrm{min}$ after cold acclimation, this would mean that $\sim 0.2 \%$ of glucose is taken up by BAT during insulin stimulation.

Thus, despite several reported associations between BAT- and whole-body insulinstimulated glucose uptake in humans, it seems that BAT only plays a minor role in whole-body glucose metabolism. In future human studies on the effects of prolonged cold exposure on insulin sensitivity, it is therefore highly important to not only focus on BAT, but also on other tissues. Skeletal muscle is the primary target in this respect, given its major role in glucose disposal during insulinstimulated conditions (31).

\section{Skeletal muscle seems to be the main tissue responsible for cold-induced improvements in insulin sensitivity}

The effects of cold acclimation on skeletal muscle metabolism have only been marginally studied. Therefore, its exact role in cold-induced improvements in glucose metabolism and insulin sensitivity remains largely unknown.

In 1984, Budohoski et al. reported that rats that were cold exposed for several days displayed increased insulin sensitivity in soleus muscle (32). Several years later, it was described that basal glucose uptake was enhanced in some muscle groups of rats that were cold-acclimated compared to warm-acclimated rats (33). In addition, 
it was shown that acute cold exposure of previously warm-acclimated rats markedly increased glucose uptake and insulin sensitivity in skeletal muscle (20), and that this increase was still present in these rats after several weeks of cold acclimation (5). Importantly, this long-term enhanced glucose uptake in skeletal muscle occurred in the absence of shivering (suggesting the occurrence of nonshivering thermogenesis), and was associated with improvements in whole-body glucose tolerance and insulin sensitivity upon cold acclimation (5). Whether such effects of prolonged cold exposure on skeletal muscle non-shivering thermogenesis and glucose uptake could be achieved in humans as well remained completely unknown. Our observation of increased insulin-stimulated glucose disposal upon cold acclimation (chapter $\mathbf{3}$ ) therefore represents the first clear indication that skeletal muscle insulin sensitivity and glucose uptake is indeed enhanced by cold. Importantly, these improvements were noticeable during thermoneutrality. In skeletal muscle biopsies, taken after an overnight fast, we show that these metabolic effects are likely caused by enhanced basal GLUT4 translocation to the cell membrane; an effect that had been previously observed in cold-acclimated rats as well (34). The mechanisms responsible for GLUT4 translocation upon cold stimulation remain to be elucidated. It is well documented that GLUT4 translocation can take place upon either activation of the insulin-signaling cascade by insulin (such as after a meal) or by activation of AMPK by exercise. We investigated several key proteins involved in these pathways, but did not observe any changes herein (Figure 1). Recently, a third pathway has been identified that can induce GLUT4 translocation, namely via sympathetic stimulation of $\beta_{2^{-}}$ adrenergic receptors on the muscle cell membrane and subsequent signaling via mTORC2 (Figure 1) (35). Since repeated cold exposure represents repeated stimulation of the sympathetic nervous system, as evidenced by elevated norepinephrine levels (chapters 2 and 4), it would be highly interesting to further explore the role of this alternative pathway in cold-acclimated humans. Alternatively, it has been postulated that brown adipocytes may secrete endocrine factors, such as Nrg4 (36) and FGF21 (37), that can affect other metabolic tissues. It would therefore be highly interesting to explore whether such factors may affect pathways that lead to GLUT4 translocation and enhanced skeletal muscle glucose uptake capacity. 


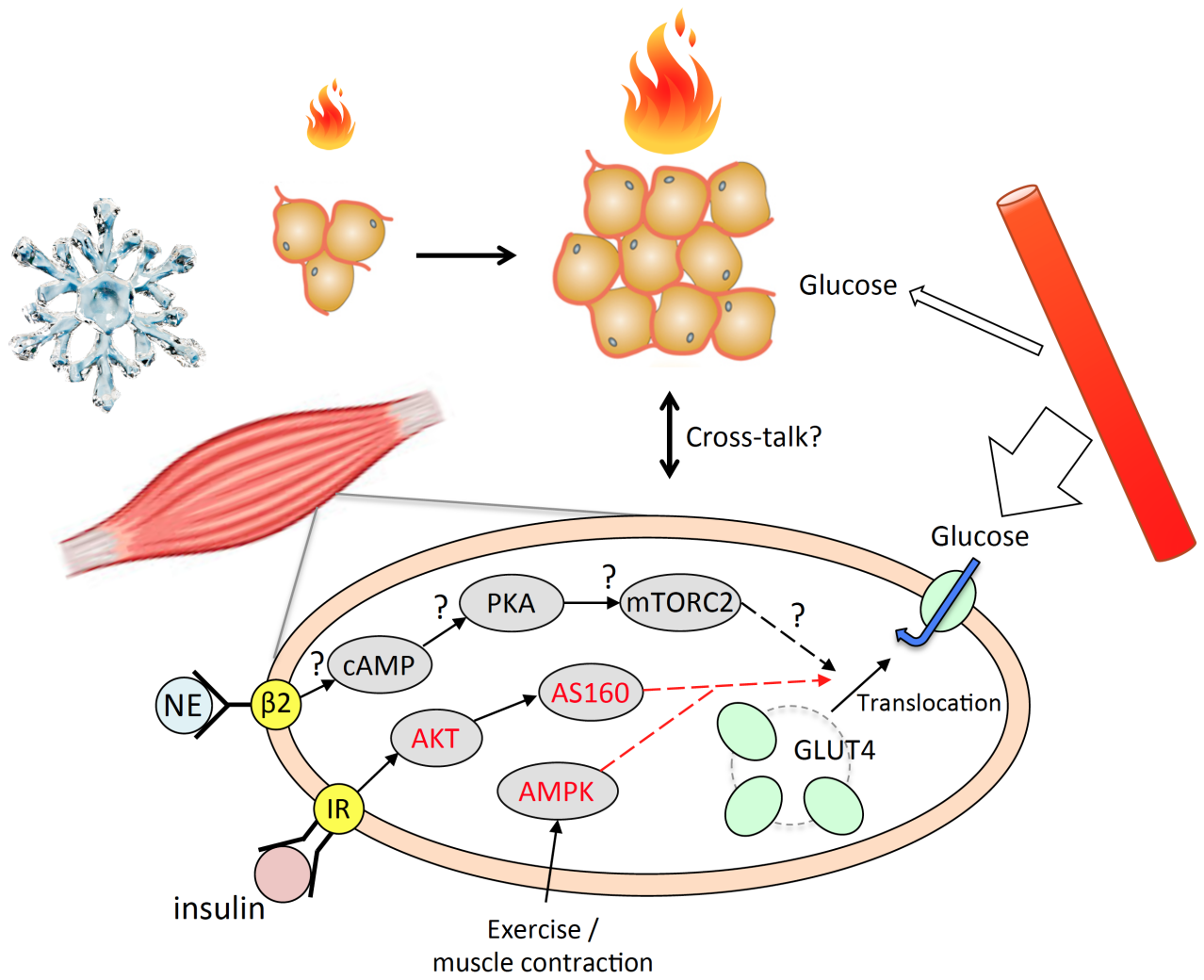

Figure 1. Effects of cold acclimation on glucose uptake into BAT and skeletal muscle. Top: Cold acclimation enhances BAT volume and activity, thereby increasing its thermogenic capacity. Upon metabolic heat production, glucose is actively taken up by BAT from the circulation. Bottom: Cold acclimation induces GLUT4 translocation in skeletal muscle cells, thereby increasing skeletal muscle glucose uptake capacity. Insulin can stimulate GLUT4 translocation via the insulin signaling pathway that involves phosphorylation and activation of AKT and AS160. Exercise stimulates GLUT4 translocation via phosphorylation and activation of AMPK. Cold may be a third mechanism leading to GLUT4 translocation: Sympathetic stimulation of the $\beta_{2}$-adrenergic receptors may be involved in coldinduced GLUT4 translocation, via production of CAMP and subsequent phosphorylation and activation of PKA and mTORC2. In addition, endocrine factor released by BAT may affect skeletal muscle, or vice versa. NE, norepinephrine; IR, insulin receptor; CAMP, cyclic AMP; protein Kinase $A$; $m T O R C 2$, mammalian target of rapamycin complex 2; AMPK, AMP-activated protein kinase. Indications in red: not activated upon cold acclimation. 


\section{Concluding remarks and future perspectives}

The recent appreciation of considerable amounts of metabolically active BAT in adult humans has revived the interest in this tissue as a potential target for the prevention and treatment of obesity and type 2 diabetes. While rodent studies have consistently shown that BAT recruitment by cold acclimation or other means is positively associated with metabolic health, evidence for a role of BAT in human metabolic disturbances is still scarce. In this thesis we explored the role of human BAT in the pathophysiology and treatment of type 2 diabetes. By using a model of fasting-induced insulin resistance, we show that cold-stimulated glucose uptake into BAT is strongly decreased under such conditions. In addition, we show that BAT can be recruited upon cold acclimation in both obese subjects and in patients with type 2 diabetes. However, the metabolic adaptations with the greatest systemic impact occurred in skeletal muscle, where we observed enhanced GLUT4 translocation (i.e. increased glucose uptake capacity), which translated into enhanced insulin-stimulated glucose disposal during hyperinsulinemic euglycemic clamps. Thus, while BAT can be regarded as a team player in improved glucose metabolism upon cold acclimation, skeletal muscle seems to be the key player in this respect. It is therefore unfortunate that this tissue has been often overlooked in both mice and human studies that focus on the effects of cold acclimation on insulin sensitivity. Unraveling the exact mechanisms that induce these metabolic adaptations in skeletal muscle would be highly interesting for future studies and highly relevant for alternative therapies to treat type 2 diabetes.

To determine the efficacy of BAT-focused therapies to treat metabolic disease, it would be interesting to investigate whether (pharmacological or dietary) interventions that specifically target BAT, are capable of impacting whole-body energy expenditure and substrate metabolism in humans. To this end, it is also important to more precisely quantify the contribution of BAT to whole-body (nonshivering) thermogenesis. Next to direct effects of enhanced BAT on thermogenesis, cross-talk between BAT and other tissues via endocrine factors secreted by brown adipocytes is an interesting field of research as well.

Taken together, this thesis provides important insight into the roles of BAT and skeletal muscle in whole-body glucose metabolism upon cold exposure. This knowledge opens up a new therapeutic window for the treatment of type 2 diabetes and associated metabolic conditions. 


\section{References}

1. Page E, Babineau LM: The effects of high fat diets and cold environment on the ascorbic acid content of the brown adipose tissue. Canadian journal of research Section E, Medical sciences 1950;28:196-201

2. Smith RE: Thermoregulatory and Adaptive Behavior of Brown Adipose Tissue. Science 1964;146:1686-1689

3. Vallerand AL, Lupien J, Bukowiecki LJ: Cold exposure reverses the diabetogenic effects of high-fat feeding. Diabetes 1986;35:329-334

4. Bartelt A, Bruns OT, Reimer R, Hohenberg H, Ittrich H, Peldschus K, Kaul MG, Tromsdorf UI, Weller H, Waurisch C, Eychmuller A, Gordts PL, Rinninger F, Bruegelmann K, Freund B, Nielsen $P$, Merkel $M$, Heeren J: Brown adipose tissue activity controls triglyceride clearance. Nature medicine 2011;17:200-205

5. Vallerand AL, Perusse F, Bukowiecki LJ: Stimulatory effects of cold exposure and cold acclimation on glucose uptake in rat peripheral tissues. The American journal of physiology 1990;259:R1043-1049

6. van der Lans AA, Hoeks J, Brans B, Vijgen GH, Visser MG, Vosselman MJ, Hansen J, Jorgensen JA, Wu J, Mottaghy FM, Schrauwen P, van Marken Lichtenbelt WD: Cold acclimation recruits human brown fat and increases nonshivering thermogenesis. The Journal of clinical investigation 2013;123:3395-3403

7. Yoneshiro T, Aita S, Matsushita M, Kayahara T, Kameya T, Kawai Y, Iwanaga T, Saito M: Recruited brown adipose tissue as an antiobesity agent in humans. The Journal of clinical investigation 2013;123:3404-3408

8. Blondin DP, Labbe SM, Tingelstad HC, Noll C, Kunach M, Phoenix S, Guerin B, Turcotte EE, Carpentier AC, Richard D, Haman F: Increased brown adipose tissue oxidative capacity in cold-acclimated humans. The Journal of clinical endocrinology and metabolism 2014;99:E438-446

9. van Marken Lichtenbelt WD, Vanhommerig JW, Smulders NM, Drossaerts JM, Kemerink GJ, Bouvy ND, Schrauwen P, Teule GJ: Cold-activated brown adipose tissue in healthy men. The New England journal of medicine 2009;360:1500-1508

10. Matsushita M, Yoneshiro T, Aita S, Kameya T, Sugie H, Saito M: Impact of brown adipose tissue on body fatness and glucose metabolism in healthy humans. International journal of obesity 2014;38:812-817

11. Yoneshiro $T$, Aita $S$, Matsushita $M$, Okamatsu-Ogura $Y$, Kameya $T$, Kawai $Y$, Miyagawa $M$, Tsujisaki M, Saito M: Age-related decrease in cold-activated brown adipose tissue and accumulation of body fat in healthy humans. Obesity 2011;19:1755-1760

12. Saito M, Okamatsu-Ogura $Y$, Matsushita M, Watanabe K, Yoneshiro T, Nio-Kobayashi J, Iwanaga T, Miyagawa M, Kameya T, Nakada K, Kawai Y, Tsujisaki M: High incidence of metabolically active brown adipose tissue in healthy adult humans: effects of cold exposure and adiposity. Diabetes 2009;58:1526-1531 
13. Vosselman MJ, van der Lans AA, Brans B, Wierts R, van Baak MA, Schrauwen $P$, van Marken Lichtenbelt WD: Systemic beta-adrenergic stimulation of thermogenesis is not accompanied by brown adipose tissue activity in humans. Diabetes 2012;61:3106-3113

14. Cannon B, Nedergaard J: Brown adipose tissue: function and physiological significance. Physiol Rev 2004;84:277-359

15. Vosselman MJ, Brans B, van der Lans AA, Wierts R, van Baak MA, Mottaghy FM, Schrauwen $P$, van Marken Lichtenbelt WD: Brown adipose tissue activity after a high-calorie meal in humans. The American journal of clinical nutrition 2013;98:57-64

16. Vosselman MJ, Hoeks J, Brans B, Pallubinsky H, Nascimento EB, van der Lans AA, Broeders EP, Mottaghy FM, Schrauwen $P$, van Marken Lichtenbelt WD: Low brown adipose tissue activity in endurance-trained compared with lean sedentary men. International journal of obesity 2015;

17. Broeders EP, Nascimento EB, Havekes B, Brans B, Roumans KH, Tailleux A, Schaart G, Kouach M, Charton J, Deprez B, Bouvy ND, Mottaghy F, Staels B, van Marken Lichtenbelt WD, Schrauwen P: The Bile Acid Chenodeoxycholic Acid Increases Human Brown Adipose Tissue Activity. Cell metabolism 2015;22:418-426

18. Muzik O, Mangner TJ, Leonard WR, Kumar A, Janisse J, Granneman JG: 150 PET measurement of blood flow and oxygen consumption in cold-activated human brown fat. Journal of nuclear medicine : official publication, Society of Nuclear Medicine 2013;54:523531

19. Stanford KI, Middelbeek RJ, Townsend KL, An D, Nygaard EB, Hitchcox KM, Markan KR, Nakano K, Hirshman MF, Tseng YH, Goodyear LJ: Brown adipose tissue regulates glucose homeostasis and insulin sensitivity. The Journal of clinical investigation 2013;123:215-223

20. Vallerand AL, Perusse F, Bukowiecki LJ: Cold exposure potentiates the effect of insulin on in vivo glucose uptake. The American journal of physiology 1987;253:E179-186

21. Orava J, Nuutila P, Lidell ME, Oikonen V, Noponen T, Viljanen T, Scheinin M, Taittonen M, Niemi T, Enerback S, Virtanen KA: Different metabolic responses of human brown adipose tissue to activation by cold and insulin. Cell metabolism 2011;14:272-279

22. Guerra C, Navarro P, Valverde AM, Arribas M, Bruning J, Kozak LP, Kahn CR, Benito M: Brown adipose tissue-specific insulin receptor knockout shows diabetic phenotype without insulin resistance. The Journal of clinical investigation 2001;108:1205-1213

23. Roberts-Toler C, O'Neill BT, Cypess AM: Diet-induced obesity causes insulin resistance in mouse brown adipose tissue. Obesity 2015;23:1765-1770

24. Mercer SW, Trayhurn P: The development of insulin resistance in brown adipose tissue may impair the acute cold-induced activation of thermogenesis in genetically obese (ob/ob) mice. Biosci Rep 1984;4:933-940

25. Marette A, Mauriege P, Despres JP, Tulp OL, Bukowiecki LJ: Norepinephrine- and insulinresistant glucose transport in brown adipocytes from diabetic SHR/N-cp rats. The American journal of physiology 1993;265:R577-583

26. Orava J, Nuutila P, Noponen T, Parkkola R, Viljanen T, Enerback S, Rissanen A, Pietilainen $\mathrm{KH}$, Virtanen KA: Blunted Metabolic Responses to Cold and Insulin Stimulation in Brown Adipose Tissue of Obese Humans. Obesity 2013; 
27. Ouellet V, Routhier-Labadie A, Bellemare W, Lakhal-Chaieb L, Turcotte E, Carpentier AC, Richard D: Outdoor temperature, age, sex, body mass index, and diabetic status determine the prevalence, mass, and glucose-uptake activity of 18F-FDG-detected BAT in humans. The Journal of clinical endocrinology and metabolism 2011;96:192-199

28. Blondin DP, Labbe SM, Noll C, Kunach M, Phoenix S, Guerin B, Turcotte EE, Haman F, Richard D, Carpentier AC: Selective Impairment of Glucose but Not Fatty Acid or Oxidative Metabolism in Brown Adipose Tissue of Subjects With Type 2 Diabetes. Diabetes 2015;64:2388-2397

29. Chondronikola M, Volpi E, Borsheim E, Porter C, Annamalai P, Enerback S, Lidell ME, Saraf MK, Labbe SM, Hurren NM, Yfanti C, Chao T, Andersen CR, Cesani F, Hawkins H, Sidossis LS: Brown adipose tissue improves whole-body glucose homeostasis and insulin sensitivity in humans. Diabetes 2014;63:4089-4099

30. Lee P, Smith S, Linderman J, Courville AB, Brychta RJ, Dieckmann W, Werner CD, Chen KY, Celi FS: Temperature-acclimated brown adipose tissue modulates insulin sensitivity in humans. Diabetes 2014;63:3686-3698

31. Defronzo RA, Tripathy D: Skeletal muscle insulin resistance is the primary defect in type 2 diabetes. Diabetes care 2009;32 Suppl 2:S157-163

32. Budohoski L, Challiss RA, Lozeman FJ, McManus B, Newsholme EA: Increased insulin sensitivity in soleus muscle from cold-exposed rats: reversal by an adenosine-receptor agonist. FEBS letters 1984;175:402-406

33. Smith SA, Young P, Cawthorne MA: Quantification in vivo of the effects of insulin on glucose utilization in individual tissues of warm- and cold-acclimated rats. The Biochemical journal 1986;237:789-795

34. Gasparetti AL, de Souza CT, Pereira-da-Silva M, Oliveira RL, Saad MJ, Carneiro EM, Velloso LA: Cold exposure induces tissue-specific modulation of the insulin-signalling pathway in Rattus norvegicus. The Journal of physiology 2003;552:149-162

35. Sato M, Dehvari N, Oberg Al, Dallner OS, Sandstrom AL, Olsen JM, Csikasz RI, Summers RJ, Hutchinson DS, Bengtsson T: Improving type 2 diabetes through a distinct adrenergic signaling pathway involving mTORC2 that mediates glucose uptake in skeletal muscle. Diabetes 2014;63:4115-4129

36. Wang GX, Zhao XY, Meng ZX, Kern M, Dietrich A, Chen Z, Cozacov Z, Zhou D, Okunade AL, Su X, Li S, Bluher M, Lin JD: The brown fat-enriched secreted factor Nrg4 preserves metabolic homeostasis through attenuation of hepatic lipogenesis. Nature medicine 2014;20:1436-1443

37. Villarroya J, Cereijo R, Villarroya F: An endocrine role for brown adipose tissue? American journal of physiology Endocrinology and metabolism 2013;305:E567-572 
Summary 
The number of people suffering from overweight and obesity has increased rapidly in recent decades. Importantly, the high obesity prevalence is the main cause for a dramatically increased incidence of type 2 diabetes. Type 2 diabetes is generally caused by reduced sensitivity to the hormone insulin (i.e. insulin resistance), and is characterized by elevated blood glucose levels. The health impact of diabetes is substantial, and it is a major risk factor for the development other comorbidities, especially cardiovascular complications. Lifestyle interventions with diet and exercise have been proven to be very successful to reduce type 2 diabetes risk, but translating these interventions to the general public remains very challenging. Therefore, other strategies need to be explored. Brown adipose tissue (BAT) is an attractive target in this respect. BAT has the unique capacity to dissipate energy from glucose and fat oxidation as heat. This heat generating capacity of BAT becomes particularly apparent when individuals are exposed to cold, when BAT thermogenesis is activated to help maintain a constant core body temperature. The extra energy that is expended this way is known as non-shivering thermogenesis (NST), and contributes to increased whole-body energy expenditure. This may be very beneficial to combat obesity: when energy intake remains constant, while energy expenditure is increased, a negative energy balance is created, and hence weight is lost. In addition, when BAT is activated, this tissue utilizes large amounts of glucose for its heat production, which leads to enhanced glucose clearance from the circulation. This may be especially beneficial in a diabetic situation, characterized by elevated blood glucose levels. Therefore, in this thesis we explored the role of human BAT in the pathophysiology and treatment of type 2 diabetes.

In patients with type 2 diabetes, insulin resistance may hamper the capacity of BAT to take up glucose upon cold exposure. However, most type 2 diabetes patients are also either of high age or obese, and both of these factors had already been associated with reduced glucose uptake capacity in BAT in previous studies. Therefore, to study the effects of insulin resistance on BAT's glucose uptake capacity, we employed a prolonged-fasting (54h) model in young, healthy individuals (chapter 2); Prolonged fasting is known to induce insulin resistance in peripheral tissues, such as BAT, in order to spare glucose for the brain. As such, we showed that fasting-induced insulin resistance markedly reduced cold-induced glucose uptake in BAT, as assessed by $\left[{ }^{18} \mathrm{~F}\right] \mathrm{FDG}-\mathrm{PET} / \mathrm{CT}$ scanning. This was also paralleled by reduced non-shivering thermogenesis. Interestingly, molecular 
imaging and modeling revealed that the reduction in glucose uptake into BAT was due to decreased cellular glucose uptake in BAT, and not due to decreased glucose supply (in the face of slightly lower blood glucose levels upon fasting). It might be expected that in other insulin resistant conditions, such as type 2 diabetes, coldstimulated glucose uptake in BAT is impaired as well.

If BAT activity is indeed impaired in type 2 diabetes, increasing its presence and activity may result in improved metabolic health, due to greater glucose clearance capacity by BAT. In a previous study in young, healthy individuals, our research group had shown that BAT depots can be expanded by means of prolonged intermittent (10 days, $6 \mathrm{~h} /$ day) exposure to mild cold temperatures $\left(16{ }^{\circ} \mathrm{C}\right.$; i.e. cold acclimation). In order to investigate whether BAT can also be recruited in type 2 diabetes patients, and whether this would subsequently lead to improved glucose clearance, we employed a similar cold acclimation protocol in these patients (chapter 3). Our results showed that glucose uptake capacity in BAT was very low in these patients at baseline, and showed only a minor, albeit significant, increase upon cold acclimation. However, cold acclimation led to a very marked $\sim 40 \%$ increase in insulin sensitivity, as assessed by hyperinsulinemic euglycemic clamps. Such a large increase is likely to be accounted for by effects in skeletal muscle, as this is the major site for glucose disposal under insulin-stimulated conditions (such as during a clamp or after a meal). Indeed, in muscle biopsies we found that cold acclimation caused a very pronounced increase in basal GLUT4 translocation from the cytosol to the muscle cell membrane in order to facilitate glucose uptake. As a consequence, cold-induced glucose uptake in skeletal muscle was increased after the cold acclimation period.

In similar experiments, we investigated the effects of cold acclimation on BAT and skeletal muscle in metabolically healthy obese individuals (chapter 4). In these individuals, the cold acclimation period resulted in increased glucose uptake capacity in BAT. BAT glucose uptake was negatively related to age, and positively related to glucose uptake in visceral white adipose tissue (WAT), while visceral and subcutaneous WAT glucose uptake were unchanged upon cold acclimation. Similar to our findings in the type 2 diabetes patients, muscle biopsy analysis in these healthy obese subjects also showed increased basal GLUT4 localization in the muscle cell membrane upon cold acclimation. This was again accompanied by enhanced cold-induced glucose uptake in skeletal muscle. 
Taken together, our results in type 2 diabetes patients and healthy obese individuals indicate that, while BAT may be regarded as a team player in improved glucose metabolism upon cold acclimation, skeletal muscle seems to be the key player in this respects, as the metabolic adaptations with the greatest systemic impact occur in this tissue.

Next to activation by cold, we also explored alternative routes to stimulate BAT. In chapter $\mathbf{5}$ we studied associations between cold-induced BAT activity and FGF21, a circulating protein that had recently been suggested to have anti-diabetic properties. We showed that serum FGF21 levels are positively related to BAT activity in humans. In addition, we showed that a 10-day cold acclimation period increased serum FGF21 levels, in parallel with increased BAT activity. These results suggest that FGF21 may be a novel target via which BAT activity in humans can be enhanced, in order to improve metabolic health. However, future studies that investigate a direct effect of FGF21 on human BAT are needed to confirm our initial observations.

Individuals of South Asian origin are at increased risk to develop type 2 diabetes and associated comorbidities compared to other ethnicities. A disturbed energy metabolism may be an important contributor to their disadvantageous metabolic phenotype. Since BAT and skeletal muscle are both important players in human energy metabolism, we studied whether BAT activity and skeletal muscle respiratory capacity are different in pre-diabetic South Asian males compared to age- and BMI-matched Caucasian males (chapter 6). Our results showed that BAT volume and activity were not different between South Asians and Caucasians, neither was cold-induced glucose uptake in other tissues such as WAT and skeletal muscle. In skeletal muscle biopsies, we observed a lower muscle respiratory capacity in South Asians then in Caucasians. Six weeks of supplementation with Larginine, a precursor of nitric oxide, did not induce any significant changes in BAT or skeletal muscle respiratory capacity in either group, although it significantly increased total fat free mass in both groups. We conclude that impaired skeletal muscle oxidative capacity may indeed be involved in disturbances in energy metabolism in South Asians. Therapies aimed at improving muscle mitochondrial function may therefore be vital to reduce their risk for the development of adverse metabolic conditions. 
This thesis provides important insight into the roles of BAT and skeletal muscle in glucose metabolism upon cold exposure. Prolonged exposure to mild cold temperatures impacts metabolic activity of both tissues and consequently improves metabolic health. Our findings open up a new therapeutic window for the prevention and treatment of type 2 diabetes and associated metabolic conditions. 
Nederlandse samenvatting 
Het aantal mensen met overgewicht en obesitas is zeer sterk toegenomen in de laatste decennia. Het vele voorkomen van obesitas is de belangrijkste oorzaak voor het tevens sterk gestegen aantal mensen met type 2 diabetes. Type 2 diabetes word veroorzaakt door een verminderde gevoeligheid voor het hormoon insuline (i.e. insuline resistentie), en wordt gekenmerkt door een verhoogde hoeveelheid glucose in het bloed. Diabetes heeft een grote impact op de gezondheid en het is een sterke risicofactor voor het ontwikkelen van andere aandoeningen, zoals cardiovasculaire complicaties. Leefstijlinterventies met diëten en inspanning zijn effectief gebleken om het risico op het ontwikkelen van type 2 diabetes te verminderen. Echter, het blijft een enorm probleem om deze interventies te implementeren in de algemene bevolking. Hierdoor is het noodzakelijk om tevens andere effectieve strategieën te onderzoeken.

Bruin vet is hiervoor een veelbelovende kandidaat. Bruin vet bezit de unieke capaciteit om energie die vrijkomt uit de verbranding van glucose en vetten vrij te geven als warmte. Deze warmte-genererende capaciteit van bruin vet wordt aangesproken als personen worden blootgesteld aan een koude omgeving. Bruin vet wordt dan geactiveerd om zo bij te dragen en het op peil te houden van de kerntemperatuur. De extra energie die op deze manier wordt gebruikt wordt nietrillende thermogenese genoemd en draagt bij aan een verhoogd totaal energiegebruik van het hele lichaam. Dit zou zeer gunstig kunnen zijn in de strijd tegen overgewicht. Immers, wanneer de energie-inname constant blijft en het energiegebruik stijgt, wordt er een negatieve energie balans gecreëerd waardoor gewichtsverlies zal optreden. Daarnaast verbruikt geactiveerd bruin vet een grote hoeveelheid glucose, om hieruit warmte te genereren. Dit leidt tot een verhoogde klaring van glucose uit het bloed, en zou dus in het bijzonder gunstig zijn voor type 2 diabetes patiënten, waarbij sprake is van een verhoogde bloedglucosespiegel. In dit proefschrift hebben we onderzocht wat de rol van bruin vet is in de ontwikkeling en mogelijke behandeling van type 2 diabetes in mensen.

Bij type 2 diabetes patiënten zou insuline resistentie bij kunnen dragen aan een verminderde capaciteit van bruin vet om glucose op te nemen tijdens koude blootstelling. Echter, het merendeel van de type 2 diabetes patiënten is tevens vaak van hogere leeftijd en/of heeft overgewicht, en deze twee factoren zijn beide ook geassocieerd met een verlaagde glucose opname capaciteit in bruin vet. Hierom hebben we het effect van insuline resistentie op de glucose opname capaciteit van bruin vet onderzocht in jonge, gezonde personen na een periode van 
langdurig (54uur) vasten (hoofdstuk 2). Langdurig vasten veroorzaakt namelijk insuline resistentie in perifere weefsels, zoals bruin vet, om zo glucose te sparen als brandstof voor de hersenen. In deze studie lieten we zien dat vasten-geïnduceerde insuline resistentie leidt tot een sterke vermindering van glucose opname in bruin vet tijdens koude blootstelling, zoals we hebben gemeten middels $\left[{ }^{18} \mathrm{~F}\right] \mathrm{FDG}$-PET/CT scanning. Tevens was de niet-rillende thermogenese verminderd. Middels moleculaire beeldvorming en modellering vonden we dat de verminderde glucose opname in bruin vet werd veroorzaakt door verminderde cellulaire glucose opname en niet door verminderd aanbod van glucose (door de lagere bloedglucosespiegel na het vasten). Het zou kunnen worden verwacht dat in andere insuline resistente condities, zoals type 2 diabetes, koude-gestimuleerde glucose opname in bruin ook is verminderd.

Als bruin vet activiteit inderdaad is verminderd in type 2 diabetes, zou het verhogen van de hoeveelheid en activiteit van bruin vet mogelijk kunnen leiden tot een verbeterde metabole gezondheid door een verhoogde glucose klaring door dit weefsel. In een eerdere studie in jonge, gezonde personen had onze onderzoekgroep aangetoond dat de hoeveelheid en activiteit van bruin vet in het lichaam kan worden vergroot door middel van langdurige (10 dagen, 6u/dag) blootstelling aan milde koude temperaturen $\left(16^{\circ} \mathrm{C}\right.$; i.e. koude acclimatisatie). Om te onderzoeken of de hoeveelheid bruin vet ook kan worden verhoogd in type 2 diabetes patiënten en of dit vervolgens leidt tot verhoogde glucose klaring, hebben we eenzelfde koude acclimatisatie protocol uitgevoerd in deze patiënten (hoofdstuk 3). Onze resultaten lieten zien dat de glucose opname capaciteit in bruin vet zeer laag was bij deze patiënten bij aanvang van de studie. Na de koude acclimatisatie periode was er slechts een kleine, maar wel significante, stijging zichtbaar in de bruin vet glucose opname capaciteit. Echter, koude acclimatisatie leidde wel tot een zeer grote $\sim 40 \%$ toename in insuline gevoeligheid, gemeten met hyperinsulinemische euglycemische clamps. Zo'n grote toename kan zeer waarschijnlijk worden toeschreven aan effecten in de skeletspier; hier wordt namelijk de grootste hoeveelheid glucose opgenomen onder insulinegestimuleerde condities (zoals tijdens een clamp of na een maaltijd). Inderdaad, in spierbiopten vonden we dat koude acclimatisatie een sterke toename in basale GLUT4 translocatie vanuit het cytosol naar het spier-celmembraan had veroorzaakt, om zo glucose opname te faciliteren. Als gevolg hiervan was de 
koude-geïnduceerde glucose opname in de skeletspier dan ook verhoogd na de koude acclimatisatie periode.

In een vergelijkbare studie hebben we tevens het effect van koude acclimatisatie op bruin vet en de skeletspier onderzocht in metabool gezonde obese personen (hoofdstuk 4). Bij deze personen veroorzaakte de koude acclimatisatie periode een verhoogde glucose opname capaciteit in bruin vet. Glucose opname in bruin vet was negatief gerelateerd aan leeftijd, en positief gerelateerd aan glucose opname in visceraal wit vet. Echter, glucose opname in visceraal en subcutaan wit vet was onveranderd na koude acclimatisatie. Vergelijkbaar met onze bevindingen in de type 2 diabetes patiënten ontdekten we middels spierbiopt-analyse in deze gezonde obese personen ook een verhoogde basale GLUT4 lokalisatie in het spiercelmembraan na koude acclimatisatie. Dit vertaalde zich ook hier in een verhoogde koude-geïnduceerde glucose opname in de skeletspier na de koude acclimatisatie periode.

Tezamen wijzen onze resultaten in de type 2 diabetes patiënten en gezonde obese personen erop dat bruin vet mogelijk een belangrijke team speler is in het verbeterde glucose metabolisme na koude acclimatisatie, maar dat de skeletspier hierbij waarschijnlijk de hoofdrolspeler is, aangezien de metabole adaptaties met de grootste systemische impact in dit weefsel plaatsvinden.

Naast activatie door koude-blootstelling hebben we ook alternatieve methoden om bruin vet te stimuleren onderzocht. In hoofdstuk $\mathbf{5}$ onderzochten we associaties tussen koude-geïnduceerde bruin vet activiteit en FGF21, een circulerend eiwit waarvan is aangetoond dat het anti-diabetes effecten heeft. Wij lieten zien dat serum FGF21 concentraties positief gerelateerd zijn aan bruin vet activiteit in mensen. Daarnaast vonden we dat een 10-daagse koude acclimatisatie periode leidde tot verhoogde serum FGF21 concentraties, parallel aan verhoogde bruin vet activiteit. Deze resultaten suggereren dat FGF21 een nieuw doelwit zou kunnen zijn waardoor bruin vet activiteit in mensen kan worden verhoogd, om zo de metabole gezondheid te verbeteren. Echter, aanvullende studies naar het directe effect van FGF21 op bruin vet in mensen zijn noodzakelijk om onze bevindingen hieromtrent te bevestigen.

Mensen van Zuid Aziatische afkomst hebben een verhoogd risico op de ontwikkeling van type 2 diabetes en aanverwante aandoeningen in vergelijking met mensen van andere etniciteit. Een verstoord energie metabolisme zou in 
belangrijke mate kunnen bijdragen aan hun nadelige metabole fenotype. Aangezien bruin vet en de skeletspier beide een belangrijke rol spelen in humaan energie metabolisme, hebben we onderzocht of bruin vet activiteit en respiratoire capaciteit in de skeletspier verschillend zijn tussen pre-diabete Zuid Aziatische mannen en leeftijd- en BMI-gematchte Kaukasische mannen (hoofdstuk 6). Onze resultaten lieten zien dat het volume en de activiteit van bruin vet niet verschillend waren tussen de Zuid Aziaten en de Kaukasiërs. Tevens was koude-geïnduceerde glucose opname in andere weefsels, zoals wit vet en de skeletspier, niet verschillend. In skeletspier-biopten ontdekten we een lagere respiratoire capaciteit in spierweefsel van de Zuid Aziaten in vegelijking met de Kaukasiërs. Zes weken suppletie met L-arginine, een voorloper van stikstofoxide in het lichaam, resulteerde in geen van beide groepen in veranderingen in bruin vet of respiratoire capaciteit in de skeletspier. Er vond wel in beide groepen een significante stijging in vetvrije massa plaats na L-arginine suppletie. Uit deze bevindingen concluderen we dat een verminderde oxidatieve capaciteit in de skeletspier inderdaad kan bijdragen aan verstoringen in het energie metabolisme in Zuid Aziaten. Therapieën gericht op het verbeteren van hun mitochondriële functie zouden hierdoor essentieel kunnen zijn om hun risico op het ontwikkelen van stofwisselingsziekten te verminderen.

Dit proefschrift biedt belangrijke inzichten in de rol van bruin vet en de skeletspier in glucose metabolisme tijdens koude blootstelling. Langdurige blootstelling aan milde koude temperaturen beïnvloedt de metabole activiteit van deze weefsels en hierdoor wordt de metabole gezondheid bevorderd. Onze bevindingen openen hiermee nieuwe therapeutische mogelijkheden voor het voorkomen en behandelen van type 2 diabetes en aanverwante aandoeningen. 


\section{Valorization}




\section{Relevance}

The worldwide prevalence of overweight and obesity has reached epidemic proportions in recent decades. According to the World Health Organization, more than 1.9 billion adults are currently considered overweight, and 600 million of these are obese. This equals 39\% and 13\%, respectively, of the world's adult population. In the Netherlands, these numbers are slightly higher, with $\sim 48 \%$ of the Dutch adult population being overweight, and $\sim 13 \%$ being obese. Several other western countries show even more dramatic records: In the US, over two third of the population is considered overweight, while over a third suffers from obesity. This high obesity prevalence is the main cause for a dramatically increased incidence and prevalence of type 2 diabetes during the past decades. Currently, $\sim 6.4 \%$ of the world's population is affected by this disease. Until a couple of decades ago, type 2 diabetes was especially known as "diabetes of the elderly", since high age was the main risk factor for developing this condition. However, rising (childhood-)obesity rates have caused increased type 2 diabetes incidence in all age categories, and is now even ever more diagnosed in teenagers and young adults. This is especially worrisome, since diabetes may cause several other longterm complications such as end-stage renal disease, myocardial infarction and cerebrovascular stroke, reduction of quality of life and reduced overall life expectancy with 5-10 years. Thus, increased diabetes prevalence inevitably impacts health care systems around the globe. As a consequence of this increased health care burden, the economic costs of type 2 diabetes are rising as well. In the US alone, it was estimated that the total economic costs of diagnosed diabetes in 2012 were $\$ 245$ billion, which represents a staggering increase of $41 \%$ compared to estimations of these costs in 2007. In other words, 1 in 5 health care dollars in the US are currently spend on diabetes care. Since similar trends are ongoing globally, it is projected that type 2 diabetes-related health care costs will continue to grow in the coming years as well.

Successful strategies to counteract obesity and type 2 diabetes include diet and exercise programs. However, despite their proven efficacy, these lifestyle interventions remain very challenging to implement in the general population. Therefore, therapeutic alternatives need to be evaluated. In this thesis, we explored the role of brown adipose tissue (BAT) in the pathophysiology of type 2 diabetes and determined whether cold-induced BAT activation can be exploited as 
novel means to increase energy expenditure and glucose disposal, and thereby counteract obesity and type 2 diabetes.

\section{Target group}

The main target groups that may benefit from novel BAT-centered therapies are subjects that are currently being overweight/obese or diagnosed with type 2 diabetes or associated metabolic conditions. In addition, individuals that are at increased risk for the development of type 2 diabetes (e.g. through genetic predisposition) may benefits from such therapies. As such, it is essential to translate our scientific knowledge to the general population. In this thesis, we clearly demonstrated that lowering ambient temperature results in enhanced energy expenditure. In addition, prolonged exposure to such lower ambient temperatures greatly improved insulin sensitivity, which may translate into lower blood glucose levels in type 2 diabetes patients on the long term. Thus, lowering housing and office temperatures may represent a simple, but very effective means to improve metabolic health in the general population. At this moment, more research is required in other population groups and it should be determined whether compliance and metabolic improvements persist during more long-term intervention periods. Nonetheless, it is essential to communicate these observations to the general public outside science, in order to create general awareness and support and to achieve our desired health effects.

Pharmaceutical and food companies could also play a major role in the development of BAT-centered therapies to combat obesity and type 2 diabetes. In this thesis, we determined that serum FGF21 concentrations were positively correlated to BAT activity in young, healthy individuals. Thus, FGF21 analogs may in fact be able to stimulate BAT and thereby have favorable effects on metabolic health, which has also been suggested from rodent studies, Such positive effects of FGF21 analogue drugs may also be achieved in humans.

We also studied the effect of 6-weeks L-arginine (an $\alpha$-amino acid) supplementation on BAT activity, but found to changes herein. Some food components, notably capsaicin-related compounds found in chili peppers, have been suggested to activate BAT in previous studies. It is highly relevant to evaluate whether other food component exert similar stimulatory effects on BAT; these can subsequently be included in dietary regimens to provide additional metabolic 
benefits through the activation of BAT.

\section{Activities and products}

All studies described in this thesis were conducted at the Department of Human Biology and Human Movement Sciences in close collaboration with the Department of Nuclear Medicine of Maastricht University Medical Center. Their expertise with respect to $\left.{ }^{18} \mathrm{~F}\right] \mathrm{FDG}-\mathrm{PET} / \mathrm{CT}$ scanning was essential for us in order to visualize and quantify BAT activity in vivo. This collaboration between basic physiologists from the university and medical specialist from the academic hospital is a good example of how basic science can be performed in the clinic. In addition, such a collaborative, multi-disciplinary approach opens up the doors for an effective translational medicine working environment.

The results presented in this thesis are described in original articles that have been published or submitted to peer-reviewed scientific medical journals. Importantly, these articles can be accesses online and can be used by other researchers in this field and others who are interested in this topic. Furthermore, our results have been presented to the scientific community at several (inter)national conferences and have been communicated to the general public through several national mass media (newspapers, radio, tv).

\section{Innovation}

Since the 'rediscovery' of BAT in adult humans in 2009, scientific interest in BAT as a novel tool to combat obesity and type 2 diabetes has increased exponentially. Our research group was among the first to show that young, lean adults possessed significant amounts of functionally active BAT, by exposing individuals to mild cold temperatures and subsequently visualizing BAT activity by means of $\left[{ }^{18} \mathrm{~F}\right] \mathrm{FDG}$ PET/CT scanning. In addition, our group has shown that prolonged intermittent cold exposure (i.e. cold acclimation) is an effective method to enhance BAT quantity and activity in young, lean adults. In this thesis, we now show that also in obese subjects, BAT can be recruited by means of cold acclimation. In addition, we show for the first time that cold acclimation results in very remarkable improvements in insulin sensitivity in patients with type 2 diabetes, although it is unlikely that these improvements can be attributed to the minimal increase in BAT activity that we observed in these patients. However, we did find very pronounced 
effects of cold acclimation on skeletal muscle GLUT4 protein localization, which may explain the remarkable effects on insulin sensitivity. We were the first to describe such effects in humans, and these findings represent a solid base for future studies investigating the effects of mild cold on skeletal muscle glucose metabolism.

Furthermore, in this thesis we explored alternative methods to expand the BAT depot in individuals of Caucasian and South Asian descent. Specifically, we tested whether L-arginine supplementation would lead to BAT recruitment. Unfortunately, we did not observe any significant effects of L-arginine on BAT in either ethnicity. However, we did observe an interesting other phenomenon during this study, again residing in skeletal muscle: muscle oxidative capacity was significantly lower in South Asians than in Caucasians. Such functional skeletal muscle mitochondrial impairments had never been reported yet, but could play a vital role in the enhanced susceptibility of South Asians to develop obesity and type 2 diabetes compared to Caucasians. These results also raise the question whether improving muscle mitochondrial function specifically in South Asians could subsequently lead to improvements in their metabolic profile. This could be subject of future studies.

In this thesis we also explored the role FGF21 in BAT activity, and observed a positive relationship between circulating FGF21 levels and BAT activity in young, healthy subjects. Thus, increasing FGF21 levels or enhancing FGF21 sensitivity may represent a novel means to enhance BAT activity. Whether this is indeed the case, and whether this may subsequently impact metabolic health, could be subject of future studies.

\section{Planning and realization}

In this thesis we clearly demonstrated that short-term cold acclimation can have a major impact on metabolic health. It remains to be elucidates, however, to what extent BAT contributed to these metabolic improvements, as we noticed only a relatively small effect of cold acclimation on BAT in type 2 diabetes patients, whereas they showed very pronounced improvements in whole-body insulin sensitivity. Our data strongly suggests that skeletal muscle plays a major in these improvements. Our research group is currently investigating in more detail how skeletal muscle glucose metabolism is affected by cold exposure and cold acclimation, and whether cold acclimation also affects lipid metabolism. In 
addition, it is being explored whether the positive effects on insulin sensitivity persist several weeks after the cold acclimation period.

As stated above, it is highly important to quantify in more detail to what extent BAT actually contributes to whole body energy expenditure and glucose and lipid metabolism. To study this, alternative radioactive tracers, such as ${ }^{15} \mathrm{O}$ and $\left[{ }^{18} \mathrm{~F}\right] \mathrm{FTHA}$, may be used to study oxygen metabolism and free fatty acid uptake, respectively, in BAT upon activation. In addition, novel tracers may be developed to measure incorporation of free fatty acids from circulation triglycerides into brown adipocytes. Ideally, a combination of such tracers is used in each individual under similar cold-exposed circumstances, in combination with whole-body energy expenditure measurements, to get a complete picture of BAT metabolism in relation to whole-body metabolism. However, this poses several insurmountable practical issues, as well as increased radioactive exposure for test subjects. The latter point may be partly overcome by using alternative methods to visualize BAT. In this respect, our research group has investigated the potential use of MRI to identify BAT. Although the initial results were promising, more research is necessary at this point in order for MRI to compete with the current "golden standard" [ $\left.{ }^{18} \mathrm{~F}\right]$ FDG-PET/CT scanning to quantify BAT presence and activity.

Another important aspect in BAT research at this moment is the identification of other strategies, besides cold exposure, to activate BAT in humans. Our research group recently showed that the bile acid CDCA may activate BAT, although to a much lesser extent than cold exposure. Other studies have shown that the $\beta_{3^{-}}$ agonistic drug Mirabegron activates BAT to a similar extent as cold exposure. However, such drugs may have substantial cardiovascular side effects, especially in individuals at increased risk for such comorbidities (i.e. obese or type 2 diabetes patients). It is therefore crucial to identify other ways to activate BAT in humans, and to determine whether these strategies impact metabolic health, without imposing other negative side effects.

Finally, future studies should also focus on the effects of long term BAT stimulation on energy and substrate metabolism. The cold acclimation periods that we used in our studies were relatively short and intense (10 days, 6 hours/day), and it would thus be interesting to investigate the effects of longer, less intense intervention periods. Such studies are necessary to determine how the human body adapts to a continuous cold stimulus, both physiologically and psychologically, and whether compensation mechanisms, such as increasing energy intake, may take place. 
VALORIZATION 
Dankwoord 
Daar zijn ze dan, de aller-laatste woorden die ik op papier zet voordat het proefschrift helemaal klaar is om naar de drukker te sturen. Na 4 jaar zwoegen, en een half jaartje reizen om bij te komen, kan ik niet wachten om binnenkort ' $d r$.' aan mijn naam toe te voegen. Voordat het zover is, wil ik uiteraard eerst iedereen ontzettend bedanken voor de mooie en leerzame tijd en alle steun en hulp die ik heb gehad bij het tot stand komen van dit proefschrift.

Wouter, na een mooie stage-periode in Pittsburgh bleek er bij terugkomst een PhD-plek vrij te komen op het bruin vet onderzoek. Ik ben je heel erg dankbaar dat mijn veronderstelde sollicitatie-gesprek hiervoor achteraf meer een kennismakings-gesprek bleek te zijn en dat ik al snel als Thermu-er aan de slag kon! Je zorgt altijd voor een prettige sfeer binnen de groep, zowel op werk als op sociaal gebied (zeilen, etentjes (Anne bedankt!), GLOW, etc...) en het is ontzettend fijn dat je deur altijd open staat voor je promovendi. We hebben binnen het DIABATproject ook een aantal mooie tripjes (inclusief gedenkwaardige taxiritjes) kunnen maken de afgelopen jaren die steevast werden vergezeld van lokale pinten en werden afgesloten met een dag sightseeing (ja, het leven als promovendus is zwaar...). Tijdens mijn promotie ben je zelf ook gepromoveerd tot professor en ik wil je dan ook heel veel verdere successen toewensen in deze rol.

Patrick, allereerst heel erg bedankt dat je me niet alleen aan een mooie stage bij Bret Goodpaster hebt geholpen, maar vervolgens ook hebt geïntroduceerd bij het bruin vet onderzoek van Wouter. Naast bruin vet, wezen mijn onderzoeksresultaten ook steeds meer richting de spier, waardoor je betrokkenheid bij mijn studies gaandeweg nog meer is gegroeid. Ik blijf me verbazen over hoe je vraagstukken waar ik al dagen mee rondloop op een ogenschijnlijk simpele manier kunt verduidelijken en oplossen, en hoe je het voor elkaar krijgt om manuscripten zo ontzettend snel van commentaar te voorzien. Bedankt voor al je hulp en adviezen, en ik wens je heel veel verdere successen met de Shock-groep.

Felix, u was voor mij iets meer op de achtergrond aanwezig als hoofd van Nucleaire Geneeskunde. Dank voor uw hulp bij het analyseren en interpreteren van onze PET data, en het bieden van de faciliteiten en ondersteuning waardoor we in samenwerking met uw afdeling onze bruin vet studies hebben kunnen uitvoeren.

Als ik dan toch bij Nucleaire ben kan ik er niet omheen om de rest van deze afdeling ook heel erg te bedanken voor jullie hulpvaardigheid en kennis. Boudewijn, je hebt heel wat tijd gestoken in het beoordelen en mee-analyseren 
van mijn bruin vet scans. Naast je inhoudelijke vakkennis was er hierbij gelukkig ook altijd ruimte voor de nodige relativerende filosofische discussies. Bedankt en heel veel succes in Gent! Roel, ik heb veel geleerd van die mooie tekeningen die je altijd maakte tijdens het kinetisch modelleren van mijn dynamische PET data (enkele van je meesterwerken hebben nog jaren achter mijn bureau op de muur gehangen, totdat ze begonnen te vergelen); we hebben het 2-tissue compartment model naar nieuwe hoogten gebracht! Bedankt voor al je PMOD-hulp! Matthias, het was altijd heel interessant om te horen wat voor metingen je met je proefdieren kon doen en hoe het fabriceren van een nieuwe tracer in $z^{\prime} n$ werk gaat; voor jou een koud kunstje, voor mij nog steeds veel abracadabra ;-). Verder natuurlijk heel erg bedankt aan iedereen die heeft geholpen bij alles wat er komt kijken bij het uitvoeren van onze scans: Emiel, Mariëlle, Christian, Kyra, Lotte, Roy, Florence, Denise, Christel, Marieke, Renee, Ivo, Maartje, Serve - Bedankt voor de fijne samenwerking! Martine, Cindy en Marie-Louise bedankt voor al jullie inplanhulp en voor de altijd vrolijke ontvangst bij Nucleaire.

Onderzoek doe je niet alleen, het is teamwork, en gelukkig is onze Thermu-groep een goed draaiend team waarbij iedereen altijd voor elkaar klaar staat. Boris, groeps-oudste, je kon na een kleine zijstap de drang naar de wetenschap toch niet weerstaan. Je neemt lang niet alles voor lief en geeft daarmee de groep vaak stof tot nadenken. Sorry nogmaals dat ik die rare gast in $z^{\prime} n$ rubber bootje in eerste instantie over het hoofd zag ;-). Succes in je nieuwe rol als UD-er en met je steeds groter wordende gezin. Vosselman, Maarten, ik heb veel van je geleerd tijdens mijn eerste stappen als BAT-ter en het was altijd een uitdaging om tijdens discussies met je net even een stapje verder te kijken en nog meer uit onze data te halen. Ik kon het met jou ook altijd goed over andere belangrijke levenszaken (reizen, voetbal, zaad..) hebben. Bedankt nog voor het onverwachte crashen na het promotie-feest van Guy en dat je me altijd liet winnen met ruzzle ;-). Docter Vijgen, Guy, ik was nog maar een paar weken aan het werk en toen lag ik al bij jou op de pijnbank om een spierbiopt te laten afnemen. Gelukkig ging je dat als volleerd professioneel butcher goed af en kon ik nog gewoon op 2 benen staan na afloop. Je hebt als allereerste Nederlandse humaan BAT promovendus de weg voor ons vrijgemaakt en ik kon altijd bij je terecht voor arts-raad-en-daad. Bedankt ook voor het afnemen van vele spierbiopten en succes met butcheren in Rotterdam!

De Thermu is niet compleet zonder de dames. Lisje, jij kwam vanuit de TU ons team versterken. Eindelik eemus woar ig plat mit kos proate! Ik kon met name met 
alle 'technische' vraagjes altijd bij je terecht, en later met de grotere levensvragen (to post-doc or not to post-doc). Heel veel geluk met je gezin in jullie nieuwe huis! Evie, je had altijd een duidelijk doel voor ogen en je hebt hier keihard voor gewerkt en liet je door niets of niemand tegenhouden. Het doel is inmiddels iets gewijzigd, maar is zeker niet minder mooi geworden; ik weet zeker dat je gaat slagen als huisarts! Bedankt ook voor alle biopten die je in mijn studies (vaak in de vroege ochtend) hebt afgenomen. Frau Pallubinsky, Hannah, na een goeie stage-periode bij Maarten kon je al snel zelf als promovendus in onze groep beginnen, en ook hier laat je weer zien waar je toe in staat bent. Je bent altijd vrolijk en opgewekt en neemt gelukkig onze Nederlands-Duitse rivaliteiten niet al te serieus op ;-). Ik ben blij dat ik het travel-virus enigszins op je heb kunnen overbrengen, en wens je veel succes in je laatste promotie-fase. Marije, ook jij bracht vanuit de TU wat technische kennis in de groep en ging direct volop aan de slag; je kon niet wachten om te beginnen met meten. Ondertussen heb je al heel wat nachtwerk erop zitten, en blijf je desondanks ook overdag altijd opgewekt en behulpzaam (of komt dat door al onze koffie-breaks?). Heel veel succes met het opschrijven van alle mooie data die je ondertussen hebt verzameld. Christel, je hebt me veel geholpen tijdens mijn kennismaking met al onze meetapparatuur. Je hebt ondertussen je draai gevonden bij het CTCM; het gaat je goed af en je hebt er plezier in, dat is mooi om te zien. Mariëtte, als tijdelijk Thermu-er heb je heel wat voor elkaar gekregen in de tijd dat je in Maastricht werkzaam was. Je hebt je altijd enorm ingezet voor de mooie studie die we samen hebben kunnen uitvoeren: ik sta er nog steeds versteld van hoe je al die Hindoestanen vanuit de randstad naar Maastricht hebt weten te krijgen. Er staat je een mooie toekomst als arts-onderzoeker te wachten. Charlotte, bedankt voor al je hulp in de arginine studie. Het was jammer dat je ons voortijdig ging verlaten, maar ik wens je heel veel geluk en succes dichter bij friends and family. Marie-Fleur en Karin, ik heb jullie maar even meegemaakt als collega's, maar ik ben blij dat jullie het humane BAT-stokje overnemen. Jullie begonnen beiden heel enthousiast en dat beloofd veel voor de toekomst, heel veel succes!

Natuurlijk zijn er ook vele andere HB/BW-ers die hebben bijgedragen aan een aantal mooie jaren. Joris, je bent bij al mijn studies betrokken geweest, zowel als oxygraaf expert als clamper. Het was altijd prettig samenwerken en ik heb heel veel van je kunnen leren. Ondanks dat het af en toe puzzelen was met de opvang van de kids, hebben we in redelijk vlot tempo de clamps in de acclimatisatie studie kunnen afronden, en met fantastisch resultaat! Bedankt voor alles! Bas, bedankt 
voor al je expertise en advies bij het includeren van onze proefpersonen. Emmani, als halve Thermu-er heb je me veel kunnen leren over je celwerk en je was omgedraaid ook altijd geïnteresseerd in onze humane studies. Anne, bedankt voor al je biopt-hulp en het vroege opstaan tijdens mijn eerste studie. Gert, Johanna en Esther, ontzettend bedankt voor al het 'labwerk' dat jullie voor onze studies hebben gedaan; het heeft fantastische resultaten opgeleverd! Hasibe, Wendy en Jos (de Godfather van HB), bedankt voor alle bloed-analyses! Loek, Paul en Marc, jullie technische assistentie was onmisbaar. Ook voor alle andere collega's waarbij ik altijd voor raad en daad terecht kon en die bovendien ook altijd hebben gezorgd voor een goeie sfeer op de afdeling: Bedankt!

Dames van het secretariaat: Claudia, Yolanda en double D (Desiree en Desiree), ik kon bij jullie altijd terecht voor een praatje/paaseitje of als ik weer eens niet wist hoe de scanner werkte (wat een systeem!). Bedankt voor al jullie hulp.

José, Kelly en Cindy, jullie hebben fantastisch meegedraaid met mijn studies als stagiaires, dat kunnen ook al onze proefpersonen wel beamen. Bedankt en heel veel succes met jullie eigen onderzoeks-toekomst.

Cyril, ongelofelijk hoe goed en snel jij als Fransman je draai had gevonden op onze afdeling. Je hebt kneiterhard gewerkt, maar je was bovenal ook altijd supersociaal. Ondanks dat Star Wars nog steeds niet mijn ding is, hoop ik in de toekomst nog vaak je onnavolgbare dans-moves te kunnen aanschouwen tijdens bbq-reünies!

Anouk, ik vond het super om jou bij te staan tijdens je moment of fame, en ik ben heel erg blij dat je nu ook mijn paranimf wil zijn. Ik heb veel van je geleerd over het doen van alle metingen, en uiteindelijk hebben we als team de laatste acclimatisatie-studies uitgevoerd. Mooi om te zien hoe je na een superdrukke periode aan het daten sloeg met Pieter-Jan en je helemaal opbloeide: Ja...nou...ik weet het nog niet zeker hoor.....Jaaa Anouk, we zien het toch aan je, PJ gaat het worden! ;-) Nu jullie al een tijdje zijn gesetteld in Herten hoop ik dat we nog regelmatig samen op het terras kunnen gaan zitten in Remunj.

Roel, Dja, Dries, van alle collega's ken ik jou waarschijnlijk het langst. We hebben samen dezelfde master gedaan, en zijn daarbij allebei naar de US vertrokken voor stages, die we hebben afgesloten met een fantastische roadtrip (vooral 3x de Tioga pass rijden was prachtig ;-) ) en mooie avonden in Vegas baby, unforgettable! Naast het feit dat je een fantastische infuus-zetter bent, konden we het ook altijd over alles met elkaar hebben, zowel onzinnig als de meer serieuze kant van het leven. Fantastisch dat mij bijstaat tijdens mijn laatste uur als promovendus. 
Een speciaal woord van dank ook voor alle proefpersonen die hebben meegedaan aan mijn studies. Het is niet niks om 2,5 dag te vasten, 10 dagen in de kou te bivakkeren, spierbiopten te ondergaan, uren op bed te liggen tijdens een clamp, en zo kan ik nog wel even doorgaan.... Kortom, ik respecteer het enorm dat jullie de wetenschap met jullie bijdragen weer een stapje vooruit hebben geholpen!

I would like to thank the defense committee, prof. Schaper, dr. Bucerius, prof. Klingenspor, prof. Pijl and prof. Schols, for evaluating my thesis and for your presence at my dissertation. Prof. Klingenspor, thank you for coming over from Munich, and a special thanks for your tour guide services after our first DIABAT meeting in Berlin.

KLMDZ, wea zien al joare kamereuj en det zal aug altied zoë blieve. Vakanties, weekenden, vasteloavend, ontelbare pils-oavenden en neet nader te beneumen sjoëne zelfbedachte spellen... We hebben al un haup mit gemakt samen en ig weit zeker det de toekomst nog veul mier sjoëns zal goan bringen.

Sjoënfemilie, Peter, Hanneke, Kristel, Mark, neafke Max, het waas et aaf en toe moeilijk oet te legge wat wea nou precies aan het ongerzeuken waren, mer ig bin blij det ge altied interesesse hebt getoënd en det ge altied veur os kloar stoat. Ig hoop det we nog duk macaroni mogen komen eate in Boaksum en det ig Max nog get van mien voetbal-talenten kin overbringen.

Suus, ig bin trots desse ongertussen van klein zusje tot arts bis verworen, en blij desse altied mien groëte-broor-pesterijen hees doorstoan ;-). Samen mit Giel heesse onlangs un sjoën hoes gebouwd in dörp, woar ig ug alle geluk in toewins; we komen binnenkort un filmpje kieke in ugge bioscoop!

Pap en mam, tsja woar mot ig beginne; et is eigenlijk onbesjriefelik wat gea allemoal vur mich hebt gedoan en vur mich beteikend. Ge hebt mich altied van wieze road veurzeen en gesteund in alle keuzes die ig heb gemakt, aug al beteikende det regelmatig det ig veur langere tied aan de angere kank van de wereld zoot. Ig kin heij nog wiejer goan oetwijden, met ig weit det veur ug un simpel 'bedankt' voldoende is: Bedankt veur alles wat ge veur mich hebt gedoan.

Rianne, ozze leefde begos joare geleeje in 't dörpse Kubke. Ein van ozze groëte druime hebbe we onlangs woar gemakt, en ig kiek der noar oet um de rest in de toekomst aug te loate oetkomen. Zoeas Rowwen Heze al hiel toepasselik, mit un knipaug noar mien proefschrift, zong: "ow wil ik vur altied verwerme, vur altied mit 'n bietje geluk." Ig hoaj van dich. 
DANKWOORD 
List of publications 


\section{Published papers}

MJW Hanssen, AAJJ van der Lans, B Brans, J Hoeks, K Jardon, G Schaart, FM Mottaghy, P Schrauwen, WD van Marken Lichtenbelt. Short-term cold acclimation recruits brown adipose tissue in obese humans. Diabetes 2016; 65: 1179-1189.

Y Chen, JJ Buyel, MJW Hanssen, F Siegel, R Pan, J Naumann, M Schell, AAJJ van der Lans, C Schlein, H Froelich, J Heeren, KA Virtanen, WD van Marken Lichtenbelt, A Pfeifer. Exosomal microRNA miR-92a concentration in serum reflects human brown fat activity. Nature Communications 2016; 7: 11420.

AAJJ van der Lans, MJ Vosselman, MJW Hanssen, B Brans, WD van Marken Lichtenbelt. Supraclavicular skin temperature and BAT activity in lean healthy adults. Journal of Physiological Sciences 2016; 66: 77-83.

MJW Hanssen, J Hoeks, B Brans, AAJJ van der Lans, G Schaart, JJ van den Driessche, JA Jörgensen, MV Boekschoten, MKC Hesselink, B Havekes, S Kersten, FM Mottaghy, WD van Marken Lichtenbelt, P Schrauwen. Short-term cold acclimation improves insulin sensitivity in patients with type 2 diabetes mellitus. Nature Medicine 2015;21:863-5.

MJW Hanssen, E Broeders, RJ Samms, MJ Vosselman, AAJJ van der Lans, CC Cheng, AC Adams, WD van Marken Lichtenbelt, P Schrauwen. Serum FGF21 levels are associated with brown adipose tissue activity in humans. Scientific Reports 2015;5:10275.

MJW Hanssen, R Wierts, J Hoeks, A Gemmink, B Brans, FM Mottaghy, P Schrauwen, WD van Marken Lichtenbelt. Glucose uptake in human brown adipose tissue is impaired upon fasting-induced insulin resistance. Diabetologia 2015;58:586-595. 


\section{Submitted papers}

MJW Hanssen, MR Boon, B Brans, J Hoeks, C Bakker, C Hülsman, PCN Rensen, WD van Marken Lichtenbelt. Brown adipose tissue activity and skeletal muscle respiration in South Asian and Caucasian pre-diabetic males: effects of L-arginine. In preparation.

AD van Dam, MJW Hanssen, R van Eenige, E Quinten, HC Sips, J Hoeks, WD van Marken Lichtenbelt, MC Haks, PCN Rensen, MR Boon. South Asians exhibit lower expression of IL-5 and interferon signaling in white adipose tissue compared to Caucasians. In preparation. 
Curriculum Vitae 
CURRICULUM VITAE 


\section{About the author}

Mark Hanssen was born on March 13, 1987 in Venlo, the Netherlands. He completed secondary school at the Bouwens van der Boije College in Panningen in 2005. Hereafter, he started his studies in General Health Sciences at Maastricht University in 2006. After he received his Bachelor's degree in 2009, he continued with a research master in Molecular Life Sciences, with specialization in Nutrition and Metabolism, at Maastricht University. During his master studies, he completed an 8-month internship at the Endocrinology and Metabolism Research Center at the University of Pittsburgh, USA, focusing on energy metabolism in obesity. He obtained his Master's degree in 2011, and was awarded with the Unilever Research Prize 2011 for best master thesis. Hereafter, he started working as a PhD-student at the Department of Human Biology and Human Movement Sciences at Maastricht University, under supervision of prof. W. van Marken Lichtenbelt, prof. P. Schrauwen and prof. F. Mottaghy. During his PhD trajectory, he studied the role of brown adipose tissue in the pathophysiology and treatment of insulin resistance and type 2 diabetes, as demonstrated in this thesis and publications in scientific journals. 